\title{
Carbon and Nitrogen Removal in a Granular Bed Baffled Reactor
}

\author{
Muhammad Imran Baloch, BSc (Hons), MSc
}

A thesis submitted in partial fulfilment of the requirements of the University of Abertay Dundee for the degree of

Doctor of Philosophy

February 2004

I certify that this is a true and accurate version of the thesis approved by the examiners.
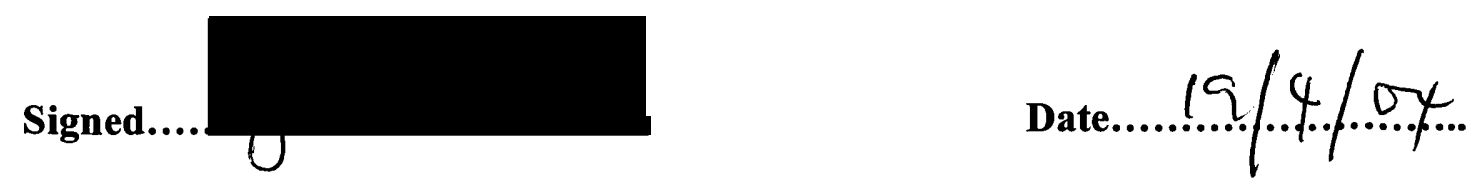

Director of Studies

(C) Muhammad Imran Baloch, 2004 


\section{ABSTRACT}

One of the primary concerns for the treatment of high strength carbonaceous wastewaters in anaerobic systems is to achieve an optimum growth environment for acidogenesis and methanogenesis. Such wastewaters with high nutrient levels could cause additional problems as anaerobic units are usually designed for the removal of organic matter. In addition, nitrate inhibition to methanogenesis in anaerobic environment could cause further problems during treatment. Therefore, a type of high rate anaerobic system is required which could accommodate nitrogen removal in addition to organic carbon removal, and comply with the increasingly stringent discharge standards adopted by environmental protection agencies worldwide. This research was carried out by developing a new reactor by using a bed of anaerobic granular sludge in an anaerobic baffled reactor, the granular bed baffled reactor (GRABBR). The aims of this study were to investigate the performance of GRABBR in terms of treatment efficiency for carbon and nitrogen removal, long term and shock load stability, occurrence and effectiveness of phase separation, characteristics of granular biomass in different phases, and to examine the physical, microbiological and kinetic parameters of biomass. A 10 litre GRABBR divided into five equal sized compartments was operated under mesophilic $\left(35^{\circ} \mathrm{C}\right)$ conditions. The GRABBR system achieved high chemical oxygen demand removal, biomass retention and methane yield under various operational strategies, particularly at high organic loading rates (OLRs), with synthetic glucose and brewery wastewaters. Phase separation between acidogenesis and methanogenesis mainly occurred at high OLRs. The reactor configuration and microbial environment encouraged the acidogenic dominant zone to produce intermediate products suitable for the methanogenic dominant zone. Acidogenesis in the upstream compartments of GRABBR caused breaking and flotation of granular sludge, along with the formation of microbial mass identified as mainly Gram-negative Klebsiella pneumoniae, while downstream methanogenic compartments retained the original granular structure. The reactor was efficiently operated at high OLR with short hydraulic retention time (HRT) on a long-term basis. The system was capable of treating highly varying flow rates. Simultaneous denitrification and methane production was observed in GRABBR during nitrate addition in the acidogenic and methanogenic dominant zones. It is shown that the microbial arrangement in a layered granular structure, containing vast diversity of species with strong association of facultative and methanogenic populations, and phase separation characteristics of the GRABBR, brought about simultaneous denitrification and methane production. No noticeable ammonification was observed with glucose and brewery wastewaters during nitrate reduction. The simpler forms of carbon sources, like acetate and VFA, were found to be a more efficient substrate in terms of carbon and nitrate removal than glucose. The presence of simpler forms of substrate and higher concentrations of methanogenic granules exhibited higher nitrate and carbon removal rates in the methanogenic dominant zone than the acidogenic dominant zone of GRABBR. This study demonstrated that the combination of granular bed, compartmentalisation and plug flow in a single system could achieve ideal anaerobic configuration for wastewater treatment to accomplish carbon and nitrogen removal. The findings of this research suggest that the application of a GRABBR is suitable for the treatment of multiple pollutants of complex or high strength wastewaters, where each phase or compartment acts as a separate specialised treatment unit. 


\section{ACKNOWLEDGEMENTS}

I would like to express my deepest gratitude to my supervisors Dr. J. C. Akunna and Dr. P. J. Collier for their guidance, advice, encouragement and patience throughout the duration of the study.

Special thanks to Prof. G. K. Anderson, Head of Environmental Engineering Group at University of Newcastle, for the use of analytical facilities in the Environmental Engineering Laboratory at Newcastle University. Thanks to Mrs Pat Johnston and Mrs Fiona Reed for assisting me in carrying out analytical work at Newcastle University.

Thanks to Prof. Chris Jefferies, Head of Urban Water Technology Centre, for granting me an extension to my studentship. I would also like to thank Prof. Harry Staines, School of Computing and Advanced Technologies, for his advice on statistical analysis. The co-operation of Dr. Behnam Taidi (Process Innovation Manager, Scottish Courage, Edinburgh) is appreciated for providing brewery wastewater samples for the study.

I would like to thank Prof. R. M. Ashley (Bradford University) and Dr. David Blackwood (Urban Water Technology Centre) for their invaluable advice and support during my research study. Martin Kierans, Department of Biological Sciences at Dundee University, helped a great deal in providing an invaluable insight and knowledge into electron microscopy including sample preparation. I appreciate the support of An Hung Tseng for providing me every possible assistance for reactor operation during his MSc dissertation at Abertay University. Thanks to Tony Breen, School of Contemporary Sciences, for joining different pieces of perspex to construct the reactor for the study. The support of Kevin Tosh, Davidsons and Sons, Aberdeen, is also valued for helping me in the sampling of granular sludge from the anaerobic reactor in Aberdeen. Alex Thomson, School of Contemporary Sciences, kindly sorted out all my research and non-research related issues, and his help in this regard is greatly acknowledged.

Olga Shtepenko, Elizabeth Bastida, Lynne Duncan, Gabriela Constantino, Hazem Gouda, Ruben Sakrabani, Talib Butt, Abdus Salam - all have been a source of great support, wonderful friendship and fantastic entertainment during my studies. Thanks also goes to my colleagues and friends - Adolf Spitzer, Trevor McIlhatton, Daniel Gilmour, Dominic McBennett, Wolfram Schlueter, Ahmed Almas, Stella Apostolaki, and other staff members in the Urban Water Technology Centre for their great time over the last few years. The encouragement and advice from Bhai Khan Shar, Ambrat Lal and Khalil Ibupoto at Newcastle were invaluable for me to commence my research in Dundee.

I would like to say thanks to my family members - Mum, Dad, Mona, Shazia, Faisal and Sara for their continuing love and support over the course of my studies. They have always been a source of strength to me during this long journey.

Finally, I gratefully acknowledge the award of $\mathrm{PhD}$ studentship for this study from the University of Abertay Dundee. 


\section{PUBLICATIONS}

Baloch, M. I. and Akunna, J. C. (2003). Granular bed baffled reactor (Grabbr): Solution to a two-phase anaerobic digestion system. J. Environ. Engrg. (ASCE), 129, 1015-1021.

Baloch, M. I. and Akunna, J. C. (2003). Effect of rapid hydraulic shock loads on the performance of granular bed baffled reactor. Environ. Technol., 24, 361-368.

Akunna, J. C. and Baloch, M. I. (2003). GRABBR: A new system configuration for the treatment of high strength wastewaters. Paper presented at the IWA Asian Waterqual 2003 Conference, 20-22 Oct., Bangkok, Thailand, 8 pages on CD-ROM.

Baloch, M. I. and Akunna, J. C. (2002). Simultaneous Denitrification and anaerobic digestion in Granular Bed Baffled Reactor (GRABBR). Paper presented at the CSCEEWRI of ASCE International Conference on Environmental Engineering, 21-24 July, Niagara Falls, Canada, 9 pages on CD-ROM.

Akunna, J. C. and Baloch, M. I. (2002). Treatment of brewery and distillery wastewaters using anaerobic granular bed baffled reactor (GRABBR). Paper presented at the $2^{\text {nd }}$ Biennial Conference on Management of Wastewaters, 15-17 April, Edinburgh, Scotland, 2, 311-316.

Baloch, M. I. and Akunna, J. C. (2002). Anaerobic treatment using phase separated granular bed bioreactor. Paper presented at the $3^{\text {rd }}$ IWA UK Young Researcher Conference, 17-18 April, Nottingham, England.

Baloch, M. I., Tseng, A. H. and Akunna, J. C. (2001). Denitrification in an anaerobic granular bed baffled reactor (GRABBR). Poster at the $9^{\text {th }}$ IWA World Congress on Anaerobic Digestion, 2-6 Sept., Antwerp, Belgium. 


\section{CONTENTS}

$\begin{array}{ll}\text { Abstract } & \text { ii }\end{array}$

Acknowledgements iii

Publications iv

Contents $\quad$ v

List of Tables $\quad x$

List of Figures

List of Abbreviations $\quad$ xxi

$\begin{array}{lll}\text { CHAPTER } 1 \quad \text { INTRODUCTION } & 1\end{array}$

1.1 Anaerobic treatment of wastewater 1

$\begin{array}{ll}1.2 & \text { Anaerobic granules } \\ \end{array}$

$\begin{array}{ll}\text { 1.2.1 Granulation process } & 7\end{array}$

$\begin{array}{ll}\text { 1.3 Anaerobic systems } & 9\end{array}$

$\begin{array}{ll}\text { 1.4 Phase separation in anaerobic systems } & 11\end{array}$

$\begin{array}{ll}\text { 1.4.1 Anaerobic baffled reactor } & 13\end{array}$

1.5 Concept of granular bed baffled reactor 15

$\begin{array}{ll}1.6 \text { Nitrogen removal from wastewaters } & 19\end{array}$

$\begin{array}{ll}\text { 1.6.1 Biological nitrification } & 20\end{array}$

$\begin{array}{ll}\text { 1.6.2 Biological denitrification } & 22\end{array}$

1.7 Nitrogen removal from anaerobically treated wastewaters 24

$\begin{array}{ll}1.8 \text { Research aims } & 28\end{array}$

1.9 Thesis outline $\quad 29$

CHAPTER 2 MATERIALS AND METHODS 31

2.1 Laboratory-scale reactor set-up 31

2.2 Synthetic feed 31

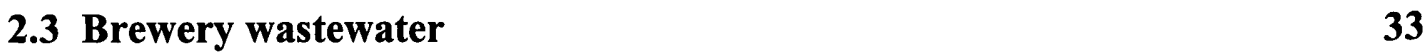


2.4 Seed sludge $\quad 33$

2.5 Analytical methods $\quad 34$

$\begin{array}{ll}\text { 2.5.1 Chemical oxygen demand } & 34\end{array}$

$\begin{array}{ll}2.5 .2 \mathrm{pH} & 34\end{array}$

$\begin{array}{ll}\text { 2.5.3 Volatile fatty acids } & 34\end{array}$

$\begin{array}{ll}\text { 2.5.4 Ammoniacal nitrogen } & 34\end{array}$

2.5.5 Gas composition and volume $\quad 35$

$\begin{array}{ll}\text { 2.5.6 Solids } & 35\end{array}$

2.5.7 Nitrate and nitrite nitrogen 35

$\begin{array}{lll}\text { 2.5.8 Analytical profile index } 20 \mathrm{E} & 36\end{array}$

2.5.9 Buoyant density 36

$\begin{array}{ll}\text { 2.5.10 Particle size distribution } & 37\end{array}$

$\begin{array}{ll}\text { 2.5.11 Transmission electron microscope } & 37\end{array}$

2.5.12 Scanning electron microscope 38

$\begin{array}{ll}2.6 \text { Statistics } & 38\end{array}$

CHAPTER 3 PERFORMANCE OF GRANULAR BED BAFFLED REACTOR AT VARIOUS LOADING RATES 39

3.1 Introduction 39

3.2 Experimental design $\quad 40$

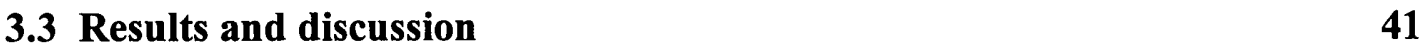

3.3.1 Soluble chemical oxygen demand removal 41

3.3.2 Volatile fatty acid profile $\quad 42$

$3.3 .3 \mathrm{pH} \quad 45$

3.3.4 Ammoniacal nitrogen 46

$\begin{array}{ll}\text { 3.3.5 Gas production and composition } & 47\end{array}$

3.3.6 Effect of phase separation on granular bed 48

3.3.7 Non-granular biomass identification $\quad 50$

3.4 Summary and conclusions $\quad 51$ 
CHAPTER 4 PERFORMANCE OF GRANULAR BED BAFFLED REACTOR DURING RAPID HYDRAULIC SHOCK LOADS

$\begin{array}{ll}\text { 4.1 Introduction } & 54\end{array}$

4.2 Experimental design

4.3 Results $\quad 55$

4.3.1 Soluble chemical oxygen demand removal 55

4.3.2 Volatile fatty acid profile $\quad 57$

$\begin{array}{ll}\text { 4.3.3 Biomass retention } & 59\end{array}$

$\begin{array}{ll}\text { 4.3.4 Biogas production } & 60\end{array}$

$\begin{array}{ll}4.4 \text { Discussion } & 60\end{array}$

$\begin{array}{lc}4.5 \text { Conclusions } & 63\end{array}$

CHAPTER 5 COMBINED DENITRIFICATION AND

ANAEROBIC DIGESTION IN GRANULAR BED BAFFLED

REACTOR $\quad 64$

5.1 Introduction $\quad 64$

$\begin{array}{ll}5.2 & \text { Experimental method }\end{array}$

$\begin{array}{lll}5.3 \text { Results } & 69\end{array}$

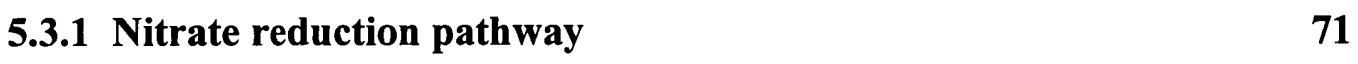

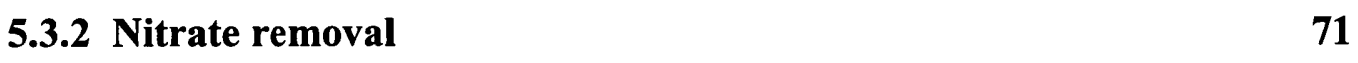

5.3.2.1 Nitrate addition in the acidogenic dominant zone (compartment 1) 71

5.3.2.2 Nitrate addition in the methanogenic dominant zone (compartment 5) 71

5.3.3 Soluble chemical oxygen demand removal 73

5.3.3.1 Nitrate addition in the acidogenic dominant zone (compartment 1) 73

5.3.3.2 Nitrate addition in the methanogenic dominant zone (compartment $5 \mathbf{7 3}$

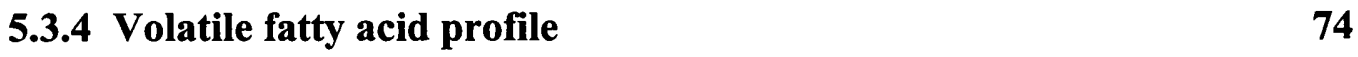

$\begin{array}{ll}\text { 5.3.5 Methane composition } & 76\end{array}$

$\begin{array}{ll}5.4 \text { Discussion } & 76\end{array}$

$\begin{array}{ll}5.5 \text { Conclusions } & 79\end{array}$ 


\section{CHAPTER 6 NITRATE REDUCTION AND METHANE PRODUCTION ACTIVITIES OF SLUDGES FROM GRANULAR BED BAFFLED REACTOR}

6.1 Introduction

6.3.1 Acidogenic and methanogenic dominant zone sludges previously unadapted to nitrate

6.3.1.1 Sludge from the acidogenic dominant zone (nitrate-free cultures) $\quad \mathbf{8 5}$

6.3.1.2 Sludge from the methanogenic dominant zone (nitrate-free cultures) 86

6.3.1.3 sludge from the acidogenic dominant zone (nitrate-added cultures) $\quad \mathbf{8 6}$

6.3.1.4 Sludge from the methanogenic dominant zone(nitrate-added cultures) 87

6.3.2 Acidogenic dominant zone sludge previously adapted to nitrate $\quad 90$

6.3.2.1 Sludge from the acidogenic dominant zone (nitrate-free cultures) 90

6.3.2.2 Sludge from the acidogenic dominant zone (nitrate-added cultures) 91

6.4 Discussion

6.4.1 Nitrate-free cultures 91

6.4.2 Nitrate-added cultures

6.5 Concluding discussion

\section{CHAPTER 7 PHYSICAL AND MICROBIAL ECOLOGY} OF ANAEROBIC GRANULES

7.2 Experimental conditions $\quad 102$

$\begin{array}{ll}7.3 \text { Results } & 102\end{array}$

$\begin{array}{ll}\text { 7.3.1 Particle size distribution } & 102\end{array}$

7.3.2 Electron microscopy 102

7.3.2.1 Transmission electron microscope 104

7.3.2.2 Scanning electron microscope 105

$\begin{array}{ll}7.4 \text { Discussion } & 118\end{array}$

$\begin{array}{ll}7.5 \text { Conclusions } & 122\end{array}$ 


\section{CHAPTER 8 COMBINED INTEGRATED SYSTEM FOR}

BREWERY WASTEWATER TREATMENT

8.1 Introduction 123

8.2 Materials and methods 125

8.2.1 Nitrification unit $\quad 125$

8.2.2 Experimental design $\quad 125$

$\begin{array}{ll}\text { 8.3 Results and discussion } & 127\end{array}$

8.3.1 Reactor performance prior to nitrogen removal 127

8.3.2 Reactor performance during nitrate addition 130

$\begin{array}{ll}\text { 8.4 Conclusions } & 134\end{array}$

$\begin{array}{lll}\text { CHAPTER } 9 & \text { GENERAL DISCUSSION }\end{array}$

9.1 Reactor performance for organic matter removal 135

9.2 Biomass characteristics in acidogenic phase 138

9.3 Combined denitrification and carbon removal in GRABBR 139

9.3.1 Treatment of glucose wastewater for organic carbon and nitrogen removal 139

9.3.2 Treatment of brewery wastewater for organic carbon and nitrogen removal $\quad 140$

9.4 Simultaneous nitrate reduction and methane production in batch assays 140

9.5 Granular morphology 142

9.6 Microbial ecology and disintegration of granules 143

$\begin{array}{ll}9.7 \text { Granulation } & 144\end{array}$

9.8 Additional advantages of granular bed baffled reactor 145

9.9 Conclusions 146

$\begin{array}{ll}9.10 \text { Summary } & 147\end{array}$

$\begin{array}{ll}9.11 \text { Suggestions for further work } & 147\end{array}$

REFERENCES

$\begin{array}{lll}\text { APPENDIX } & \text { Refereed journal publications } & 175\end{array}$ 


\section{LIST OF TABLES}

Table 1.1 Average chemical oxygen demand (COD) and ammoniacal nitrogen $\left(\mathrm{NH}_{4}-\right.$ $\mathrm{N})$ concentrations of some high strength wastewaters.

Table 2.1 Composition of synthetic wastewater.

Table 3.1 Performance of various anaerobic systems under high loading rates at mesophilic conditions.

Table 4.1 Performance of baffled reactors at high (shock) loads.

Table 5.1 Cumulative soluble chemical oxygen demand (SCOD) removal efficiencies in the compartments of granular bed baffled reactor before nitrate addition in Compartment 1 and 5 at steady state conditions.

69

Table 5.2 Operating conditions of granular bed baffled reactor during nitrate addition into Compartment 1.

Table 5.3 Operating conditions of granular bed baffled reactor during nitrate addition into Compartment 5.

Table 5.4 Individual soluble chemical oxygen demand (SCOD) removal efficiency of acidogenic dominant zone (Compartment 1) and methanogenic dominant zone (Compartment 5) of granular bed baffled reactor during denitrification.

Table 6.1 Experimental set-up for batch assays with sludge from Compartment 1 and 5 of granular bed baffled reactor unadapted to nitrate.

Table 6.2 Experimental set-up for batch assays with sludge from Compartment 1 of granular bed baffled reactor acclimatised to nitrate. 
Table 6.3 Nitrate removal rates and methane production under various batch cultures.

Table 8.1 Flow conditions for integrated system (granular bed baffled reactor and nitrification unit) for brewery wastewater treatment.

Table 9.1 Chemical oxygen demand removal efficiencies under different operational conditions at steady state for glucose and brewery wastewaters using granular bed baffled reactor.

\section{LIST OF FIGURES}

Figure 1.1 Comparison of aerobic and anaerobic processes for treating $100 \mathrm{~kg}$ of chemical oxygen demand (COD) to achieve COD removal efficiency of $90 \%$. Anaerobic carbon conversion generally produces 6 times less sludge (sometimes even less than this figure) than aerobic process, as most of the carbon would be utilised for methane production, which is a source of energy (from Wheatley et al., 1997).

Figure 1.2 Simplified schematic diagram of different reactions involved in anaerobic digestion of complex organic matter (adapted from Kasper and Wuhrmann, 1978; Gujer and Zehnder, 1983).

4

Figure 1.3 Cumulative number of full-scale anaerobic treatment systems for industrial applications in the world (from Frankin, 2001).

Figure 1.4 One of the early designs presented for an anaerobic baffled reactor (Figure 1.4a) modified from anaerobic rotating biological contactor system (Figure 1.4b) by removing rotating discs (from McCarty, 1981).

Figure 1.5 Operating organic loading rate (OLR) data of anaerobic baffled reactor studies and its modified configurations. On top left and right of each bar represents the corresponding hydraulic retention time. In front of each study (bar), percentage shows the 
chemical oxygen demand (COD) removal at the end of the experiment. Percentage COD removal are also shown at $20 \mathrm{~kg} \mathrm{COD} \mathrm{m}^{-3} \mathrm{~d}^{-1}$, for studies exceeding this OLR. 18

Figure 1.6a \& b Schematic diagrams of conventional treatment configuration for biological carbon and nitrogen removal for anaerobically treated high strength nitrogenous wastewaters.

Figure 1.6c Schematic diagram of combined anaerobic digestion and denitrification in a single unit followed by a downstream nitrification unit for anaerobically treated high strength nitrogenous wastewaters.

Figure 2.1 Schematic diagram of five-compartment granular bed baffled reactor.

Figure 2.2 Schematic definition of long and short axis of granules measured by vernier measuring microscope.

Figure 3.1 Soluble chemical oxygen demand (SCOD) concentrations in each compartment of granular bed baffled reactor at different organic loading rates: (ם)

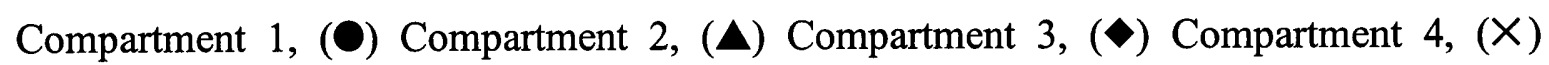
Compartment 5, (O) percentage total SCOD removal during the length of reactor operation. Organic loading rates of $1,1.25,1.7,2.5,5,10$ and $20 \mathrm{~kg}$ COD m $\mathrm{d}^{-1}$ were initiated at days $1,20,31,34,43,73$ and 93 respectively.

Figure 3.2 Percentage soluble chemical oxygen demand (SCOD) removal contributed by each compartment of granular bed baffled reactor at different organic loading rates:

$20 \mathrm{~kg} \mathrm{COD} \mathrm{m}^{-3} \mathrm{~d}^{-1}$, (A) $10 \mathrm{~kg} \mathrm{COD} \mathrm{m}^{-3} \mathrm{~d}^{-1}$, (口) $5 \mathrm{~kg} \mathrm{COD} \mathrm{m}^{-3} \mathrm{~d}^{-1}$, (४) $2.5 \mathrm{~kg} \mathrm{COD} \mathrm{m}^{-3} \mathrm{~d}^{-}$ ${ }^{1},(\Delta) 1.7 \mathrm{~kg} \mathrm{COD} \mathrm{m}^{-3} \mathrm{~d}^{-1},(\square) 1.25 \mathrm{~kg} \mathrm{COD} \mathrm{m}^{-3} \mathrm{~d}^{-1},(\diamond) 1 \mathrm{~kg} \mathrm{COD} \mathrm{m}^{-3} \mathrm{~d}^{-1}$.

Figure 3.3 Total volatile fatty acid (VFA) (acetate, propionate, butyrate and valerate) profile in each compartment of granular bed baffled reactor at organic loading rates of $(O)$ $10 \mathrm{~kg} \mathrm{COD} \mathrm{m}^{-3} \mathrm{~d}^{-1}$ and (O) $20 \mathrm{~kg} \mathrm{COD} \mathrm{m}^{-3} \mathrm{~d}^{-1}$. 
Figure 3.4 Profile of intermediate volatile fatty acid products in each compartment of granular bed baffled reactor at organic loading rate of $10 \mathrm{~kg} \mathrm{COD} \mathrm{m}^{-3} \mathrm{~d}^{-1}:(\mathbf{O})$ acetate, (A) propionate, $(\mathbf{Q})$ butyrate, $(\diamond)$ valerate.

Figure 3.5 Profile of intermediate volatile fatty acid products in each compartment of granular bed baffled reactor at organic loading rate of $20 \mathrm{~kg} \mathrm{COD} \mathrm{m}^{-3} \mathrm{~d}^{-1}:(\mathbf{O})$ acetate, (A) propionate, $(\square)$ butyrate, $(\diamond)$ valerate.

Figure 3.6 $\mathrm{pH}$ profile in the compartments of granular bed baffled reactor at different organic loading rates: (O) $20 \mathrm{~kg} \mathrm{COD} \mathrm{m}^{-3} \mathrm{~d}^{-1}$, (A) $10 \mathrm{~kg} \mathrm{COD} \mathrm{m}^{-3} \mathrm{~d}^{-1}$, (口) $5 \mathrm{~kg} \mathrm{COD} \mathrm{m}^{-3}$ $\mathrm{d}^{-1}$, (O) $2.5 \mathrm{~kg} \mathrm{COD} \mathrm{m}^{-3} \mathrm{~d}^{-1},(\Delta) 1.7 \mathrm{~kg} \mathrm{COD} \mathrm{m}^{-3} \mathrm{~d}^{-1}$, (口) $1.25 \mathrm{~kg} \mathrm{COD} \mathrm{m}^{-3} \mathrm{~d}^{-1},(\diamond) 1 \mathrm{~kg}$ $\operatorname{COD~m^{-3}} \mathrm{d}^{-1}$.

Figure 3.7 Methane production (O) and composition (O) of granular bed baffled reactor for organic loading rates of 1 to $20 \mathrm{~kg} \mathrm{COD} \mathrm{m}^{-3} \mathrm{~d}^{-1}$ at steady state conditions.

Figure 3.8 (a) Provided granular bed at the start of reactor operation at day 8 (operating at organic loading rate of $1 \mathrm{~kg} \mathrm{COD} \mathrm{m}^{-3} \mathrm{~d}^{-1}$ ). (b) Continuous reactor operation for 148 days, while treating organic loading rates of 1 to $20 \mathrm{~kg} \mathrm{COD} \mathrm{m} \mathrm{d}^{-1}$, caused breaking and flotation of granular sludge in the upstream compartments with the formation of white mass identified as mainly Klebsiella pneumoniae.

Figure 4.1 Soluble chemical oxygen demand (SCOD) concentrations in each compartment of granular bed baffled reactor at different organic loading rates: ( $\square$ )

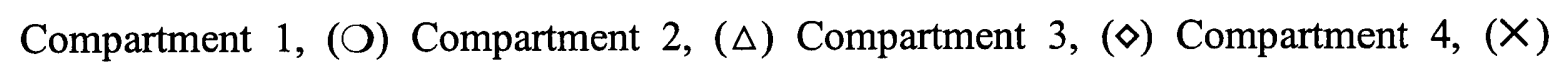
Compartment 5, (O) percentage total SCOD removal during the length of reactor operation.

Figure 4.2 Percentage soluble chemical oxygen demand (SCOD) removal contributed by each compartment of granular bed baffled reactor at different organic loading rates: (O) $20 \mathrm{~kg} \mathrm{COD} \mathrm{m}^{-3} \mathrm{~d}^{-1},(\boldsymbol{\Delta}) 10 \mathrm{~kg} \mathrm{COD} \mathrm{m}^{-3} \mathrm{~d}^{-1},(\square) 5 \mathrm{~kg} \mathrm{COD} \mathrm{m}^{-3} \mathrm{~d}^{-1}$, (४) $2.5 \mathrm{~kg} \mathrm{COD} \mathrm{m}^{-3} \mathrm{~d}^{-}$ 1 . 
Figure 4.3 Volatile fatty acid profile in the compartments of granular bed baffled reactor at organic loading rate of $20 \mathrm{~kg} \mathrm{COD} \mathrm{m}^{-3} \mathrm{~d}^{-1}:(\boldsymbol{O})$ acetate, (A) propionate, (ם) butyrate, $(\bullet)$ valerate.

Figure 4.4 $\mathrm{pH}$ profile in the compartments of granular bed baffled reactor at different organic loading rates: (О) $20 \mathrm{~kg} \mathrm{COD} \mathrm{m}^{-3} \mathrm{~d}^{-1}$, (A) $10 \mathrm{~kg} \mathrm{COD} \mathrm{m}^{-3} \mathrm{~d}^{-1}$, (口) $5 \mathrm{~kg} \mathrm{COD} \mathrm{m}^{-3}$ $\mathrm{d}^{-1},(\diamond) 2.5 \mathrm{~kg} \mathrm{COD} \mathrm{m}^{-3} \mathrm{~d}^{-1}$.

Figure 5.1 Schematic diagram of nitrate addition in the acidogenic dominant zone (Compartment 1) and methanogenic dominant zone (Compartment 5) of granular bed baffled reactor.

68

Figure 5.2 $\mathrm{NOx}-\mathrm{N}\left(\mathrm{NO}_{3}-\mathrm{N}\right.$ and $\left.\mathrm{NO}_{2}-\mathrm{N}\right)$ levels in the compartments of granular bed baffled reactor at different nitrate nitrogen $\left(\mathrm{NO}_{3}-\mathrm{N}\right)$ concentrations added in the acidogenic dominant zone (Compartment 1): (ם) $50 \mathrm{mg} \mathrm{l}^{-1} \mathrm{NO}_{3}-\mathrm{N}$, (O) $100 \mathrm{mg} \mathrm{l}^{-1} \mathrm{NO}_{3}-\mathrm{N}$, ( $\left.\mathbf{\Delta}\right) 150$ $\mathrm{mg} \mathrm{l}^{-1} \mathrm{NO}_{3}-\mathrm{N},(\times) 200 \mathrm{mg} \mathrm{l}^{-1} \mathrm{NO}_{3}-\mathrm{N}$.

Figure 5.3 NOx-N $\left(\mathrm{NO}_{3}-\mathrm{N}\right.$ and $\left.\mathrm{NO}_{2}-\mathrm{N}\right)$ levels in the compartments of granular bed baffled reactor at different nitrate nitrogen $\left(\mathrm{NO}_{3}-\mathrm{N}\right)$ concentrations added in the methanogenic dominant zone (Compartment 5): (口) $50 \mathrm{mg} \mathrm{l}^{-1} \mathrm{NO}_{3}-\mathrm{N}$, (O) $100 \mathrm{mg} \mathrm{l}^{-1} \mathrm{NO}_{3}$ $\mathrm{N},(\Delta) 150 \mathrm{mg} \mathrm{l}^{-1} \mathrm{NO}_{3}-\mathrm{N},(\times) 200 \mathrm{mg} \mathrm{l}^{-1} \mathrm{NO}_{3}-\mathrm{N}$.

Figure 5.4 Denitrification rates for varying nitrate nitrogen $\left(\mathrm{NO}_{3}-\mathrm{N}\right)$ concentrations added in the acidogenic dominant zone (Compartment 1) and methanogenic dominant zone (Compartment 5) of granular bed baffled reactor: $(O)$ Compartment $1\left(\mathrm{R}^{2}=0.9993\right)$, Compartment $5\left(\mathrm{R}^{2}=0.9998\right)$.

Figure 5.5 Soluble chemical oxygen demand (SCOD) levels in different compartments of granular bed baffled reactor at varying nitrate nitrogen $\left(\mathrm{NO}_{3}-\mathrm{N}\right)$ concentrations added in acidogenic dominant zone (Compartment1): ( $\square$ ) before nitrate addition, $(\times) 50 \mathrm{mg} \mathrm{l}^{-1} \mathrm{NO}_{3}$ $\mathrm{N},(\Delta) 100 \mathrm{mg} \mathrm{l}^{-1} \mathrm{NO}_{3}-\mathrm{N},(\boldsymbol{\Delta}) 150 \mathrm{mg} \mathrm{l}^{-1} \mathrm{NO}_{3}-\mathrm{N}$, (O) $200 \mathrm{mg} \mathrm{l}^{-1} \mathrm{NO}_{3}-\mathrm{N}$. 
Figure 5.6 Soluble chemical oxygen demand (SCOD) levels in different compartments of the granular bed baffled reactor at varying nitrate nitrogen $\left(\mathrm{NO}_{3}-\mathrm{N}\right)$ concentrations added in methanogenic dominant zone (Compartment 5): ( $\square$ ) before nitrate addition, $(\times)$ $50 \mathrm{mg} \mathrm{l}^{-1} \mathrm{NO}_{3}-\mathrm{N},(\triangle) 100 \mathrm{mg} \mathrm{l}^{-1} \mathrm{NO}_{3}-\mathrm{N},(\Delta) 150 \mathrm{mg} \mathrm{l}^{-1} \mathrm{NO}_{3}-\mathrm{N},(\mathrm{O}) 200 \mathrm{mg} \mathrm{l}^{-1} \mathrm{NO}_{3}-\mathrm{N}$.

Figure 5.7 Profile of intermediate volatile fatty acid products in Compartment 1 (shaded) and Compartment 5 (hollow) of granular bed baffled reactor for nitrate nitrogen $\left(\mathrm{NO}_{3}-\mathrm{N}\right)$ concentrations of 50 to $200 \mathrm{mg} \mathrm{l}^{-1}:(\boldsymbol{O}, \mathrm{O})$ acetate, $(\boldsymbol{\Delta}, \Delta)$ propionate, $(\boldsymbol{\square}, \square)$ butyrate.

Figure 6.1 Profile of percentage methane (hollow) and carbon dioxide (shaded) composition for various cultures with time using acidogenic dominant zone sludge previously unadapted to nitrate: acetate $(\bigcirc, \boldsymbol{O})$, volatile fatty acid $(\Delta, \boldsymbol{\Delta})$, glucose $(\square, \boldsymbol{\square})$.

Figure 6.2 Profile of percentage methane (hollow) and carbon dioxide (shaded) composition with time using various cultures with methanogenic dominant zone sludge previously unadapted to nitrate: acetate $(O, \bigcirc)$, volatile fatty acid $(\Delta, \mathbf{\Delta})$, glucose $(\square, \mathbf{\square})$.

Figure 6.3 Profile of percentage methane (hollow) and carbon dioxide (shaded) composition for various media in nitrate added cultures with time using acidogenic dominant zone sludge previously unadapted to nitrate: acetate $(O, \odot)$, volatile fatty acid $(\Delta, \Delta)$, glucose $(\square, \square)$.

88

Figure 6.4 Profile of $\mathrm{NOx}-\mathrm{N}\left(\mathrm{NO}_{3}-\mathrm{N}\right.$ and $\left.\mathrm{NO}_{2}-\mathrm{N}\right)$ concentrations with time for various cultures using acidogenic dominant zone sludge previously unadapted to nitrate: acetate $(\bigcirc)$, volatile fatty acid $(\triangle)$, glucose $(\square)$.

88

Figure 6.5 Profile of percentage methane (hollow) and carbon dioxide (shaded) composition with time in nitrate added cultures using methanogenic dominant zone sludge 
previously unadapted to nitrate: acetate $(O, \boldsymbol{O})$, volatile fatty acid $(\Delta, \boldsymbol{\Delta})$, glucose $(\square, \boldsymbol{\square})$. Data for acetate $(\boldsymbol{O})$, volatile fatty acid $(\mathbf{A})$ were all at 0 and therefore these symbols overlap with each other giving the appearance of 0 .

Figure 6.6 Profile of $\mathrm{NOx}-\mathrm{N}\left(\mathrm{NO}_{3}-\mathrm{N}\right.$ and $\left.\mathrm{NO}_{2}-\mathrm{N}\right)$ concentrations with time using various cultures with methanogenic dominant zone sludge previously unadapted to nitrate: acetate $(\bigcirc)$, volatile fatty acid $(\Delta)$, glucose $(\square)$.

89

Figure 6.7 Profile of percentage methane (hollow) and carbon dioxide (shaded) composition for various media with time using acidogenic dominant zone sludge previously adapted to nitrate: acetate $(O, \boldsymbol{O})$, volatile fatty acid $(\Delta, \mathbf{\Delta})$, glucose $(\square, \mathbf{\square})$. Data for acetate $(O)$, volatile fatty acid $(\Delta)$, glucose $(\square)$ were all at 0 and therefore these symbols overlap with each other.

Figure 6.8 Profile of percentage methane (hollow) and carbon dioxide (shaded) composition with time in nitrate added cultures using acidogenic dominant zone sludge previously adapted to nitrate: acetate $(O, \boldsymbol{O})$, volatile fatty acid $(\Delta, \boldsymbol{\Delta})$, glucose $(\square, \square)$. Data for acetate $(\bigcirc, \Theta)$, volatile fatty acid $(\Delta, \mathbf{\Delta})$, glucose $(\square)$ were all at 0 and therefore these symbols overlap with each other giving the appearance of duplicate

92

Figure 6.9 Profile of $\mathrm{NOx}-\mathrm{N}\left(\mathrm{NO}_{3}-\mathrm{N}\right.$ and $\left.\mathrm{NO}_{2}-\mathrm{N}\right)$ concentrations with time using various cultures with acidogenic dominant zone sludge previously adapted to nitrate: acetate $(O)$, volatile fatty acid $(\Delta)$, glucose $(\square)$.

Figure 6.10 Proposed biochemical structure of methanogenic granular sludge for simultaneous denitrification and methanogenesis. Nitrates and some carbonaceous matter would be utilised in the outer zone(s) of the granule by facultative populations, while the remaining carbon content would penetrate into the core of the granule for methane production. 
Figure 7.1 Proposed granular structure showing arrangement of metabolic groups in different layers related to substrate diffusion for carbohydrate-fed granules (from Macleod et al., 1990).

Figure 7.2 Granular size distribution along long axis of seed granules obtained from upflow anaerobic sludge blanket system using vernier measuring microscope (Average and maximum error bars were calculated as $2.41 \%$ and $5.65 \%$ respectively).

103

Figure 7.3 Granular size distribution along short axis of seed granules obtained from upflow anaerobic sludge blanket system using vernier measuring microscope (Average and maximum error bars were calculated as $1.78 \%$ and $3.46 \%$ respectively).

Figure 7.4 Ellipsoid shape of anaerobic granules obtained from upflow anaerobic sludge blanket system was evident from image analyser $($ Bar $=1.25 \mathrm{~mm})$.

Figure 7.5 (a) Five apparent microbial zones are visible from outer surface to the core of the granule sampled from methanogenic dominant zone of granular bed baffled reactor (GRABBR). Vast diversity of bacterial species is evident with few open spaces. Methanothrix spp. is dominant in the central core (Bar $=2 \mu \mathrm{m})$. (b) Four apparent microbial zones are visible from outer layer to the core of the granule sampled from acidogenic dominant zone of GRABBR. The exterior surface is adversely affected with no defined boundary due to high acidogenic activities in this zone of GRABBR. Layering within the granule is not distinct with few open spaces and relatively less numbers of Methanothrix spp. are visible at the central core $(\mathrm{Bar}=2 \mu \mathrm{m})$.

Figure 7.6 Densely packed microorganisms are observed at the exterior layer of granular sludge obtained from methanogenic dominant zone of granular bed baffled reactor $(\mathrm{Bar}=500 \mathrm{~nm})$.

Figure 7.7 Methanothrix-like species are predominant organism in the core of methanogenic granular sludge $(\mathrm{Bar}=1 \mu \mathrm{m})$. 
Figure 7.8 Regular shape viruses are visible in the ghost cell of granule. This suggest the presence of bacteriophage $(\mathrm{Bar}=100 \mathrm{~nm})$.

Figure 7.9 Transmission electron micrograph showing cell division of rod shape morphotype with cell wall in between cytoplasm of granule. DNA area is visible within the cell $($ Bar $=100 \mathrm{~nm})$.

108

Figure 7.10 Cluster of coccoid cells or transverse section of a bundle or rod shape bacteria in granular biomass $(\mathrm{Bar}=200 \mathrm{~nm})$.

109

Figure 7.11 Electron micrograph revealing structure resembling with spirochaete bacteria in granular consortium $(B a r=50 \mathrm{~nm})$.

Figure 7.12 (a) Image showing the granule from methanogenic dominant zone of granular bed baffled reactor. As evident from above electron micrograph, the observed samples from this zone mainly revealed densely packed structure with smooth regular surface.

Figure 7.12 (b) Scanning electron micrograph showing the granule from acidogenic dominant zone of granular bed baffled reactor. As shown in above image, the granules from this zone contained fissures with an irregular surface morphology, caused mainly by acidogenic organisms.

Figure 7.13 (a) Protozoa-like structure is visible on the surface of granule.

Figure 7.13 (b) High magnification of Fig. 7.13a shows openings on this specie, which could be the plausible excystment scars or vacuoles for waste removal.

Figure 7.14 Methanogenic species are found to be dominant in the core zone of anaerobic granule. Large numbers of cavities are visible in the core of granular structure, which are believed to be the sites for possible gas vents.

112

Figure 7.15 Extracellular polymeric substances were observed within the entire granule. It could be acting as a binding material between different groups of microorganisms. 
Figure 7.16 (a) Scanning electron micrograph showing bacterial cells in granule covered in extracellular polymeric substances.

Figure 7.16 (b) High magnification of Fig. 7.16a shows extracellular polymeric substances (EPS) peeled away from the bacterial cell.

Figure 7.16 (c) Image showing arrangement of bacterial cells in granule surrounded by extracellular polymeric substances (EPS).

114

Figure 7.17 Outer zones of granule reveals large amount of extracellular polymeric substances.

Figure 7.18 High magnification of granule showing a regular alignment of methanogenlike bacterial cells.

115

Figure 7.19 Surface of the few granules showed layering / scouring in different directions which could have formed due to the reactor hydrodynamics causing abrasions by other granules or reactor walls.

Figures 7.20 (a \& b) Scanning electron micrographs showing large cracks on the granular structure. These possibly show the signs of granule disintegration.

116

Figure 7.20 (c) Micrograph showing the part of broken granule with fissures or excision scars after possible granular disintegration.

Figure 7.21 Schematic diagram of possible granule breaking in the acidogenic dominant environment of stage anaerobic reactor. (1) Granular sludge present as inoculum. (2) Unacidified substrate in the acidogenic dominant zone of the system may favour the environment for granular organisms to lose their structure due to increased acidogenic activities. (3) Ultimately, disintegration of granular consortium into sheath like debris of granule combined with the formation of new microbial mass, which might be washed out from the reactor due to their non-granular nature and light dense structure. 
Figure 8.1 Schematic diagram of combined carbon and nitrogen removal in granular bed baffled reactor with downstream aerobic (nitrification) unit.

Figure 8.2 Chemical oxygen demand (COD) concentrations in each compartment of granular bed baffled reactor at different organic loading rates: (O) $13.38 \mathrm{~kg} \mathrm{COD} \mathrm{m}^{-3} \mathrm{~d}^{-1}$, (A) $5 \mathrm{~kg} \mathrm{COD} \mathrm{m} \mathrm{d}^{-1}$, (口) $3.36 \mathrm{~kg} \mathrm{COD} \mathrm{m}^{-3} \mathrm{~d}^{-1}$, (O) $2.16 \mathrm{~kg} \mathrm{COD} \mathrm{m}^{-3} \mathrm{~d}^{-1}$.

Figure 8.3 Volatile fatty acid profile in the first compartment of the granular bed baffled reactor at organic loading rate (OLR) of 3.36 and $5 \mathrm{~kg} \mathrm{COD} \mathrm{m}^{-3} \mathrm{~d}^{-1}$.

Figure 8.4 Methane production ( $)$ and composition (O) for different organic loading rates (OLRs) at steady state conditions for brewery wastewater treatment in granular bed baffled reactor.

Figure 8.5 Chemical oxygen demand (COD) profile at different recycling ratios of influent to nitrified effluent. Recycling ratio of zero $(O)$, recycling ratio of $1(\square)$, recycling ratio of $1.5(\mathbf{A})$ and recycling ratio of $2(\boldsymbol{O})$. Key: C1, C2, C3, C4 and C5 represents compartments of granular bed baffled reactor, In = influent of granular bed baffled reactor and Eff = effluent of aerobic unit.

Figure 8.6 NOx-N (nitrate and nitrite nitrogen) profile at different recycling ratios of influent to nitrified effluent. Recycling ratio of zero $(O)$, recycling ratio of $1(\square)$, recycling ratio of $1.5(\mathbf{A})$ and recycling ratio of $2(\mathbf{O})$. Key: C1, C2, C3, C4 and C5 represents compartments of granular bed baffled reactor, In = influent of granular bed baffled reactor and Eff = effluent of aerobic unit.

Figure 8.7 Ammonium nitrogen $\left(\mathrm{NH}_{4}-\mathrm{N}\right)$ profile at different recycling ratios of influent to nitrified effluent. Recycling ratio of zero $(O)$, recycling ratio of $1(\square)$, recycling ratio of $1.5(\mathbf{A})$ and recycling ratio of $2(\mathbf{O})$. Key: C1, C2, C3, C4 and C5 represents compartments of granular bed baffled reactor, In = influent of granular bed baffled reactor and Eff = effluent of aerobic unit. 


\section{LIST OF ABBREVIATIONS}

ABR

APHA

API

$\mathrm{C} / \mathrm{N}$

COD

$\mathrm{COD} / \mathrm{NO}_{3}-\mathrm{N}$

COD/NOx-N

CSTR

DNRA

DO

EGSB

EPS

GC

GRABBR

HRT

IC

MPN

NLR

OLR

SCOD

SEM

SRT

TEM

TSS

UASB

VFA

VSS
Anaerobic baffled reactor

American Public Health Association

Analytical Profile Index

Carbon to nitrogen ratio

Chemical oxygen demand

Chemical oxygen demand to nitrate nitrogen ratio

Chemical oxygen demand to nitrate nitrogen and nitrite nitrogen ratio

Continuously stirred tank reactor

Dissimilatory nitrate reduction to ammonium

Dissolved oxygen

Expanded granular sludge bed

Extracellular polymeric substances

Gas Chromatograph

Granular bed baffled reactor

Hydraulic retention time

Internal circulation

Most probable number

Nitrate loading rate

Organic loading rate

Soluble chemical oxygen demand

Scanning electron microscope

Solid retention time

Transmission electron microscope

Total suspended solids

Upflow anaerobic sludge blanket

Volatile fatty acid

Volatile suspended solids 


\section{CHAPTER 1}

\section{INTRODUCTION}

This chapter reviews the brief literature related to this research work with a description of various parameters used and investigated in this study, research aims and thesis structure. The basic principles of the anaerobic digestion process, different reactor configurations, properties of anaerobic granules and nitrogen removal from wastewaters are elucidated. The importance of phasing in anaerobic systems has been emphasised with an explanation of the anaerobic baffled reactor and its modification, the granular bed baffled reactor.

\subsection{ANAEROBIC TREATMENT OF WASTEWATER}

Sustainable processes for the biological treatment of wastewater require optimal growth conditions for microorganisms in engineered design systems, which are simple, safe, low cost and require fewer resources to operate. These processes should be capable of treating wastewaters to high standards in order to abide by increasingly stringent effluent discharge standards adopted by environmental protection agencies world-wide (European Union Council of Ministers - European Urban Waste Water Treatment Directive 91/271/EEC, 1991; U.S. EPA Effluent Guidelines and Standards, 2003). Such biological wastewater treatment can be accomplished within either aerobic or anaerobic systems. In the 1970s, greater environmental awareness resulted in proposing regulations for addressing pollution control strategies (U.K. Royal Commission on Environmental Pollution, 2003), which encouraged extensive research in innovative technologies for the treatment of wastewaters generated from various sources, particularly industries. During the same time the energy crisis brought about an increase in energy prices, which made operation of aerobic treatment plants expensive. This led to the success of anaerobic digestion processes for the treatment of a wide range of wastewaters, since these processes offer a solution to environmental regulations and 
public concern. Consequently, a number of anaerobic systems were developed and installed throughout the world (Frankin, 2001). Since then these processes are of special interest for treating medium to high strength wastewaters for environmental engineers and microbiologists.

Intensive research work on the anaerobic degradation of wastewaters has led to a superiority of this process over alternative traditional methods, like aerobic processes. There are perceptible advantages of anaerobic systems over aerobic metabolic systems, and these have been widely reported in last four decades (McCarty, 1964; Ghosh et al., 1975; Anderson et al., 1980; Speece, 1983; Lettinga, 1995), viz.

- High degree of waste stabilisation.

- Low (well-stabilised) sludge production, thus savings in excess sludge handling and disposal.

- Methane-rich biogas production provides an economically valuable end-product.

- Low energy consumption with no oxygen requirements.

- Potential of applying high loading rates, thus compact reactor design with low space requirements.

- Low nutrient requirements.

- Low operational and maintenance costs.

Some of these advantages are indicated in the schematic mass balance diagram (Figure 1.1) for carbon removal in anaerobic and aerobic processes.

Anaerobic degradation of organic matter is a multi-step process, involving a number of different bacterial species (McCarty, 1964; Kasper and Wuhrmann, 1978; Gujer and Zehnder, 1983; Pavlostathis and Giraldo-Gomez, 1991). The simplified methane fermentation diagram of complex polymers is shown in Figure 1.2. Methanogenic activity of anaerobic systems depends on the presence of methanogenic bacteria and of substrates converted by these to methane (Dolfing and Bloeman, 1985). Due to the slow growth rates of methanogenic bacteria, their metabolism is generally a rate-limiting step in anaerobic wastewater treatment. This necessitates a long hydraulic retention time (HRT) in the anaerobic systems for creating optimum environment of efficient waste 
treatment. In the past and even for most of the current anaerobic systems, one of the main setbacks is the relatively long biomass retention time (or solid retention time, SRT) required for effective treatment to avoid washout of methanogenic bacteria. In conventional anaerobic systems, HRT within the system has to be maintained long enough in order to ensure long SRT, thus necessitating the need for designing relatively large reactor systems. However, with the advent of high rate anaerobic systems, which are capable of separating HRT and SRT, anaerobic processes are presently proving to be a preferred technology for the treatment of intermediate to high strength wastewaters. Due to this separation, improved cost effective systems of wastewater treatment are now available.
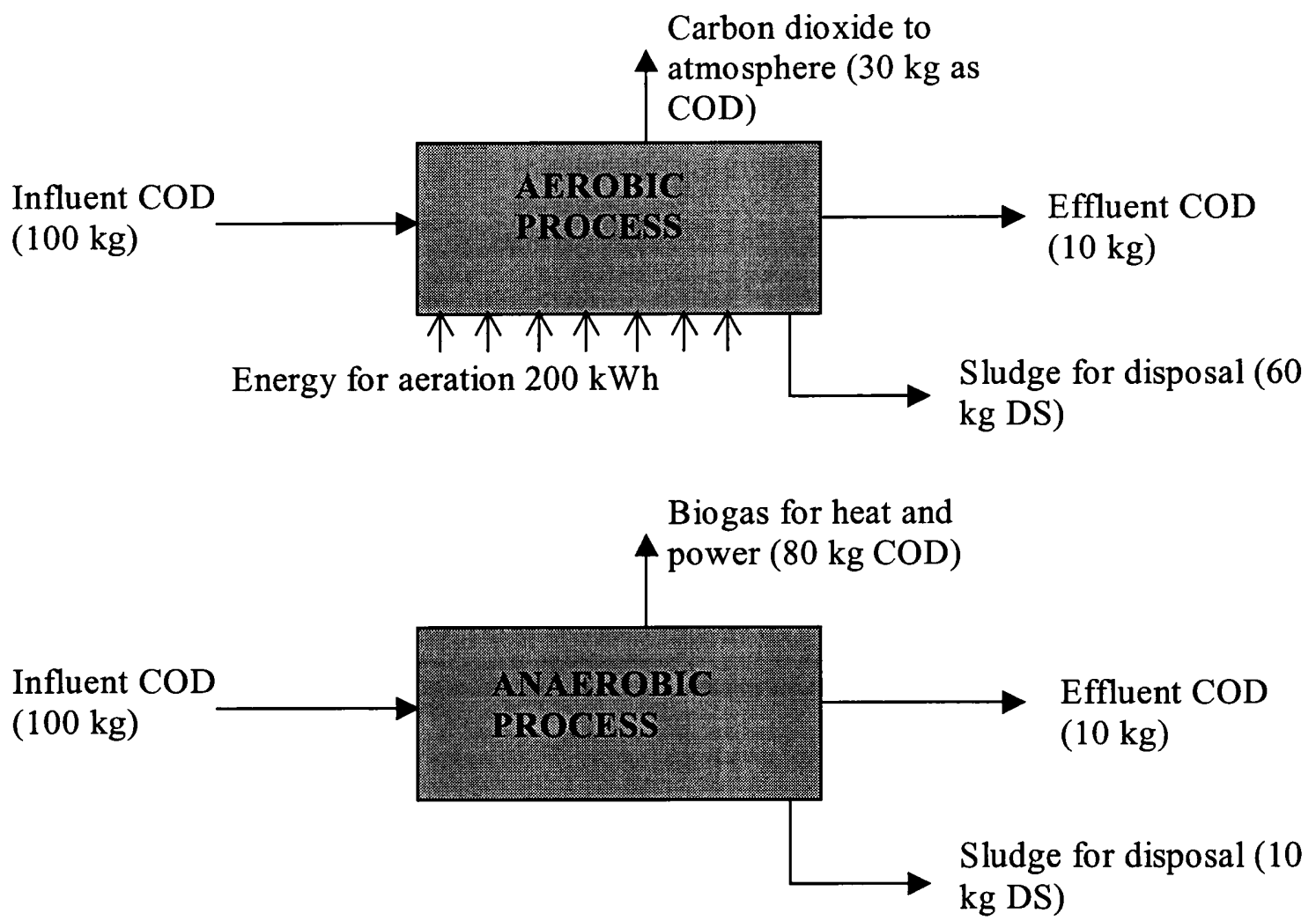

Figure 1.1 Comparison of aerobic and anaerobic processes for treating $100 \mathrm{~kg}$ of chemical oxygen demand (COD) to achieve COD removal efficiency of $90 \%$. Anaerobic carbon conversion generally produces 6 times less sludge (sometimes even less than this figure) than aerobic process, as most of the carbon would be utilised for methane production, which is a source of energy (from Wheatley et al., 1997). 


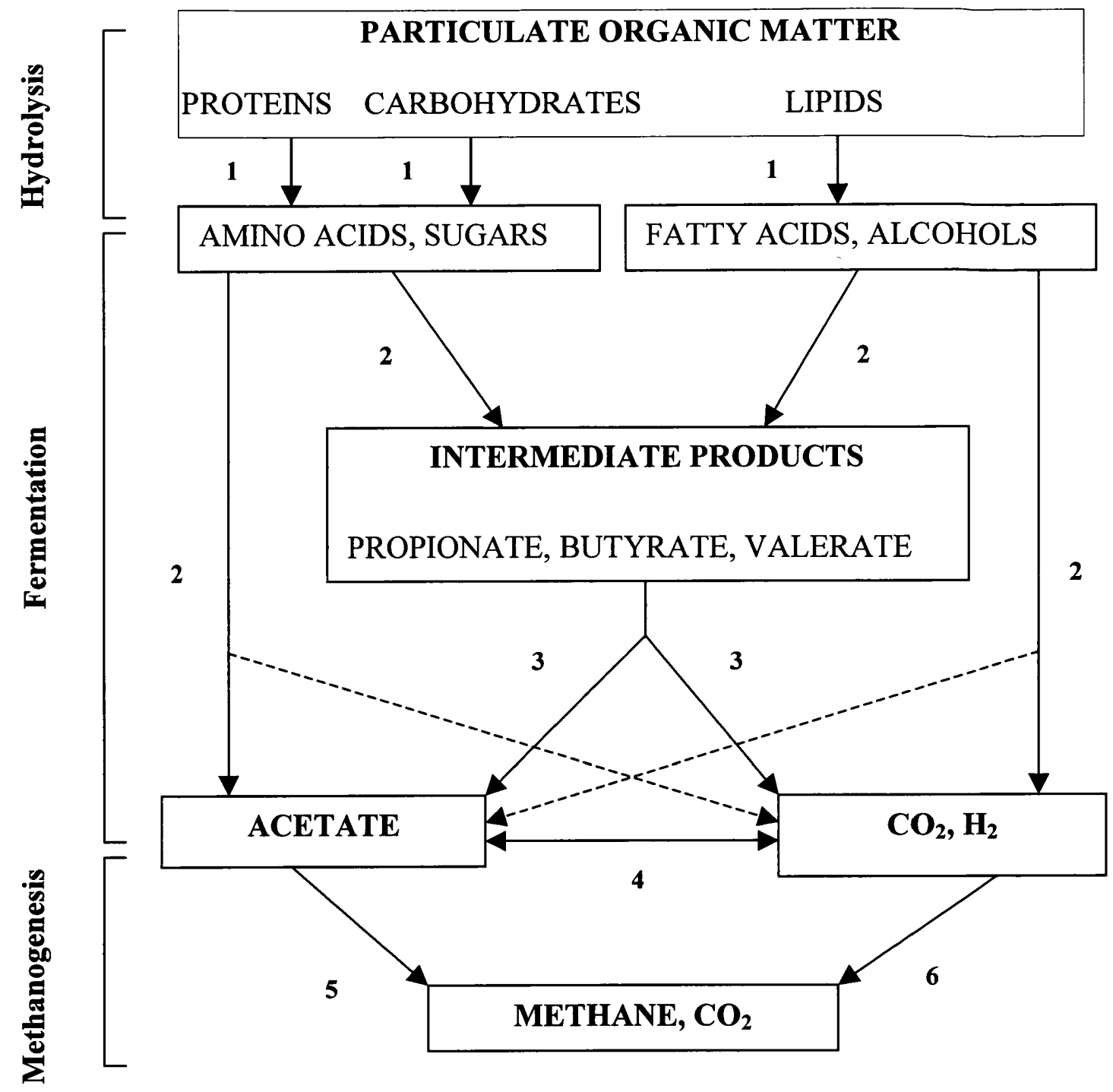

Figure 1.2 Simplified schematic diagram of different reactions involved in anaerobic digestion of complex organic matter (adapted from Kasper and Wuhrmann, 1978; Gujer and Zehnder, 1983).

Key:

1. Hydrolysis of complex polymers by extracellular enzymes to simpler soluble products.

2. Fermentative bacteria converts simpler compounds to short chain fatty acids, alcohols, ammonia, hydrogen, carbon dioxide.

3. Break down of short chain fatty acids to acetate, hydrogen and carbon dioxide, which acts as substrate for methanogenic bacteria.

4. Reaction carried out by homoacetogenic bacteria.

5. About $70 \%$ of methane is produced by aceticlastic methanogens using acetate as substrate.

6. Methane production by hydrogenophilic methanogens using carbon dioxide and hydrogen. 
The concept of high rate anaerobic systems is generally based on three characteristics of the system (Hulshoff Pol et al., 1983; Iza et al., 1991):

- High biomass retention within the system.

- Good contact between wastewater and sludge.

- High specific activity of the biomass.

The optimum contact between active biomass and wastewater has been considered as an important operational condition in order to achieve high stability of anaerobic wastewater treatment system (Iza et al., 1991). Three factors can adversely affect the above property of high rate systems (Iza et al., 1991):

1. Channelling or short-circuiting of the wastewater through the biomass.

2. Clogging of the reactor system.

3. Formation of dead zones in the system, either due to reactor configuration or due to above-mentioned points.

For many years, the application of anaerobic digestion processes was confined to the treatment of concentrated sewage sludges. However, due to the better understanding of controlling and operating these systems, microbial conversion and reactor design, anaerobic treatment is now applied to high strength wastewaters, which includes a wide variety of industrial wastewaters. The number of full-scale anaerobic treatment systems has increased markedly in last 20 years, as evident from Figure 1.3, with its current application for wastewater treatment in over 65 countries to treat industrial waste (Frankin, 2001). This success was mainly achieved due to the development of a better understanding of reactor configuration, substrate complexity and operational parameters (Azbar et al., 2001). Most anaerobic systems are designed for the treatment of medium to high strength wastewaters (Seeler and Jennett, 1978), as they are cost effective for these types of wastewaters. However, more recently, the process application has been extended to treat low strength wastewaters (Kato et al., 1994; Jeison and Chamy, 1999; Langenhoff et al., 2000; Langenhoff and Stuckey, 2000; Foresti, 2002). 
Favourable environmental conditions for the growth of microorganisms are prerequisite for successful operation of anaerobic systems (McCarty, 1964; Anderson et al., 1980), viz.

- Anaerobic conditions.

- Optimum $\mathrm{pH}$ conditions ( $\mathrm{pH}$ between 6 to 8 , though a $\mathrm{pH}$ near 7 is preferred for optimum performance).

- Appropriate constant temperature (psychrophilic, mesophilic or thermophilic range).

- Absence of toxic compounds at inhibitory levels.

- Presence of essential nutrients, macro-nutrients (nitrogen and phosphorus) and micro-nutrients (trace nutrients), in appropriate quantity.

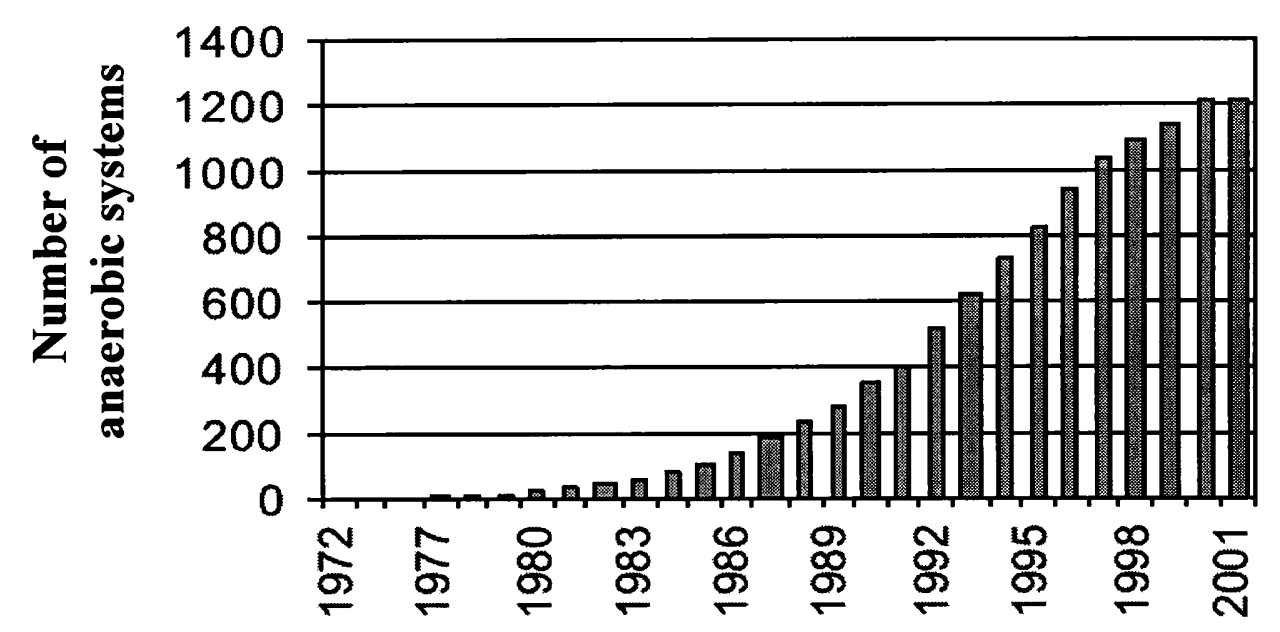

Figure 1.3 Cumulative number of full-scale anaerobic treatment systems for industrial applications in the world (from Frankin, 2001).

In addition, wastewater and seed sludge characteristics, and operation mode of anaerobic system also contribute to its optimal performance (Lettinga, 1995). Though, there are energy requirements for heating the system to maintain the reactor temperature, if operating under mesophilic or thermophilic conditions, gas production during the process can be utilised in the form of heat energy (hot water or steam) in a boiler or energy for electrical power generation. 


\subsection{ANAEROBIC GRANULES}

Anaerobic granules or biogranules are formed by the activities of various groups of microorganisms involved in the anaerobic degradation of wastewater. Hence, granular consortia grown in anaerobic environments involve a diversity of microorganisms (Macleod et al., 1990; Fang et al., 1994). The microbial community in a biogranule is highly dependent on the type of wastewater (substrate), thus leading to the formation of layered or non-layered structures (Grotenhuis et al., 1991b; Fang et al., 1994). Anaerobic granules have been characterised physically, chemically and microbiologically (Dolfing et al., 1985; Hulshoff Pol et al., 1986; Alibhai and Forster, 1986a \& 1986b; Dubourguier et al., 1988a \& 1988b; Batstone and Keller, 2001), and thus different relationships have been developed between granular properties. For example, black granules are reported to posses a higher methanogenic activity than grey granules (Kosaric et al., 1990; Daffonchio et al., 1995). The black colour of granules is mainly associated with the presence of high concentrations (approximately 30\%) of $\mathrm{FeS}$ in the ash content (Dolfing et al., 1985). The predominant minerals found in anaerobic granules are calcium, iron, potassium, phosphorus, sulphur, magnesium and sodium (Alibhai and Forster, 1986b; Dubourguier et al., 1988a \& 1988b; Bhatti et al., 1995), and have been found to play a key role in granule stabilisation. Granules contains extracellular polymeric substances (EPS) which mainly consist of proteins, carbohydrates and nucleic acids (Bhatti et al., 1995). The chemical composition of anaerobic granules is comparable to bacteria in general (Dolfing et al., 1985). Methanothrix sp. has been reported to be a key population in the initiation or formation of granular consortia (Alibhai and Forster, 1986a; Macleod et al., 1990; Fang et al., 1994).

\subsubsection{GRANULATION PROCESS}

The upflow anaerobic sludge blanket (UASB) reactor is one of the most attractive technologies for anaerobic wastewater treatment (Lettinga, 1995). The first laboratoryscale UASB system was operated in 1971 at the Agricultural University of Wegeningen, The Netherlands (de Zeeuw, 1988). The first reported observation of granular sludge in a UASB system was in a $6 \mathrm{~m}^{3}$ pilot plant, inoculated with digested sewage sludge, during 1974-1976 for treating beet sugar factory wastewater in Breda, The Netherlands 
(Lettinga et al., 1979 \& 1980; de Zeeuw, 1988). The success of UASB reactor systems has been attributed to the formation of the granules that have been found to be wellsettled and active biomass (Hulshoff Pol et al., 1983; Wiegant et al., 1986; Alibhai and Forster, 1986b; de Zeeuw, 1988; Hickey et al., 1991; Fang et al., 1994; Bae et al., 1995; Liu and Tay, 2002).

Granulation results from microbial self-immobilisation and subsequently aggregate formation and growth (Yan and Tay, 1997). Granulation enhances biomass settleability (i.e. high biomass retention) and improves physiological conditions in the anaerobic unit (McCarty and Smith, 1986), thus enabling the reactor to operate at high loading rates with low biomass washout (Hulshoff Pol, 1989). Reactor hydrodynamics have been reported to play a key role in the granulation process (Hulshoff Pol, 1989; Arcand et al., 1994; Liu and Tay, 2002). The formation of anaerobic granules has been favoured in a relatively high hydrodynamic shear force environment (Liu and Tay, 2002). Although the granulation process has been observed in various anaerobic systems, it is generally associated with UASB systems (Liu and Tay, 2002). The main reason could be that the flow pattern (circular flow) in column-type upflow systems, with high reactor height to diameter ratio, short HRT and high upflow velocity may favour granulation (Liu and Tay, 2002). These authors reported that circular flow pattern could force microbial aggregates to form regular shaped granules (Liu and Tay, 2002). Low substrate concentrations in the influent wastewaters can also enhance the granulation process (Hulshoff Pol, 1989; Lettinga, 1995).

A lot of research work has been attempted to explain the commencement of granulation process in anaerobic systems, however the mechanism of granule formation is still not very clear (Schmidt and Ahring, 1993). The mechanism of granulation has also been associated with the bacterial adhesion to inert matter or to inorganic precipitates such as iron sulphide or calcium phosphate or by adhesion of bacteria to each other (Ross, 1984; Dolfing et al., 1985; Mahoney et al., 1987; Grotenhuis et al., 1991a). The role of EPS in granule formation has also been emphasised by a number of researchers (Ross, 1984; Alibhai and Forster, 1986a; Shen et al., 1993). Furthermore, environmental factors, such as temperature, $\mathrm{pH}$, type of wastewater and availability of nutrients, also play a key role in the granulation process (Hulshoff Pol et al., 1983). 
The formation of granular sludges in anaerobic systems is generally desired, but cannot be guaranteed. Sludge granulation has been reported to be an important observation to achieve high performance of UASB systems (de Zeeuw, 1988). These sludges can be stored without feeding (without substrate) for a long period of times (more than a year). Lettinga and Hulshoff Pol (1991) reported that anaerobic granule can be a suitable inoculum for starting new systems regardless of their composition and strength. Dense or compact packing of anaerobic granules has several advantages over dispersed growth systems (McCarty and Smith, 1986), as reported in the Section 1.5.

\subsection{ANAEROBIC SYSTEMS}

Reactor design plays an important role in selecting the operational conditions of the system. Furthermore, selection of microbial populations within the system is believed to be dependent on the reactor configuration (Speece et al., 1997). Environmental engineers are keen to achieve the following main objectives for the design of new anaerobic systems (Iza et al., 1991). It should be:

- capable of treating significant amount of organic matter,

- tolerant to shock load conditions,

- high gas production to achieve improved natural mixing within the system without using any form of mechanical mixing,

- achieve maximal SRT in the system with minimal sludge production,

- operate the system on minimal HRT (high loading rates) to minimise the reactor volume, and

- high methane production in order to utilise it as a form of energy.

Anaerobic lagoons or ponds are low rate systems, requiring high hydraulic and solid retention time for efficient anaerobic degradation. These systems require large space and are odoriferous. However, they do not require skilled supervision, and generally have low operational and maintenance costs (Peña et al., 2000).

The first generation of reactors for anaerobic biotechnology were suspended growth continuously stirred tank reactors (CSTRs), with no recycling of solids (Speece et al., 
1983). In order to increase the SRT in the CSTR, solids recycling was introduced and the system was called the anaerobic contact process (Speece et al., 1983). Anaerobic contact processes consist of two parts; the contact reactor and the biomass settling tank. These systems are also known as the anaerobic activated sludge process. The settling tank separates the biomass from the treated wastewater, which (biomass) is recycled to the contact reactor to seed the influent wastewaters.

The anaerobic filter system (Young and McCarty, 1969) is an attached growth treatment process, which requires bulky carrier material for the treatment of wastewaters. The wastewater contacting the media during upflow or downflow movement enhances the growth of anaerobic bacteria on the media. Clogging and channelling have been observed with these systems, particularly when the influent contained fat, insoluble organics or high solid contents (Environment Canada, 1986). Solids accumulation on the media can adversely affect reactor hydraulics and internal mass transfer characteristics, and hence needs to be washed on a regular basis.

Fluidised or expanded bed reactors (Switzenbaum and Jewell, 1980) are also attached growth treatment processes and require fluidised carrier material as an appropriate medium. However, these reactors have similar problems as anaerobic filters. Clogging of the fluidised bed can cease the treatment process due to excessive growth of microorganisms on the carrier material with long start-up times. There are few full-scale fluidised bed systems in operation due to higher energy demand for fluidisation and difficulty in construction and operation (Iza et al., 1991).

In UASB systems, wastewater is fed to the bottom of the reactor and flows upward through a sludge blanket or bed comprised of granules or flocs. The application of UASB reactors has been extensively researched for the treatment of industrial and domestic wastewaters (Lettinga, 1995). However, the UASB process has some disadvantages; biomass washout with the effluent, possibility of excessive bed expansion, long start-up time, susceptibility to hydraulic shock loads (Hulshoff Pol et al., 1983; Sayed et al., 1987; Guiot et al., 1995; Lettinga, 1995, Nachaiyasit and Stuckey, 1995, Shin et al., 2001). Even distribution of wastewater can also pose problems in UASB systems, as it may require adequate number and placement of feed inlets at the bed of the reactor (Iza et al., 1991). Furthermore, deterioration of the 
granular structure in a UASB reactor was found with influent wastewater containing a high solids content (Iza et al., 1991).

A modification of the UASB system is the expanded granular sludge bed (EGSB) system, which uses an expanded sludge bed throughout the height of the reactor. These reactors are usually initiated with an expanded bed of granular biomass. This allows EGSB units to operate on high loads (upflow velocities of 7 to $10 \mathrm{~m} \mathrm{~h}^{-1}$ ) as compared to UASB systems, which generally operate at upflow velocities of 0.5 to $2 \mathrm{~m} \mathrm{~h}^{-1}$ (Jeison and Chamy, 1999; Gonzalez-Gill et al., 2001). This also increases mixing within the system and improves wastewater-sludge contact (Kato et al., 1994). However, these authors observed sludge washout problems and sludge bed expansion due to high gas production (Kato et al., 1994). The market for EGSBs has increased in the last 10 years and it is currently most popular than any other systems (Frankin, 2001). The average operating OLR of full-scale EGSB systems is calculated as $20 \mathrm{~kg} \mathrm{COD} \mathrm{m}^{-3} \mathrm{~d}^{-1}$, while the average operating OLR for UASB systems is $10 \mathrm{~kg} \mathrm{COD} \mathrm{m}^{-3} \mathrm{~d}^{-1}$ (Frankin, 2001). UASB and EGSB reactors contribute to about $72 \%$ of the world market for anaerobic treatment systems (Frankin, 2001). Internal circulation (IC) reactor operates on the concept of the EGSB system, characterised by the biogas separation in two stages within a reactor with a large height to diameter ratio and gas-driven internal effluent circulation (Driessen and Yspeert, 1999).

\subsection{PHASE SEPARATION IN ANAEROBIC SYSTEMS}

The anaerobic systems described in the above section are considered as single-stage reactors, since all the activities involved take place in the same environmental condition. Although anaerobic degradation processes involve large numbers of different microorganisms, as shown in Figure 1.2, the process is mainly driven by two types of reactions, i.e. acidogenesis and methanogenesis (Zoetemeyer et al., 1982). Excess volatile fatty acid (VFA) concentrations in the effluent are mainly due to improper balance between acidogenesis and methanogenesis due to the dominance of the acidogenic process and suppression of methanogenic activity. In phase separation systems, optimised conditions are achieved for the growth of different microorganisms, particularly acidogens and methanogens, in different zones. Since the optimum growth conditions for these two groups of microorganisms are different, favourable 
environmental conditions in their respective phase are provided to maximise their activities (Anderson et al., 1994).

In a two-phase system (Pohland and Ghosh, 1971; Anderson et al., 1994; Shin et al., 2001), complex organic substances (carbohydrates, proteins, fats) are hydrolysed and fermented mainly to VFAs in the first phase by a number of microorganisms, collectively known as acidogenic bacteria. In the second phase, acid products are mainly converted to methane by methanogenic bacteria (Dinopoulou and Lester, 1989). In general, the retention time in an acidogenic reactor is shorter than that in the methanogenic unit.

The main advantages of phase separation and/or two-phase configurations are as follows (Ghosh et al., 1975; Cohen et al., 1980 \& 1982; Anderson and Saw, 1984; Anderson et al., 1994; Speece et al., 1997):

- Optimised environmental conditions for acidogens and methanogens.

- Maximised substrate conversion with lower effluent VFA concentrations.

- Increased process stability.

- Operation of system at high loading rates.

- Acidogenic phase can serve as a buffering system for subsequent methanogenic phase.

- Improved gas yield.

In comparative studies between single and phase separated anaerobic systems, phase separation processes outperformed single stage systems (Bull et al., 1984). Effluent recycling to an acid phase was found to reduce the consumption of alkali to maintain appropriate $\mathrm{pH}$ levels in the acidogenic reactor of a two-phase system (Romli et al., 1994). Azbar et al. (2001) compared various possibilities of reactor configurations and observed high treatment performance with multiple stage processes (phase separation) and plug flow systems, hence elucidating the importance of plug flow phase separated systems. Cohen et al. (1980 \& 1982) observed maximum COD conversion rate with greater overall process stability in a two-phase system when compared with one-phase system. Cohen et al. (1982) observed faster recovery of two-phase systems towards 
stabilisation than that observed with a single-phase system after removing the overloading conditions. However, two-phase systems require supervision and maintenance in order to control the operation of the system.

Compartmentalisation in anaerobic systems is one way of incorporating phase separation and plug flow conditions in a single unit. The concept of compartmentalisation in anaerobic reactors was first introduced by Bachmann et al. (1983), the system was known as an anaerobic baffled reactor. A detailed description of this system with its performance levels with various types of wastewaters is explained in the following section.

\subsubsection{ANAEROBIC BAFFLED REACTOR}

Speece (1983) in his article on the suitability of anaerobic processes for industrial wastewater treatment reported that '....significant developments in reactor design are now laying a strong foundation for the development of efficient and reliable anaerobic biotechnology for treatment of wide variety of industrial wastewaters.' At the same time, Bachmann et al. (1983) made a fascinating discovery whilst evaluating an anaerobic rotating biological contactor system. These authors (Bachmann et al., 1983) observed that no rotation of the disc is necessary for wastewater treatment, and thus the concept of the anaerobic baffled reactor (ABR) was developed (Figure 1.4). The ABR system comprises a series of vertical baffles to force the wastewater to flow under and over them as it passes from inlet point to outlet point. The microorganisms within the reactor tend to rise and settle with gas production. Due to compartmentalisation, the horizontal movement of bacteria is slow giving a high biomass retention within the system and allows more contact between wastewater and solids without the use of any fixed media (Barber and Stuckey, 1999). The reactor design has been described as simple, inexpensive to construct, with low operational and maintenance costs, and requires no separate gas collection unit (Bachmann et al., 1985; Barber and Stuckey, 1999). It has been also reported that such a reactor configuration reduces the risk of clogging and sludge bed expansion (Bachmann et al., 1985). These authors (Bachmann et al., 1985) have also reported that the compartmentalised construction of the reactor 
gives an optimum contact between the wastewater and the active retained biomass in the reactor, thus precluding any requirement for mechanical mixing.

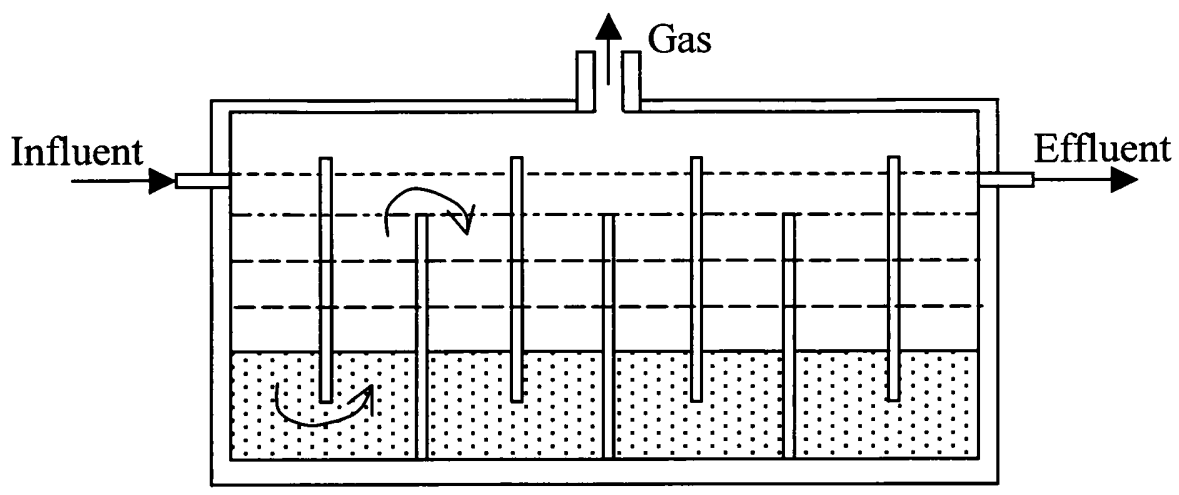

$1.4 a$

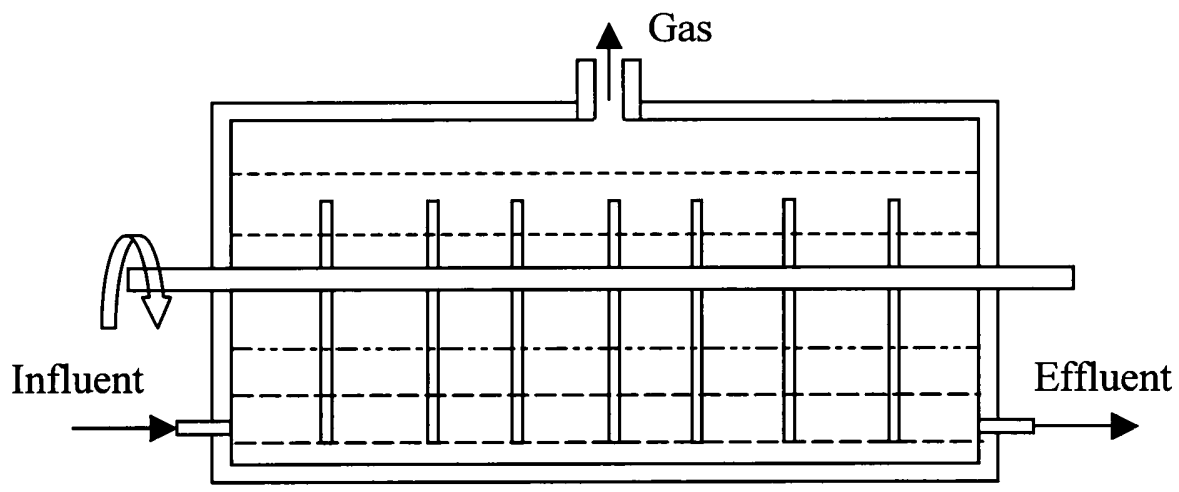

1.4b

Figure 1.4 One of the early designs presented for an anaerobic baffled reactor (Figure 1.4a) modified from anaerobic rotating biological contactor system (Figure 1.4b) by removing rotating discs (from McCarty, 1981).

The $A B R$ is one of the high rate suspended growth anaerobic wastewater treatment systems. It is different from other high rate anaerobic systems because of its compartmentalised nature, which encourages phase separation along the length of the reactor (Barber and Stuckey, 1999). The ABR contains a number of compartments, which are separated by baffles, thus giving a plug flow pattern and minimises biomass washout (Barber and Stuckey, 1999). Each compartment of an ABR by itself is believed to be a separate treatment unit and completely mixed. Some authors believe that an $\mathrm{ABR}$ does not require granulation for high treatment performance (Barber and Stuckey, 1999). However, sludge granulation has been observed in various ABR studies (Tilche and Yang, 1988; Boopathy and Tilche, 1991; Uyanik et al., 2002a). The system has 
been evaluated for its hydrodynamic characteristics and found to possess low dead space i.e. low unused volume of the reactor (Grobicki and Stuckey, 1992), and hence an optimum utilisation of reactor volume.

The ABR system and its modified configurations have been applied for various wastewater treatment applications, such as, slaughterhouse wastewater (Polprasert et al., 1992), ice-cream wastewater (Uyanik et al., 2002a), whisky wastewater (Boopathy et al., 1988), molasses wastewater (Boopathy and Tilche, 1991 \& 1992; Xing and Tilche, 1992), piggery manure (Boopathy and Sievers, 1991), palm oil wastewater (Faisal and Unno, 2001), phenolic wastewater (Holt et al., 1997) and pharmaceutical wastewater (Fox and Venkatasubbiah, 1996). More recently, the treatment application of ABR has been extended for the treatment of low strength wastewaters (Langenhoff et al., 2000; Langenhoff and Stuckey, 2000).

Despite its uniqueness and many advantages, it is surprising that $A B R$ systems are still not commonly in use at full-scale. A decrease in process performance was observed with ABR systems at high OLRs, particularly at short HRTs (Bachmann et al., 1985; Grobicki and Stuckey, 1991; Boopathy and Tilche, 1992; Nachaiyasit and Stuckey, 1997b), as also shown in Figure 1.5. Furthermore, it has also been described as a series of UASB systems (Boopathy et al., 1988). However reactor efficiency in comparison with UASB configurations was lower, particularly at high OLRs. This process instability at high loads appears to be the main reason why other high rate anaerobic systems (namely, UASB and EGSB) outcompete ABR type systems on full-scale installations. Hence, modification of ABR systems is required to overcome the above problems and hence one of the amended configurations is discussed in the following section.

\subsection{CONCEPT OF GRANULAR BED BAFFLED REACTOR}

Different types of microbial aggregates have been developed or used as inoculum in anaerobic systems for treating wastewaters. Generally, these microbial aggregates are broadly divided into non-granular dispersed sludge or flocs and granules (Dolfing, 1987; Bellouti et al., 1997): 
- Flocs are non-granular aggregates with a loose structure. These aggregates cannot be individualised after settling.

- Granules are dense pallets with a granular shape. These aggregates are visible as separate entities after settling.

A number of studies have reported the advantages of granular structure over nongranular aggregates, and the findings are summarised as follows:

- Dense granular sludge settles discretely, with settling velocities in the range of 2 to $90 \mathrm{~m} \mathrm{~h}^{-1}$ (de Zeeuw and Lettinga, 1983; Lettinga et al., 1983; Dolfing et al., 1985). Flocculent sludge settle as a homogenous layer with low settling velocities $(0.1$ to 1 $\mathrm{m} \mathrm{h}^{-1}$ ). High settling velocities of granular sludge are mainly associated with their dense nature (densities of 1 to $1.05 \mathrm{~kg} \mathrm{~m}^{-3}$ ) and large particle size (0.14 to $5 \mathrm{~mm}$ ), while dispersed cell size varies from 0.5 to $3 \mu \mathrm{m}$ (Dolfing et al., 1985; Grotenhuis et al., 1991a; Yan and Tay, 1997; Laguna et al., 1999).

- Granular sludge is a suitable inoculum for the start-up of high rate systems and accelerates the start-up process as compared to flocculent type sludge (Hulshoff Pol et al., 1983; Lettinga and Hulshoff Pol, 1991; Lettinga, 1995; Banik et al., 1997).

- Flocculent sludge has washout problems during the start-up of the upflow systems (Hulshoff Pol et al., 1983), while granular sludge is subjected to little washout during start-up period. This is due to the stable (compact) structure of granules, which reduce the effect of channelling.

- Granulation ensures high growth rate for the methanogenic bacteria when compared to flocculent sludge (Wijbenga and Bos, 1988). Hence, granular sludge has been found to possess higher specific methanogenic activity than non-granular sludge (Hulshoff Pol et al., 1983). This characteristic also improves the hydraulic mixing within the system.

- Anaerobic granular sludge is less sensitive to substrate inhibition when compared to non-granular sludge (Morvai et al., 1992). The improved performance of anaerobic systems when seeded with granular sludge has been found during process shocks, toxins and other environmental stresses (Chang et al., 1994; Schmidt and Ahring, 1996).

- Methanogens in the granular sludge are more tolerant to oxygen than methanogens in dispersed sludge (Shen and Guiot, 1996). This is due to the presence of 
facultative bacteria in the outer layers of anaerobic granules. This layer will utilise the oxygen before it penetrates into the core of granules, which predominantly consists of methanogens.

- The thermodynamics of substrate conversion to intermediate products and their further degradation to final end-products is enhanced in a system with anaerobic granular sludge due to the presence of various bacterial groups in the granular structure (Schink and Thauer, 1988; Wirtz and Dague, 1996).

Interestingly, despite all the above advantages of granular biomass over non-granular (dispersed or flocculent) sludge, little attention has been paid to use such an ideal microbial aggregate as inoculum in ABR systems. The use of non-granular biomass is believed to be the main reason for the relatively poor performance of ABR type systems at high OLRs or short HRTs. This unstable performance was mainly due to biomass losses or channelling at short HRTs, which posed serious problems and eventually led to poor treatment, as also evident from performance levels of number of studies shown in Figure 1.5.

In order to withstand higher loading rates at short HRTs in the baffled type systems without compromising the effluent quality, it is essential to use biomass that is not only highly active but also structurally stable and possesses good settling characteristics. In this study, the properties of an ABR system and granular sludge have been brought together to create the granular bed baffled reactor (GRABBR). It is believed that such a configuration would not only ensure high treatment efficiency but also encourage relatively high retention of sludge within the reactor even under high hydraulic or organic loading rates (Baloch and Akunna, 2002; Akunna and Baloch, 2002; Baloch and Akunna, 2003a \& 2003b; Akunna and Baloch, 2003) ${ }^{*}$. The latter property will also discourage significant inter-compartmental biomass transfer and consequently minimises biomass losses. Moreover, it is believed that such a system would also encourage greater flow dispersion, low short-circuiting and increased mixing within its compartments than a simple ABR system.

\footnotetext{
${ }^{*}$ Studies from this research work.
} 
Grobicki and Stuckey, 1991

Fox and Venkatsubbiah, 1996

Grover et al., 1999

Nachaiyasit and Stuckey, 1997b

Nachaiyasit and Stuckey, 1997a

Faisal and Unno, 2001

Boopathy et al., 1988

Barber and Stuckey, 1998

Polprasert et al., 1992

Uyanik et al., 2002a

Boopathy and Tilche 1992

Bae et al., 1997

Bachmannn et al., 1985

$$
0
$$

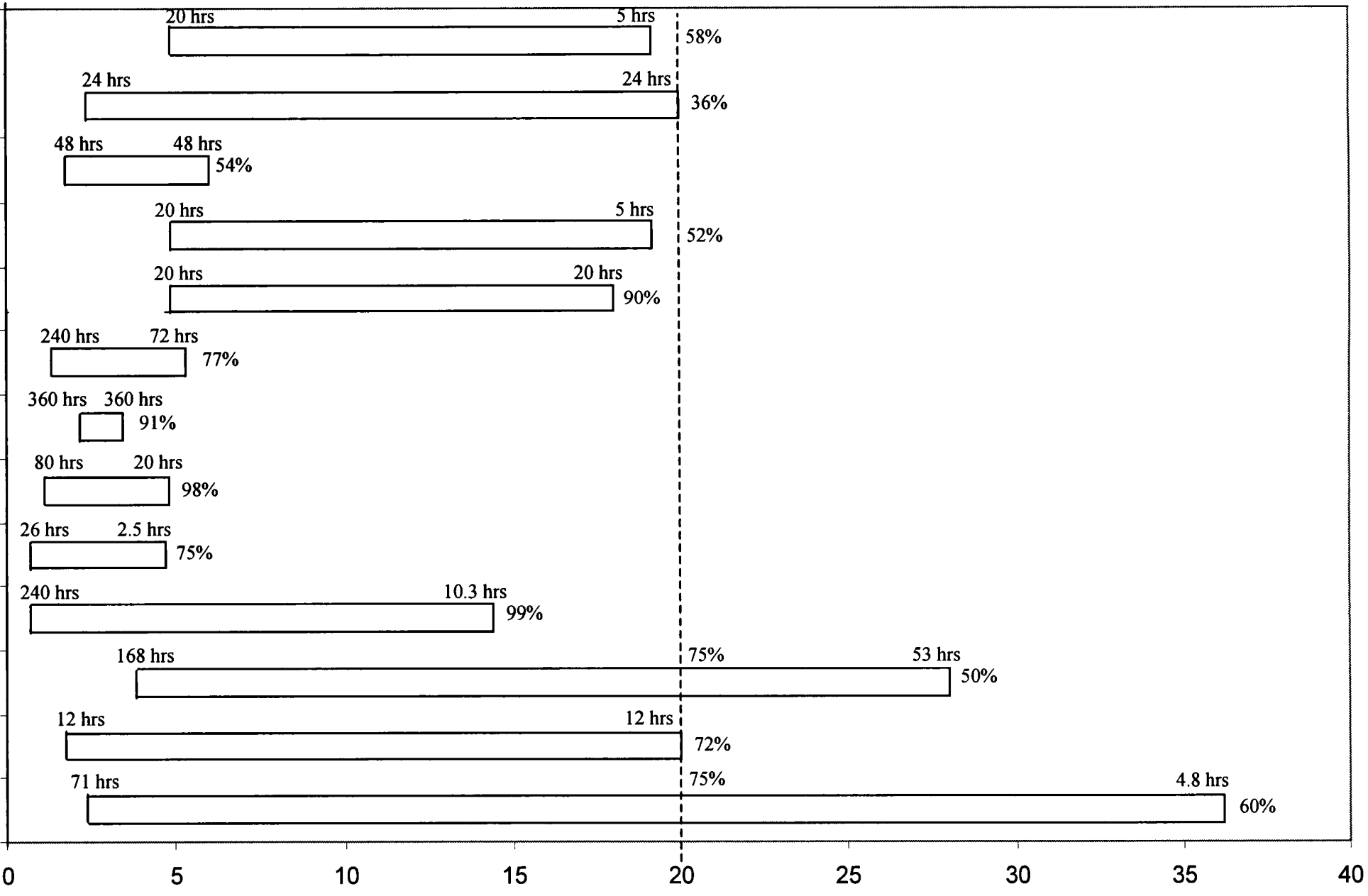

OLR ( $\left.\mathrm{kg} \mathrm{COD} \mathrm{m}^{-3} \mathrm{~d}^{-1}\right)$

Figure 1.5 Operating organic loading rate (OLR) data of anaerobic baffled reactor studies and its modified configurations. On top left and right of each bar represents the corresponding hydraulic retention time. In front of each study (bar), percentage shows the chemical oxygen demand (COD) removal at the end of the experiment. Percentage COD removal are also shown at $20 \mathrm{~kg} \mathrm{COD} \mathrm{m}^{-3} \mathrm{~d}^{-1}$, for studies exceeding this OLR. 


\subsection{NITROGEN REMOVAL FROM WASTEWATERS}

Accumulation of nitrogenous compounds in water bodies can adversely effect the environment, ecology, economic and public health (Chong and Loehr, 1978). This includes eutrophication, high oxygen demand of waters, adverse effects on aquatic life, interference with chlorination of water supplies (if the water body is used as a drinking water source), affecting the suitability of wastewaters for reuse and other public health hazards (Suthersan and Ganczarczyk, 1986, Metcalf and Eddy, 1991). Eutrophication is a major problem caused by nutrient discharge resulting in excessive plant growth and algal blooms in the receiving water bodies. Nitrogen and phosphorus are the main elements causing eutrophication. Ammoniacal nitrogen (in the form of free unionised $\mathrm{NH}_{3}$ and ionised $\mathrm{NH}_{4}^{+}$) is the most common form of nutrients. Ammonia contributes $80 \%$ to $90 \%$ of the total nitrogen in the municipal wastewaters (Suthersan and Ganczarczyk, 1986). Various industrial effluents, particularly food processing and beverage wastewaters, also contain high amounts of nitrogenous compounds.

The European Union Urban Waste Water Treatment Directive (91/271/EEC) requires standards for total nitrogen, at sensitive areas, less than $10 \mathrm{mg} \mathrm{l}^{-1}$ (>100000 population equivalent) for discharge into eutrophic receiving waters (European Union Council of Ministers, 1991).

Biological nitrogen removal is the most common method of removing nitrogenous compounds from wastewaters (Skrinde and Bhagat, 1982; Werner and Kayser, 1991). Biological nitrogen removal is a two-step process and involves nitrification and denitrification systems, with nitrogen gas released as the end product. The main advantages of such system are (Metcalf and Eddy, 1991):

- High process performance, stability and reliability.

- Less skilled supervision is required as compared to other processes.

- Low land requirements and moderate operating cost. 


\subsubsection{BIOLOGICAL NITRIFICATION}

Autotrophic nitrifying microorganisms oxidise ammonia to nitrate, a process called nitrification. Nitrification is a prerequisite for denitrification. Nitrification is a two-step process carried out mainly by two genera of nitrifying species, as illustrated in the following equations (U.S. EPA, 1993):

Conversion of ammonia to nitrite by Nitrosomonas bacteria:

$$
\mathrm{NH}_{4}^{+}+1.5 \mathrm{O}_{2} \rightarrow \mathrm{NO}_{2}^{-}+2 \mathrm{H}^{+}+\mathrm{H}_{2} \mathrm{O}
$$

Followed by further conversion of nitrite to nitrate by Nitrobacter bacteria:

$$
\mathrm{NO}_{2}^{-}+0.5 \mathrm{O}_{2} \rightarrow \mathrm{NO}_{3}^{-}
$$

Both groups of microorganism utilise mainly carbon dioxide as the carbon source for biosynthesis and nitrifiers gain energy by oxidation of ammonia to nitrite or nitrate (Antoniou et al., 1990). The energy yield of Equation (1.2) is less than that of Equation (1.1), and hence, the rate of conversion of ammonia to nitrite controls the rate of overall nitrification reaction (Adams and Eckenfelder, 1977). The overall oxidation of ammonium by both groups of microorganisms, by adding Equations 1.1 and 1.2, can be represented as (Equation 1.3):

$$
\mathrm{NH}_{4}^{+}+2 \mathrm{O}_{2} \rightarrow \mathrm{NO}_{3}^{-}+2 \mathrm{H}^{+}+\mathrm{H}_{2} \mathrm{O}
$$

Considering a part of ammonia utilised for cell synthesis (by assuming an empirical formula of $\mathrm{C}_{5} \mathrm{H}_{7} \mathrm{O}_{2} \mathrm{~N}$ for synthesis of bacterial cells), the overall complete nitrification process can be represented by the following expression (Equation 1.4) (Randall et al., 1992; U.S. EPA, 1993):

$$
\begin{aligned}
& \mathrm{NH}_{4}^{+}+1.83 \mathrm{O}_{2}+1.98 \mathrm{HCO}_{3}^{-} \rightarrow 0.021 \mathrm{C}_{5} \mathrm{H}_{7} \mathrm{O}_{2} \mathrm{~N}+0.98 \mathrm{NO}_{3}^{-}+1.041 \mathrm{H}_{2} \mathrm{O}+ \\
& 1.88 \mathrm{H}_{2} \mathrm{CO}_{3}
\end{aligned}
$$

The above equation illustrates the stoichiometry of the nitrification process. For each gramme of $\mathrm{NH}_{4}{ }^{+}-\mathrm{N}$ converted to $\mathrm{NO}_{3}-\mathrm{N}, 4.57 \mathrm{~g}$ of $\mathrm{O}_{2}$ is required, $0.1 \mathrm{~g}$ of nitrifiers are produced as volatile suspended solids and $7.1 \mathrm{~g}$ of alkalinity $\left(\right.$ as $\left.\mathrm{CaCO}_{3}\right)$ is utilised (U.S. 
EPA, 1993). Hence, the process consumes ammonia, oxygen and bicarbonate. If sufficient alkalinity is available in the wastewaters, the oxygen requirement will be lower (approximately $4.3 \mathrm{~g}$ ) for $1 \mathrm{~g}$ ammonium conversion to nitrate (Adams and Eckenfelder, 1977). These authors (Adams and Eckenfelder, 1977) further stated that this figure might be of an order of about $3.9 \mathrm{~g}$, as some nitrogen will be utilised for cell synthesis. If nitrification processes are not limited by insufficient inorganic carbon, some oxygen will be obtained from other sources, for example, carbon dioxide, carbonates and bicarbonates (Adams and Eckenfelder, 1977). Generally, the growth rate of the nitrifiers is relatively slow and large nitrifying plants are designed to meet this criterion (Maurer et al., 2002).

The growth of nitrifying bacteria is affected by a number of factors such as $\mathrm{pH}$, temperature, dissolved oxygen and toxic compounds (Gullicks and Cleasby, 1990; Randall et al., 1992; U.S. EPA, 1993). The optimum $\mathrm{pH}$ range for nitrification is 6.5 to 8 (U.S. EPA, 1993). In nitrifying biofilms, decreases in $\mathrm{pH}$ below 7 increase the nitrite oxidation rate, but decrease the ammonia oxidation rate (Szwerinski et al., 1986). Free ammonia and nitrous acid are the main inhibitors of nitrification process at higher and lower $\mathrm{pH}$ levels respectively (Anthonisen et al., 1976). These researchers (Anthonisen et al., 1976) reported that free ammonia $\left(\mathrm{NH}_{3}\right)$ concentrations of 0.1 to $1.0 \mathrm{mg}^{-1}$ and 10 to $150 \mathrm{mg} \mathrm{l}^{-1}$ are inhibitive to Nitrobacter and Nitrosomonas nitrification processes. Inhibition caused by free ammonia (unionised ammonia) is considered more toxic than that of nitrous acid (Prakasam and Loehr, 1972), as it causes incomplete nitrification due to nitrite build-up (Prakasam and Loehr, 1972; Anthonisen et al., 1976; Turk and Mavinic, 1989; Carley and Mavinic, 1991; Abeling and Seyfried, 1992; Fdz-Polanco et al., 2002). The concentration of free ammonia can be controlled by continuous measurement of ammonium and $\mathrm{pH}$ in the nitrification unit (Abeling and Seyfried, 1992). A temperature range of 4 to $45^{\circ} \mathrm{C}$ has been used for various nitrification processes. The optimum range is described as 28 to $32^{\circ} \mathrm{C}$, with complete cessation of the process below $5^{\circ} \mathrm{C}$ (Adams and Eckenfelder, 1977). Nitrifying organisms can be inhibited by various organic and inorganic compounds, if present above toxic levels. These compounds include heavy metals, phenols, halogenated compounds, cyanides etc. (Adams and Eckenfelder, 1977). The growth rate of nitrifiers reduces when dissolved oxygen (DO) concentrations are low (U.S. EPA, 1993). The DO levels varying from 0.5 
to $2.5 \mathrm{mg} \mathrm{l}^{-1}$ in either suspended or attached growth can prove limited for the process (U.S. EPA, 1993).

Nitrification processes may proceed outwith the above-mentioned limits, if the process is acclimatised to such conditions (U.S. EPA, 1993). The nitrification process eliminates the oxygen demand of nitrogen by changing it from ammonia to nitrate nitrogen, but requires further treatment (denitrification) to remove nitrogen (nitrate) from wastewaters.

\subsubsection{BIOLOGICAL DENITRIFICATION}

Heterotrophic as well as autotrophic microorganisms can convert nitrate to nitrogen gas, a process called denitrification. The process is carried out under anoxic conditions (i.e. in the absence of oxygen) and requires an organic (heterotrophic) or inorganic (autotrophic) electron donor. In wastewater treatment processes, the presence of biodegradable organic compounds serving as electron donors makes heterotrophic denitrification a common pathway of nitrate reduction (Bode et al., 1987). When carbon sources in the medium are unavailable in sufficient quantities, external sources must be provided. For this purpose, methanol has been extensively used (Monteith et al., 1980; U.S EPA, 1993).

In biological denitrification, nitrate is reduced to nitrogen gas with nitrite, nitric oxide and nitrous oxide as intermediates, as shown in Equation 1.5 (Metcalf and Eddy, 1991):

$$
\mathrm{NO}_{3}^{-} \rightarrow \mathrm{NO}_{2}^{-} \rightarrow \mathrm{NO} \rightarrow \mathrm{N}_{2} \mathrm{O} \rightarrow \mathrm{N}_{2}
$$

The last three compounds are gaseous products. Another dissimilatory reaction for nitrate is its reduction to ammonium nitrogen (Tiedje, 1988; Akunna et al., 1992), a process also called "dissimilatory nitrate reduction to ammonium" (DNRA) or ammonification. This reaction has been observed in anaerobic systems (Tiedje, 1988; Akunna et al., 1992).

In the denitrification process, a portion of nitrate is reduced to ammonia nitrogen (assimilatory nitrate reduction) to supply nitrogen (nutrient) for cell synthesis (Stensel $e t$ 
$a l .$, 1973). Denitrification is generally considered a two-step process, the first reaction is the reduction of nitrate to nitrite and the second is the conversion of nitrite to molecular nitrogen, as shown in the following expressions (1.6, 1.7 and 1.8) by assuming methanol as an electron donor (Monteith et al., 1980):

$$
\begin{aligned}
& \mathrm{NO}_{3}^{-}+0.33 \mathrm{CH}_{3} \mathrm{OH} \rightarrow \mathrm{NO}_{2}^{-}+0.33 \mathrm{CO}_{2}+0.67 \mathrm{H}_{2} \mathrm{O} \\
& \mathrm{NO}_{2}^{-}+0.5 \mathrm{CH}_{3} \mathrm{OH} \rightarrow 0.5 \mathrm{~N}_{2}+0.5 \mathrm{CO}_{2}+0.5 \mathrm{H}_{2} \mathrm{O}+\mathrm{OH}^{-}
\end{aligned}
$$

The overall reaction (ignoring carbon utilisation for cell synthesis) can be shown as (Bode et al., 1987):

$$
5 \mathrm{CH}_{3} \mathrm{OH}+6 \mathrm{NO}_{3}^{-} \rightarrow 5 \mathrm{CO}_{2}+3 \mathrm{~N}_{2}+7 \mathrm{H}_{2} \mathrm{O}+6 \mathrm{OH}^{-}
$$

A wide diversity of species have been observed to carry out denitrification (Payne, 1981). The most common facultative heterotrophic microorganisms includes the genera: Achromobacter, Bacillus, Micrococcus, Pseudomonas and Spirillum (Stensel et al., 1973; Monteith et al., 1980; Carley and Mavinic, 1991), with Pseudomonas species the most common facultative genera in denitrification (Payne, 1981; Horsley et al., 1982). In the absence of molecular oxygen, most of these microorganisms use nitrate or nitrite as terminal electron acceptors while oxidising organic matter for energy.

The reduction of each gram of nitrate nitrogen will reduce $2.86 \mathrm{~g}$ of oxygen demand and produce $3.57 \mathrm{~g}\left(\right.$ as $\mathrm{CaCO}_{3}$ ) of alkalinity (U.S. EPA, 1993). DO concentrations of $0.5 \mathrm{mg}$ $1^{-1}$ or less are recommended for successful denitrification process (Christensen and Harremoes, 1977). Increasing levels of DO have been found to decrease the denitrification rate (Tiedje, 1988). However, some authors have reported that denitrification can occur in a wide range of aeration conditions or high DO concentrations (Robertson and Kuenen, 1984; Patureau et al., 1994). Denitrifiers have also been found to be less sensitive to inhibitory compounds than nitrifiers (Randall et al., 1992).

The optimal $\mathrm{pH}$ range of denitrification process is between $\mathrm{pH} 6$ and 8 (U.S. EPA, 1993). The conversion reaction of nitrate to nitrite is less sensitive to $\mathrm{pH}$ drops than 
nitrite to nitrogen gas (Francis and Callahan, 1975). The denitrification process is inhibited by nitrous acid, and concentration as low as $0.13 \mathrm{mg} \mathrm{l}^{-1}$ can destabilised the process (Abeling and Seyfried, 1992). Hence, far-reaching complete denitrification is vital to control the influence of this inhibition on the process (Abeling and Seyfried, 1992). Optimum temperature for denitrification has been reported as $60^{\circ} \mathrm{C}$ (Francis and Callahan, 1975). Temperature less than $10^{\circ} \mathrm{C}$ noticeably decrease denitrification activities (Stensel et al., 1973).

Nitrate reduction processes have been well studied in agricultural soils (Paul et al., 1989). Dissimilatory nitrate reduction to ammonium has been found to be favoured in anaerobic soils (Nommik, 1956; Buresh and Patrick, 1978). The complexity of carbon sources may favour nitrate reduction to ammonium (Francis and Callahan, 1975). Cole (1978) observed $75 \%$ of added nitrate nitrogen was accumulated as ammonium with glucose substrate by Escherichia coli. In soil studies, anaerobic ecosystems (Smith, 1982) and anaerobic digested sludge (Kasper et al., 1981) favoured nitrate nitrogen conversion to ammonium nitrogen. This is also the preferred pathway for nitrate reduction in soils, which conserves soil nitrogen (Buresh and Patrick, 1978), rather than losing it as nitrogen gas. However, biological removal of nitrogenous compounds to nitrogen gas is preferred in the wastewater treatment plants, if treated effluent is to be discharged into the aquatic environment.

\subsection{NITROGEN REMOVAL FROM ANAEROBICALLY TREATED WASTEWATERS}

In a conventional process, the treatment of high strength wastewaters is usually concerned with the removal of organic matter. However, recently greater efforts have been made for nutrient removal, in addition to carbon removal, due to increasingly stringent discharge standards adopted by environmental protection agencies world-wide (European Union Council of Ministers, 1991; U.S. EPA, 1993). These measures are deemed necessary because of various environmental concerns (as mentioned in Section 1.6) caused by nutrient enrichment of the aquatic system.

Unfortunately, anaerobic treatment of high strength nitrogenous wastewaters only eliminates carbonaceous matter and does not remove significant amounts of nitrogenous 
pollution. Organic nitrogen compounds are mainly reduced to ammonia, which is not usually further degraded in anaerobic treatment. A relatively small portion of nitrogen will be utilised for biomass growth. Thus, the effluent of anaerobically treated wastewater would be rich in ammonia if the raw wastewater contained high amounts of nitrogenous compounds. As an indication of the potential impact of nitrogen pollution, $1 \mathrm{~kg}$ of nitrogen could potentially simulate the manufacture of $16 \mathrm{~kg}$ of algal biomass, which would be equivalent to $20 \mathrm{~kg}$ of COD (Randall et al., 1992). Most of the high strength wastewaters from industries, such as food and beverage processing effluents, contain high amount of organic matter and in certain cases high nitrogenous compounds in the form of ammoniacal and/or organic nitrogen. Therefore, post treatment is required to remove nitrogen from such effluents. Typical high strength nitrogenous wastewaters with their average COD and ammoniacal nitrogen concentrations are listed in Table 1.1.

Table 1.1 Average chemical oxygen demand (COD) and ammoniacal nitrogen $\left(\mathrm{NH}_{4}-\mathrm{N}\right)$ concentrations of some high strength wastewaters.

\begin{tabular}{lccc}
\hline Type of waste & $\begin{array}{c}\mathrm{COD} \\
\left(\mathrm{mg} \mathrm{l}^{-1}\right)\end{array}$ & $\begin{array}{c}\mathrm{NH}_{4}-\mathrm{N} \\
\left(\mathrm{mg} \mathrm{l}^{-1}\right)\end{array}$ & Reference \\
\hline Piggery & 25533 & 790 & Tilche et al., 1994 \\
& 17138 & 2400 & Font et al., 1997 \\
Tuna processing & $11700-25000$ & $100-200$ & Veiga et al., 1994 \\
Rendering plant & 2470 & 350 & Brond and Sund, 1994 \\
Sanitary landfill leachate & 31000 & 1000 & Borzacconi et al., 1999 \\
Potato starch wastewater & 17000 & 200 & Abeling and Seyfried, 1992 \\
Landfill leachate & $21300-26940$ & $1635-1810$ & Im et al., 2001 \\
\hline
\end{tabular}

For high strength nitrogenous wastewaters to be treated anaerobically, post-treatment for nitrogen removal involving nitrification and denitrification units, in addition to an anaerobic system is required (Borzacconi et al., 1999). This necessitates at least three treatment units, viz. anaerobic digester, denitrification and nitrification units, as shown in Figure 1.6a. The nitrification unit reduces the oxygen demand of ammonia by converting it to nitrate, which is finally reduced to nitrogen gas in the denitrification unit. In addition to requiring three different units, another problem associated with this type of treatment is that nitrogenous wastewaters, with relatively low carbon content 
after anaerobic unit (digested effluent), require additional organic carbon source in the denitrification unit to complete the denitrification process.

The problems stated above led to the development of combined denitrification/methane production in anaerobic digestion systems (Kuroda et al., 1988; Hanaki and Polprasert, 1989; Akunna et al., 1992 \& 1994b; Lin and Chen, 1995; Hendriksen and Ahring, 1996a; Chen et al., 1997; Bernet et al., 2000; Mosquera-Corral et al., 2001). Such a combined integrated system utilises the carbon source available in the wastewater as an electron donor for the denitrification process. This will eliminate the operational problems associated with maintaining three independent treatment units and an additional cost for external substrate for the completion of denitrification. With this combined system, the organic carbon remaining after denitrification will be converted to methane gas. Ammonia can be nitrified in the following nitrification unit, which not only converts this ammonia to nitrate, but also completes carbon removal. The nitrified wastewater can then be recycled to the anaerobic digester for denitrification. The schematic of such conventional treatment process is shown in Figure 1.6b. The success of a combined integrated system would enhance the treatment efficiency in terms of low effluent carbon and nitrate content along with reduced cost and complexity in the treatment of high strength nitrogenous wastewaters.

The development and wide application of combined denitrification/anaerobic digestion has been hampered by nitrate inhibition to methane producing bacteria (Akunna et al., 1992, 1993 \& 1994a; Hendriksen and Ahring, 1996a; Clarens et al., 1998). They mainly attributed this inhibition to the different environmental conditions required to mediate methane production and nitrate reduction. Hence the integration of these processes in a single reactor may produce complexity in controlling the overall system. Therefore, a reactor design is required which can provide zoning for the optimum growth of microbial species for the integrated process, so that favourable conditions can be obtained for acidifiers, denitrifiers and methanogens. Furthermore, a suitable microbial inoculation is required in order to enhance specific activities, and withstand (and adapt) to varying operational conditions for carbon and nitrate removal to bring about high process stability and efficiency. 


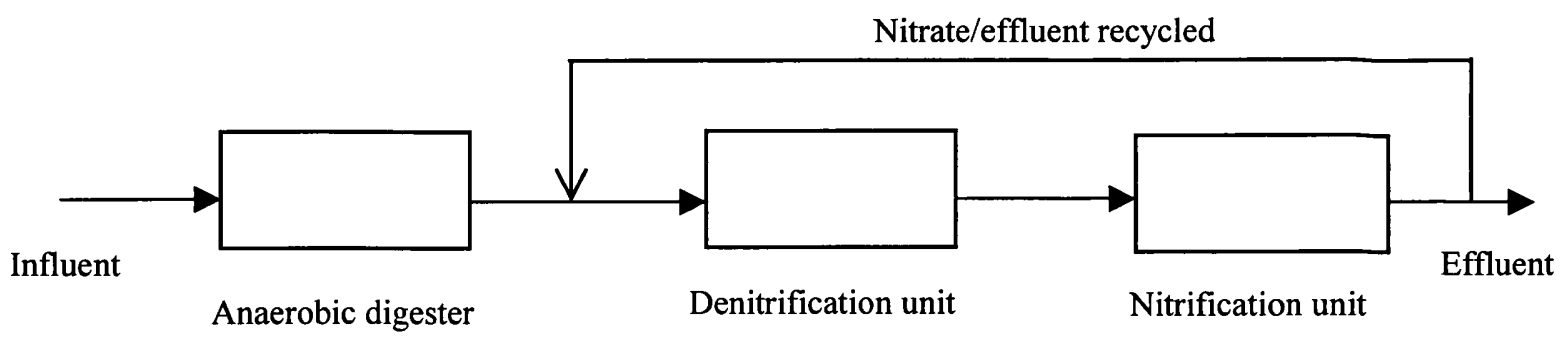

$1.6 a$

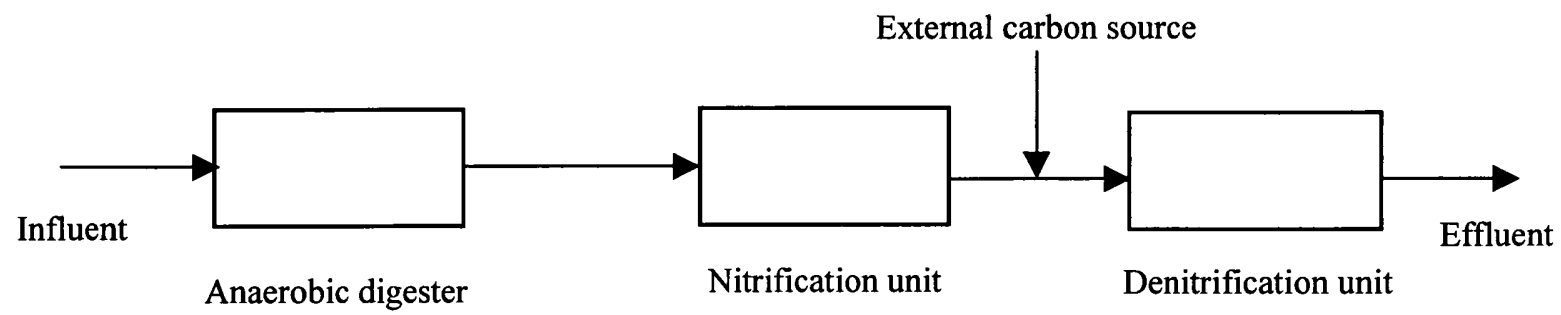

\section{$1.6 b$}

Figure 1.6a \& b Schematic diagrams of conventional treatment configuration for biological carbon and nitrogen removal for anaerobically treated high strength nitrogenous wastewaters.

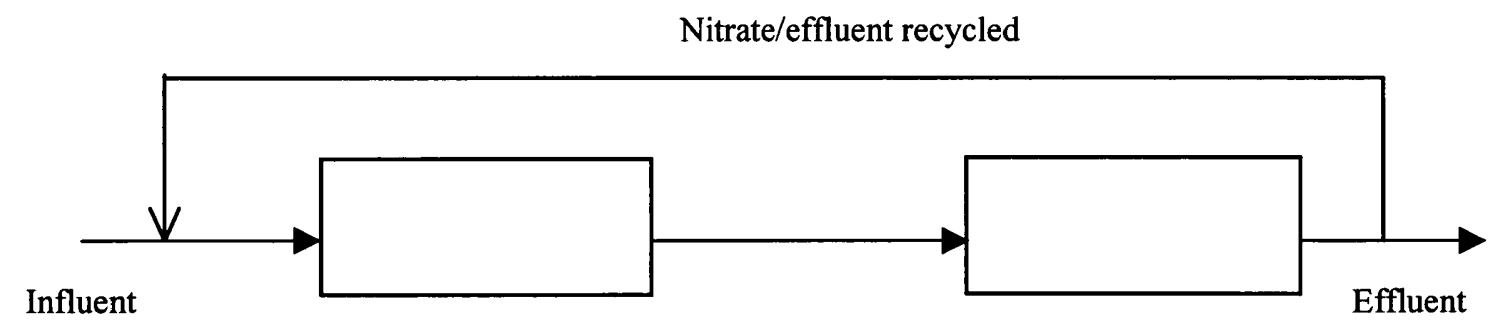

Anaerobic digestion/Denitrification unit

Nitrification unit

Figure 1.6c Schematic diagram of combined anaerobic digestion and denitrification in a single unit followed by a downstream nitrification unit for anaerobically treated high strength nitrogenous wastewaters. 
A plug flow multi-phase granular bed bioreactor, like GRABBR, may prove to be a more suitable system for the combined removal of carbonaceous and nitrogenous pollution than the traditional anaerobic bioreactors, due to its properties illustrated in Section 1.5. The other advantages of performing combined denitrification and methanogenesis in a GRABBR type system are described in Chapter 5. This Chapter also reviews other studies related to such integrated approach.

\subsection{RESEARCH AIMS}

The following aims were set for this research work:

- To examine the performance of a new suspended growth system, a GRABBR, over a wide range of operating conditions, particularly at high OLR (short HRT), in terms of treatment efficiency, long term stability, occurrence and effectiveness of phase separation, and the characteristics of granular biomass in the different phases within the reactor.

- To investigate the performance of a GRABBR in terms of treatment efficiency and reliability to withstand hydraulic shock load conditions.

- To investigate the feasibility of a GRABBR for simultaneous denitrification and methanogenesis for carbon and nitrate removal by assessing the denitrifying capabilities of different microorganisms within the system.

- To examine the nitrate reducing and methane producing capabilities of different sludges enriched in the various compartments of GRABBR in batch assays.

- To evaluate the physical and microbiological characteristics of anaerobic granular sludge, and any changes in its ultrastructure brought about by different microbial (substrate) environment of the reactor.

- To investigate the feasibility of a GRABBR with natural industrial wastewater for combined denitrification and anaerobic treatment by employing a two-stage anaerobic-aerobic configuration. 


\subsection{THESIS OUTLINE}

This thesis contains 9 Chapters, including this Chapter of Introduction. Each experimental Chapter (Chapters 3 to 8 ) contains an introduction, results and discussion, and conclusions. The following Chapters of the thesis are as follows:

\section{Chapter 2 - Materials and methods}

This Chapter presents the reactor design, feed description, analytical methods, equipment details and chemicals used in this study.

\section{Chapter 3 - Performance of granular bed baffled reactor at various loading rates}

This Chapter discusses the performance of the GRABBR in terms of treatment efficiency, occurrence and effectiveness of phase separation, and the characteristics of biomass within the compartments of the system at various operational conditions.

Chapter 4 - Performance of granular bed baffled reactor during rapid hydraulic shock loads

This Chapter describes the efficiency and reliability of the GRABBR system when accommodating unpredictable rapid hydraulic shock loads.

\section{Chapter 5 - Combined denitrification and anaerobic digestion in granular bed}

\section{baffled reactor}

This Chapter evaluates the characteristics of the reactor for combined denitrification and anaerobic digestion by identifying the most suitable environment for denitrification within the reactor.

Chapter 6 - Nitrate reduction and methane production activities of sludges from granular bed baffled reactor

This Chapter investigates the nitrate reduction and methane production capabilities of the biomass obtained from different zones of the reactor in batch assays. 


\section{Chapter 7 - Physical and microbial ecology of anaerobic granules}

This Chapter discusses the importance of granular morphology in determining granular properties, microbial ecology of granules and the effect of phase separation on the microbial characteristics of granular sludge in a GRABBR.

\section{Chapter 8 - Combined integrated system for brewery wastewater treatment}

This part of the thesis elucidates the practical application of the reactor for carbon and nitrogen removal, with a nitrification system installed downstream, using brewery wastewater.

\section{Chapter 9 - General Discussion}

This Chapter concludes the main findings of this research with recommendations for future work. 


\section{CHAPTER 2}

\section{MATERIALS AND METHODS}

This chapter describes the reactor design, feed description, analytical methods, equipment details and chemicals used in this study.

\subsection{LABORATORY-SCALE REACTOR SET-UP}

A rectangular shaped bench-scale granular bed baffled reactor (GRABBR) configuration, designed for this research project, was made of perspex and is shown in Figure 2.1. The other materials used during the construction of the reactor include silicon glue, screws, TEFEN Food Grain Nylon blanking plugs and taper male $\chi$ hose tails. The reactor was divided into five equal sized compartments, separated by vertical baffles alternatively hanging and standing, in order to achieve phase separation characteristics within the system. The reactor dimensions were $50 \mathrm{~cm}(\mathrm{~L}) \times 12 \mathrm{~cm}(\mathrm{~W})$ $X 32 \mathrm{~cm}(\mathrm{H})$ with an effective working volume of 10 litres. The depth of the feed in the reactor was $25 \mathrm{~cm}$. The thickness of the standing and hanging baffles were $1.2 \mathrm{~cm}$ and $0.6 \mathrm{~cm}$ respectively. The bottom of each hanging baffle was angled at $45^{\circ}$ to distribute the flow towards the centre of the upcomer (second half of the compartment). Sampling ports were provided for liquid and gas collection. A constant temperature of $35^{\circ} \mathrm{C}$ was obtained by recirculating heated water through a water jacket attached to the reactor. The raw wastewater (influent) was pumped into the reactor by using variable speed Masterflex peristaltic pump (Bernant, Barrington USA). Treated effluent level and excess solids washout were controlled using a U-tube at the effluent discharge point.

\subsection{SYNTHETIC FEED}

Glucose was the main source of organic carbon in the synthetic feed used in the study. A concentrated stock solution was initially prepared and diluted to the correct strength. 
The composition of the feed is shown in Table 2.1. All chemicals were supplied by Fisher Scientific, UK. Sodium bicarbonate was the main component for buffering the system as it has several advantages over other forms of chemicals for controlling the $\mathrm{pH}$ (McCarty, 1964). Throughout the experiment the $\mathrm{pH}$ of the feed was about 8.3.

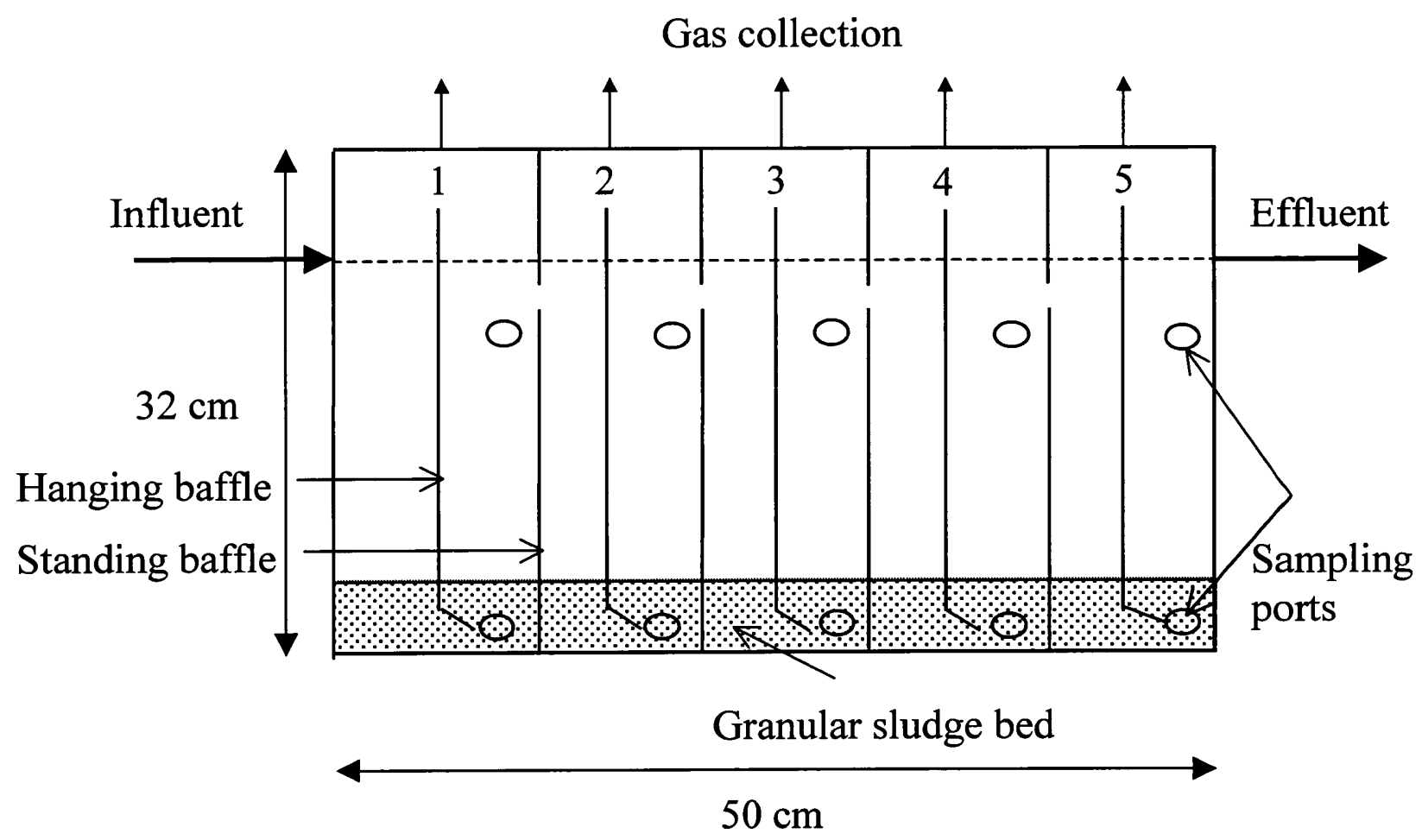

Figure 2.1 Schematic diagram of five-compartment granular bed baffled reactor.

Table 2.1 Composition of synthetic wastewater.

Component

Concentration $\left(\mathrm{mg} \mathrm{l}^{-1}\right)$

Glucose $\left(\mathrm{C}_{6} \mathrm{H}_{12} \mathrm{O}_{6}\right)$

Ammonium hydrogen carbonate $\left(\mathrm{NH}_{4} \mathrm{HCO}_{3}\right)$

1000

Potassium di-hydrogen phosphate $\left(\mathrm{KH}_{2} \mathrm{PO}_{4}\right)$

400

Sodium hydrogen carbonate $\left(\mathrm{NaHCO}_{3}\right)$

Magnesium sulphate $\left(\mathrm{MgSO}_{4}\right)$

Ferric chloride $\left(\mathrm{FeCl}_{3}\right)$

Calcium chloride $\left(\mathrm{CaCl}_{2}\right)$

Potassium chloride $(\mathrm{KCl})$

Cobalt chloride $\left(\mathrm{CoCl}_{2}\right)$

Nickel chloride $\left(\mathrm{NiCl}_{2}\right)$ 


\subsection{BREWERY WASTEWATER}

The brewery wastewater was obtained from the tank bottoms of a local brewery. The principal stages in brewing beer are mashing, boiling and fermentation followed by cooling, clarification, pasteurisation and packaging. The tank bottom wastes were the remains at the bottom of the fermentation and maturation vessels after the beer has spent some time in these vessels during the brewery process. Waste yeast is produced in the fermentation tanks. This waste is passed to maturation vessels where beer is held for a period of time in order to improve its flavour and to allow any remaining yeast to settle. The raw wastewater contained chemical oxygen demand (COD) of 115000 to 125000 $\mathrm{mg} \mathrm{l}^{-1}$, total suspended solids of 1550 to $1750 \mathrm{mg} \mathrm{l}^{-1}$, volatile suspended solids of 1400 to $1600 \mathrm{mg} \mathrm{l}^{-1}$ and $\mathrm{pH}$ of 4.25 . The wastewater was diluted to the required strength, with the addition of sodium hydrogen carbonate $\left(\mathrm{NaHCO}_{3}\right)$ and ammonium hydrogen carbonate $\left(\mathrm{NH}_{4} \mathrm{HCO}_{3}\right)$ to provide buffering in the system and nutrient in the feed. For combined denitrification and anaerobic digestion studies in the GRABBR, ammonium chloride $\left(\mathrm{NH}_{4} \mathrm{Cl}\right)$ was also added to the brewery feed to simulate an average ammonium concentration of $382 \mathrm{mg} \mathrm{l}^{-1}$. The average $\mathrm{pH}$ of the feed was about 8.10 . The brewery waste was stored in a closed container (under anaerobic conditions) at $4^{\circ} \mathrm{C}$ in order to minimise changes in feed characteristics.

\subsection{SEED SLUDGE}

Granular sludge was obtained from a $1600 \mathrm{~m}^{3}$ upflow anaerobic sludge blanket (UASB) reactor in Aberdeen UK, operating under mesophilic conditions $\left(35^{\circ} \mathrm{C}\right)$. The UASB system has been in operation for more than 10 years and is used to treat paper mill wastewater. The sampling point for granules was $2 \mathrm{~m}$ above the bed of the UASB reactor. The UASB reactor was operating at an organic loading rate (OLR) of $12 \mathrm{~kg}$ COD $\mathrm{m}^{-3} \mathrm{~d}^{-1}$ and hydraulic retention time (HRT) of $8 \mathrm{hrs}$, with a COD removal efficiency of $66 \%$, when the granular sludge sample was collected for synthetic glucose wastewater studies. While the reactor was operating at an OLR of $16 \mathrm{~kg} \mathrm{COD} \mathrm{m}^{-3} \mathrm{~d}^{-1}(6$ hrs HRT), with COD removal efficiency of $67 \%$, seed granules were collected for brewery wastewater study. 


\subsection{ANALYTICAL METHODS}

\subsubsection{Chemical Oxygen Demand}

Total COD and soluble COD (SCOD) were determined using a colorimetric method on a Direct Reading DR/2000 Spectrophotometer (Hach, Loveland USA) as described in Hach (1992). Palintest COD vials (mercury-free digestion solution) were used as COD reagent containing sulphuric acid $(84 \%)$, potassium dichromate $(<1 \%)$ and silver sulphate $(<1 \%)$. The samples (vials) were heated (digested) in a COD reactor (Hach, Loveland USA) for $2 \mathrm{hrs}$ at $150^{\circ} \mathrm{C}$. The spectrophotometer was operated at a wavelength of $620 \mathrm{~nm}$ with method number 950 (Hach, 1992). Filtrate samples for SCOD were obtained by filtering liquid samples through $1.2 \mu \mathrm{m}$ glass microfibre GF/C filter papers (Whatman, Maidstone UK).

\subsection{2 pH}

$\mathrm{pH}$ values were obtained using pH meter M240 (Corning, Sudbury UK) fitted with Ross pH Combination electrode 8102 (Orion, Beverly USA). The $\mathrm{pH}$ meter was calibrated with Fisher Scientific, UK, buffer tablets ( $\mathrm{pH} 4$ and 7) before each set of measurements.

\subsubsection{Volatile Fatty Acids}

Volatile fatty acids (acetate, propionate, butyrate and valerate) were determined using a Unicam 610 series Gas Chromatograph (GC) with autojector and PU 4811 computing integrator. The GC column was $2 \mathrm{~m} \mathrm{x} 2 \mathrm{~mm}$ inside diameter glass packed with $10 \%$ AT - 1000 on $80 / 100$ Chromosorb W - AW, with a column temperature of $140^{\circ} \mathrm{C}$ on Flame Ionization Detector (FID). The carrier gas was nitrogen at a flow rate of $20 \mathrm{ml} \mathrm{min}^{-1}$ at $180^{\circ} \mathrm{C}$.

\subsubsection{Ammoniacal Nitrogen}

Ammoniacal nitrogen $\left(\mathrm{NH}_{4}{ }^{+} \mathrm{N}\right)$ was determined using a basic ion selective meter (Thermo Orion, Beverly USA) fitted with ammonium combination glass body electrode (Cole-Parmer, Vernon Hills USA). The electrode was filled with $0.1 \mathrm{M}$ sodium chloride 
$(\mathrm{NaCl})$ solution. The standard ammonium chloride $\left(\mathrm{NH}_{4} \mathrm{Cl}\right)$ solutions of $10^{-4} \mathrm{M} \mathrm{NH} \mathrm{N}_{4} \mathrm{Cl}$, $10^{-3} \mathrm{M} \mathrm{NH}_{4} \mathrm{Cl}$ and $10^{-2} \mathrm{M} \mathrm{NH}_{4} \mathrm{Cl}$ were used for calibration. During all measurements, 2 $\mathrm{ml}$ of $5 \mathrm{M} \mathrm{NaCl}$ was added as ionic strength adjuster (ISA) to every $100 \mathrm{ml}$ of standard solutions or sample. The concentration of ammoniacal nitrogen was determined from a calibration curve, which is a plot of electrode potential in millivolt versus ammonium concentration.

\subsubsection{Gas Composition and Volume}

Gas volume was measured using a water displacement method. Composition of the gas for reactor study was measured using LFG 20 gas analyser (Analytical Development Company, Hoddesdon UK).

For batch study, gas composition (methane and carbon dioxide) was measured on a Becker model 403 with Unicam 4815 computing integrator on thermal conductivity detector (TCD). The column was $2 \mathrm{~m} \mathrm{x} 4 \mathrm{~mm}$ inside diameter metal packed with Porapak Q, with a column temperature of $55^{\circ} \mathrm{C}$. The carrier gas was helium at a flow rate of $50 \mathrm{ml} \mathrm{min}^{-1}$ with an injection temperature of $66^{\circ} \mathrm{C}$.

\subsubsection{Solids}

The total suspended solids (TSS) and volatile suspended solids (VSS) were determined according to Standard Methods (APHA, 1992). The TSS were determined by drying the samples at $105^{\circ} \mathrm{C}$ in the oven, while the VSS were measured by igniting the samples, obtained after oven drying, in the muffle furnace at $550^{\circ} \mathrm{C}$. Ash was calculated as the difference between TSS and VSS.

\subsubsection{Nitrate and Nitrite Nitrogen}

For the reactor study, nitrate nitrogen $\left(\mathrm{NO}_{3}-\mathrm{N}\right)$ and nitrite nitrogen $\left(\mathrm{NO}_{2}-\mathrm{N}\right)$ were determined using the colorimetric method on Direct Reading DR/2000 Spectrophotometer (Hach, Loveland USA) as described in the Hach (1992). The cadmium reduction method and ferrous sulphate method were used for nitrate and nitrite determination by using Hach NitraVer 5 nitrate reagent powder pillows and Hach 
NitriVer 2 nitrite powder pillows, respectively, for $25 \mathrm{ml}$ sample. The samples were mixed with respective reagent powders for $1 \mathrm{~min}$ and left for $5 \mathrm{~min}$ for reaction. The nitrate nitrogen concentration on spectrophotometer was measured at a wavelength of $500 \mathrm{~nm}$ with method number 355 (Hach, 1992). While, the nitrite nitrogen concentration was measured at a wavelength of $585 \mathrm{~nm}$ with method number 373 (Hach, 1992).

For batch studies, nitrate and nitrite were measured by injecting samples into $0.2 \mu \mathrm{m}$ syringe filters on DX-100 Ion Chromatograph with Dionex 4400 integrator with conductivity detector. The analytical column was an Ionpac AS4A (4 x $250 \mathrm{~mm})$ and guard column was an Ionpac AG4A $(4 \times 50 \mathrm{~mm})$. Both columns were in series and samples were initially passed through the guard column before analysed by the analytical column. The eluent was made as a concentrated solution of Sodium carbonate $(19.078 \mathrm{~g})$ and sodium bicarbonate $(14.282 \mathrm{~g})$ in a litre of distilled water. The final diluted concentration of 1:100 was used as chromatograph eluent. The pump flow rate was $2 \mathrm{ml} \mathrm{min}^{-1}$.

\subsubsection{Analytical Profile Index 20 E}

A Gram staining technique on pure cultures was adopted from Lim (1989). The detailed procedure of Analytical Profile Index (API) $20 \mathrm{E}$ was adopted from bioMérieux sa (1998). Gram staining and API $20 \mathrm{E}$ test were performed on pure cultures grown by aseptic techniques for microbial identification of non-granular white microorganisms. Pure cultures were obtained on the petri dish for both tests. Samples were obtained from upstream compartments of the GRABBR, where the occurrence of such biomass was relatively high in the reactor.

\subsubsection{Buoyant Density}

Buoyant density of the granules was calculated by measuring the weight of tissue-dried granules to remove extra granular water and submerging the same amount in the distilled water (Hulshoff Pol et al., 1986). The weight of tissue-dried granules was measured in a pre-weighed volumetric cylindrical flask. The granules were then 
submerged with distilled water until the top layer of granules was just covered. The volume of added water was deducted from the total volume when granules were submerged to obtain the volume of granules. The buoyant density of granules was measured as mass of granules per unit volume.

\subsubsection{Particle Size Distribution}

Particle size distribution was analysed by using the vernier measuring microscope (Baker, London UK) on 150 granules used as seed sludge from the UASB system. Microscopic studies were carried out by placing granules on the glass slide, which was then placed on the stage plate to measure the long and short axes of each granule as shown in Figure 2.2. These observations were made by moving the slide for each granule to measure one of the axes and then moving the slide at an angle of approximately $90^{\circ}$ for the measurement of other axis. In order to validate the accuracy of results of observed number of samples in this study, statistical analysis was performed by plotting the standard $\mathrm{Y}$-error bars as standard deviation for each set of bar data.

Individual plates of granules were obtained by placing granules on standard microscopic slide. Images were taken by using a Quantimet-600 image analyser (Leica, Milton Keynes UK).

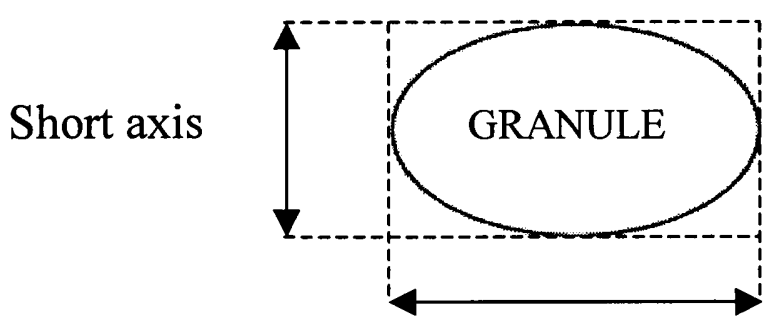

Long axis

Figure 2.2 Schematic definition of long and short axis of granules measured by vernier measuring microscope.

\subsubsection{Transmission Electron Microscope}

Granular samples were fixed overnight in Eppendorff tubes containing a buffer solution of $0.1 \mathrm{M}$ sodium cacodylate $(\mathrm{pH} 7.2)$ with $2.5 \% \mathrm{v} / \mathrm{v}$ glutaraldehyde at $4^{\circ} \mathrm{C}$. Samples 
were washed twice in cacodylate buffer solution and fixed with $1 \% \mathrm{v} / \mathrm{v}$ osmium tetraoxide. The samples were then washed twice in distilled water for 30 mins. Uranyl acetate solution $(2 \% \mathrm{v} / \mathrm{v})$ was then added to the samples and left overnight. The samples were then rinsed twice with distilled water for 30 mins. Granules were then dehydrated through a graded ethanol series. Granules were infiltrated with $1: 1(\mathrm{v} / \mathrm{v})$ mixture of propylene oxide and Durcupan resin (Sigma) on a rotary wheel (4 rev $\left.\mathrm{min}^{-1}\right)$ for $2 \mathrm{hrs}$ at room temperature. The granules were then infiltrated with 100\% Durcupan resin overnight and then placed in a $60^{\circ} \mathrm{C}$ oven with fresh resin for $24 \mathrm{hrs}$ to polymerise the resin. Thin sections (approximately $80 \mathrm{~nm}$ ) of resin fixed granules were cut on a Reichart OMU-3 ultramicrotome fitted with a diamond knife and collected on 50 mesh pioloform coated copper grids. After staining with uranyl acetate and lead citrate, sections were examined with a JEOL $1200 \mathrm{EX}$ TEM operating at $80 \mathrm{kV}$.

\subsubsection{Scanning Electron Microscope}

Granular samples were fixed overnight in Eppendorff tubes containing a buffer solution of $0.1 \mathrm{M}$ sodium cacodylate $(\mathrm{pH} 7.2)$ with $2.5 \% \mathrm{v} / \mathrm{v}$ glutaraldehyde at $4^{\circ} \mathrm{C}$. Samples were washed twice in cacodylate buffer solution and fixed with $1 \% \mathrm{v} / \mathrm{v}$ osmium tetraoxide. The samples were then washed twice in distilled water for 30 mins. Uranyl acetate solution $(2 \% \mathrm{v} / \mathrm{v})$ was then added to the samples and left overnight. The samples were then rinsed twice with distilled water for 30 mins. The fixed granules were cleaved by quick frozen infiltration in liquid nitrogen using a mortar and pestle. Granules were then dehydrated through a graded ethanol series and then washed twice with acetone for 30 mins. Critical point drying was achieved in a BAL-TEC Critical Point Dryer CPD 030. Granules were mounted on aluminum stubs using double-sided carbon tabs and coated with $30 \mathrm{~nm}$ of $\mathrm{Au} / \mathrm{Pd}$ in a Cressington high-resolution sputter coater $208 \mathrm{HR}$. The specimens were examined with a Hitachi S-4700 field emission scanning electron microscope (FE-SEM) operating at $5 \mathrm{kV}$.

\subsection{STATISTICS}

Experimental data presented in Chapters 3, 4, 5, 6 and 8 were derived from the mean of triplicate data sets. In Chapter 7, standard Y-error bars were plotted as the standard deviation of each set data points (Figures 7.2 and 7.3). 


\section{CHAPTER 3}

\section{PERFORMANCE OF GRANULAR BED BAFFLED REACTOR AT VARIOUS LOADING RATES}

This chapter evaluates the performance of the granular bed baffled reactor in terms of treatment efficiency, occurrence and effectiveness of phase separation, and the characteristics of granular biomass in the different phases at various operational conditions. This study was carried out by initially starting the reactor at a low organic loading rate, and loading rates were steadily increased by shortening the hydraulic retention time to finally operate at high load.

\subsection{INTRODUCTION}

Anaerobic treatment of wastewater at high loadings may lead to accumulation of intermediate acid products, thus providing an unfavourable environment for methanogenesis due to the consequential decrease in the $\mathrm{pH}$ (Pohland and Bloodgood, 1963; Cohen et al., 1982; Anderson et al., 1994). In order to obtain an improved treatment performance for high strength wastewater in anaerobic reactors, separation between acidogenesis and methanogenesis may have to be attained in order to minimise the potential inhibitory effect of excessive accumulation of by-products of the former on the latter. In order to overcome this problem a two-phase anaerobic digestion system has been proposed (Pohland and Ghosh, 1971; Cohen et al., 1980 \& 1982; Dinopoulou and Lester, 1989; Anderson et al., 1994; Ince, 1998; Shin et al., 2001), one phase responsible for acid formation and another optimised for only methane production. In each of these two-phases, carried out in different units, optimum environmental conditions for each group of microorganisms can be maintained. However, the main 
disadvantage of achieving two-phase conditions in separate systems is the high cost of the treatment process, as two serial units are installed with associated operational and maintenance requirements (Vandevivere et al., 2002). In order to overcome the above problem, a type of reactor system is required, which not only can provide phase separation, where different groups of microbes can live separately at minimal capital and operational costs, but also are capable of treating the high strength wastewater to high standards. It is believed that a single unit multi-phase plug flow granular bed system would bring about greater reactor stability in terms of efficiency and reliability for treating high strength wastewaters, and also overcome the above problems associated with two-phase systems.

The study outlined in this chapter was aimed at investigating the performance of the granular bed baffled reactor (GRABBR) at various organic loading rates (OLRs), particularly at high OLR (short hydraulic retention time, HRT), in terms of treatment efficiency, occurrence and effectiveness of phase separation, and the characteristics of granular biomass in the different phases within the reactor. This study was carried out using a synthetic glucose feed at $35^{\circ} \mathrm{C}$.

\subsection{EXPERIMENTAL DESIGN}

The reactor was inoculated with 2 litres of granular sludge, equivalent to $20 \%$ of the reactor working volume. The GRABBR was left with seed sludge for 1 day at $35^{\circ} \mathrm{C}$ so that seed sludge would adapt to the new environment. During the entire length of the reactor operation, the concentration of the feed was kept constant, and the OLR was varied by varying the HRT. The reactor was started with an OLR of $1 \mathrm{~kg}$ chemical oxygen demand (COD) $\mathrm{m}^{-3} \mathrm{~d}^{-1}$, which corresponded to an HRT of $120 \mathrm{hrs}$. Loading rates of $1.25,1.7,2.5,5,10$ and $20 \mathrm{~kg} \mathrm{COD} \mathrm{m}^{-3} \mathrm{~d}^{-1}$, corresponded to HRTs of $96 \mathrm{hrs}, 72 \mathrm{hrs}$, $48 \mathrm{hrs}, 24 \mathrm{hrs}, 12 \mathrm{hrs}$ and $6 \mathrm{hrs}$, were initiated at days 20,31, 34, 43, 73 and 93, respectively. The hydraulic loading rates in this study varied from 0.2 to $4 \mathrm{~m}^{3} \mathrm{~m}^{-3} \mathrm{~d}^{-1}$. The reactor was operated continuously for 148 days. HRTs were only reduced (or OLRs increased) when steady state conditions were obtained for the existing loading rates. In general, steady state condition was believed to have been achieved when relatively 
small variation in the levels of determinants within the compartments for three different samples, sampled during three retention times of the applied load, was observed. The data points presented in Figures 3.2, 3.3, 3.4 3.5, 3.6 and 3.7 were based on the sample analysis obtained just before applying increment in the loading rate. Samples were collected at regular intervals and no effluent recirculation was carried out throughout the study. There was also no effluent settling prior to discharge.

\subsection{RESULTS AND DISCUSSION}

\subsubsection{Soluble Chemical Oxygen Demand Removal}

The soluble COD (SCOD) concentrations in different compartments during various operational conditions for the entire length of the study are shown in Figure 3.1. The effluent SCOD removal efficiency was $96 \%$ to $98 \%$ during all applied loadings at steady state conditions. The contribution to final SCOD removal by each compartment of the reactor under various loading conditions is shown in Figure 3.2. SCOD removal efficiency of over $84 \%$ was obtained in the first compartment of the reactor for OLRs of 1 to $5 \mathrm{~kg} \mathrm{COD} \mathrm{m}^{-3} \mathrm{~d}^{-1}$, with effluent SCOD removal of $97 \%$ to $98 \%$. At an OLR of 10 $\mathrm{kg} \mathrm{COD} \mathrm{m} \mathrm{d}^{-3} \mathrm{~d}^{-1}(12 \mathrm{hrs}$ HRT), the first and second compartments contributed individual SCOD removal of $37 \%$ and $50 \%$, respectively, with an overall SCOD removal of $98 \%$ by the entire system. A marked decrease in SCOD removal was recorded when the OLR was initially increased from 10 to $20 \mathrm{~kg} \mathrm{COD} \mathrm{m}^{-3} \mathrm{~d}^{-1}$, with an effluent SCOD removal efficiency of $61 \%$ (Figure 3.1). At steady state, all compartments accounted noticeably for SCOD removal at an OLR of $20 \mathrm{~kg} \mathrm{COD} \mathrm{m}^{-3} \mathrm{~d}^{-1}$ (6 hrs HRT).

At lower loading rates (up to $5 \mathrm{~kg} \mathrm{COD} \mathrm{m}^{-3} \mathrm{~d}^{-1}$ ) or long HRTs, the reactor operated as one completely mixed unit without any noticeable phase separation. Phase separation in the reactor occurred at high loading rates (or short HRTs) due to the inability of the initial compartments to completely treat the wastewater caused by the increased load in a relatively short interval of time. Phase separation was particularly observed at an OLR

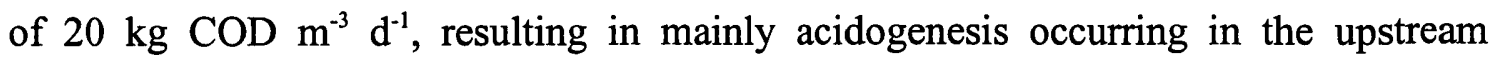
compartments (causing a relative decrease in SCOD removal efficiency of these 
compartments) and methanogenesis in the downstream compartments, converting the high amount of volatile fatty acid (VFA) produced in the upstream compartments to methane.

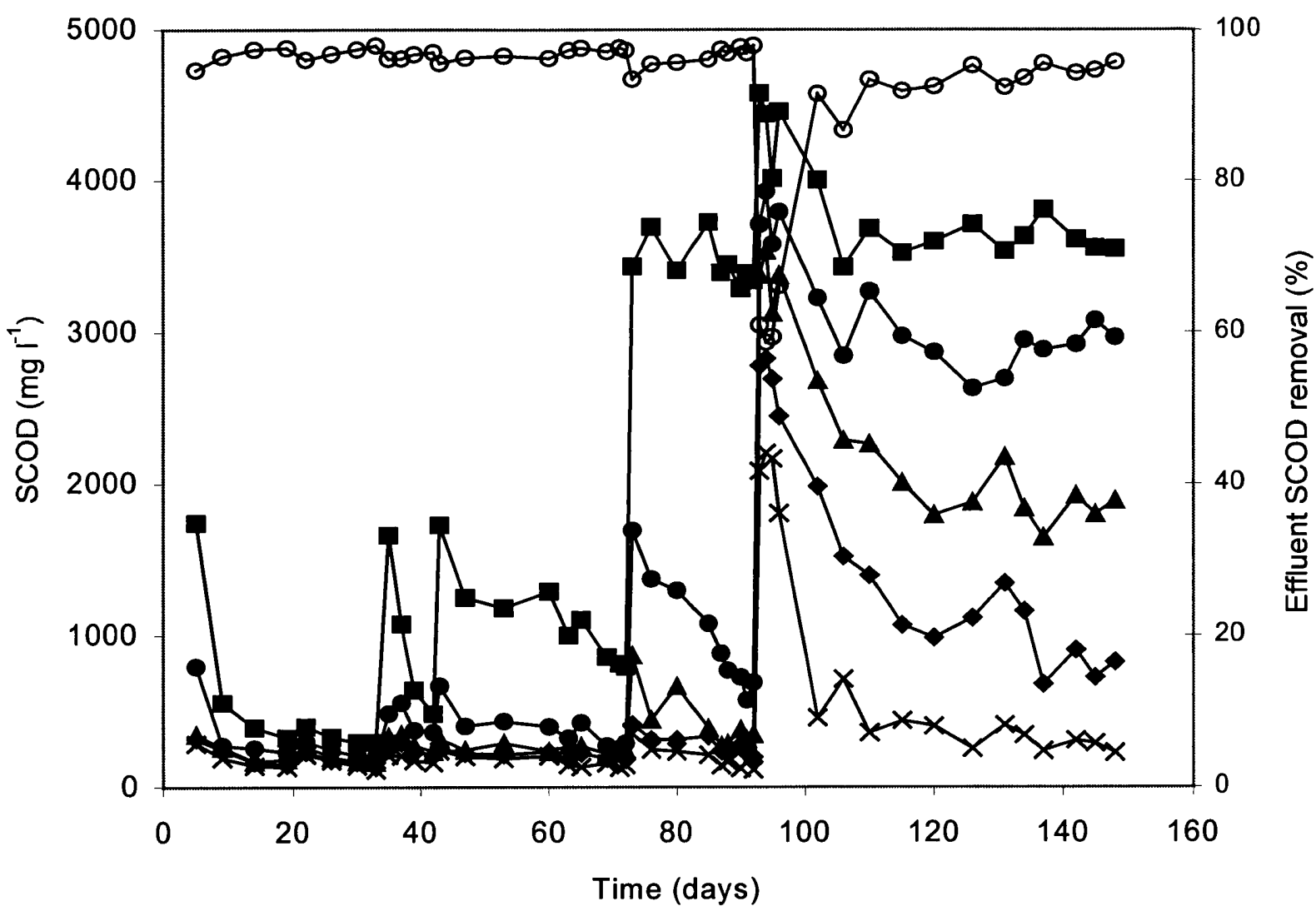

Figure 3.1 Soluble chemical oxygen demand (SCOD) concentrations in each compartment of granular bed baffled reactor at different organic loading rates: (耳)

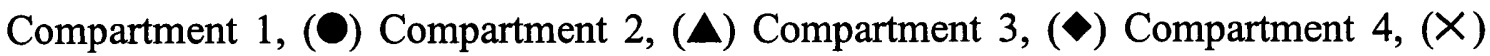
Compartment 5, (O) percentage total SCOD removal during the length of reactor operation. Organic loading rates of $1,1.25,1.7,2.5,5,10$ and $20 \mathrm{~kg} \mathrm{COD} \mathrm{m}^{-3} \mathrm{~d}^{-1}$ were initiated at days $1,20,31,34,43,73$ and 93 respectively.

\subsubsection{Volatile Fatty Acid Profile}

Due to the high SCOD removal efficiency observed for OLRs of 1 to $5 \mathrm{~kg} \mathrm{COD} \mathrm{m}^{-3} \mathrm{~d}^{-1}$, there were no appreciable VFAs recorded at these OLRs in the compartments. An 
increase in OLR from 5 to $10 \mathrm{~kg} \mathrm{COD} \mathrm{m}^{-3} \mathrm{~d}^{-1}$ produced noticeable amount of VFA in the first compartment, and thereafter a drop in acid levels was observed downstream of the reactor. Marked VFA concentrations were observed in the compartments when the OLR was increased from 10 to $20 \mathrm{~kg} \mathrm{COD} \mathrm{m}^{-3} \mathrm{~d}^{-1}$. The total VFA concentration in the second compartment was found to be higher than in the first compartment at OLR of 20 $\mathrm{kg} \operatorname{COD~\mathrm {m}^{-3}} \mathrm{d}^{-1}$, and thereafter a gradual decrease in VFA levels was observed downstream of the reactor. The total VFA profile at OLRs of 10 and $20 \mathrm{~kg} \mathrm{COD} \mathrm{m}^{-3} \mathrm{~d}^{-1}$ in the system is shown in Figure 3.3.

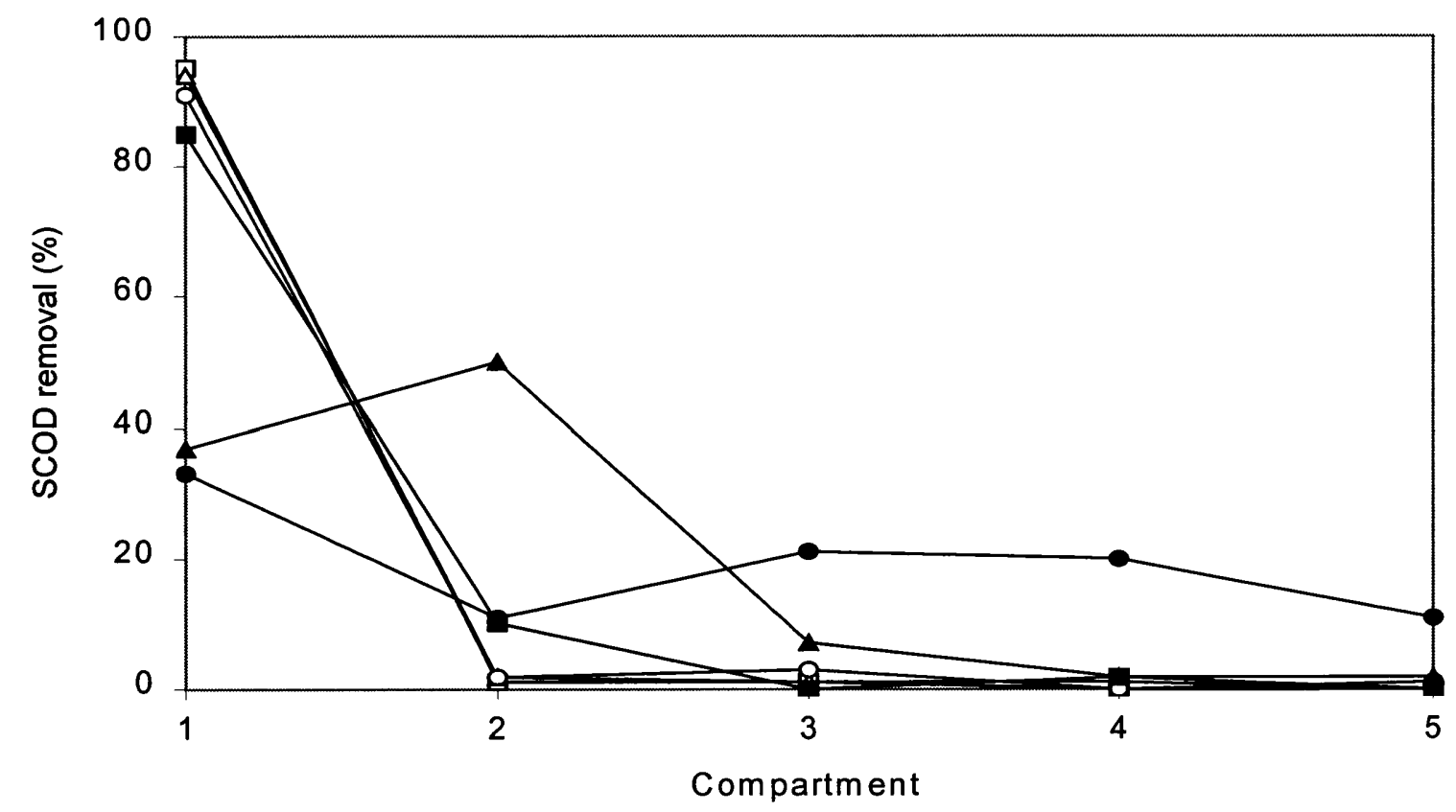

Figure 3.2 Percentage soluble chemical oxygen demand (SCOD) removal contributed by each compartment of granular bed baffled reactor at different organic loading rates: (๑) $20 \mathrm{~kg} \mathrm{COD} \mathrm{m}^{-3} \mathrm{~d}^{-1},(\boldsymbol{\Delta}) 10 \mathrm{~kg} \mathrm{COD} \mathrm{m}^{-3} \mathrm{~d}^{-1},(\square) 5 \mathrm{~kg} \mathrm{COD} \mathrm{m}^{-3} \mathrm{~d}^{-1},(\bullet)$ $2.5 \mathrm{~kg} \mathrm{COD} \mathrm{m}^{-3} \mathrm{~d}^{-1},(\Delta) 1.7 \mathrm{~kg} \mathrm{COD} \mathrm{m}^{-3} \mathrm{~d}^{-1},(\square) 1.25 \mathrm{~kg} \mathrm{COD} \mathrm{m}^{-3} \mathrm{~d}^{-1},(\diamond) 1 \mathrm{~kg} \mathrm{COD} \mathrm{m}^{-}$ ${ }^{3} \mathrm{~d}^{-1}$.

Figures 3.4 and 3.5 show the levels of intermediate VFA products in each compartment at OLRs of 10 and $20 \mathrm{~kg} \mathrm{COD} \mathrm{m}^{-3} \mathrm{~d}^{-1}$, respectively. An increase in acetate and butyrate levels was observed when the OLRs were increased from 10 to $20 \mathrm{~kg} \mathrm{COD} \mathrm{m}^{-3} \mathrm{~d}^{-1}$. 
Valerate also accounted for total VFA in the early compartments for both loading rates with a maximum value of around $100 \mathrm{mg} \mathrm{l}^{-1}$. Acetate levels were higher than other acid products in all the compartments for applied loads. Propionate levels were recorded greater than butyrate, until at an OLR of $20 \mathrm{~kg} \mathrm{COD} \mathrm{m}^{-3} \mathrm{~d}^{-1}$, butyrate concentrations were higher in the upstream compartments. This phenomenon was also observed at high loads by other authors (Nachaiyasit and Stuckey, 1997a).

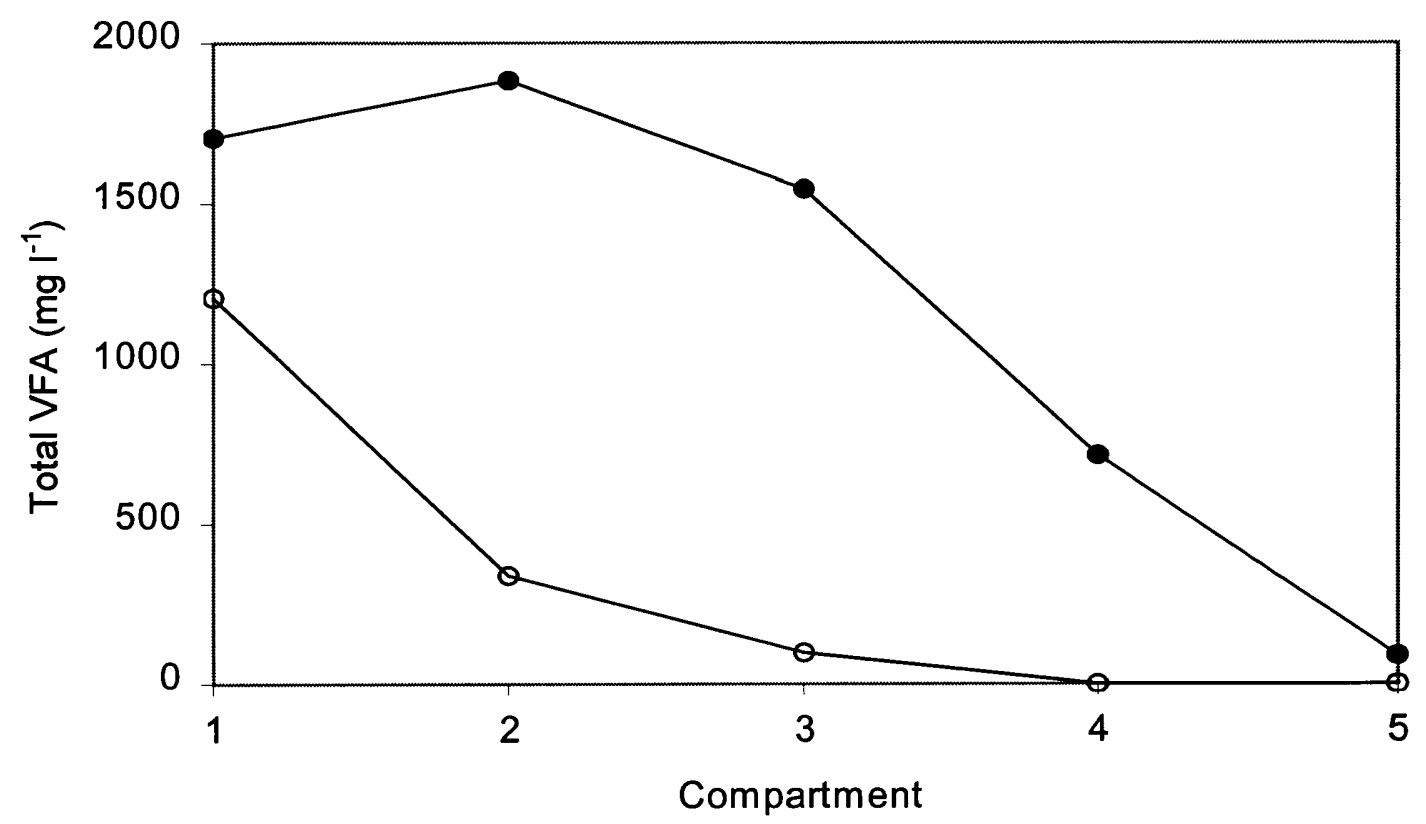

Figure 3.3 Total volatile fatty acid (VFA) (acetate, propionate, butyrate and valerate) profile in each compartment of granular bed baffled reactor at organic loading rates of $(O) 10 \mathrm{~kg} \mathrm{COD} \mathrm{m}^{-3} \mathrm{~d}^{-1}$ and (O) $20 \mathrm{~kg} \mathrm{COD} \mathrm{m}^{-3} \mathrm{~d}^{-1}$.

Higher levels of VFAs were detected in the front compartments (near the influent point) at high loads and it decreased downstream of the reactor as shown in Figures 3.4 and 3.5. The fall in the acid concentrations down the reactor is indicative of the increased activities of mainly the methanogenic population in the latter compartments (near the effluent point) of the reactor. A noticeable decrease in the effluent quality was observed when loadings were initially increased from 10 to $20 \mathrm{~kg} \mathrm{COD} \mathrm{m}^{-3} \mathrm{~d}^{-1}$ (Figure 3.1). This was believed to be due to a sudden increase in VFA concentrations, which was probably excessive for methanogenesis at the time. However, the methane forming microbes 
quickly adapted to the increased VFA as indicated by the high effluent SCOD removal at steady state. This production of acid in the upstream compartments and its consumption in the downstream compartments at high load, encouraged acidogenesis and methanogenesis to flourish in these respective compartments. The effect of increasing the loading rate was thus to increase the acidogenic zone at the expense of the methanogenic zone.

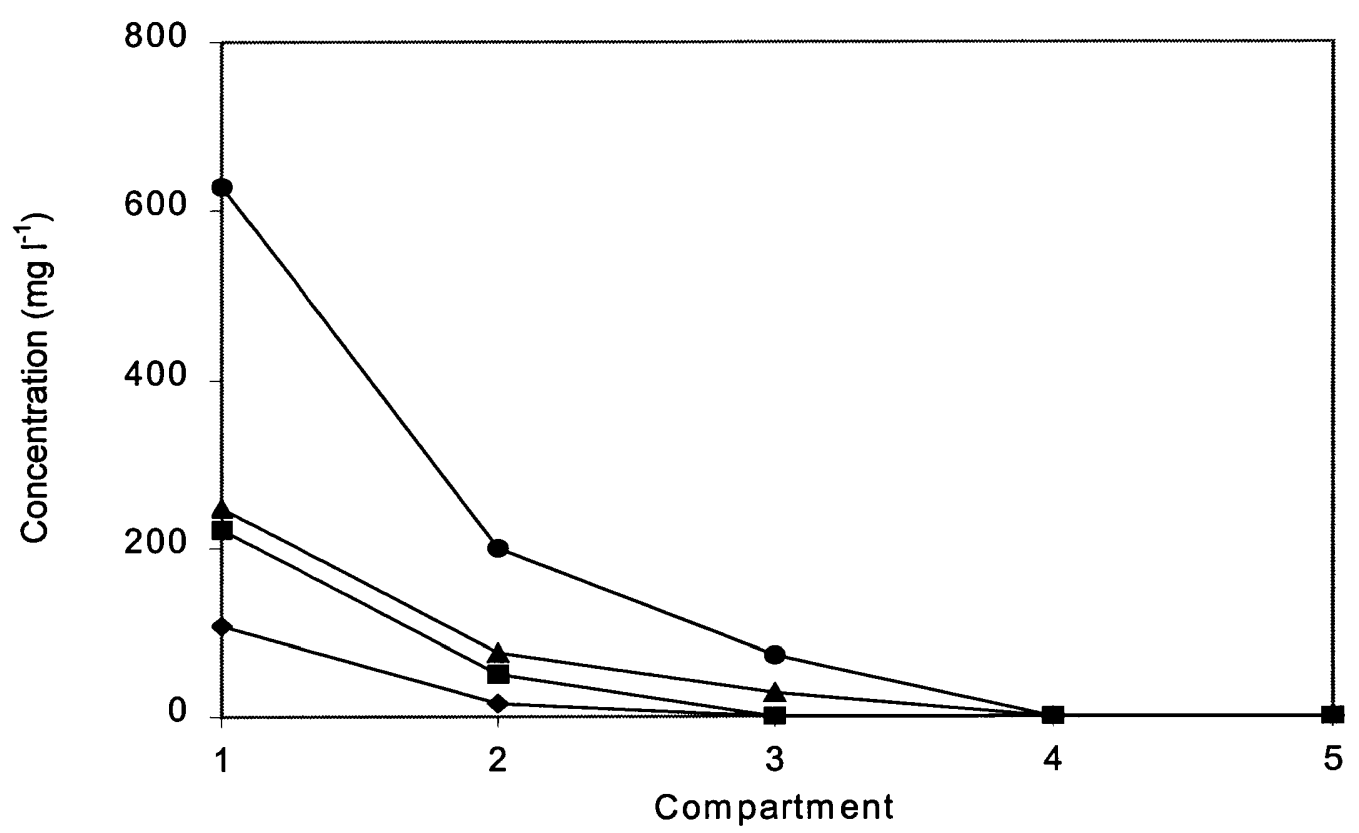

Figure 3.4 Profile of intermediate volatile fatty acid products in each compartment of granular bed baffled reactor at organic loading rate of $10 \mathrm{~kg} \mathrm{COD} \mathrm{m}^{-3} \mathrm{~d}^{-1}:(\mathbf{)})$ acetate, $(\boldsymbol{A})$ propionate, $(\boldsymbol{\square})$ butyrate, $(\diamond)$ valerate.

\subsection{3 pH}

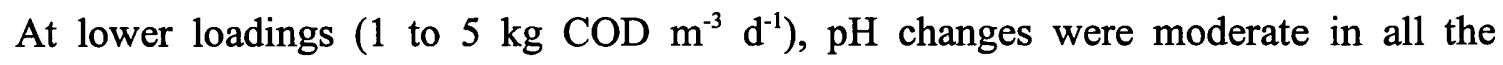
compartments of the system as shown in Figure 3.6. When the OLR was increased to 10 $\mathrm{kg} \mathrm{COD} \mathrm{m} \mathrm{m}^{-3} \mathrm{~d}^{-1}$, there was a marked fall in the $\mathrm{pH}$ of only the first compartment. The noticeable decrease in the $\mathrm{pH}$ was observed in almost all the compartments (except the last compartment) when the OLR was doubled from 10 to $20 \mathrm{~kg} \mathrm{COD} \mathrm{m}^{-3} \mathrm{~d}^{-1}$. This was expected because of the production of more intermediate acid products at high OLRs in 
the upstream compartments. In general, $\mathrm{pH}$ values increased down the reactor (near effluent point) due to the degradation of VFA in these compartments. The $\mathrm{pH}$ profile is a further indication of the degree of phase separation created within the system.

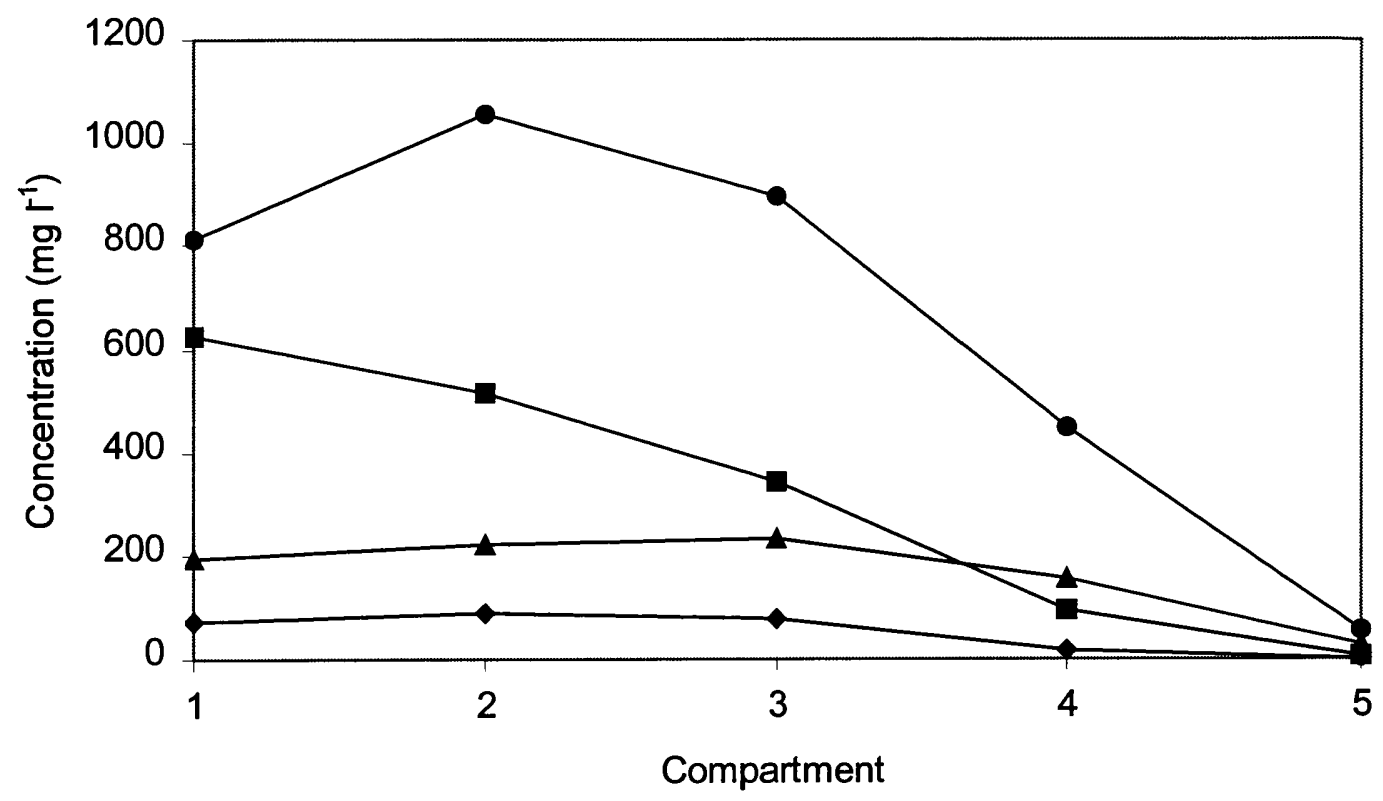

Figure 3.5 Profile of intermediate volatile fatty acid products in each compartment of granular bed baffled reactor at organic loading rate of $20 \mathrm{~kg} \mathrm{COD} \mathrm{m}^{-3} \mathrm{~d}^{-1}:(0)$ acetate, $(\mathbf{A})$ propionate, $(\boldsymbol{\square})$ butyrate, $(\diamond)$ valerate.

\subsubsection{Ammoniacal Nitrogen}

A decrease of up to $30 \%$ in ammoniacal nitrogen $\left(\mathrm{NH}_{4}^{+}-\mathrm{N}\right)$ of the raw synthetic feed was observed in the first compartment, and thereafter very little change in ammoniacal nitrogen concentrations was observed downstream of the reactor. This amount of nitrogen was believed to be assimilated for the synthesis of new microbial growth mainly in the first compartment. This difference was apparent in the abundance of whitish non-granular microbial mass produced in the upstream compartments. The production of a newly formed microbial population was less obvious downstream of the reactor and might be the reason for very little change in ammoniacal nitrogen 
concentrations in the rear compartments of the reactor, an indication of the differential growth characteristics of the populations in the front and rear compartments.

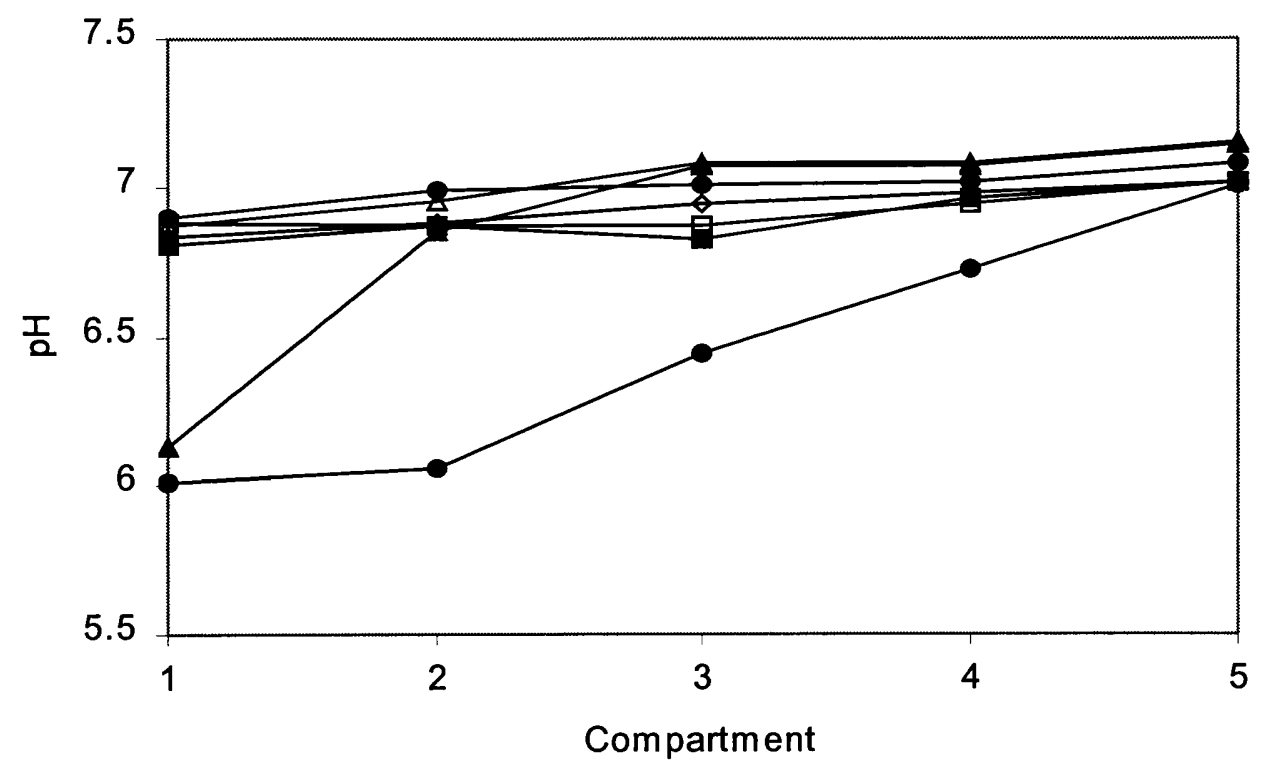

Figure 3.6 $\mathrm{pH}$ profile in the compartments of granular bed baffled reactor at different organic loading rates: (O) $20 \mathrm{~kg} \mathrm{COD} \mathrm{m}^{-3} \mathrm{~d}^{-1}$, (A) $10 \mathrm{~kg} \mathrm{COD} \mathrm{m}^{-3} \mathrm{~d}^{-1}$, (口) $5 \mathrm{~kg}$

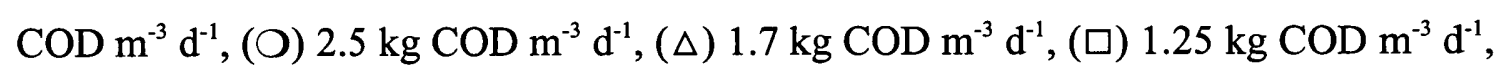
$(\diamond) 1 \mathrm{~kg} \mathrm{COD} \mathrm{m}^{-3} \mathrm{~d}^{-1}$.

\subsubsection{Gas Production and Composition}

The overall gas production increased with increase in OLR, varying from 6 to $1151 \mathrm{~d}^{-1}$ as OLRs were increased from 1 to $20 \mathrm{~kg} \mathrm{COD} \mathrm{m}^{-3} \mathrm{~d}^{-1}$. Although biogas production increased, the proportion of methane production decreased with increase in OLR as shown in Figure 3.7, probably due to the increase in acidogenic activities. Methane yield varied from 0.30 to $0.38 \mathrm{~m}^{3} \mathrm{CH}_{4} \mathrm{~kg}^{-1} \mathrm{COD}_{\text {removed, }}$, with higher loads causing a decrease in the yield. 


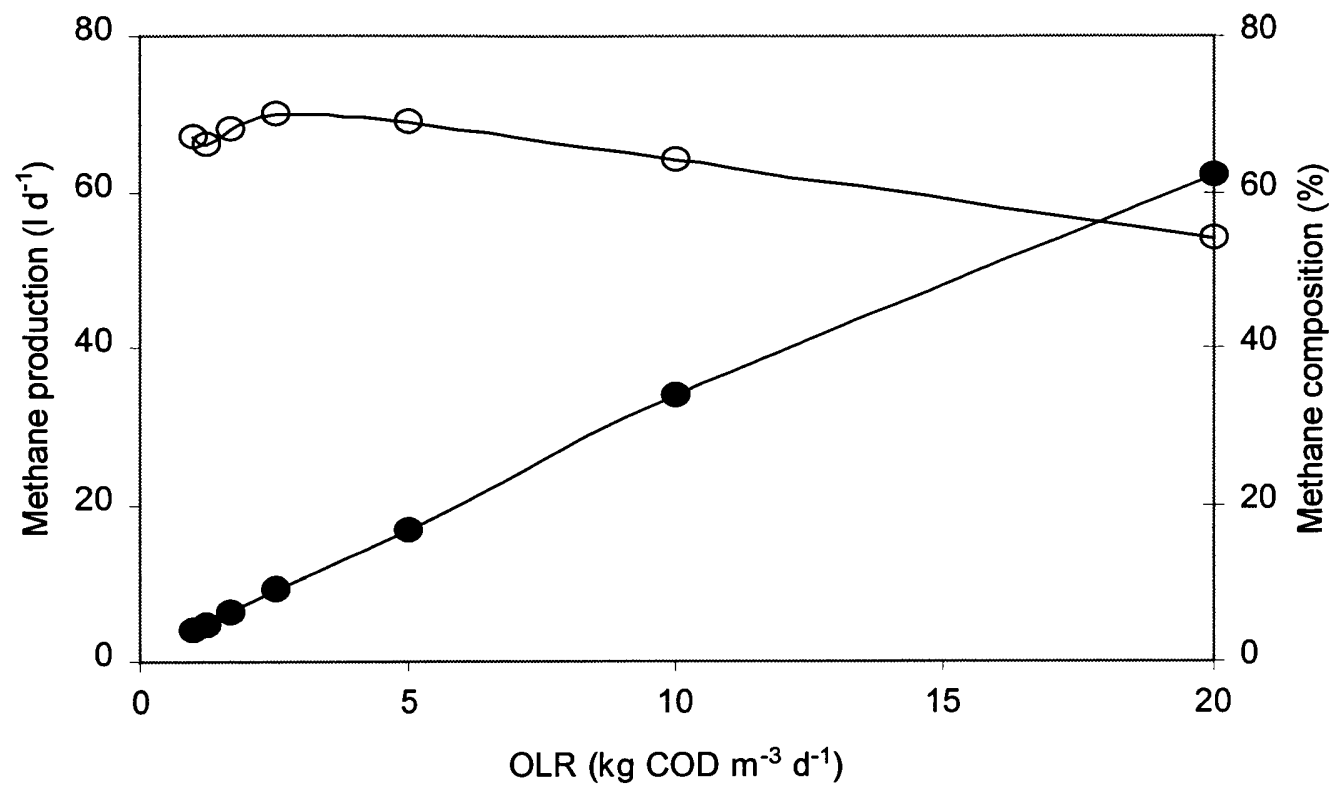

Figure 3.7 Methane production ( $(\Theta)$ and composition $(O)$ of granular bed baffled reactor for organic loading rates of 1 to $20 \mathrm{~kg} \mathrm{COD} \mathrm{m}^{-3} \mathrm{~d}^{-1}$ at steady state conditions.

\subsubsection{Effect of Phase Separation on Granular Bed}

Different characteristics of the granular sludge bed were observed in the acidogenic and methanogenic dominant zones of the GRABBR as shown in Figure 3.8. Granule flotation and breaking* were observed in the front compartments of the GRABBR, where acidogenesis was the dominant activity. Breaking of granules caused an increase in non-granular biomass in these compartments. Similar observations has been made when treating whisky wastewater using the GRABBR (Akunna and Clark, 2000). On the other hand, most of the granular sludge in the rear compartments of the reactor, where methanogenesis was dominant, retained their original structure. This marked difference in the physical properties of biomass in different microbial environment would not have been more clearly observed in a completely mixed system, where all microbial populations exist in one mixed environment without any phase separation.

\footnotetext{
* The process of disintegration or breakdown of a granule (Pereboom, 1994)
} 


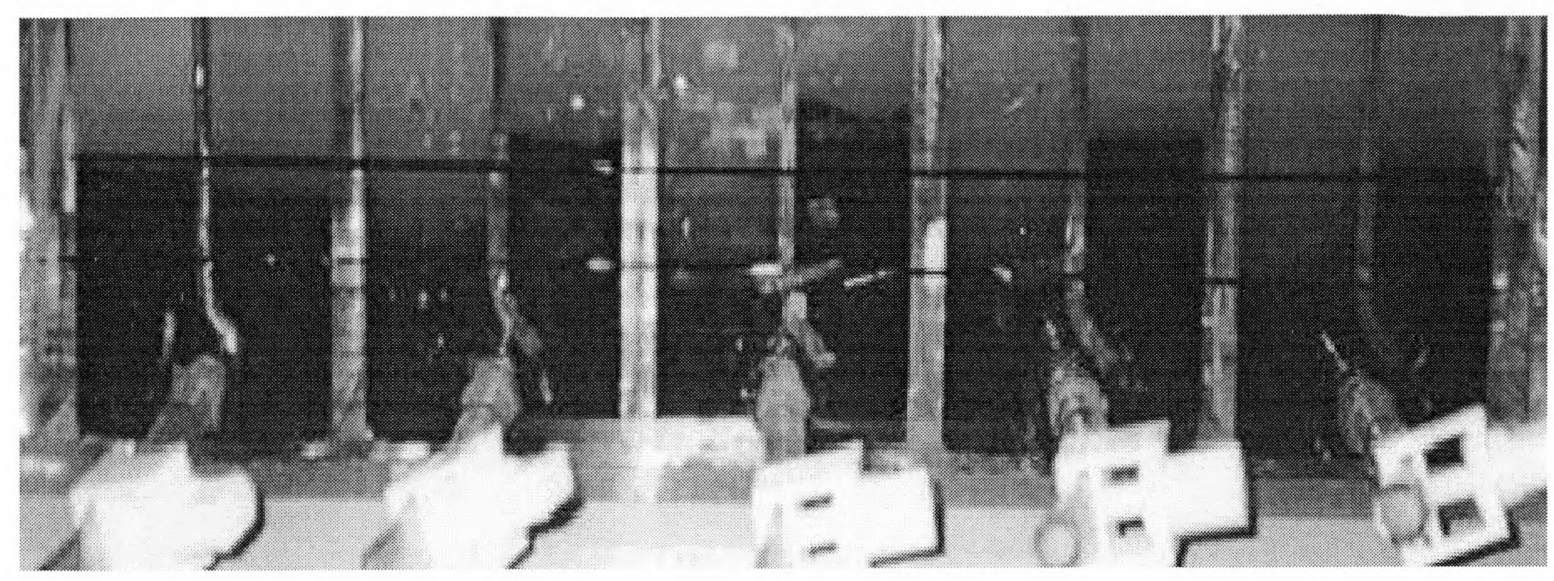

(3.8a)

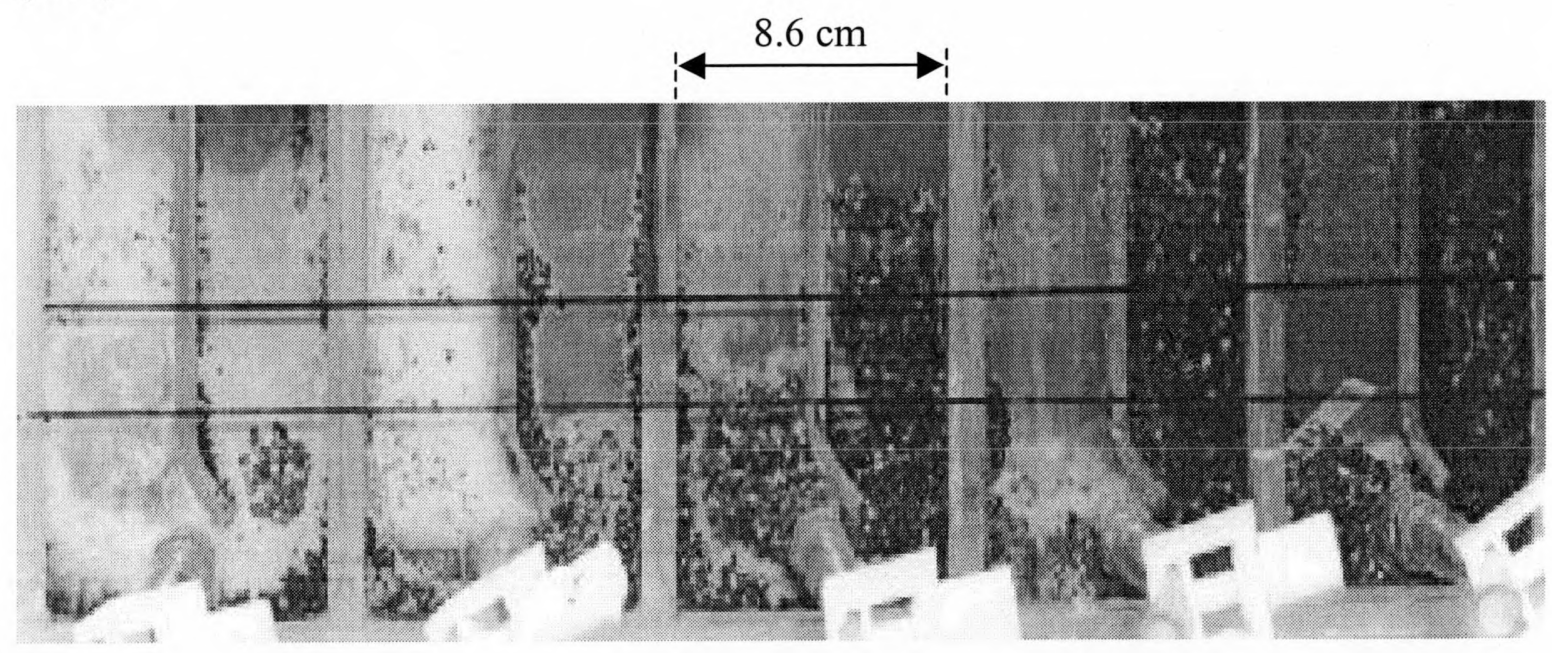

(3.8b)

Figure 3.8 (a) Provided granular bed at the start of reactor operation at day 8 (operating at organic loading rate of $1 \mathrm{~kg} \mathrm{COD} \mathrm{m}^{-3} \mathrm{~d}^{-1}$ ). (b) Continuous reactor operation for 148 days, while treating organic loading rates of 1 to $20 \mathrm{~kg} \mathrm{COD} \mathrm{m}^{-3} \mathrm{~d}^{-1}$, caused breaking and flotation of granular sludge in the upstream compartments with the formation of white mass identified as mainly Klebsiella pneumoniae.

When the GRABBR was initially started, the original dark seed granular sludge was the only biomass in all the compartments. Soon after start-up, white sticky mass started to form in the first compartment and spreading downstream with decreasing HRT (increasing OLR). This biomass was either lying free (not adhered to granules) or attached as a layer on a number of granules. Most of the granules covered in white biomass remained in the upstream compartments. Due to the sticky nature of this biomass, some granules were clustered. Most of the granules covered in white biomass ended up breaking with time. Though traces of these new cells were observed in the 
methanogenic dominant zone (downstream compartments), their presence in these compartments was mainly due to their washout from early compartments.

Washout or breaking of granules in the acidogenic phase of staged digestion systems has been reported (van Lier et al., 1996; Rebac et al., 1998). These authors noted that the formation of attached 'fluffy layer' on the granules due to excessive growth of acidogenic populations can enhance granule flotation. In this study, the deterioration of the seed granular structure occurred in the upstream compartments of the GRABBR receiving mainly glucose, while the granular structure was retained in the downstream compartments receiving mainly VFA. Thus, the formation of non-granular biomass was believed to be mainly associated with fermentative substrates. Hydrophobicity has been reported to play a key role in the aggregation of bacterial species (van Loosdrecht et al., 1987a \& 1987b), and thus resulting in granule formation (Grotenhuis et al., 1992). Methanogens are mainly hydrophobic cells (Grotenhuis et al., 1992; Daffonchio et al., 1995; Thaveesri et al., 1995), and it is believed that these microorganisms played an important role in maintaining granular consortia in the downstream compartments of the GRABBR. In this study, aggregation of seed granules was not favoured in the environment dominated by fermentative activities. This environment was mainly dominated by acidogenic organisms, predominantly hydrophilic cells (Thaveesri et al., 1995; Daffonchio et al., 1995), and thus resulted in species dispersion out of granular structure into the liquid phase.

Effluent total suspended solids (TSS) concentrations were in the range of 40 to $240 \mathrm{mg}$ $1^{-1}$. At high loading rates, newly formed non-granular microbial mass and the debris of broken granules contributed to most of the effluent solids, although most of them were withheld by the denser granular sludge in the methanogenic zone.

\subsubsection{Non-granular Biomass Identification}

The whitish non-granular biomass formed in the acidogenic-dominant compartments were found to be Gram-negative cells by Gram stain. Analytical Profile Index (API) 20 E test was conducted on the pure cultures for the identification of Enterobacteriaceae 
and other non-fastidious Gram-negative bacteria. Further identification by API 20 E revealed the closest match to be Klebsiella pneumoniae (identification number 5005773, with $83 \%$ probability), which is also called Friedländer's bacillus. Most strains of this Enterobacteriaceae genus can use citrate and glucose as a sole carbon source. They have the capability of fermenting glucose with the production of acid and gas. These rod-shaped bacteria produced large sticky colonies when plated on nutrient media, as also reported in the literature for such species (Brenner, 1984). They are facultatively anaerobic, tolerant to low levels of dissolved oxygen, having both a respiratory and a fermentative type of metabolism (Brenner, 1984). These characteristics are also associated with acidogenic bacteria.

\subsection{SUMMARY AND CONCLUSIONS}

The GRABBR encouraged phase separation by accommodating different microbial populations in different compartments according to their favourable substrate conditions, thus operating as a two-stage anaerobic digestion system. This highlighted the main property of the plug flow compartmentalised design of the granular bed

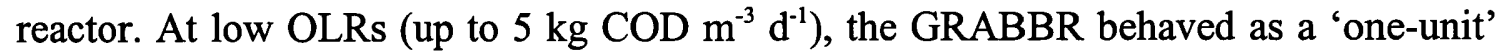
system, utilising only one compartment for complete treatment. The number of compartments involved in the treatment increased with increase in OLR. At high loadings, phase separation became more apparent because each compartment of the reactor acted as a specialised treatment unit, with acidogenesis dominating the upstream compartments and methanogenesis the downstream compartments. This provided optimal environmental conditions for acidogenic and methanogenic activities, which consequently enhanced process efficiency of the system. Increase in OLRs caused an increase in the acidogenic zone and decrease in the methanogenic zone. Results of this study suggest that the GRABBR was able to achieve high SCOD removal (96\% to $98 \%$ ) at high OLRs (up to $20 \mathrm{~kg} \mathrm{COD} \mathrm{m}^{-3} \mathrm{~d}^{-1}$ ) with low biomass washout because of its phase separation capability and granular bed characteristics, with optimum contact between the wastewater and the biomass. Table 3.1 shows that the performance of the GRABBR compares favourably well with other anaerobic treatment systems at high loads. 
Higher concentrations of acetate and butyrate were observed in the upstream compartments of GRABBR at high OLR $\left(20 \mathrm{~kg} \mathrm{COD} \mathrm{m}^{-3} \mathrm{~d}^{-1}\right)$, combined with low $\mathrm{pH}$ in these compartments. McCarty and Mosey (1991) considered anaerobic fermentation of carbohydrates as a competition between butyrate and propionate producing bacteria, with the former dominant at low $\mathrm{pH}$. This could be the reason for butyrate being higher than propionate. In other studies (Zoetemeyer et al., 1982; Inanc et al., 1996; Horiuchi et al., 2002), the dynamics of the microbial population in the acidogenic zone appeared to be dependent on the $\mathrm{pH}$ of the medium, as also observed in the upstream compartments (acidogenic dominant phase) of this study at high load.

The formation of non-granular microbial mass was observed along with granule breaking and flotation in the compartments where acidogenesis was dominant, whilst the original seed granular structure was retained and accumulated in the methanogenic zone. The whitish microbial mass dominant in the acidogenic zone was identified as Gram-negative Klebsiella pneumoniae, a facultative anaerobic microorganism (a property also associated with acidogenic bacteria). It is believed that the substrate conditions in the upstream compartments encouraged the proliferation of these microorganisms. The growth rate of newly formed microorganisms increased with the increase in OLR. In general, the results of this study suggest that acidogens are mainly dispersed biomass forming microorganisms with hydrophilic characteristics, while methanogens initiate granule formation with hydrophobic properties. This study also showed that the GRABBR could minimise biomass washout even at relatively short HRTs. This is probably because in the GRABBR, the denser methanogenic granular sludge possessed good settling characteristics, and in the form of sludge bed it also acted as a filtration bed for the non-granular biomass formed upstream of the reactor. 
Table 3.1 Performance of various anaerobic systems under high loading rates at mesophilic conditions.

\begin{tabular}{|c|c|c|c|c|c|}
\hline Substrate & Reactor type & $\begin{array}{c}\text { OLR }^{a} \\
\left(\mathrm{~kg} \mathrm{COD} \mathrm{m}^{-3} \mathrm{~d}^{-1}\right)\end{array}$ & $\begin{array}{l}\mathrm{HRT}^{\mathrm{b}} \\
\text { (hrs) }\end{array}$ & $\begin{array}{l}\text { COD }^{c} \text { removal } \\
\text { efficiency (\%) }\end{array}$ & Reference \\
\hline Sucrose-protein & $\mathrm{ABR}^{\mathrm{d}}$ & $2-20$ & & $79-82$ & Bachmann et al., 1983 \\
\hline Sucrose-protein & $\mathrm{ABR}$ & $2.5-36.2$ & $4.8-71$ & $55-93$ & Bachmann et al., 1985 \\
\hline Sucrose-protein & $\mathrm{ABR}$ & $1.2-19.2$ & $5-80$ & $55-96$ & Grobicki and Stuckey, 1991 \\
\hline Glucose & $\mathrm{UASB}^{\mathrm{e}}$ & $2-15$ & 12 & $<50-97$ & Bae et al., 1997 \\
\hline Sucrose-protein & $\mathrm{ABR}$ & $4.8-18$ & 20 & $90-98$ & Nachaiyasit and Stuckey, 1997a \\
\hline Sucrose-protein & $\mathrm{ABR}$ & $4.8-19.2$ & $5-20$ & $52-98$ & Nachaiyasit and Stuckey, 1997b \\
\hline Glucose & $\mathrm{ABR}$ & $2-20$ & 12 & $72-99$ & Bae et al., 1997 \\
\hline Molasses & $\mathrm{HABR}^{\mathrm{f}}$ & $4.3-28$ & $53-168$ & $50-89$ & Boopathy and Tilche, 1992 \\
\hline Molasses & UASB & $2.45-23.3$ & $48-406$ & $72-81$ & Sanchez Riera et al., 1985 \\
\hline Molasses & $\mathrm{AF}^{\mathrm{g}}$ & $11-18.6$ & & $29-36$ & Hilton and Archer, 1988 \\
\hline Molasses stillage & DFFR $^{h}$ & $14.2-20.4$ & $79.2-60$ & $60-73$ & Bories et al., 1988 \\
\hline Slaughterhouse & $\mathrm{AFBR}^{\mathrm{i}}$ & $2-18.5$ & $12-120$ & $30-85$ & Tritt, 1992 \\
\hline Pharmaceutical & $\mathrm{ABR}$ & $2.5-20$ & 24 & $36-68$ & Fox and Venkatasubbiah, 1996 \\
\hline Food waste & 2-phase UASB & $1.8-21.4$ & $7.9-93.6$ & $55-96$ & Shin et al., 2001 \\
\hline Glucose & $\mathrm{GRABBR}^{\mathrm{j}}$ & $1-20$ & $6-120$ & $96-98$ & This study \\
\hline
\end{tabular}

\footnotetext{
${ }^{\mathrm{a}}$ Organic loading rate, ${ }^{\mathrm{b}}$ Hydraulic retention time, ${ }^{\mathrm{c}}$ Chemical oxygen demand, ${ }^{\mathrm{d}}$ Anaerobic baffled reactor, ${ }^{\mathrm{e}}$ Upflow anaerobic sludge blanket,

${ }^{\mathrm{f}}$ Hybrid anaerobic baffled reactor, ${ }^{\mathrm{g}}$ Anaerobic filter, ${ }^{\mathrm{h}}$ Downflow fixed film reactor, ${ }^{\mathrm{i}}$ Anaerobic fixed bed reactor, ${ }^{\mathrm{j}}$ Granular bed baffled reactor
} 


\section{CHAPTER 4}

\section{PERFORMANCE OF GRANULAR BED BAFFLED REACTOR DURING RAPID HYDRAULIC SHOCK LOADS}

This chapter describes the importance of the granular bed baffled reactor when accommodating unpredictable rapid hydraulic shock loads. This study was carried out by rapidly increasing influent flow rate with constant feed concentration.

\subsection{INTRODUCTION}

The performance of anaerobic processes is generally regarded as suitable for the treatment of steady-state wastewaters, with less variation in composition and flow. However, the character of the effluent from an industry can differ remarkably in time, due to different operations involved in industrial activities, leading to the complexity of waste load and flow entering a treatment unit. Due to the sensitivity of the microorganisms involved in the treatment process, shock loads could adversely affect the performance of anaerobic reactors by producing unfavourable conditions for microbial populations. This excessive variability of industrial wastewater, both in quality and quantity, can lead to an environment favourable to the growth of one microbial population (acidogens), which may produce conditions within the media that may constitute a limiting factor to the other group of organisms (methanogens). Such conditions encourage volatile fatty acids (VFAs) accumulation and destabilise the microbial ecology within the anaerobic system. This could eventually lead to system failure (Xing et al., 1997).

The effect of hydraulic shock loads or short hydraulic retention times (HRTs) on the performance of anaerobic systems has been widely reported (Bull et al., 1983; Grobicki 
and Stuckey, 1991; Boopathy and Tilche, 1991; Zhang and Noike, 1994; Borja et al., 1995; Nachaiyasit and Stuckey, 1997b; Pozo et al., 2000). They observed that channelling, high biomass washout and VFA accumulation could hamper the performance of anaerobic systems to withstand hydraulic shock loading conditions. This study was designed at evaluating the stability of the granular bed baffled reactor (GRABBR) in terms of efficiency and reliability during shock load conditions created by a rapid increase in hydraulic (and organic) loadings. The study was carried out with synthetic glucose wastewater under mesophilic conditions.

\subsection{EXPERIMENTAL DESIGN}

This study was conducted by inoculating the reactor with 3 litres of granular sludge. After seeding the reactor, it was left with the inoculum for 1 day at $35^{\circ} \mathrm{C}$ so that the granular sludge would adapt to the new environment. Shock loads were created by doubling the hydraulic loading rates in very short intervals of time, while maintaining the constant feed concentration. The reactor was started with an organic loading rate

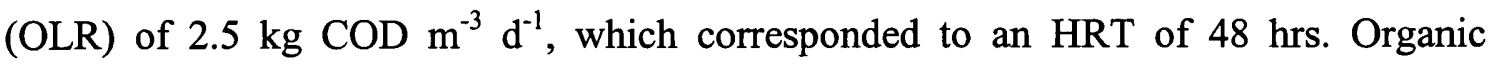
loading rates of 5,10 and $20 \mathrm{~kg} \mathrm{COD} \mathrm{m}^{-3} \mathrm{~d}^{-1}$ were achieved by applying HRTs of 24 hrs, $12 \mathrm{hrs}$ and $6 \mathrm{hrs}$ respectively. The system was operated continuously for 33 days. Organic loading rates were increased when a relatively small variation in the soluble COD (SCOD) of the final effluent for three different samples was observed, hence referred to as steady-state conditions in this study. The results presented in Figures 4.2, 4.3 and 4.4 were based on the sample analysis obtained just before changing the loading rate. No effluent recirculation was carried out throughout the study and there was also no effluent settling prior to discharge.

\subsection{RESULTS}

\subsubsection{Soluble Chemical Oxygen Demand Removal}

Dynamic response based on SCOD variations within the compartments of the GRABBR is shown in Figure 4.1. Although rapid increases in OLR brought about transitional increases in SCOD within the compartments, the final effluent SCOD (i.e. SCOD levels

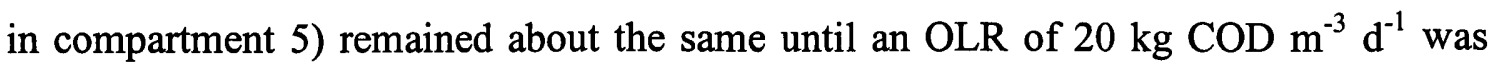


applied. Increase in OLR brought about initial instability in the compartments. However, the overall time required to attain steady state conditions was relatively short.

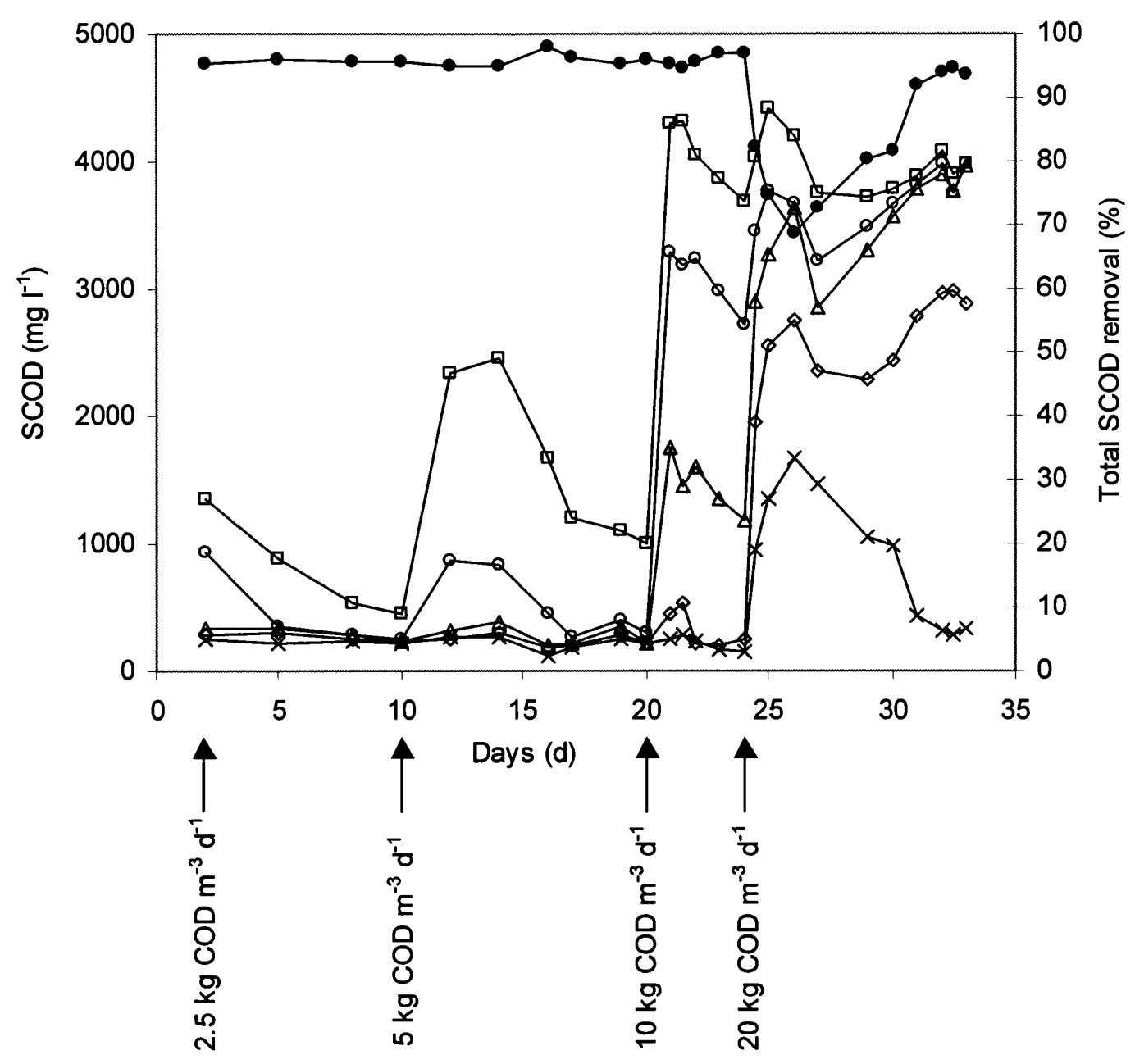

Figure 4.1 Soluble chemical oxygen demand (SCOD) concentrations in each compartment of granular bed baffled reactor at different organic loading rates: $(\square)$

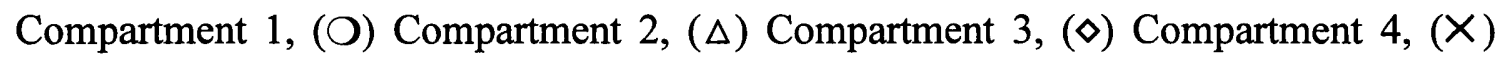
Compartment 5, (@) percentage total SCOD removal during the length of reactor operation.

The relative contributions to total SCOD removal by each compartment under different loading conditions are shown in Figure 4.2. Throughout the study, effluent SCOD removal efficiencies were measured $94 \%$ to $97 \%$ for all applied loading conditions at steady state. The first compartment was able to achieve $91 \%$ and $81 \%$ of SCOD 
removal at OLRs of $2.5 \mathrm{~kg} \mathrm{COD} \mathrm{m}^{-3} \mathrm{~d}^{-1}$ (48 hrs HRT) and $5 \mathrm{~kg} \mathrm{COD} \mathrm{m}^{-3} \mathrm{~d}^{-1}(24 \mathrm{hrs}$ HRT) respectively. Increasing the OLR from 5 to $10 \mathrm{~kg} \mathrm{COD} \mathrm{m}^{-3} \mathrm{~d}^{-1}(12 \mathrm{hrs} \mathrm{HRT})$ brought about a SCOD removal of only $31 \%$ in the first compartment and $18 \%$ in the second compartment. A SCOD removal of $25 \%$ was achieved in the first compartment at an OLR of $20 \mathrm{~kg}$ COD m $\mathrm{m}^{-3}$. No noticeable reduction in SCOD removal was observed in compartments 2 and 3 with this rapid increase in the load. However, high treatment efficiencies were obtained in compartments 4 and 5 , particularly in compartment 5 , which was solely responsible for achieving $48 \%$ of SCOD removal.

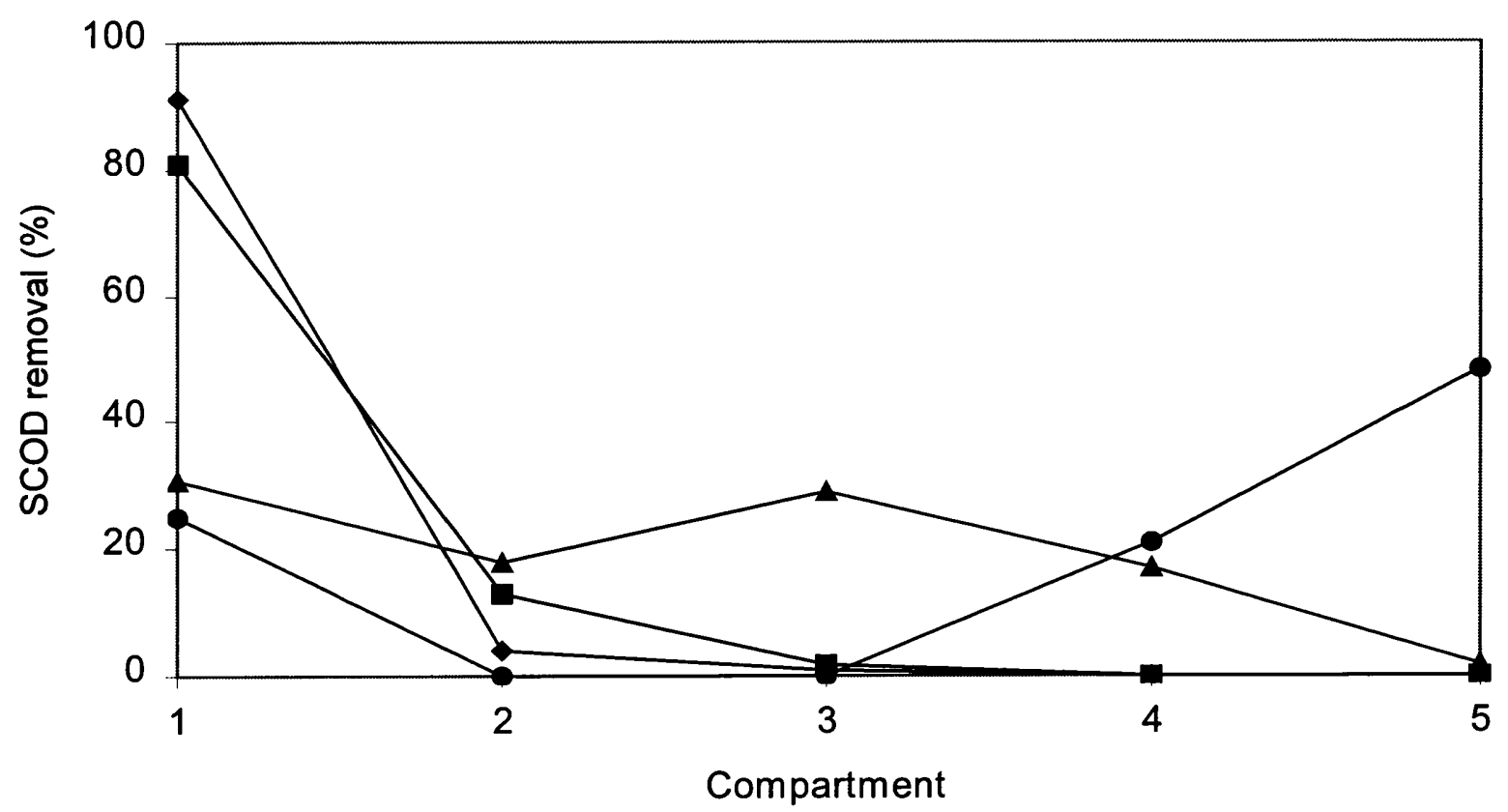

Figure 4.2 Percentage soluble chemical oxygen demand (SCOD) removal contributed by each compartment of granular bed baffled reactor at different organic loading rates: (O) $20 \mathrm{~kg} \mathrm{COD} \mathrm{m}^{-3} \mathrm{~d}^{-1}$, (A) $10 \mathrm{~kg} \mathrm{COD} \mathrm{m}^{-3} \mathrm{~d}^{-1}$, (口) $5 \mathrm{~kg} \mathrm{COD} \mathrm{m}^{-3} \mathrm{~d}^{-1}$, (४) $2.5 \mathrm{~kg} \mathrm{COD} \mathrm{m}^{-3} \mathrm{~d}^{-1}$.

\subsubsection{Volatile Fatty Acid Profile}

Due to the high treatment efficiency recorded in the upstream compartments at OLRs of 2.5 and $5 \mathrm{~kg} \mathrm{COD} \mathrm{m}^{-3} \mathrm{~d}^{-1}$, no significant amount of VFAs were measured within the system at these loadings. Increasing the OLR to $10 \mathrm{~kg} \mathrm{COD} \mathrm{m}^{-3} \mathrm{~d}^{-1}(24 \mathrm{hrs} \mathrm{HRT})$ produced a noticeable amount of VFA in the first compartment. Subsequently, a drop in 
VFA levels was observed downstream of the reactor, with almost no VFA being detected in compartments 4 and 5. Marked VFA levels were found in the first four compartments when an OLR of $20 \mathrm{~kg} \mathrm{COD} \mathrm{m}^{-3} \mathrm{~d}^{-1}(6 \mathrm{hrs} \mathrm{HRT})$ was applied as shown in Figure 4.3. Most of these VFAs were removed in compartment 5. At this load, the first three compartments were believed to be dominated by acidogenesis, resulting in VFA accumulation. Subsequently, a decrease in VFA levels was observed downstream of the reactor. Acetate and butyrate were the main VFAs at an OLR of $20 \mathrm{~kg} \mathrm{COD} \mathrm{m}^{-3}$ $\mathrm{d}^{-1}$.

There was a general increase in $\mathrm{pH}$ values downstream of the reactor as shown in Figure 4.4. Increase in OLR (decrease in HRT) brought about a decrease in $\mathrm{pH}$ levels in the upstream compartments of the reactor. $\mathrm{pH}$ levels were around 7 or slightly more in the final effluent for all applied shock loads.

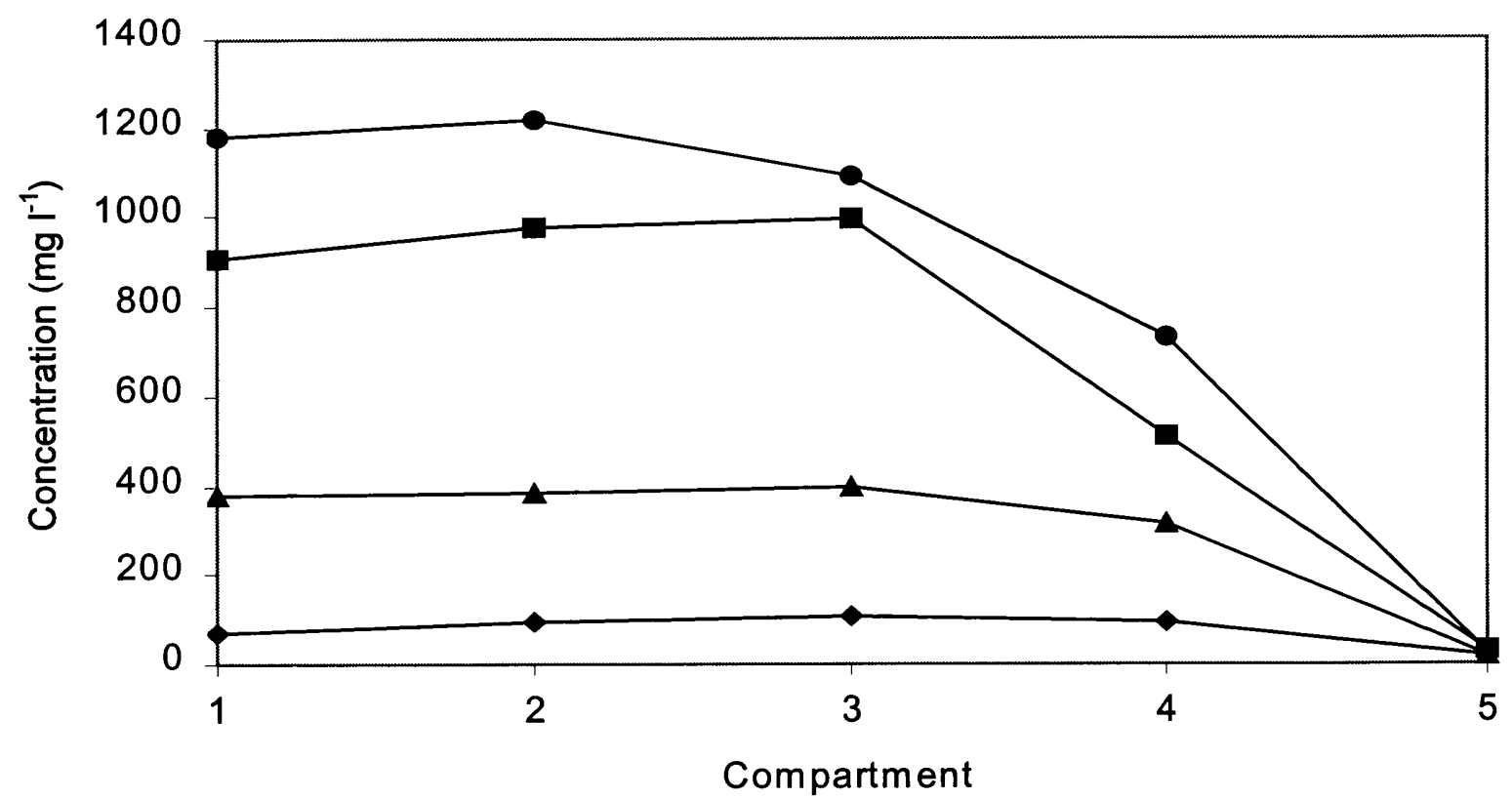

Figure 4.3 Volatile fatty acid profile in the compartments of granular bed baffled reactor at organic loading rate of $20 \mathrm{~kg} \mathrm{COD} \mathrm{m}^{-3} \mathrm{~d}^{-1}:(\boldsymbol{)})$ acetate, (A) propionate, $(\square)$ butyrate, $(\diamond)$ valerate. 


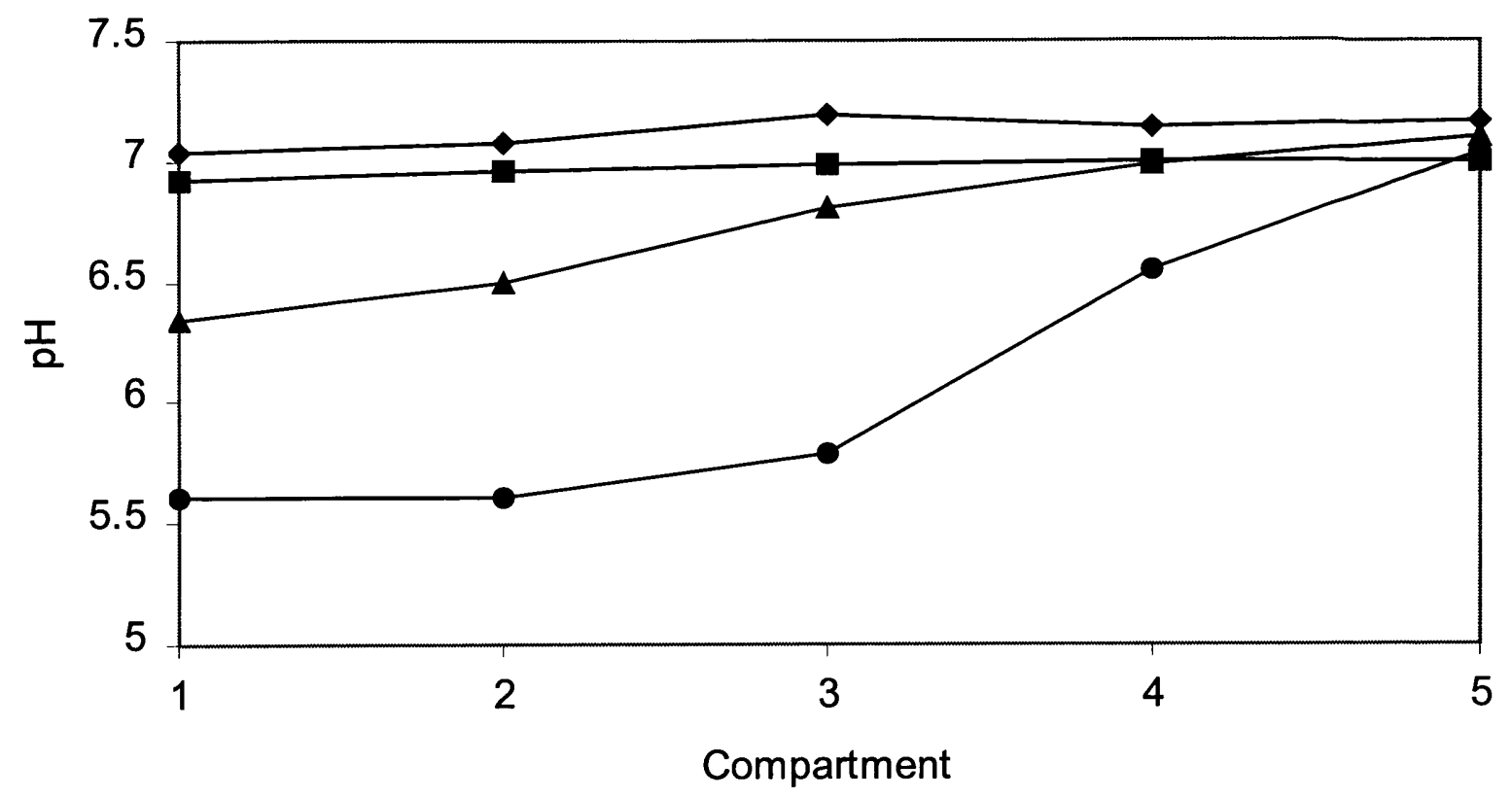

Figure 4.4 $\mathrm{pH}$ profile in the compartments of granular bed baffled reactor at different organic loading rates: (๑) $20 \mathrm{~kg} \mathrm{COD} \mathrm{m}^{-3} \mathrm{~d}^{-1},(\boldsymbol{\Delta}) 10 \mathrm{~kg} \mathrm{COD} \mathrm{m}^{-3} \mathrm{~d}^{-1}$, (口) 5 $\mathrm{kg} \mathrm{COD} \mathrm{m} \mathrm{d}^{-3},(\diamond) 2.5 \mathrm{~kg} \mathrm{COD} \mathrm{m}^{-3} \mathrm{~d}^{-1}$.

\subsubsection{Biomass Retention}

Granule breaking and flotation was observed in the upstream compartments, whilst the granular structure of the original seed sludge was retained in the downstream compartments. The reactor was able to retain high granular biomass concentration at high loading rates. It is worth noting that there was no effluent settling for biomass separation after the last compartment. Effluent total suspended solids (TSS) concentrations were measured in the range of 60 to $255 \mathrm{mg} \mathrm{l}^{-1}$. Most of the solids washout consisted of non-granular newly-formed microbial mass and debris of broken granules from the upstream compartments of the reactor. The non-granular biomass was also observed to be withheld within the denser granular bed. The density of the seed granules was calculated as $1051 \mathrm{~kg} \mathrm{~m}^{-3}$ and ash content was measured as $20 \%$. 


\subsubsection{Biogas Production}

The methane content of the gas was in the range of $55 \%$ to $70 \%$ throughout the study. Increase in loadings brought about an increase in biogas production. The total gas increased from 14 to $120 \mathrm{ld}^{-1}$ for loading rates of 2.5 to $20 \mathrm{~kg} \mathrm{COD} \mathrm{m}^{-3} \mathrm{~d}^{-1}$.

\subsection{DISCUSSION}

It is evident that the GRABBR has a high tolerance to rapid hydraulic shock loads and requires a relatively short recovery time to attain steady state conditions (Figure 4.1). Rapid increments in OLR initially upset the microbial ecology of the upstream compartments for a short period of time, however the system recovered quickly and adjusted to the new loading conditions. The number of compartments actively involved in the treatment increased with the increase in OLR. Like the previous study (Chapter 3 ), the reactor behaved as one completely mixed unit at low OLR (up to $5 \mathrm{~kg} \mathrm{COD} \mathrm{m}^{-3}$ $\mathrm{d}^{-1}$ ) or long HRT due to high treatment performance achieved in the first compartment. The first sign of noticeable phase separation in the reactor was observed when OLR was increased from $5 \mathrm{~kg} \mathrm{COD} \mathrm{m}^{-3} \mathrm{~d}^{-1}$ (24 hrs HRT) to $10 \mathrm{~kg} \mathrm{COD} \mathrm{m}^{-3} \mathrm{~d}^{-1}$ (12 hrs HRT). With further rapid increase in hydraulic load, at an OLR of $20 \mathrm{~kg} \mathrm{COD} \mathrm{m}^{-3} \mathrm{~d}^{-1}(6 \mathrm{hrs}$ HRT), different groups of microorganisms established in different compartments, acidogenesis and methanogenesis were dominant in the upstream and downstream compartments respectively. These conditions appeared to have ensured reactor stability under stressed hydraulic and organic loading conditions.

Channelling and biomass washout have been reported as the main causes of inferior SCOD removal at hydraulic shock load conditions in baffled systems (Grobicki and Stuckey, 1991; Nachaiyasit and Stuckey, 1997b). This mainly resulted in poor contact between microorganisms and the wastewater, and less availability of active biomass within the system. This inherent problem in an ABR system appears to be corrected by GRABBR system. High biomass retention within the GRABBR during hydraulic shock loads was due to the stabilised compact structure of granular sludge which has been reported to possess good settling characteristics (Alibhai and Forster, 1986a). The average density of seed granules was found to be slightly higher than that of water, which might have been the reason for the good settling properties of the granular sludge 
within the GRABBR along with the large particle size. High density and large particle size of aggregates have been associated with good settling characteristics of sludge (Hulshoff Pol et al., 1986; Beetfink and Heuvel, 1988). The low ash content of granular sludge is an indication of the more active nature of biomass in the system. These qualities of granular biomass seemed to have contributed to the effective treatment and relatively high biomass retention in the GRABBR during hydraulic shock load conditions. Like the previous study (Chapter 3), most of the solids washout at high flow rate consisted of non-granular biomass formed in the upstream compartments where acidogenesis was dominant. The relatively lower density and dispersed nature of biomass in the acidogenic dominant zone might be the reason for their easy washout.

Table 4.1 shows the performance level in terms of COD removal efficiency of the GRABBR in this study when compared to other studies carried out with ABR systems at high (shock) loads. For instance, using concentrated sucrose enriched wastewater, some authors have reported SCOD removal of $90 \%$ in the ABR system operating at an OLR of $18 \mathrm{~kg} \mathrm{COD} \mathrm{m}^{-3} \mathrm{~d}^{-1}$ at $20 \mathrm{hrs} \mathrm{HRT} \mathrm{(Nachaiyasit} \mathrm{and} \mathrm{Stuckey,} \mathrm{1997a).} \mathrm{However,}$ with less concentrated wastewater at an OLR of $19.2 \mathrm{~kg} \mathrm{COD} \mathrm{m}^{-3} \mathrm{~d}^{-1}$, these authors observed a SCOD removal of only $52 \%$ at 5 hrs HRT (Nachaiyasit and Stuckey, 1997b). On the other hand, the GRABBR achieved a SCOD removal of $94 \%$ when a hydraulic shock load of $6 \mathrm{hrs}$ HRT (OLR of $20 \mathrm{~kg} \mathrm{COD} \mathrm{m}^{-3} \mathrm{~d}^{-1}$ ) was applied. This shows the vulnerability of flocculent sludge baffled systems towards hydraulic shock loads or short HRTs, and potential benefits of GRABBR to withstand stressed loading conditions.

VFA accumulation at high shock loads produced low $\mathrm{pH}$ levels in the upstream compartments (near influent point) due to the abundance of fast-growing acidogenic population in this part of the system. Like the study reported in Chapter 3, the production of acetate and butyrate increased in the early compartments at high hydraulic (shock) loads. An increase in loading rates caused a shift of acidogenesis further down the reactor, thereby reducing the methanogenic dominant zone. The GRABBR was able to create substrate-induced separate zones of microbial population in different compartments, thereby offering more protection to the most sensitive microbial group (methanogens) from the adverse effects of rapid overloadings. 
Table 4.1 Performance of baffled reactors at high (shock) loads.

\begin{tabular}{lccccc}
\hline Substrate & OLR $^{\mathrm{a}}$ & $\mathrm{HRT}^{\mathrm{b}}$ & Days of & COD $^{\mathrm{c}}$ removal & Reference \\
& $\left(\mathrm{kg} \mathrm{COD} \mathrm{m}^{-3} \mathrm{~d}^{-1}\right)$ & $(\mathrm{hrs})$ & Operation & efficiency (\%) &
\end{tabular}

\begin{tabular}{|c|c|c|c|c|c|}
\hline \multirow[t]{9}{*}{ Sucrose-protein } & 2.5 & 71 & 22 & 93 & \multirow{9}{*}{$\begin{array}{l}\text { Bachmann et al., } \\
1985\end{array}$} \\
\hline & 4.2 & 48 & 28 & 88 & \\
\hline & 8.9 & 22 & 28 & 81 & \\
\hline & 11.4 & 18 & 21 & 91 & \\
\hline & 15.3 & 12 & 113 & 77 & \\
\hline & 20 & 10 & 33 & 75 & \\
\hline & 27.3 & 6.7 & 32 & 68 & \\
\hline & 31.8 & 5.6 & 11 & 55 & \\
\hline & 36.2 & 4.8 & 10 & 60 & \\
\hline \multirow[t]{3}{*}{ Sucrose-protein } & 4.8 & 20 & & 96 & \multirow{3}{*}{$\begin{array}{l}\text { Grobicki and } \\
\text { Stuckey, } 1991\end{array}$} \\
\hline & 9.6 & 10 & & 82 & \\
\hline & 19.2 & 5 & & 58 & \\
\hline \multirow[t]{4}{*}{ Sucrose-protein } & 4.8 & 20 & 30 & 97 & \multirow{4}{*}{$\begin{array}{l}\text { Nachaiyasit and } \\
\text { Stuckey, 1997a }\end{array}$} \\
\hline & 9.6 & 20 & 20 & 98 & \\
\hline & 4.8 & 20 & 30 & 98 & \\
\hline & 18 & 20 & 20 & 90 & \\
\hline \multirow[t]{3}{*}{ Sucrose-protein } & 4.8 & 20 & 30 & 98 & \multirow{3}{*}{$\begin{array}{l}\text { Nachaiyasit and } \\
\text { Stuckey, 1997b }\end{array}$} \\
\hline & 9.6 & 10 & 14 & 90 & \\
\hline & 19.2 & 5 & 24 & 52 & \\
\hline \multirow[t]{7}{*}{ Glucose $^{d}$} & 2 & 12 & 14 & 99 & \multirow[t]{7}{*}{ Bae et al., 1997} \\
\hline & 3 & 12 & 18 & 94 & \\
\hline & 4.5 & 12 & 97 & 95 & \\
\hline & 6.8 & 12 & 22 & 93 & \\
\hline & 10 & 12 & 14 & 88 & \\
\hline & 15 & 12 & 26 & 87 & \\
\hline & 20 & 12 & 7 & 72 & \\
\hline \multirow[t]{4}{*}{ Molasses } & 4.33 & 168 & 50 & 89 & \multirow{4}{*}{$\begin{array}{l}\text { Boopathy and } \\
\text { Tilche, } 1992\end{array}$} \\
\hline & 12.5 & 120 & 28 & 82 & \\
\hline & 20 & 72 & 25 & 73 & \\
\hline & 28 & 53 & 21 & 50 & \\
\hline \multirow[t]{4}{*}{ Glucose } & 2.5 & 48 & 10 & 96 & \multirow[t]{4}{*}{ This study } \\
\hline & 5 & 24 & 10 & 96 & \\
\hline & 10 & 12 & 4 & 97 & \\
\hline & 20 & 6 & 9 & 94 & \\
\hline
\end{tabular}

${ }^{\text {a }}$ Organic loading rate

${ }^{\mathrm{b}}$ Hydraulic retention time

${ }^{c}$ Chemical oxygen demand

${ }^{d}$ Days in operation calculated from graph 


\subsection{CONCLUSIONS}

The reactor was able to attain SCOD removal efficiencies of $94 \%$ to $97 \%$ for OLRs of 2.5 to $20 \mathrm{~kg} \mathrm{COD} \mathrm{m}^{-3} \mathrm{~d}^{-1}$ (HRTs of $48 \mathrm{hrs}$ to $6 \mathrm{hrs}$ ) at steady state conditions. This study demonstrated that the GRABBR system has a high tolerance to sudden increase in the flow rate (OLR) without compromising the effluent quality. The capability of the GRABBR to achieve high treatment efficiency and its high capacity storage to metabolise intermediate products during hydraulic shock loads were attributed mainly to its plug flow phase separation characteristics, and the highly active and dense nature of the granular bed in the reactor. The acidogenic dominant phase (upstream compartments) act as a protecting shield for the methanogenic dominant zone (downstream compartments) from adverse microbial conditions created by rapid hydraulic shock loads. This reactor configuration offers separation between different microbial groups along the reactor flow gradient, quick recovery from shock loads, high retention of active (granular) biomass, optimum contact between the wastewater and the biomass, and reduces the effect of channelling at high hydraulic shock loads. 


\section{CHAPTER 5}

\section{COMBINED DENITRIFICATION AND ANAEROBIC DIGESTION IN GRANULAR BED BAFFLED REACTOR}

This study evaluates the suitability of the granular bed baffled reactor for combined denitrification and anaerobic digestion, and examines the effect of nitrate addition in different zones of the reactor.

\subsection{INTRODUCTION}

The feasibility of combined carbon and nitrate removal in anaerobic reactors has been researched with various reactor configurations (Kuroda et al., 1988; Hanaki and Polprasert, 1989; Akunna et al., 1992 \& 1994b; Lin and Chen, 1995; Hendriksen and Ahring, 1996a; Chen et al., 1997; Barber and Stuckey, 2000a; Bernet et al., 2000; Mosquera-Corral et al., 2001; Garrido et al., 2001; Im et al., 2001). Different degrees of denitrification rates and methane production were obtained in anaerobic systems depending on the nature of the substrate, carbon to nitrogen $(\mathrm{C} / \mathrm{N})$ ratio, reactor type and other operational conditions.

Integration of denitrification and methanogenesis reactions in a single system has many advantages (as stated earlier in Section 1.7), however, due to different growth conditions of denitrifying and methanogenic organisms, process complications have been encountered. Methanogenesis has been widely reported to proceed after the denitrification process, i.e. after the elimination of nitrate or nitrogen oxides (Hanaki and Polprasert, 1989; Chen and Lin, 1993; Akunna et al., 1993 \& 1994a; Lin and Chen, 1995; Hendriksen and Ahring, 1996b). Hence, according to these authors (Akunna et al., 1994a, Hendriksen and Ahring, 1996b), the inhibition of methanogenesis by nitrate 
or nitrogen oxides is reversible. Nitrate or nitrite reduction is a far more energy yielding process than methanogenesis, therefore, carbon metabolism via denitrification is expected to dominate in an environment containing nitrogen oxides (Hendriksen and Ahring, 1996a).

The exact causes of inhibition of nitrate or nitrite to methanogens are still not very clear (Mosquera-Corral et al., 2001). One of the reasons for this inhibition has been explained as the competition between nitrate reducing bacteria and methane producing bacteria for a carbon source (electron donor). However, experiments carried out with excess carbon concentrations for combined methanogenesis and denitrification showed no such competition, with no methane production during denitrification process (Akunna et al., 1993 \& 1994a). Furthermore, with acetate rich media (a suitable substrate for methanation), similar behaviour was observed (Akunna et al., 1993).

The other reason suggested in the literature for this inhibition is the relatively high redox potential associated with the presence of nitrogen oxides. Methanogens are believed to grow under low redox potential environment. In a nitrate free environment, methane production was observed at redox potentials between -115 and $-330 \mathrm{mV}$ (Chen and Lin, 1993; Lin and Chen, 1995; Akunna et al., 1998). However, no methane production was observed at low redox potential $(-300 \mathrm{mV})$ in the presence of nitrate (Akunna et al., 1998). Similarly in another study, at low redox potential (-400 mV), no methane production was observed in the presence of nitrogen oxide (Chen and Lin, 1993).

The most plausible cause of nitrate-induced inhibition of methane producing bacteria is the concurrent growth of denitrifying microorganisms. In batch assays, the growth of intermediate denitrifying microorganisms has been found to possess higher inhibition towards methanogenic bacteria than nitrate (Balderston and Payne, 1976; Quevedo et al., 1996; Clarens et al., 1998; Klüber and Conrad, 1998). Nitrite is reported to be a more inhibitory compound to methanogens than nitrate (Chen and Lin, 1993; Quevedo et al., 1996; Clarens et al., 1998).

Dissimilatory nitrate reduction to ammonium (DNRA) has been reported in an anaerobic environment (Kasper et al., 1981; Garcia, 1982; Tiedje, 1988; Akunna et al., 
1992, 1993 \& 1994a; Rustrian et al., 1997). The nature of the carbon source and C/N ratio influence the nitrate reduction pathway, i.e. denitrification and/or DNRA under anaerobic conditions (Akunna et al., 1992, 1993 \& 1994a; Bernet et al., 1996a \& 1996b; Rustrian et al., 1997; Bernet et al., 2000). High chemical oxygen demand to nitrate nitrogen $\left(\mathrm{COD} / \mathrm{NO}_{3}-\mathrm{N}\right)$ ratios were found to favour ammonium formation during nitrate reduction in the presence of fermentative type substrates, like glucose and glycerol, whilst denitrification was the major nitrate reduction pathway at low $\mathrm{COD} / \mathrm{NO}_{3}-\mathrm{N}$ ratios (Akunna et al., 1992, 1993 \& 1994a; Rustrian et al., 1997). The denitrification activity of anaerobic sludge has been found to increase with respect to ammonification as $\mathrm{COD} /($ nitrate and nitrite nitrogen, $\mathrm{NOx}-\mathrm{N})$ ratio decreases with glucose substrate (Akunna et al., 1992). On the other hand, with non-fermentable carbon sources (acetate, volatile fatty acids), denitrification was found to be the major pathway for nitrate or nitrite reduction irrespective of the COD/NOx-N ratio (Akunna et al., 1993).

Most of the studies on combined denitrification and methanogenesis have been carried out with completely mixed reactor systems (Kuroda et al., 1988; Hanaki and Polprasert, 1989; Akunna et al., 1992; Lin and Chen, 1995; Hendriksen and Ahring, 1996a; Bernet et al., 2000; Mosquera-Corral et al., 2001). Depending upon the operational conditions, these studies encountered problems, viz. nitrate inhibition to methanogenesis, DNRA and biogas as a mixture of methane and nitrogen (less useful energy source) due to no gas separation within the system.

The use of fixed film systems for combined denitrification and methanogenesis have been found promising for an integrated approach due to the fixed nature of media, creating zoning for different microbial activities within the system (Hanaki and Polprasert, 1989). Using an anaerobic upflow filter fed with varying methanol to nitrate ratios, Hanaki and Polprasert (1989) observed three reaction zones depending upon the wastewater $\mathrm{COD} / \mathrm{NO}_{3}-\mathrm{N}$ ratio, viz. incomplete denitrification, complete denitrification, and complete denitrification with methane production. However, a high solids content in the wastewaters could limit the use of fixed film systems in combined processes due to clogging of filter media, which could also cause short-circuiting. 
In order to reduce nitrate inhibition to methanogenesis, two-phase anaerobic configurations have been investigated (Rustrian et al., 1997 \& 1999; Delgenès et al., 1998). The first phase was used for acidogenesis and denitrification process, while the second phase for methane production only. However, with varying nitrate loading conditions where high pulses of nitrates are expected, the first phase might only obtain partial or incomplete denitrification, and therefore nitrogen oxides could find their way into the second phase methanogenic reactor. Another development was the utilisation of the front compartments for nitrate removal in a baffled system (Barber and Stuckey, 2000a). These authors (Barber and Stuckey, 2000a) observed complete nitrate removal, however $50 \%$ of the nitrate was converted to ammonia with sucrose (a fermentative substrate) wastewater.

From the discussion in preceding paragraphs, it is evident that completely mixed conditions may not provide the optimum growth environment for different microbial populations involved in denitrification and methane production to flourish. Therefore, phasing in anaerobic systems seems to be the preferred arrangement to achieve combined denitrification and methanogenesis with a mixed culture containing organic carbon and nitrate compounds. The study reported in this Chapter investigates the feasibility of a granular bed baffled reactor (GRABBR) for simultaneous denitrification and anaerobic digestion. This study will also evaluate the optimum entry point for nitrate addition for simultaneous denitrification and anaerobic digestion, and the effect of adding varying concentrations of nitrate to two different microbial zones (i.e. acidogenic and methanogenic dominant zones) of the GRABBR. Acidogenic and methanogenic dominant zones were created in the GRABBR by operating the reactor at a high organic loading rate (OLR) using glucose enriched synthetic wastewater before nitrate addition.

\subsection{EXPERIMENTAL METHOD}

Potassium nitrate $\left(\mathrm{KNO}_{3}\right)$ was used to simulate nitrate addition in the reactor. The addition of nitrate was started with relatively low concentrations (i.e. high $\mathrm{COD} / \mathrm{NO}_{3}-\mathrm{N}$ ratio), when the GRABBR was operating at an OLR of $20 \mathrm{~kg}$ COD m $\mathrm{m}^{-3} \mathrm{~d}^{-1}$ (6 hrs hydraulic retention time, HRT). Nitrate was not mixed with the feed, but pumped continuously at $101 \mathrm{~d}^{-1}$ from a concentrated stock solution directly into the reactor for 
two separate studies via the top port of Compartment 1 (first study) and Compartment 5 (second study), as shown in Figure 5.1. These compartments were chosen, as prior to nitrate addition studies, acidogenic and methanogenic activities were dominant in Compartments 1 and 5 within the GRABBR respectively. Nitrate loading rates (NLRs) were increased by increasing the nitrate concentration in the nitrogenous feed. No organic carbon source was added in the nitrate feed in order to mimic the realistic situation, in which most of the organic matter would be removed in the nitrification unit, and nitrates will be mainly present in the recycled stream from a second stage aerobic unit.

Nitrate addition point Nitrate addition point (First study) (Second study)

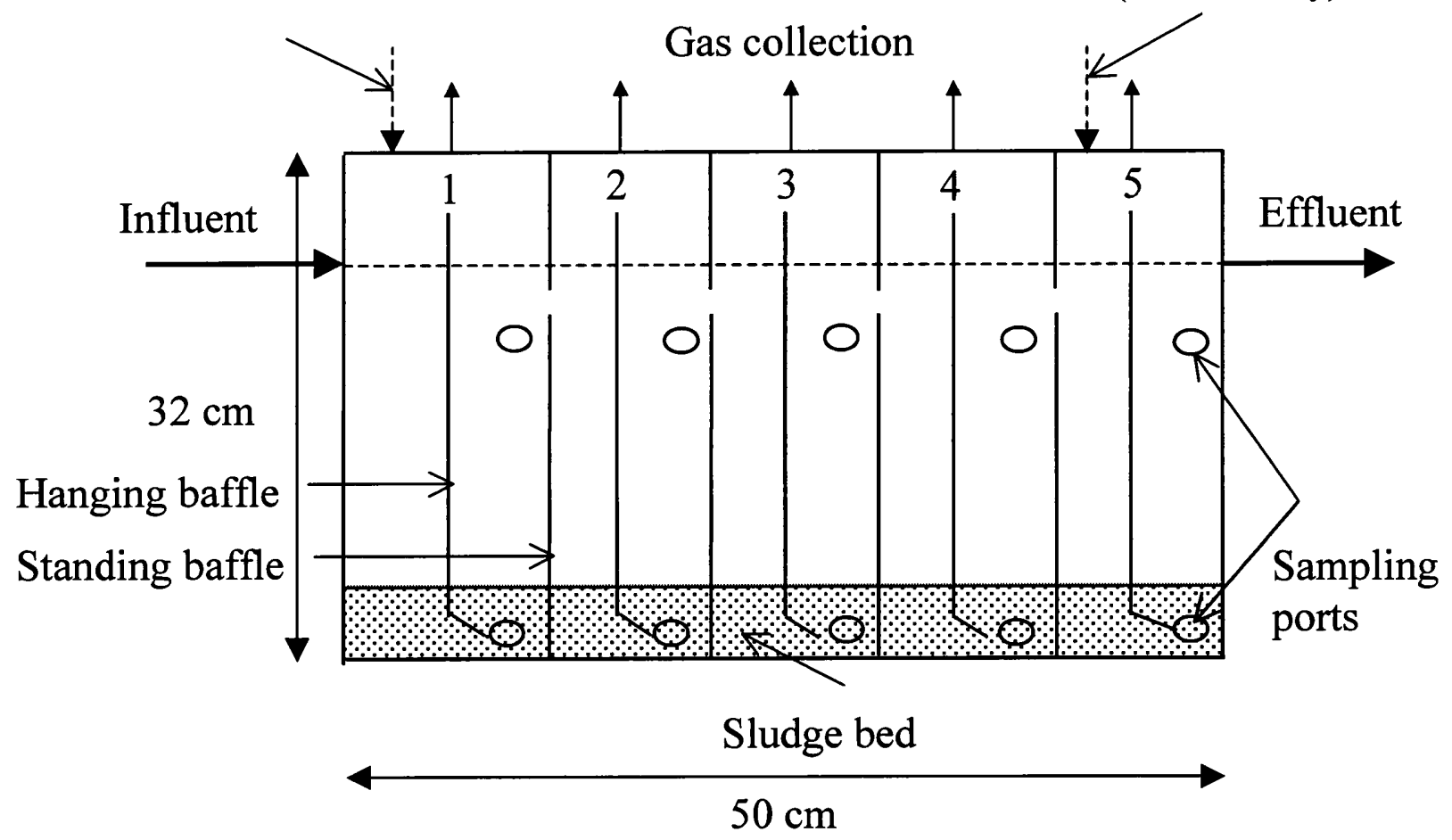

Figure 5.1 Schematic diagram of nitrate addition in the acidogenic dominant zone (Compartment 1) and methanogenic dominant zone (Compartment 5) of granular bed baffled reactor.

The overall soluble COD (SCOD) removal efficiencies in the GRABBR at an OLR of $20 \mathrm{~kg} \mathrm{COD} \mathrm{m} \mathrm{m}^{-3}(6 \mathrm{hrs} \mathrm{HRT})$ were $63 \%$ and $61 \%$, before nitrate addition in Compartment 1 and 5, respectively, as shown in Table 5.1. High acidogenic activities were observed in the first four compartments of the reactor, with high SCOD removal in the last compartment (Table 5.1), due to the high consumption of volatile fatty acid 
(VFA) produced in the upstream compartments to methane. VFA accumulation resulted in low $\mathrm{pH}$ levels in the front compartments (near the influent point), followed by a decrease in the acid levels down the reactor, with a general increase in $\mathrm{pH}$. The original structure of the seed granules was retained in the methanogenic dominant zone, whilst granular breaking and flotation was observed in the acidogenic dominant zone. The latter zone mainly consists of non-granular biomass in the form of newly formed white mass and debris of broken granules, with fewer granules.

Table 5.1 Cumulative soluble chemical oxygen demand (SCOD) removal efficiencies in the compartments of granular bed baffled reactor before nitrate addition in Compartment 1 and 5 at steady state conditions.

\begin{tabular}{l|ccccc}
\hline & \multicolumn{5}{c}{ Cumulative SCOD removal efficiency (\%) } \\
& $\mathrm{C} 1$ & $\mathrm{C} 2$ & $\mathrm{C} 3$ & $\mathrm{C} 4$ & $\mathrm{C} 5$ \\
\cline { 2 - 6 } Compartment 1 & 22 & 22 & 24 & 31 & 63 \\
Compartment 5 & 23 & 26 & 27 & 35 & 61 \\
\hline
\end{tabular}

Key: C1, C2, C3, C4 and C5 represents compartments of the granular bed baffled reactor

Nitrate nitrogen $\left(\mathrm{NO}_{3}-\mathrm{N}\right)$ concentrations were increased in a stepwise fashion in Compartment 1 to correspond to 50,100, 150 and $200 \mathrm{mg} \mathrm{l}^{-1} \mathrm{NO}_{3}-\mathrm{N}$ in the reactor. At the end of the first study, nitrate addition was discontinued and the reactor was fed with only glucose feed at an OLR of $20 \mathrm{~kg} \mathrm{COD} \mathrm{m}^{-3} \mathrm{~d}^{-1}$ ( $\left.6 \mathrm{hrs} \mathrm{HRT}\right)$ for 30 days to allow the system to recover from the nitrate addition in Compartment 1 and re-establish the same conditions prior to nitrate addition. The second nitrate addition study into Compartment 5 followed the same operational (nitrate addition) pattern of Compartment 1 study. The data points mentioned in this study were based on the sample analysis obtained at steady state conditions. No effluent recirculation was carried out throughout the study and there was no effluent settling prior to discharge. Throughout the entire study, the COD concentration and HRT of the influent wastewater were kept constant. The operating conditions of this study are shown in Tables 5.2 and 5.3.

\subsection{RESULTS}

In this study, $\mathrm{NOx}-\mathrm{N}$ represents $\mathrm{NO}_{3}-\mathrm{N}$ and $\mathrm{NO}_{2}-\mathrm{N}$. The acidogenic dominant zone 
mainly refers to Compartment 1 , whereas the methanogenic dominant zone refers to Compartment 5.

Table 5.2 Operating conditions of granular bed baffled reactor during nitrate addition into Compartment 1 .

\begin{tabular}{ccccccc}
\hline $\begin{array}{c}\mathrm{SCOD}^{\mathrm{a}} \\
\left(\mathrm{mg} \mathrm{l}^{-1}\right)\end{array}$ & $\begin{array}{c}\mathrm{KNO}_{3}{ }^{\mathrm{b}} \\
(\mathrm{g})\end{array}$ & $\begin{array}{c}\mathrm{NO}_{3}-\mathrm{N}^{\mathrm{c}} \\
\left(\mathrm{mg} \mathrm{l}^{-1}\right)\end{array}$ & $\begin{array}{c}\mathrm{SCOD} \mathrm{NO}_{3}-\mathrm{N} \\
\mathrm{HRT}^{\mathrm{d}}\end{array}$ & $\begin{array}{c}\mathrm{OLR}^{\mathrm{e}} \\
(\mathrm{hrs})\end{array}$ & $\begin{array}{c}\mathrm{NLR}^{\mathrm{f}} \\
\left(\mathrm{kg} \mathrm{COD} \mathrm{m}^{-3} \mathrm{~d}^{-1}\right)\end{array}$ & $\begin{array}{c} \\
\left(\mathrm{kg} \mathrm{NO}_{3}-\mathrm{N} \mathrm{m}^{-3} \mathrm{~d}^{-1}\right)\end{array}$ \\
\hline 4240 & 18.0357 & 50 & 84.8 & 4.8 & 20 & 0.25 \\
4240 & 36.0714 & 100 & 42.4 & 4.8 & 20 & 0.5 \\
4240 & 54.1071 & 150 & 31.8 & 4.8 & 20 & 0.75 \\
4240 & 72.1428 & 200 & 21.2 & 4.8 & 20 & 1 \\
\hline
\end{tabular}

\footnotetext{
${ }^{a}$ Revised soluble chemical oxygen demand (SCOD) in Compartment 1 after considering dilution factor due to nitrate addition. SCOD of feed entering the reactor was measured as 5300 $\mathrm{mg} \mathrm{l}^{-1}$

b Potassium nitrate $\left(\mathrm{KNO}_{3}\right)$ added in 10 litre of tap water to make stock nitrogenous solution

${ }^{c}$ Nitrate nitrogen

d Hydraulic retention time

e Organic loading rate

${ }^{f}$ Nitrate loading rate
}

Table 5.3 Operating conditions of granular bed baffled reactor during nitrate addition into Compartment 5.

\begin{tabular}{ccccccc}
\hline $\begin{array}{c}\mathrm{SCOD}^{\mathrm{a}} \\
\left(\mathrm{mg} \mathrm{l}^{-1}\right)\end{array}$ & $\begin{array}{c}\mathrm{KNO}_{3}{ }^{\mathrm{b}} \\
(\mathrm{g})\end{array}$ & $\begin{array}{c}\mathrm{NO}_{3}-\mathrm{N}^{\mathrm{c}} \\
\left(\mathrm{mg} \mathrm{l}^{-1}\right)\end{array}$ & $\begin{array}{c}\mathrm{SCOD}^{-1} \mathrm{NO}_{3}-\mathrm{N} \\
\mathrm{HRT}^{\mathrm{d}} \\
(\mathrm{hrs})\end{array}$ & $\begin{array}{c}\mathrm{OLR}^{\mathrm{e}} \\
\left(\mathrm{kg} \mathrm{COD} \mathrm{m}^{-3} \mathrm{~d}^{-1}\right)\end{array}$ & $\begin{array}{c}\mathrm{NLR}^{\mathrm{f}} \\
\left(\mathrm{kg} \mathrm{NO}_{3}-\mathrm{N} \mathrm{m}^{-3} \mathrm{~d}^{-1}\right)\end{array}$ \\
\hline 2765 & 18.0357 & 50 & 55.296 & $4.8^{\mathrm{g}}(6)^{\mathrm{h}}$ & 20 & 0.25 \\
2765 & 36.0714 & 100 & 27.648 & $4.8(6)$ & 20 & 0.5 \\
2765 & 54.1071 & 150 & 20.736 & $4.8(6)$ & 20 & 0.75 \\
2765 & 72.1428 & 200 & 13.824 & $4.8(6)$ & 20 & 1
\end{tabular}

\footnotetext{
${ }^{a}$ Revised soluble chemical oxygen demand (SCOD) in Compartment 5 after considering dilution factor due to nitrate addition. SCOD of feed entering Compartment 5 was calculated as $3456 \mathrm{mg} \mathrm{l}^{-1}$ before nitrate addition study

${ }^{\mathrm{b}}$ Potassium nitrate $\left(\mathrm{KNO}_{3}\right)$ added in 10 litre of tap water to make stock nitrogenous solution

${ }^{c}$ Nitrate nitrogen

d Hydraulic retention time

Organic loading rate

${ }^{f}$ Nitrate loading rate

${ }^{\mathrm{g}}$ Retention time of the reactor before nitrate addition point

${ }^{\mathrm{h}}$ In parenthesis, retention time in Compartment 5 due to nitrate addition
} 


\subsubsection{Nitrate Reduction Pathway}

Prior to nitrate addition, a decrease of up to $30 \%$ in ammoniacal nitrogen $\left(\mathrm{NH}_{4}-\mathrm{N}\right)$ in the raw synthetic feed was observed in the first compartment at an OLR of $20 \mathrm{~kg}$ COD $\mathrm{m}^{-3} \mathrm{~d}^{-1}$, and thereafter very little change in $\mathrm{NH}_{4}-\mathrm{N}$ concentrations was observed downstream of the reactor. This amount of nitrogen was believed to be assimilated for the synthesis of new microbial growth in the acidogenic dominant zone.

No noticeable change in $\mathrm{NH}_{4}-\mathrm{N}$ concentrations was observed during nitrate addition in the acidogenic and methanogenic dominant zones, indicating that denitrification of the added nitrate was a major reduction pathway in both zones of the GRABBR.

\subsubsection{Nitrate Removal}

\subsubsection{Nitrate addition in the acidogenic dominant zone (Compartment 1)}

The levels of NOx-N in different compartments at varying nitrate concentrations is shown in Figure 5.2. More than $84 \%$ of the nitrate reduction was observed in the first compartment, and $100 \%$ overall. The first two compartments removed all nitrates for the applied nitrate loads. The denitrification rate in Compartment 1 increased with increase in nitrate concentration, varying from 46 to $175 \mathrm{mg} \mathrm{NOx}-\mathrm{N}^{-1} \mathrm{~h}^{-1}$.

\subsubsection{Nitrate addition in the methanogenic dominant zone (Compartment 5)}

Figure 5.3 shows the compartmentalised profile of NOx-N concentrations with varying nitrate loadings. Backmixing of nitrate from Compartment 5 to 4 was observed, as also shown in Figure 5.3. This brought about the presence of $2.9 \mathrm{mg} \mathrm{l}^{-1}, 2.5 \mathrm{mg} \mathrm{l}^{-1}, 1.8 \mathrm{mg}^{-1}$ and $1.2 \mathrm{mg} \mathrm{l}^{-1}$ of NOx-N in Compartment 4 for $\mathrm{NO}_{3}-\mathrm{N}$ concentrations of $200 \mathrm{mg} \mathrm{l}^{-1}$, $150 \mathrm{mg} \mathrm{l}^{-1}, 100 \mathrm{mg} \mathrm{l}^{-1}$ and $50 \mathrm{mg} \mathrm{l}^{-1}$ respectively. No traces of nitrates were detected in Compartments 1, 2 and 3. This study resulted in NOx-N removal in the range of $83 \%$ to $91 \%$. The denitrification rate increased with increase in nitrate concentrations, varying from 43 to $189 \mathrm{mg} \mathrm{NOx}-\mathrm{N}^{-1} \mathrm{~h}^{-1}$ in Compartment 5. A comparison of the denitrification rates in Compartments 1 and 5 is shown in Figure 5.4. 


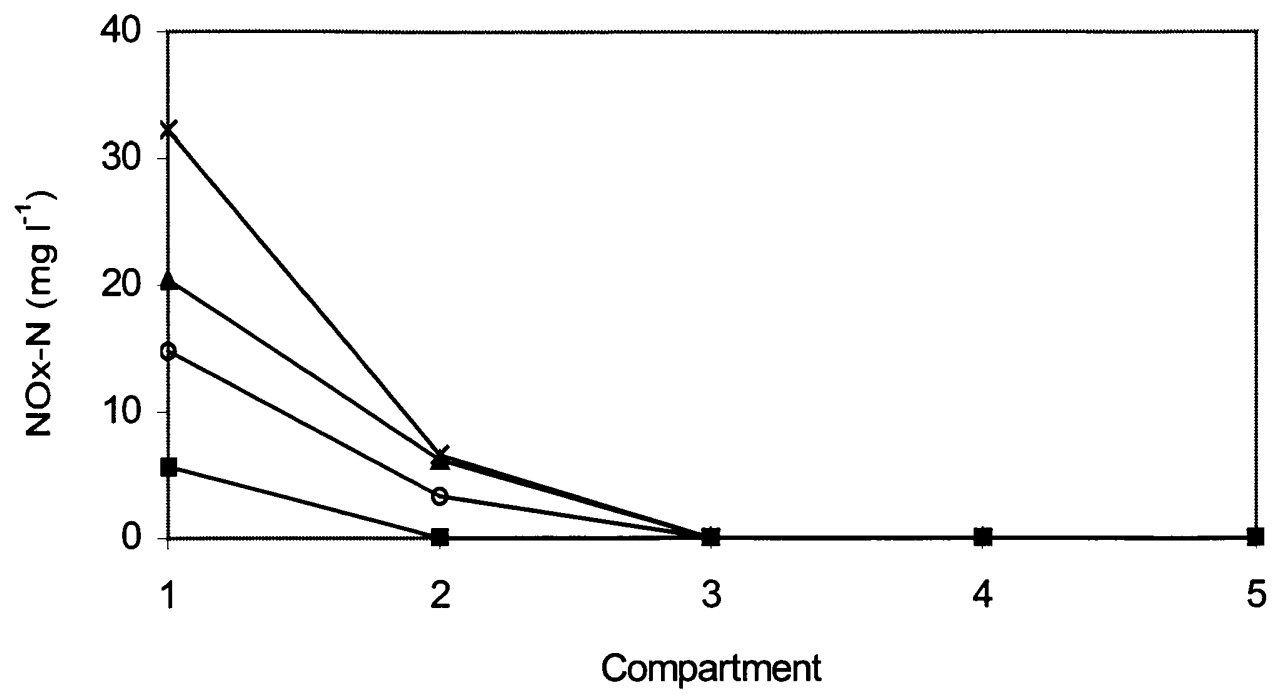

Figure 5.2 $\mathrm{NOx}-\mathrm{N}\left(\mathrm{NO}_{3}-\mathrm{N}\right.$ and $\left.\mathrm{NO}_{2}-\mathrm{N}\right)$ levels in the compartments of granular bed baffled reactor at different nitrate nitrogen $\left(\mathrm{NO}_{3}-\mathrm{N}\right)$ concentrations added in the acidogenic dominant zone (Compartment 1): (ם) $50 \mathrm{mg} \mathrm{l}^{-1} \mathrm{NO}_{3}-\mathrm{N}$, (O) $100 \mathrm{mg} \mathrm{l}^{-1} \mathrm{NO}_{3}$ $\mathrm{N},(\Delta) 150 \mathrm{mg} \mathrm{l}^{-1} \mathrm{NO}_{3}-\mathrm{N},(\times) 200 \mathrm{mg} \mathrm{l}^{-1} \mathrm{NO}_{3}-\mathrm{N}$.

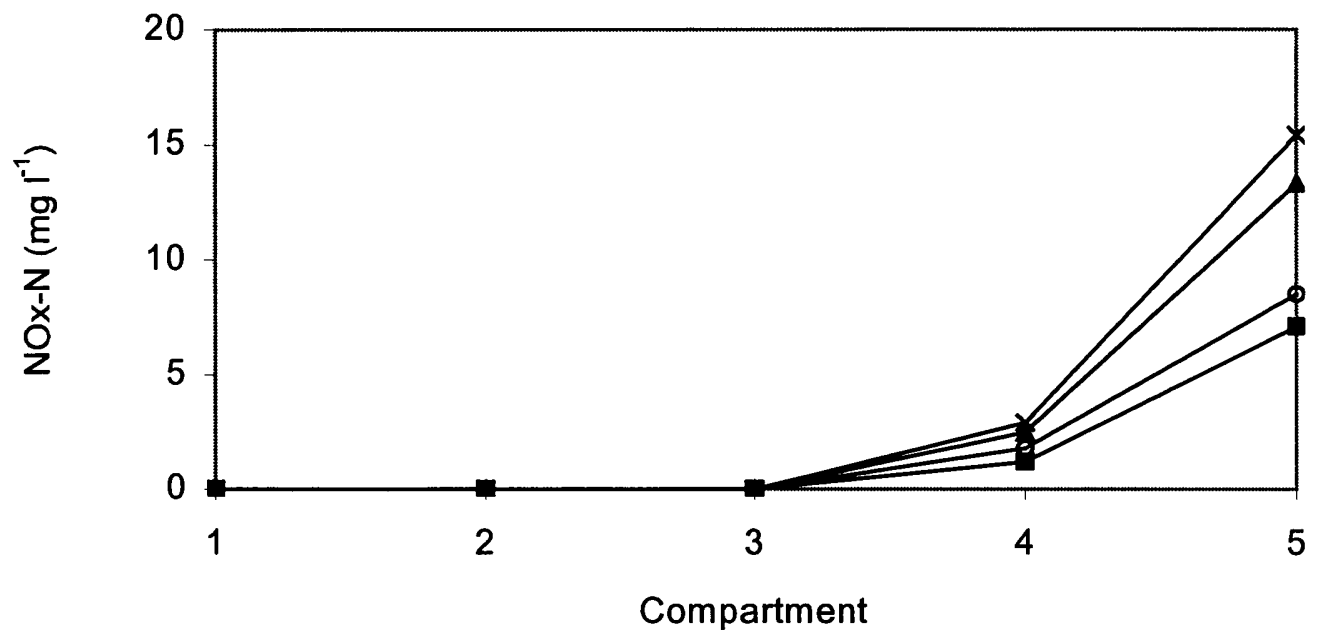

Figure 5.3 $\mathrm{NOx}-\mathrm{N}\left(\mathrm{NO}_{3}-\mathrm{N}\right.$ and $\left.\mathrm{NO}_{2}-\mathrm{N}\right)$ levels in the compartments of granular bed baffled reactor at different nitrate nitrogen $\left(\mathrm{NO}_{3}-\mathrm{N}\right)$ concentrations added in the methanogenic dominant zone (Compartment 5): (ם) $50 \mathrm{mg} \mathrm{l}^{-1} \mathrm{NO}_{3}-\mathrm{N}$, (O) $100 \mathrm{mg} \mathrm{l}^{-1}$ $\mathrm{NO}_{3}-\mathrm{N},(\boldsymbol{\Delta}) 150 \mathrm{mg} \mathrm{l}^{-1} \mathrm{NO}_{3}-\mathrm{N},(\times) 200 \mathrm{mg} \mathrm{l}^{-1} \mathrm{NO}_{3}-\mathrm{N}$. 


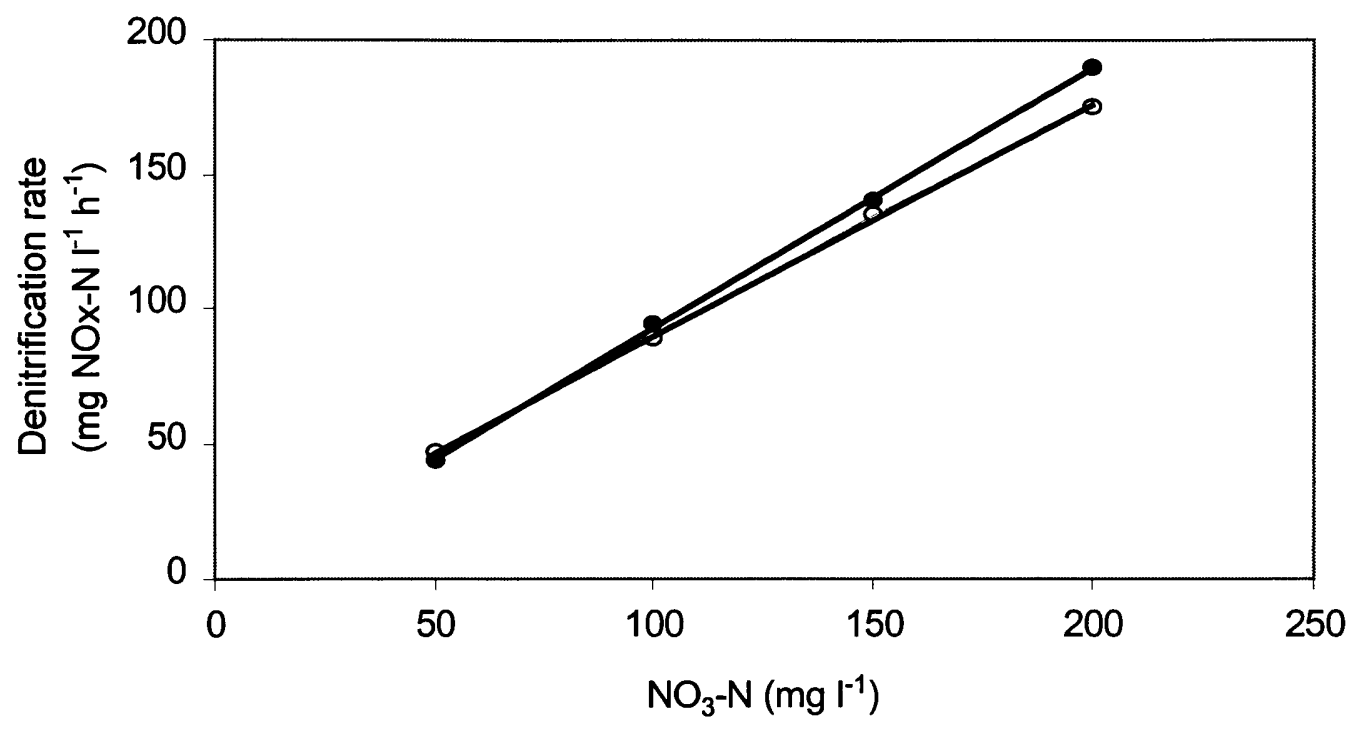

Figure 5.4 Denitrification rates for varying nitrate nitrogen $\left(\mathrm{NO}_{3}-\mathrm{N}\right)$ concentrations added in the acidogenic dominant zone (Compartment 1) and methanogenic dominant zone (Compartment 5) of granular bed baffled reactor: $(O)$ Compartment $1\left(\mathrm{R}^{2}=\right.$ 0.9993), (๑) Compartment $5\left(\mathrm{R}^{2}=0.9998\right)$.

\subsubsection{Soluble Chemical Oxygen Demand Removal}

\subsubsection{Nitrate addition in the acidogenic dominant zone (Compartment 1)}

The effect of $\mathrm{NO}_{3}-\mathrm{N}$ addition on SCOD removal at varying nitrate concentrations is shown in Figure 5.5. This figure shows that the performance of the system in terms of SCOD removal increased with increase in nitrate load, and was generally better than the SCOD levels before nitrate addition. The gains in SCOD removal for all nitrate concentrations in Compartment 1 enhanced the overall SCOD removal efficiency of the GRABBR. The overall SCOD removal efficiency of $68 \%$ to $71 \%$ was observed during nitrate addition conditions.

\subsubsection{Nitrate addition in the methanogenic dominant zone (Compartment 5)}

The effect of $\mathrm{NO}_{3}-\mathrm{N}$ addition on SCOD removal at varying nitrate concentrations is 
shown in Figure 5.6. Higher SCOD removal rates were observed when compared with the previous study (Section 5.3.4.1). In comparison to the system efficiency before this study, nitrate addition brought about slightly higher SCOD consumption in Compartment 5, and this consumption increased with increase in nitrate load. The percentage SCOD removal for individual compartments (Compartment 1 and 5) during denitrification is shown in Table 5.4, which shows that nitrate addition generally brought about an improved effluent quality in terms of SCOD removal.

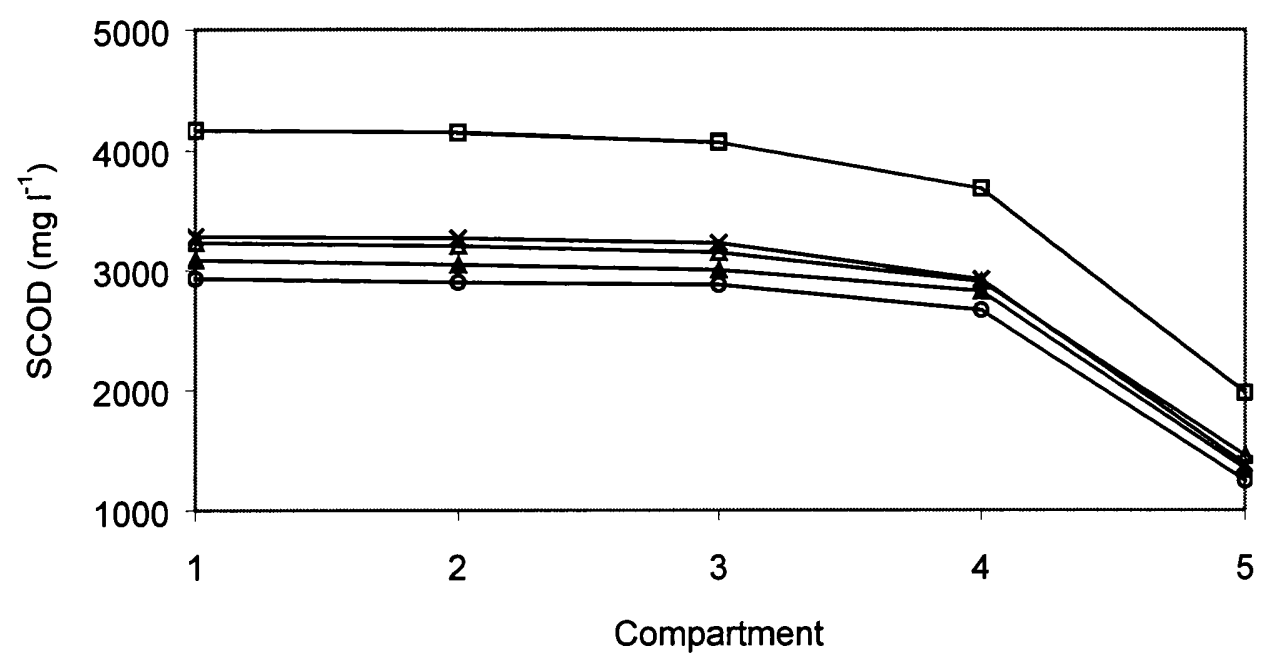

Figure 5.5 Soluble chemical oxygen demand (SCOD) levels in different compartments of the granular bed baffled reactor at varying nitrate nitrogen $\left(\mathrm{NO}_{3}-\mathrm{N}\right)$ concentrations added in acidogenic dominant zone (Compartment1): ( $\square$ ) before nitrate addition, (×) $50 \mathrm{mg} \mathrm{l}^{-1} \mathrm{NO}_{3}-\mathrm{N},(\Delta) 100 \mathrm{mg} \mathrm{l}^{-1} \mathrm{NO}_{3}-\mathrm{N},(\boldsymbol{\Delta}) 150 \mathrm{mg} \mathrm{l}^{-1} \mathrm{NO}_{3}-\mathrm{N},(\mathrm{O}) 200$ $\mathrm{mg} \mathrm{l}^{-1} \mathrm{NO}_{3}-\mathrm{N}$.

\subsubsection{Volatile Fatty Acid Profile}

The VFA profile (acetate, propionate and butyrate) at different nitrate concentrations in both studies is shown in Figure 5.7. The trend in VFA consumption during denitrification in the acidogenic dominant zone showed a noticeable decrease in acetate and butyrate concentrations. The relative concentration decrease for acetate, propionate and butyrate from $50 \mathrm{mg} \mathrm{l}^{-1}$ to $200 \mathrm{mg} \mathrm{l}^{-1} \mathrm{NO}_{3}-\mathrm{N}$ was calculated as $103 \mathrm{mg} \mathrm{l}^{-1}, 16 \mathrm{mg} \mathrm{l}^{-1}$ and $93 \mathrm{mg} \mathrm{l}^{-1}$ respectively. On the other hand, a marked decrease in butyrate concentrations was observed during nitrate reduction in the methanogenic dominant zone. In this zone, the relative concentration decrease for acetate, propionate and 
butyrate from $50 \mathrm{mg} \mathrm{l}^{-1}$ to $200 \mathrm{mg} \mathrm{l}^{-1} \mathrm{NO}_{3}-\mathrm{N}$ was calculated as $37 \mathrm{mg} \mathrm{l}^{-1}, 7 \mathrm{mg} \mathrm{l}^{-1}$ and $227 \mathrm{mg} \mathrm{l}^{-1}$ respectively.

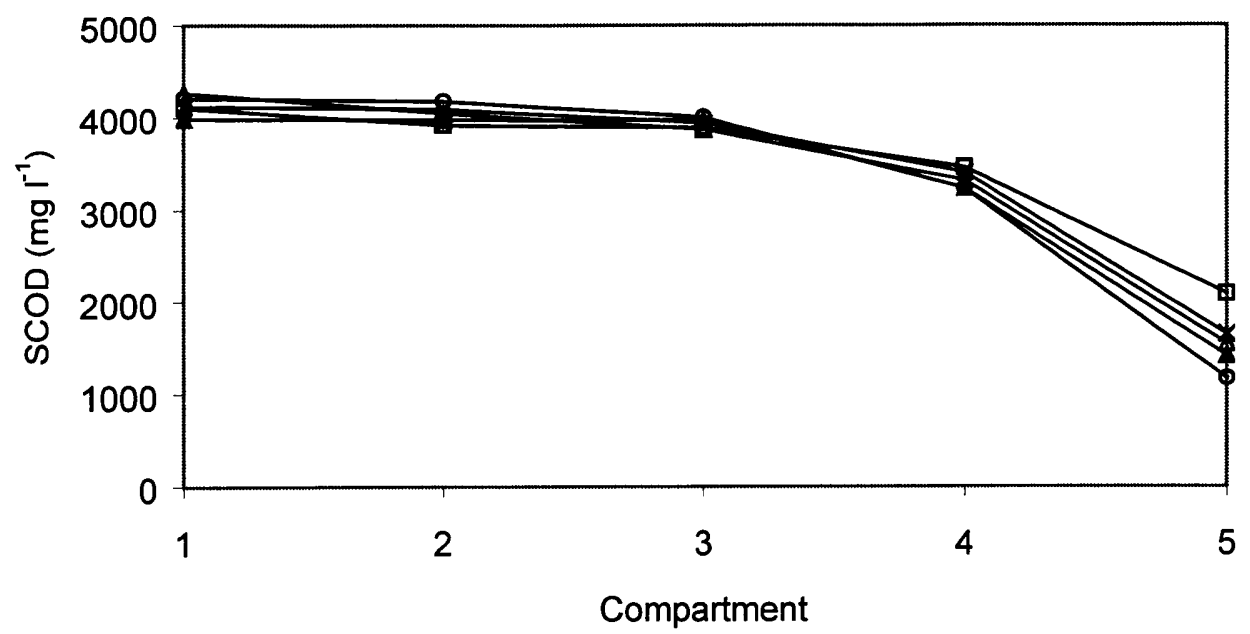

Figure 5.6 Soluble chemical oxygen demand (SCOD) levels in different compartments of the granular bed baffled reactor at varying nitrate nitrogen $\left(\mathrm{NO}_{3}-\mathrm{N}\right)$ concentrations added in methanogenic dominant zone (Compartment 5): ( $\square$ ) before nitrate addition, $(\times) 50 \mathrm{mg} \mathrm{l}^{-1}$ $\mathrm{NO}_{3}-\mathrm{N},(\Delta) 100 \mathrm{mg} \mathrm{l}^{-1} \mathrm{NO}_{3}-\mathrm{N},(\Delta) 150 \mathrm{mg} \mathrm{l}^{-1} \mathrm{NO}_{3}-\mathrm{N},(\mathrm{O}) 200 \mathrm{mg} \mathrm{l}^{-1} \mathrm{NO}_{3}-\mathrm{N}$.

Table 5.4 Individual soluble chemical oxygen demand (SCOD) removal efficiency of acidogenic dominant zone (Compartment 1) and methanogenic dominant zone (Compartment 5) of granular bed baffled reactor during denitrification.

$\begin{array}{cc}\text { SCOD removal efficiency } & \text { SCOD removal efficiency } \\ \text { of Compartment } 1(\%) & \text { of Compartment } 5(\%)\end{array}$

\begin{tabular}{lcc}
\hline $\begin{array}{l}\text { Before nitrate addition }^{a} \\
\text { Nitrate added conditions }\end{array}{ }^{b}$ & 21 & 40 \\
$50 \mathrm{mg} \mathrm{l}^{-1} \mathrm{NO}_{3}-\mathrm{N}$ & 23 & 40 \\
$100 \mathrm{mg} \mathrm{l}^{-1} \mathrm{NO}_{3}-\mathrm{N}$ & 24 & 44 \\
$150 \mathrm{mg} \mathrm{l}^{-1} \mathrm{NO}_{3}-\mathrm{N}$ & 27 & 49 \\
$200 \mathrm{mg} \mathrm{l}^{-1} \mathrm{NO}_{3}-\mathrm{N}$ & 31 & 58 \\
\hline${ }^{\text {a }}$ Percentage SCOD removal for Compartment 1 and 5 were calculated with respect to \\
$5300 \mathrm{mg} \mathrm{l}^{-1}$ (feed SCOD) and 3456 mg l ${ }^{-1}$ (Compartment 4 SCOD) respectively. \\
${ }^{\mathrm{b}}$ Percentage SCOD removal for Compartment 1 and 5 were calculated after considering \\
dilution factor of 10 l d ${ }^{-1}$ of nitrogenous feed.
\end{tabular}




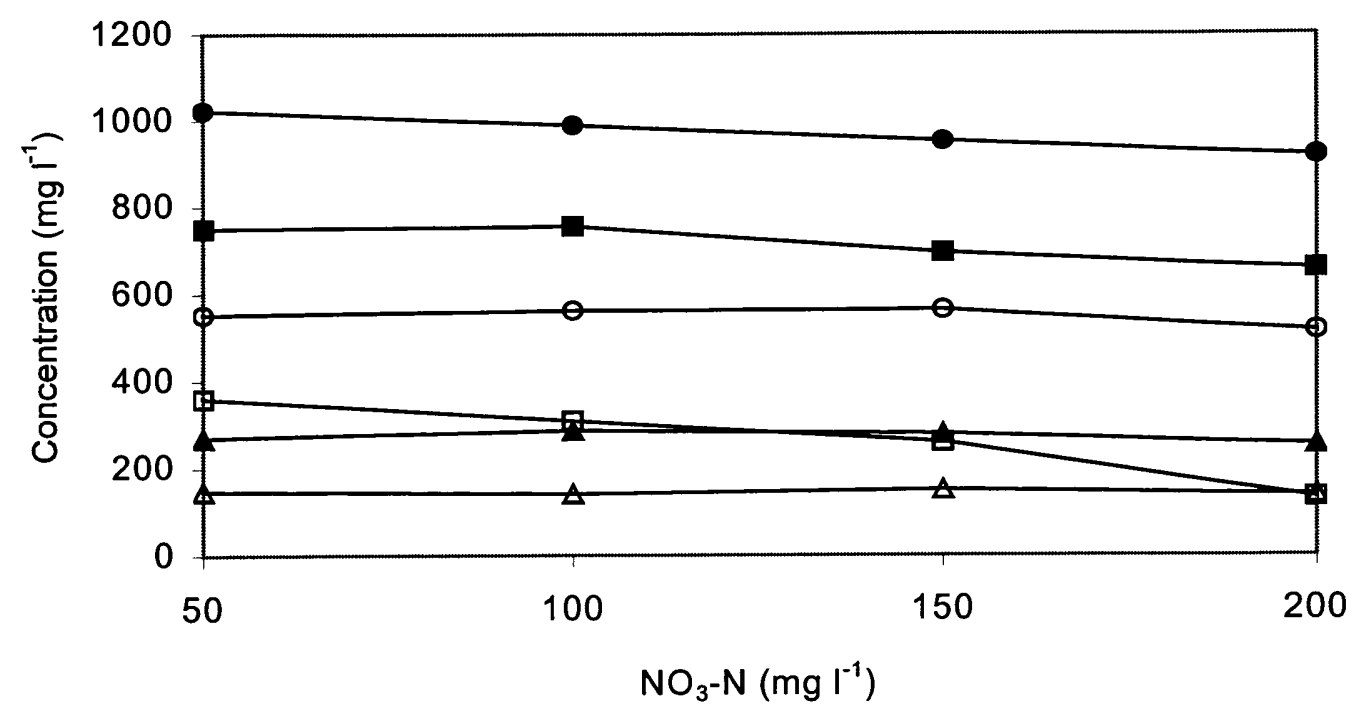

Figure 5.7 Profile of intermediate volatile fatty acid products in Compartment 1 (shaded) and Compartment 5 (hollow) of granular bed baffled reactor for nitrate nitrogen $\left(\mathrm{NO}_{3}-\mathrm{N}\right)$ concentrations of 50 to $200 \mathrm{mg} \mathrm{l}^{-1}:(\Theta, O)$ acetate, $(\Delta, \Delta)$ propionate, $(\square, \square)$ butyrate.

\subsubsection{Methane Composition}

The methane composition during denitrification in acidogenic and methanogenic dominant zones varied between $35 \%$ to $50 \%$. A slight decrease in the methane content of the gas was observed with an increase in nitrate loadings in both studies. Nitrate addition in the acidogenic dominant zone exhibited slightly higher methane proportion in the biogas than when nitrate were added in the methanogenic dominant zone.

\subsection{DISCUSSION}

Glucose was selected as the substrate to create fermentation activities within the GRABBR. This substrate was found to support ammonia formers (Akunna et al., 1994a; Rustrian et al., 1997). It is also known that with non-acclimatised anaerobic sludges, nitrate reduction to ammonification could take place with this organic carbon source (Kasper et al., 1981; Akunna et al., 1993; Rustrian et al., 1997). In this study, no 
marked ammonification was observed during all nitrate addition conditions. One would have expected significant ammonification to occur when nitrates were added in the acidogenic dominant zone, especially at lower nitrate loads (or high $\mathrm{COD} / \mathrm{NO}_{3}-\mathrm{N}$ ratio), since some carbon compounds might have been present in the form of glucose in this compartment. A possible explanation for this observation may be that the GRABBR system was comprised of five compartments, with each compartment almost independent and completely mixed. The actual $\mathrm{COD} / \mathrm{NO}_{3}-\mathrm{N}$ ratio within the compartment would be considerably lower than it would have been had the system not been compartmentalised (i.e. a completely mixed system). Hence, it is believed that compartmentalisation enhanced denitrification by ensuring a relatively low $\mathrm{COD} / \mathrm{NO}_{3}$ $\mathrm{N}$ ratio in the nitrate added compartment. Denitrification is known to increase with a decrease in $\mathrm{COD} / \mathrm{NO}_{3}-\mathrm{N}$ ratio using a glucose substrate (Akunna et al., 1994a).

This study showed that acidogenic and methanogenic dominant populations have high denitrification capabilities. There was a good linear relationship obtained between variable nitrate concentrations added into the compartments and nitrate removal efficiency (Figure 5.4). The correlation coefficient shows almost $100 \%$ reliability of the linear relationship between plotted variables. During nitrate addition in the acidogenic dominant zone, complete denitrification was observed in the first two compartments of the GRABBR, while NOx-N concentrations were observed in the effluent during nitrate addition in the methanogenic dominant zone. Accumulation of denitrifying by-products (nitrite, nitrous oxide) in an anaerobic or denitrification unit have been reported as adversely affecting the denitrification process (Beccari et al., 1983; Rustrian et al., 1997). No nitrite build-up was observed in either nitrate addition studies, and NOx-N was mainly in the form of $\mathrm{NO}_{3}-\mathrm{N}$. The microorganisms in the system quickly adapted to varying nitrate conditions in both studies. This could also be due to zoning characteristics of the GRABBR, which shortened the acclimatisation time for denitrifiers. Furthermore, an increase in nitrate concentration brought about increases in $\mathrm{pH}$ levels of up to 0.25 units from $50 \mathrm{mg} \mathrm{l}^{-1}$ to $200 \mathrm{mg} \mathrm{l}^{-1} \mathrm{NO}_{3}-\mathrm{N}$. This could be beneficial to the stability of the system by counteracting the usual decrease in $\mathrm{pH}$ associated with acidogenesis.

Comparatively, slightly better NOx-N removal efficiencies were achieved when nitrates were added to the methanogenic dominant zone than when added to the acidogenic 
dominant zone (Figure 5.4). This observation could firstly be because VFA was the main source of organic carbon in the methanogenic dominant zone as opposed to in the acidogenic dominant zone, where there would have been a mixture of VFA and glucose. Denitrifiers have been reported to possess high affinity towards VFA than to glucose (Akunna et al., 1993 \& 1994a; Fass et al., 1994; Hendriksen and Ahring, 1996a). Secondly, the methanogenic dominant zone mainly consists of anaerobic granular sludge, a highly active biomass, which could have provided improved mixing between different microorganisms to increase the specific denitrification rate. Thirdly, anaerobic sludges have been reported as possessing high denitrifying potentials (Akunna et al., 1992, 1993 \& 1994a; Hendriksen and Ahring, 1996a; Mosquera-Corral et al., 2001). Biofilm structure in the form of anaerobic granules, which harbours a diverse number of species (Macleod et al., 1990; Fang et al., 1994; Bhatti et al., 1995), could have enhanced the denitrifying activity within the methanogenic dominant zone. Fourthly, lower $\mathrm{COD} / \mathrm{NO}_{3}-\mathrm{N}$ ratios were obtained in the methanogenic dominant zone due to the consumption of organic carbon in the upstream compartments (Table 5.3). This could have improved the process efficiency in terms of nitrate removal in the methanogenic dominant zone. Denitrification rates have been found to increase at lower $\mathrm{COD} / \mathrm{NO}_{3}-\mathrm{N}$ ratios (Rustrian et al., 1997).

For all applied nitrate loadings, an increase in SCOD removal was observed when compared with conditions before nitrate addition. This was attributed to extra carbon consumption during denitrification. For a complete cycle of treatment (as illustrated in Figure 1.6b), a decrease in effluent SCOD will bring about lower oxygen demand in the downstream nitrification unit. The SCOD removal rates during nitrate addition in the methanogenic dominant zone were higher than those observed when nitrates were added in the acidogenic dominant zone.

During nitrate addition in both zones, methane production was observed. This shows that denitrification and methanogenesis occurred simultaneously in the GRABBR. The magnitude of nitrate inhibition in each denitrifying compartment of GRABBR was not specifically measured as the overall gas composition of the reactor was recorded. The VFA profile in the methanogenic dominant environment during denitrification shows a noticeable decrease in butyrate levels, while acetate and butyrate in the zone dominated by acidogenic activities. The concentrations of acetate and butyrate have been reported 
to decrease during denitrification process (Takai et al., 1997).

This study shows that higher denitrification and SCOD removal rates can be achieved when nitrates are added to the methanogenic dominant zone as compared to when added to the acidogenic dominant zone. However, in order to avoid inhibition of nitrates to methane producing bacteria, back mixing of nitrogen oxides particularly at high NLRs and partial or incomplete denitrification either due to incapability of the methanogenic dominant zone to reduce all nitrates or non-availability of sufficient amount of carbon source, it is believed that nitrate addition in the acidogenic dominant zone would ensure a more effective methanogenic population to prosper within the system. Furthermore, nitrate addition in the acidogenic environment of the GRABBR ensures that the size of denitrifying zone adjusts according to the applied nitrate loading conditions. This will also provide an advantage of collecting methane rich biogas from the methanogenic dominant zone.

\subsection{CONCLUSIONS}

This study illustrated that with the GRABBR, relatively low $\mathrm{COD} / \mathrm{NO}_{3}-\mathrm{N}$ ratios obtained in the nitrate added compartments could have favoured denitrification to be the major pathway for nitrate reduction rather than ammonification, particularly when glucose is the main carbon source. The addition of nitrate increased the overall SCOD removal efficiency of the reactor when compared to conditions before nitrate addition, mainly due to extra carbon consumption during denitrification. Addition of nitrate in the methanogenic dominant zone exhibited slightly higher denitrification and SCOD removal efficiency when compared to nitrate addition in the acidogenic dominant environment. This suggests that glucose, along with other carbon sources, could have been significantly consumed for nitrate reduction when nitrates were added in the acidogenic dominant zone, whilst non-fermentative substrate in the form of VFA was the main compound available for denitrification in the methanogenic dominant zone. Also, methanogenic granular biomass in the methanogenic dominant zone has high denitrifying and methanogenic capabilities than non-granular acidogenic bacteria. However, in order to avoid problems related to back mixing, nitrate inhibition to methane producing microorganisms and incomplete denitrification, nitrate addition in the acidogenic dominant zone would ensure more long term reactor stability and 
efficiency in terms of carbon and nitrate removal for low to high strength nitrogenous wastewaters. With this arrangement, sufficient carbon content would always be available in the denitrifying (or acidogenic) zone. Methane production was observed during nitrate addition in the compartments, showing that denitrification and methanogenesis occurred simultaneously. 


\section{CHAPTER 6}

\section{NITRATE REDUCTION AND METHANE \\ PRODUCTION ACTIVITIES OF SLUDGES \\ FROM GRANULAR BED BAFFLED \\ REACTOR}

This chapter presents the nitrate reduction and methane production capabilities of the biomass from the acidogenic dominant zone (Compartment 1) and methanogenic dominant zone (Compartment 5) of the granular bed baffled reactor in the presence of various types of carbon sources.

\subsection{INTRODUCTION}

Batch experiments are rapid and reliable methods to assess the presence of various metabolic groups in methanogenic environments (Dolfing and Bloemen, 1985). These tests have superiority over other methods, such as most probable number (MPN), which has led to ambiguous and unreliable results with anaerobic sludges (Dolfing et al., 1985; Dubourguier et al., 1988a; Uyanik et al., 2002b). These tests are usually performed with excess substrate to measure the activities of various species with anaerobic biomass.

Batch studies have been carried out with different types of sludges to obtain useful information about the characteristics of microbial populations existing in an anaerobic system. Batch assays have been used to investigate the effect of nitrate or nitrite under different substrate conditions (Chen and Lin, 1993; Akunna et al., 1993 \& 1994a; Hendriksen and Ahring, 1996b; Quevedo et al., 1996; Bernet et al., 1996a; Clarens et al., 1998; Bilanovic et al., 1999). In batch experiments for combined carbon and nitrate 
removal, nitrogen oxides were found to inhibit methane production, with methanation occurring after the denitrification process (Chen and Lin, 1993; Akunna et al., 1993 \& 1994a; Hendriksen and Ahring, 1996b).

In staged anaerobic systems, acidogenesis and methanogenesis are separated in different zones to obtain optimum environmental conditions for these microorganisms due to their different kinetics and energetics (Ghosh et al., 1975; Cohen et al., 1980 \& 1982; Anderson and Saw, 1984; Anderson et al., 1994; Speece et al., 1997). In the literature available to date, little is known about the microbial activity of these different microorganisms in two-stage or multi-phase anaerobic systems in performing simultaneous denitrification and methanogenesis. Anaerobic sludges have been reported to possess denitrifying capabilities (Akunna et al., 1993; Hendriksen and Ahring, 1996a), however their bioconversion rates as a function of nitrate removal and methane production, when acclimatised to different substrate conditions of anaerobic system, have not been well studied. Consequently, it is not known as to what magnitude each of the microbial groups, acidogens and methanogens, could contribute in denitrification and methanogenesis in the presence of nitrate. It is also not known how the nature of organic carbon can influence the activities of denitrifiers and methanogenesis for various sludges of a staged system.

In this study, batch experiments were carried out with three different carbon sources: glucose, acetate and volatile fatty acid (VFA) mixture of acetate, propionate and butyrate. Glucose substrate was selected, firstly because this was the source of carbon used as influent for the reactor study, and secondly, it is metabolised via fermentation in anaerobic degradation. Acetate and VFAs are relatively more simple forms of organic matter, and the preferred substrate for the denitrification process (Paul et al., 1989; Akunna et al., 1993; Fass et al., 1994; Hendriksen and Ahring, 1996a; Takai et al., 1997). 
The aim of this study was to investigate:

- The effect of nitrate on both acidogenic and methanogenic dominant microbial populations, not previously adapted to nitrate, for methane production and nitrate reduction.

- The effect of nitrate on nitrate adapted acidogenic dominant sludge for nitrate reduction and methane production.

- The sequence of occurrence of nitrate reduction and methane production (where both are observed), in order to determine whether both processes occur simultaneously or are separated in time.

- The importance of the nature of organic substrate present in the system on the outcome of the above biochemical activities.

\subsection{EXPERIMENTAL DESIGN}

The sludges were added in $300 \mathrm{ml}$ bottles and the volumes were brought to $275 \mathrm{ml}$ by adding a synthetic medium. The sludges were obtained from two different zones of the granular bed baffled reactor (GRABBR). The medium was prepared to obtain $3 \mathrm{~g} \mathrm{l}^{-1}$ chemical oxygen demand (COD) of either glucose, acetate or VFA mixture (acetate, propionate, butyrate; 1:1:1 on a COD basis) as carbon source. The other constituents (buffering compound, micro- and macro-nutrients) were same as shown in Table 2.1. One set of the experiment was conducted using sludge previously unadapted to nitrates from Compartments 1 and 5 of the GRABBR, obtained during the study reported in Chapter 4. The biomass from Compartment 1 was a mixture of non-granular (mainly in the form of broken granules and white microbial mass) and granular biomass, while sludge from Compartment 5 was mainly granular. The other set of experiments was run with sludge previously adapted to nitrate obtained from Compartment 1 of the GRABBR during the study reported in Chapter 5. Nitrates were added in the form of potassium nitrate $\left(\mathrm{KNO}_{3}\right)$. Nitrate reduction and methane production activities were measured by monitoring the profile of NOx-N (nitrate and nitrite nitrogen) concentrations and percentage methane composition with time. Anaerobic conditions in the bottles were obtained by flushing bottles with free nitrogen for 5 minutes. The 
bottles were then incubated at $35^{\circ} \mathrm{C}$ and placed in a temperature controlled shaker at 100 rev $\min ^{-1}$. The complete experimental set-up for this study is summarised in Tables 6.1 and 6.2.

Table 6.1 Experimental set-up for batch assays with sludge from Compartment 1 and 5 of granular bed baffled reactor unadapted to nitrate.

\begin{tabular}{lllllll}
\hline Parameter & \multicolumn{3}{c}{ Sludge unadapted to nitrate } & \multicolumn{3}{c}{ Sludge unadapted to nitrate } \\
& Glucose & Acetate & VFAc & Glucose & Acetate & VFA \\
\hline Total volume $(\mathrm{ml})$ & 275 & 275 & 275 & 275 & 275 & 275 \\
$\mathrm{COD}^{\mathrm{a}}\left(\mathrm{mg} \mathrm{l}^{-1}\right)$ & 3000 & 3000 & 3000 & 3000 & 3000 & 3000 \\
$\mathrm{NO}_{3}-\mathrm{N}^{\mathrm{b}}\left(\mathrm{mg} \mathrm{l}^{-1}\right)$ & - & - & - & 200 & 200 & 200 \\
$\mathrm{COD} / \mathrm{NO}_{3}-\mathrm{N}$ & - & - & - & 15 & 15 & 15 \\
\hline
\end{tabular}

${ }^{\text {a }}$ Chemical oxygen demand

${ }^{b}$ Nitrate nitrogen

${ }^{c}$ Volatile fatty acid

Table 6.2 Experimental set-up for batch assays with sludge from Compartment 1 of granular bed baffled reactor acclimatised to nitrate.

\begin{tabular}{lllllll}
\hline Parameter & \multicolumn{3}{c}{ Sludge adapted to nitrate } & \multicolumn{3}{c}{ Sludge adapted to nitrate } \\
& Glucose & Acetate & VFAc & Glucose & Acetate & VFA \\
\hline Total volume $(\mathrm{ml})$ & 275 & 275 & 275 & 275 & 275 & 275 \\
$\mathrm{COD}^{\mathrm{a}}\left(\mathrm{mg} \mathrm{l}^{-1}\right)$ & 3000 & 3000 & 3000 & 3000 & 3000 & 3000 \\
$\mathrm{NO}_{3}-\mathrm{N}^{\mathrm{b}}\left(\mathrm{mg} \mathrm{l}^{-1}\right)$ & - & - & - & 200 & 200 & 200 \\
$\mathrm{COD} / \mathrm{NO}_{3}-\mathrm{N}$ & - & - & - & 15 & 15 & 15 \\
\hline
\end{tabular}

${ }^{\text {a }}$ Chemical oxygen demand

${ }^{\mathrm{b}}$ Nitrate nitrogen

${ }^{c}$ Volatile fatty acid

\subsection{RESULTS}

The term methanogenic dominant zone sludge refers to biomass from Compartment 5 and acidogenic dominant zone sludge to biomass from Compartment 1. Furthermore, $\mathrm{NOx}-\mathrm{N}$ represents nitrate nitrogen $\left(\mathrm{NO}_{3}-\mathrm{N}\right)$ and nitrite nitrogen $\left(\mathrm{NO}_{2}-\mathrm{N}\right)$. 


\subsubsection{Acidogenic and Methanogenic Dominant Zone Sludges Previously} Unadapted to Nitrate

These experiments were carried out with sludge obtained from the GRABBR during the study reported in Chapter 4.

\subsubsection{Sludge from the acidogenic dominant zone (nitrate-free cultures)}

The gas composition in all substrate cultures (glucose, acetate and VFA) showed approximately $50 \%$ methane production at the end of the experiment as shown in Figure 6.1. However, the glucose enriched medium showed relatively low methane composition than acetate and VFA cultures. Methane composition was over $20 \%$ and $40 \%$ for acetate and VFA cultures at $6 \mathrm{hrs}$ and $15 \mathrm{hrs}$ respectively. Experiments with acetate and VFA mediums produced very little carbon dioxide (about $5 \%$ throughout the experiment). However, glucose media produced over $40 \%$ carbon dioxide after $3 \mathrm{hrs,}$ but its production decreased after $6 \mathrm{hrs}$ with a simultaneous increase in methane production.

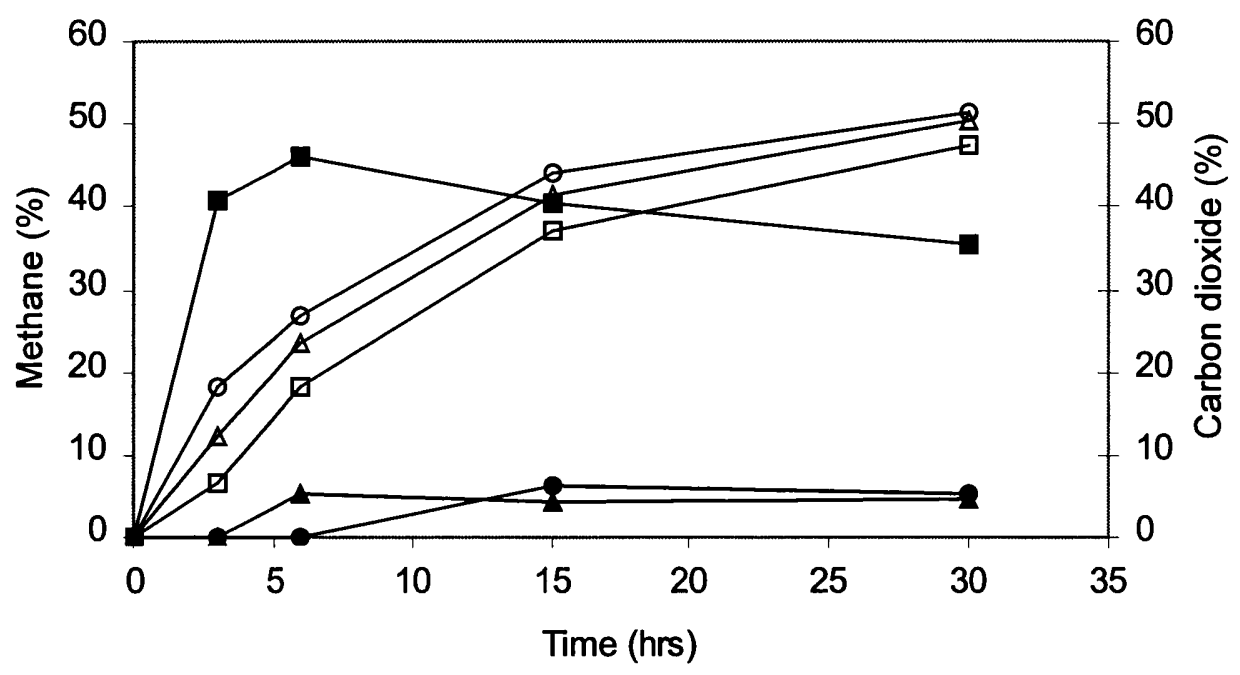

Figure 6.1 Profile of percentage methane (hollow) and carbon dioxide (shaded) composition for various cultures with time using acidogenic dominant zone sludge previously unadapted to nitrate: acetate $(O, \Theta)$, volatile fatty acid $(\Delta, \boldsymbol{\Delta})$, glucose $(\square$, ). 


\subsubsection{Sludge from the methanogenic dominant zone (nitrate-free cultures)}

The gas produced in all cultures contained approximately $60 \%$ methane at the end of the experiment as shown in Figure 6.2. All three cultures (glucose, acetate and VFA) exhibited an almost similar increase in the rate of methane production. A high carbon dioxide composition was observed with glucose media, ranging between $30 \%$ and $40 \%$ from $6 \mathrm{hrs}$ to $30 \mathrm{hrs}$, while it only appeared after $15 \mathrm{hrs}$ for the acetate and VFA cultures.

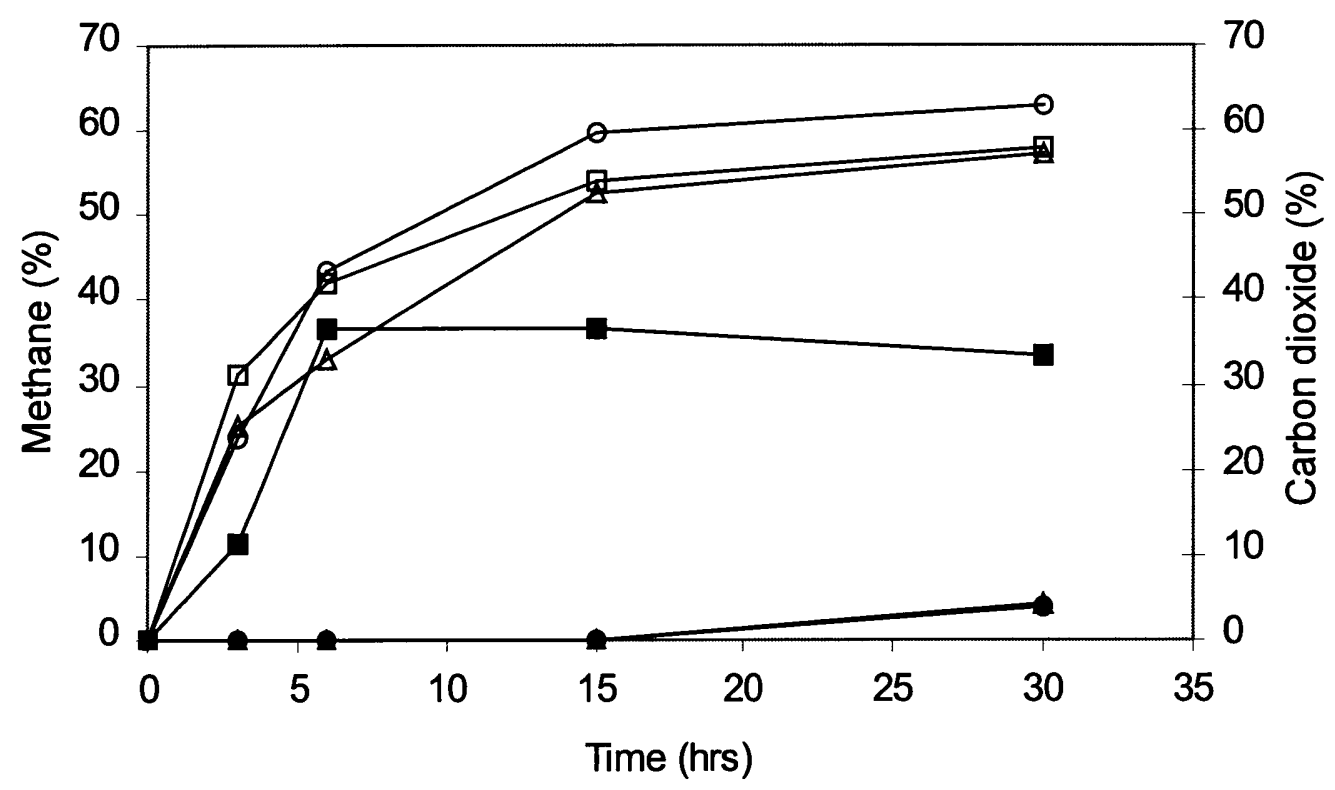

Figure 6.2 Profile of percentage methane (hollow) and carbon dioxide (shaded) composition with time using various cultures with methanogenic dominant zone sludge previously unadapted to nitrate: acetate $(O, \odot)$, volatile fatty acid $(\Delta, \boldsymbol{\Delta})$, glucose $(\square$, Ш).

\subsubsection{Sludge from the acidogenic dominant zone (nitrate-added cultures)}

Low methane production was observed for all cultures as shown in Figure 6.3. Acetate, VFA and glucose cultures produced $15 \%, 13 \%$ and $5 \%$ of methane respectively at 30 
hrs. During 6 hrs of incubation, no methane production was observed for glucose media, whilst less then $9 \%$ methane was detected for acetate and VFA cultures. The complete removal of nitrates was observed for acetate and VFA cultures during the length of study as shown in Figure 6.4. For the VFA culture, NOx-N reduced from 128 to $21 \mathrm{mg}$ $1^{-1}$ from $6 \mathrm{hrs}$ to $10 \mathrm{hrs}$ of incubation, whilst for the acetate culture it was completely eliminated within $16 \mathrm{hrs}$. The glucose culture was able to reduce $41 \%$ of added nitrate within $23 \mathrm{hrs}$. Methane production was observed when nitrate reduction was taking place, though its production was markedly low in all the cultures when compared with nitrate free cultures (Section 6.3.1.1).

\subsubsection{Sludge from the methanogenic dominant zone (nitrate-added cultures)}

An almost similar rate of methane production was observed for all cultures (acetate, VFA and glucose) in this study. Methane levels for glucose, acetate and VFA cultures were estimated as $27 \%, 31 \%$ and $30 \%$ at $6 \mathrm{hrs}$ and $34 \%, 39 \%$ and $38 \%$ at $30 \mathrm{hrs}$, respectively, as shown in Figure 6.5. All three media exhibited high and similar NOx-N removal rates. No NOx-N was detected at 23 hrs in any of the cultures, as shown in Figure 6.6. NOx-N removal efficiency for glucose, acetate and VFA cultures was calculated as $48 \%, 40 \%$ and $40 \%$ at $6 \mathrm{hrs}$, and $74 \%, 78 \%$ and $76 \%$ at $10 \mathrm{hrs}$, respectively. The methane composition in glucose, acetate and VFA cultures accounted for $27 \%, 31 \%$ and $30 \%$ respectively of the total gas composition at $6 \mathrm{hrs}$, even when noticeable amounts of NOx-N concentrations $\left(105 \mathrm{mg} \mathrm{l}^{-1}, 121 \mathrm{mg} \mathrm{l}^{-1}\right.$ and $121 \mathrm{mg} \mathrm{l}^{-1}$ of NOx-N in glucose, acetate and VFA cultures respectively) were still present in the cultures. Thus, showing that simultaneous nitrate reduction and methane production occurred in this study with all cultures. 


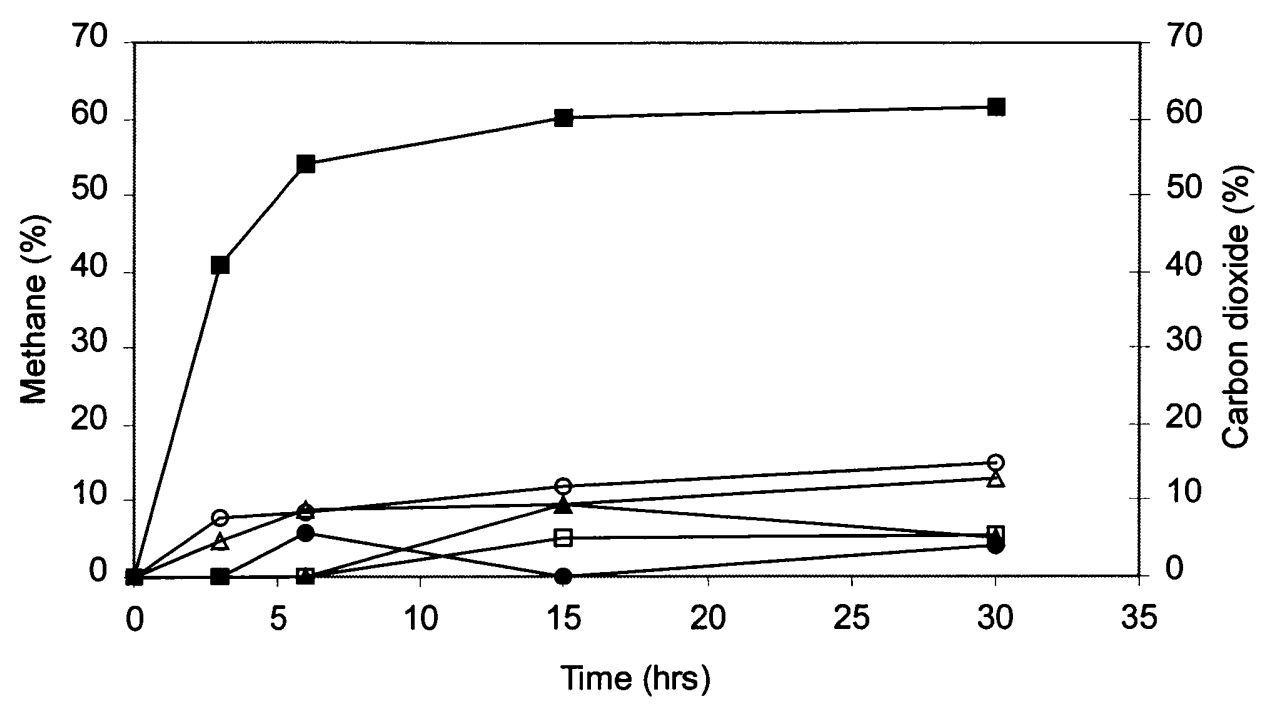

Figure 6.3 Profile of percentage methane (hollow) and carbon dioxide (shaded) composition for various media in nitrate added cultures with time using acidogenic dominant zone sludge previously unadapted to nitrate: acetate $(\mathrm{O}, \boldsymbol{\bullet})$, volatile fatty acid $(\Delta, \mathbf{\Delta})$, glucose $(\square, \mathbf{\square})$.

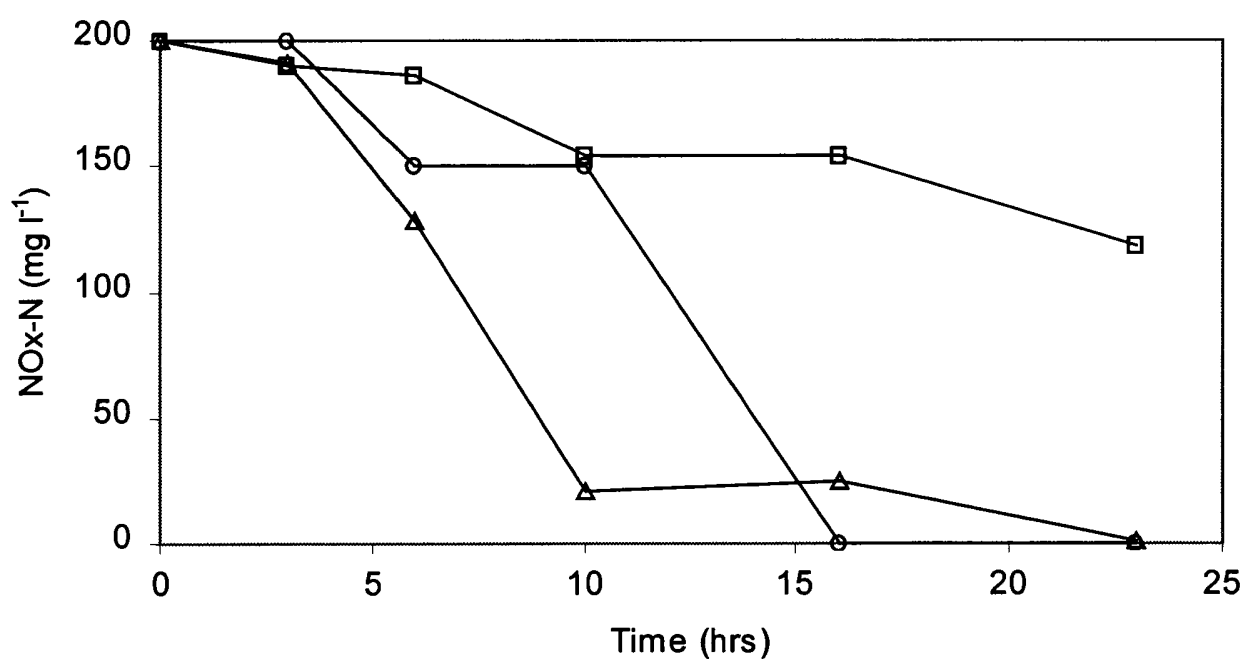

Figure 6.4 Profile of NOx-N $\left(\mathrm{NO}_{3}-\mathrm{N}\right.$ and $\left.\mathrm{NO}_{2}-\mathrm{N}\right)$ concentrations with time for various cultures using acidogenic dominant zone sludge previously unadapted to nitrate: acetate $(O)$, volatile fatty acid $(\Delta)$, glucose $(\square)$. 


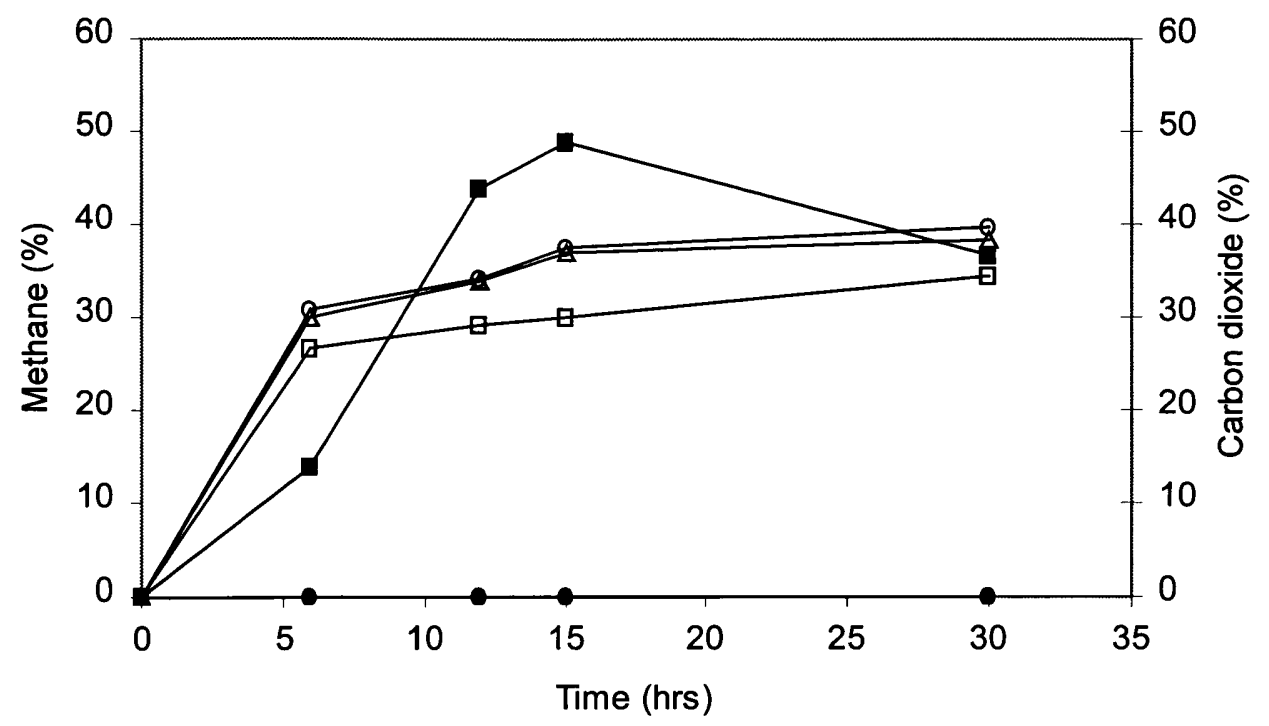

Figure 6.5 Profile of percentage methane (hollow) and carbon dioxide (shaded) composition with time in nitrate added cultures using methanogenic dominant zone sludge previously unadapted to nitrate: acetate $(O, \Theta)$, volatile fatty acid $(\Delta, \boldsymbol{\Delta})$, glucose $(\square, \square)$. Data for acetate $(\boldsymbol{O})$, volatile fatty acid $(\boldsymbol{\Delta})$ were all at 0 and therefore these symbols overlap with each other giving the appearance of .

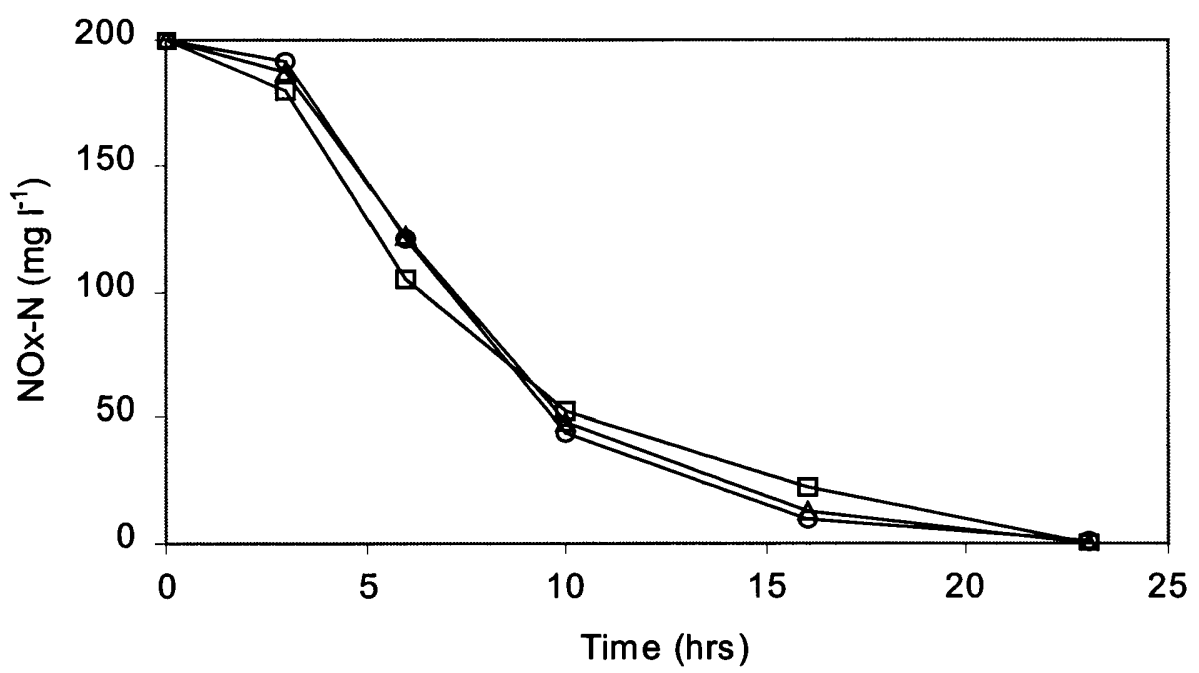

Figure 6.6 Profile of $\mathrm{NOx}-\mathrm{N}\left(\mathrm{NO}_{3}-\mathrm{N}\right.$ and $\left.\mathrm{NO}_{2}-\mathrm{N}\right)$ concentrations with time using various cultures with methanogenic dominant zone sludge previously unadapted to nitrate: acetate $(O)$, volatile fatty acid $(\Delta)$, glucose $(\square)$. 


\subsubsection{Acidogenic Dominant Zone Sludge Previously Adapted to Nitrate}

These experiments were carried out with sludge obtained from Compartment 1 of the GRABBR during the study reported in Chapter 5.

\subsubsection{Sludge from the acidogenic dominant zone (nitrate-free cultures)}

No methane production was observed from all three cultures (glucose, acetate and VFA) throughout the experimental period, suggesting that this sludge contained little or no methanogens. A high production of carbon dioxide was observed with the glucose media, while noticeably lower percentages (less than $20 \%$ ) were measured for acetate and VFA cultures at the end of experiment as shown in Figure 6.7.

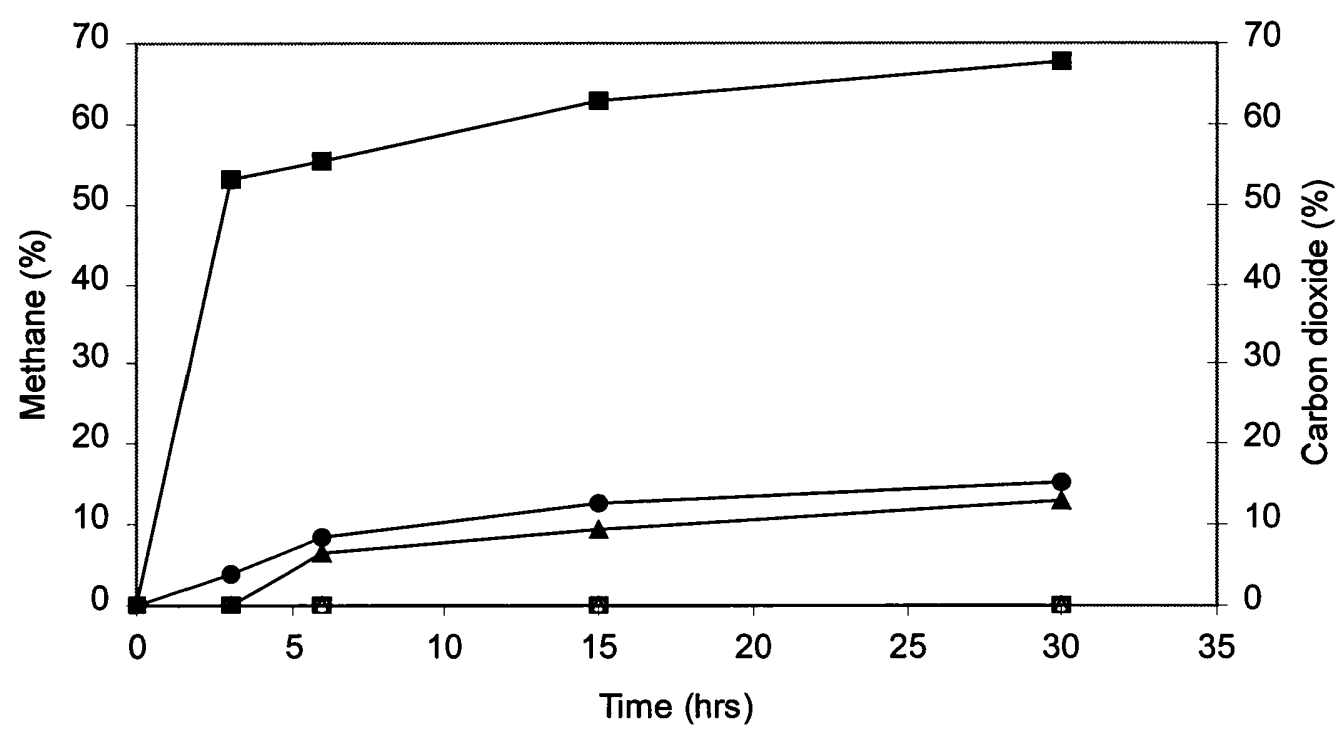

Figure 6.7 Profile of percentage methane (hollow) and carbon dioxide (shaded) composition for various media with time using acidogenic dominant zone sludge previously adapted to nitrate: acetate $(O, O)$, volatile fatty acid $(\Delta, \Delta)$, glucose $(\square, \square)$. Data for acetate $(O)$, volatile fatty acid $(\Delta)$, glucose $(\square)$ were all at 0 and therefore these symbols overlap with each other. 


\subsubsection{Sludge from the acidogenic dominant zone (nitrate-added cultures)}

No methane production was observed for all cultures (glucose, acetate and VFA) in this study. No carbon dioxide production was observed for acetate and VFA media, while the glucose medium exhibited $60 \%$ carbon dioxide composition at the end of experiment as shown in Figure 6.8. High NOx-N removal rates were observed for this sludge, with all media, as shown in Figure 6.9. No nitrate was detected at $6 \mathrm{hrs}$ and 12 hrs for acetate and VFA cultures respectively. Complete nitrate removal was observed at $23 \mathrm{hrs}$ for the glucose medium. NOx-N removal efficiency for glucose, acetate and VFA cultures at 6 hrs was calculated as $72 \%, 87 \%$ and $89 \%$ respectively.

\subsection{DISCUSSION}

The average and maximum denitrification rates obtained in this study are shown in Table 6.3. Generally, the denitrification rates achieved in this study are comparable with the levels reported in the literature with various carbon sources (Monteith et al., 1980; Bode et al., 1987; Fass et al., 1994; Bernet et al., 1996b).

\subsubsection{Nitrate-free Cultures}

Studies with acetate and VFA cultures previously unadapted to nitrate exhibited slightly higher methane production when compared with glucose cultures. Methane production appeared generally higher for cultures with methanogenic dominant zone biomass than sludge from the acidogenic dominant zone. This difference was an indication as to the degree of phase separation that occurred in the GRABBR during the period of reactor operation, which encouraged acidogenesis to flourish in the early compartments and methanogenesis in the latter compartments. The high carbon dioxide production in the glucose media was the result of acidogenesis, which is only associated with fermentable substrates, like glucose in this study. 


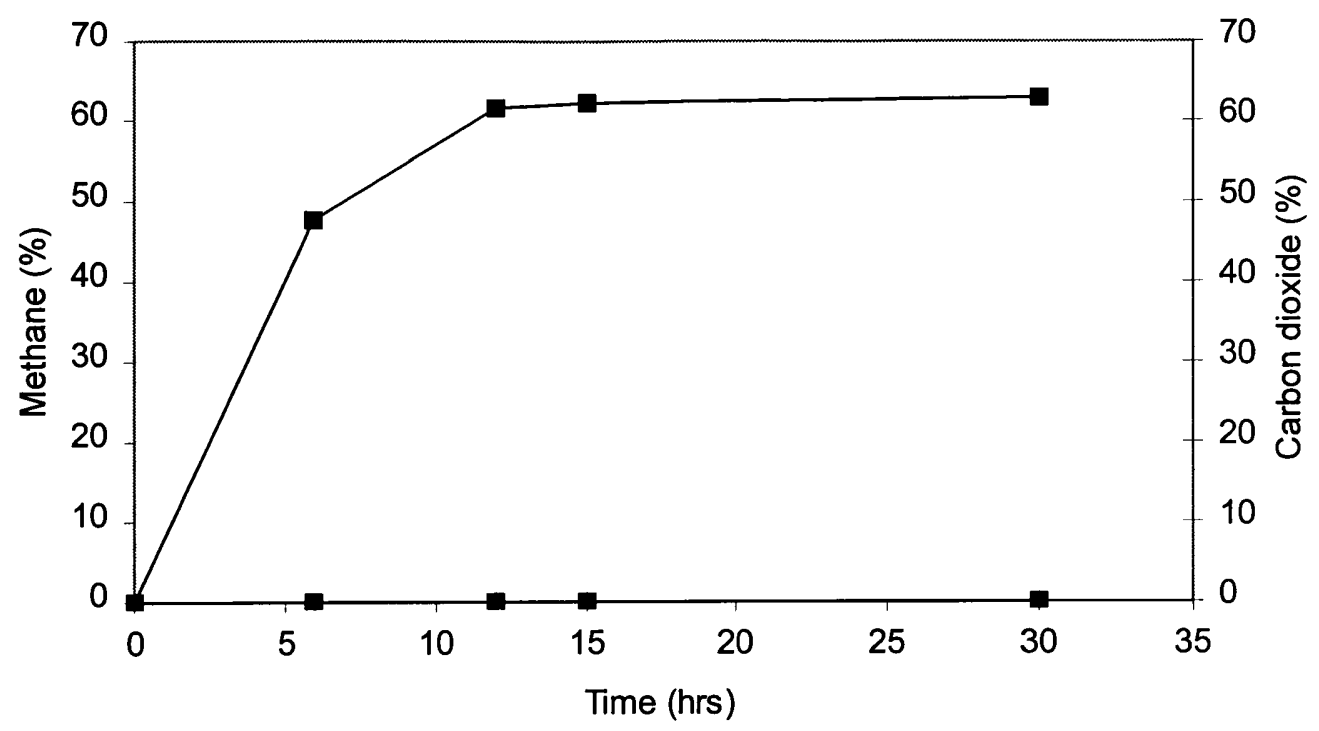

Figure 6.8 Profile of percentage methane (hollow) and carbon dioxide (shaded) composition with time in nitrate added cultures using acidogenic dominant zone sludge previously adapted to nitrate: acetate $(O, \boldsymbol{O})$, volatile fatty acid $(\Delta, \boldsymbol{\Delta})$, glucose $(\square, \square)$. Data for acetate $(\bigcirc, \bigcirc)$, volatile fatty acid $(\Delta, \boldsymbol{\Delta})$, glucose $(\square)$ were all at 0 and therefore these symbols overlap with each other giving the appearance of duplicate

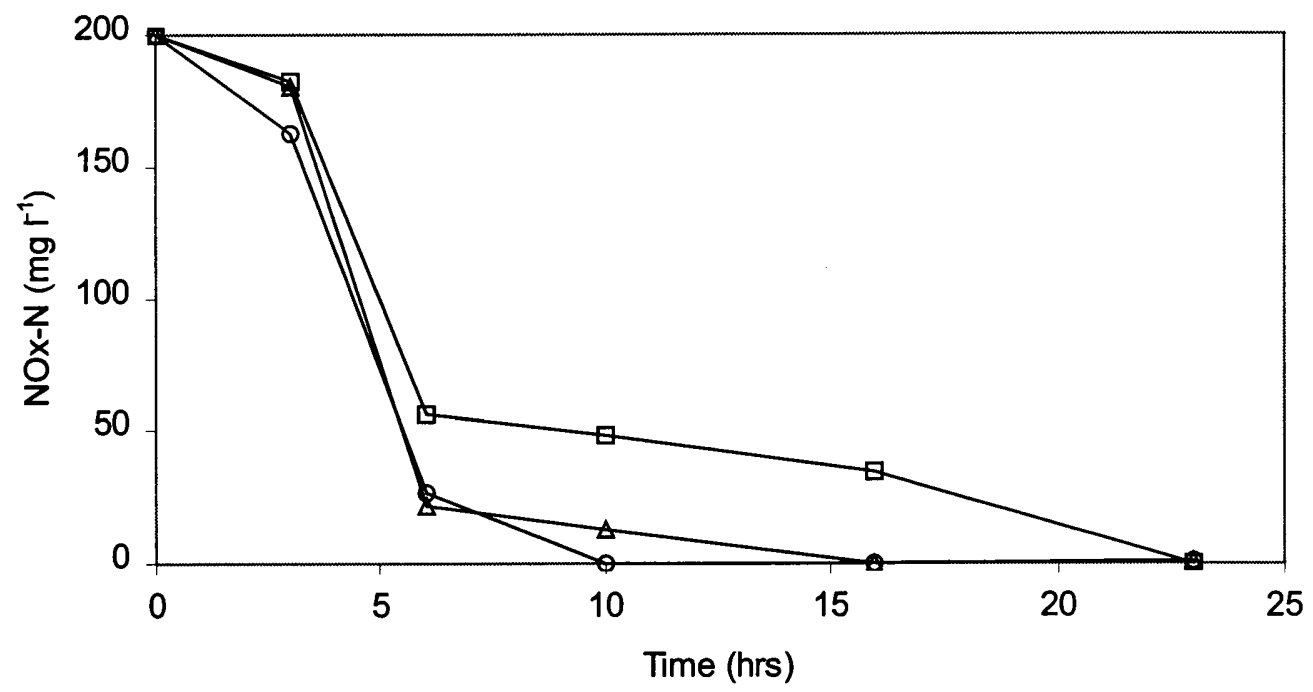

Figure 6.9 Profile of $\mathrm{NOx}-\mathrm{N}\left(\mathrm{NO}_{3}-\mathrm{N}\right.$ and $\left.\mathrm{NO}_{2}-\mathrm{N}\right)$ concentrations with time using various cultures with acidogenic dominant zone sludge previously adapted to nitrate: acetate $(\bigcirc)$, volatile fatty acid $(\triangle)$, glucose $(\square)$. 
Table 6.3 Nitrate removal rates and methane production under various batch cultures.

\begin{tabular}{|c|c|c|c|c|c|c|c|c|c|}
\hline Sludge type & $\begin{array}{l}\text { Carbon } \\
\text { Source }\end{array}$ & $\begin{array}{l}\mathrm{COD}^{\mathrm{b}} \\
\left(\mathrm{mg} \mathrm{l}^{-1}\right)\end{array}$ & $\begin{array}{l}\text { State of } \\
\text { culture }\end{array}$ & $\begin{array}{l}\text { Nitrate addition } \\
\left(\mathrm{NO}_{3}-\mathrm{N}^{\mathrm{e}} \mathrm{mg} \mathrm{l}^{-1}\right)\end{array}$ & $\mathrm{COD} / \mathrm{NO}_{3}-\mathrm{N}$ & $\begin{array}{l}\text { Av. } \mathrm{NOx}-\mathrm{N} \\
\text { removal rate } \\
\left(\mathrm{mg} \mathrm{NO}_{3}-\mathrm{N}^{-1} \mathrm{~h}^{-1}\right)\end{array}$ & $\begin{array}{l}\text { Max. NOx-N } \\
\text { removal rate } \\
\left(\mathrm{mg} \mathrm{NO}_{3}-\mathrm{N}^{-1} \mathrm{~h}^{-1}\right)\end{array}$ & $\begin{array}{l}\mathrm{CH}_{4}{ }^{\mathrm{f}} \\
\text { composition } \\
(\%)\end{array}$ & $\begin{array}{l}\mathrm{CO}_{2}{ }^{\mathrm{g}} \\
\text { composition } \\
(\%)\end{array}$ \\
\hline \multirow[t]{3}{*}{ Compartment 1} & Acetate & 3000 & $\mathrm{x}^{\mathrm{c}}$ & 0 & - & - & - & $18-51$ & $0-6$ \\
\hline & VFA $^{a}$ & 3000 & $\mathrm{x}$ & 0 & - & - & - & $12-50$ & $0-5$ \\
\hline & Glucose & 3000 & $\mathrm{x}$ & 0 & - & - & - & $6-47$ & $35-46$ \\
\hline \multirow[t]{3}{*}{ Compartment 5} & Acetate & 3000 & $x$ & 0 & - & - & - & $24-63$ & $0-4$ \\
\hline & VFA & 3000 & $\mathrm{x}$ & 0 & - & - & - & $25-57$ & $0-4$ \\
\hline & Glucose & 3000 & $\mathrm{x}$ & 0 & - & - & - & $31-58$ & $11-37$ \\
\hline \multirow[t]{3}{*}{ Compartment 1} & Acetate & 3000 & $\mathrm{x}$ & 200 & 15 & 12.47 & 24.9 & $8-15$ & $0-6$ \\
\hline & VFA & 3000 & $\mathrm{x}$ & 200 & 15 & 10.96 & 26.98 & $0-10$ & $5-13$ \\
\hline & Glucose & 3000 & $\mathrm{x}$ & 200 & 15 & 3.56 & 7.8 & $0-5$ & $41-61$ \\
\hline \multirow[t]{3}{*}{ Compartment 5} & Acetate & 3000 & $\mathrm{x}$ & 200 & 15 & 11.9 & 23.51 & $31-40$ & 0 \\
\hline & VFA & 3000 & $\mathrm{x}$ & 200 & 15 & 11.71 & 21.72 & $30-38$ & 0 \\
\hline & Glucose & 3000 & $x$ & 200 & 15 & 11.08 & 24.62 & $27-35$ & $14-49$ \\
\hline \multirow[t]{3}{*}{ Compartment 1} & Acetate & 3000 & $\sqrt{ }^{\mathrm{d}}$ & 0 & - & - & - & 0 & 0 \\
\hline & VFA & 3000 & $\sqrt{ }$ & 0 & - & - & - & 0 & 0 \\
\hline & Glucose & 3000 & $\sqrt{ }$ & 0 & - & - & - & 0 & $48-63$ \\
\hline \multirow[t]{3}{*}{ Compartment 1} & Acetate & 3000 & $\sqrt{ }$ & 200 & 15 & 28.9 & 45.45 & 0 & 0 \\
\hline & VFA & 3000 & $\sqrt{ }$ & 200 & 15 & 18.72 & 52.92 & 0 & 0 \\
\hline & Glucose & 3000 & $\sqrt{ }$ & 200 & 15 & 10.33 & 42.05 & 0 & $14-49$ \\
\hline
\end{tabular}

${ }^{\mathrm{a}}$ Volatile fatty acid, ${ }^{\mathrm{b}}$ Chemical oxygen demand, ${ }^{\mathrm{c}}$ Unadapted to nitrate, ${ }^{\mathrm{d}}$ Adapted to nitrate, ${ }^{\mathrm{e}}$ Nitrate nitrogen, ${ }^{\mathrm{f}}$ Methane, ${ }^{\mathrm{g}}$ Carbon dioxide 
For the acidogenic dominant biomass previously adapted to nitrate, no methane production was observed in all three (glucose, acetate and VFA) media. It appears that the growth of denitrifiers (due to the long-term nitrate addition) and acidifiers (due to continuous reactor operation with fermentative substrate) completely eradicated all methane producing microorganisms in this zone of GRABBR. Hence, the complete absence of methane producing bacteria could be attributed to the microbial environment created due to continuous nitrate addition with the glucose wastewater in the reactor. It is believed that the presence of denitrifiers in this culture resulted in a slight increase in carbon dioxide with all three substrate cultures when compared with the unadapted nitrate culture.

\subsubsection{Nitrate-added Cultures}

For the biomass previously unadapted to nitrate, a low methane production was observed with acidogenic and methanogenic dominant zone sludges when compared to nitrate free cultures. Comparatively, acidogenic dominant sludge exhibited poorer methane production when compared to methanogenic dominant sludge in the presence of nitrate. Higher NOx-N removal rates were also observed with sludge from the methanogenic dominant zone when compared to the acidogenic dominant zone. This indicates that sludge from the methanogenic dominant zone, which contained mainly anaerobic granular sludge, has a higher denitrifying and methanogenic capability than biomass from the acidogenic dominant zone, thus confirming results of the reactor study reported in Chapter 5. It was interesting to note that methane production was observed whilst NOx-N was still in both media, i.e. cultures with acidogenic and methanogenic biomass. This was more noticeable in the sludge from the methanogenic dominant zone, which was mainly granular. It proves that denitrification and methanogenesis can proceed simultaneously, especially with biomass that is granular in structure. Acidogenic dominant zone sludge cultures, unadapted to nitrate, generally showed a low methane composition even after complete removal of NOx-N, which was probably due to the nature of biomass (also containing non-granular microorganisms) resulting from phase separation during the reactor study. 
The acidogenic dominant sludge previously adapted to nitrates exhibited high NOx-N removal rates with no methane production. This was mainly attributed to the acclimatisation of this biomass to nitrate during nitrate addition in the GRABBR (Chapter 5).

\subsection{CONCLUDING DISCUSSION}

This study has shown that the acidogenic dominant biomass could achieve nitrate removal, and nitrate adaptation of this biomass increases the number of denitrifying microbes.

This study also shows that the methanogenic dominant sludge, being mainly granular in structure, may be considered as a consortium containing both facultative populations and methanogens. Thus, the simultaneous production of methane and denitrification in the methanogenic dominant zone sludge could be a result of the following hypotheses:

1. Some methanogenic organisms are capable of carrying out denitrification, and / or

2. The granular structure is made up of a diverse number of microorganisms, involving both the facultative microorganisms (acidifiers / denitrifiers) and the methanogens.

The first hypothesis could not result in simultaneous methane production and denitrification, since if both microorganisms carry out both processes, they must have a preferable route dictated by energy production. Consequently, denitrification will occur before methane formation since the energy production associated with the former is greater (Hendriksen and Ahring, 1996a). This hypothesis would result in reversible inhibition as reported by some authors (Akunna et al., 1994a), which would generally bring about high denitrification and markedly low methane production.

The second hypothesis appears more plausible in this study. It suggests that both organisms are present in the granules with methanogens concentrated mainly at the core 
of the granules and denitrifiers / acidogens at the outer layers. When nitrate is present in the culture, it is only the methanogens at the core of the granules that produce methane, while the microorganisms in the outer layers remove the penetrating substrates of the nitrates as it diffuses into the granule. Therefore, on the basis of the second hypothesis, a proposed biochemical description of a methanogenic granular sludge treating wastewater rich in organic carbon and nitrate is shown in Figure 6.10. With this structure, both denitrification and methane production rates would be relatively higher than if they occur with the first hypothesis.

In conclusion, this study confirms that combined denitrification and methanogenesis may not occur with non-granular methanogenic sludge, mainly due to its dispersed or flocculent structure, which offers no, or little, protection to methanogens from nitrogen oxides. Moreover, long term exposure of 'unprotected' methanogens to nitrate can also completely cease their methanogenic activities. Simultaneous denitrification and methanogenesis can proceed for all substrate cultures containing organic carbon and nitrate with methanogenic granular sludge, indicating the key role of granular ultrastructure (as detailed in Chapter 7) in the combined integrated process. However, methane production may be lower when nitrates are present due to some inhibition of methanogenesis. Hence, a layered methanogenic granular sludge within an anaerobic system behaves like fixed film systems for organic carbon and nitrate removal, which create zones of denitrification and methane production within the filter media, as suggested by some researchers (Hanaki and Polprasert, 1989; Akunna et al., 1994b). With layered granular structure, such zoning occurs within the biomass to ensure simultaneous denitrification and methane production. 


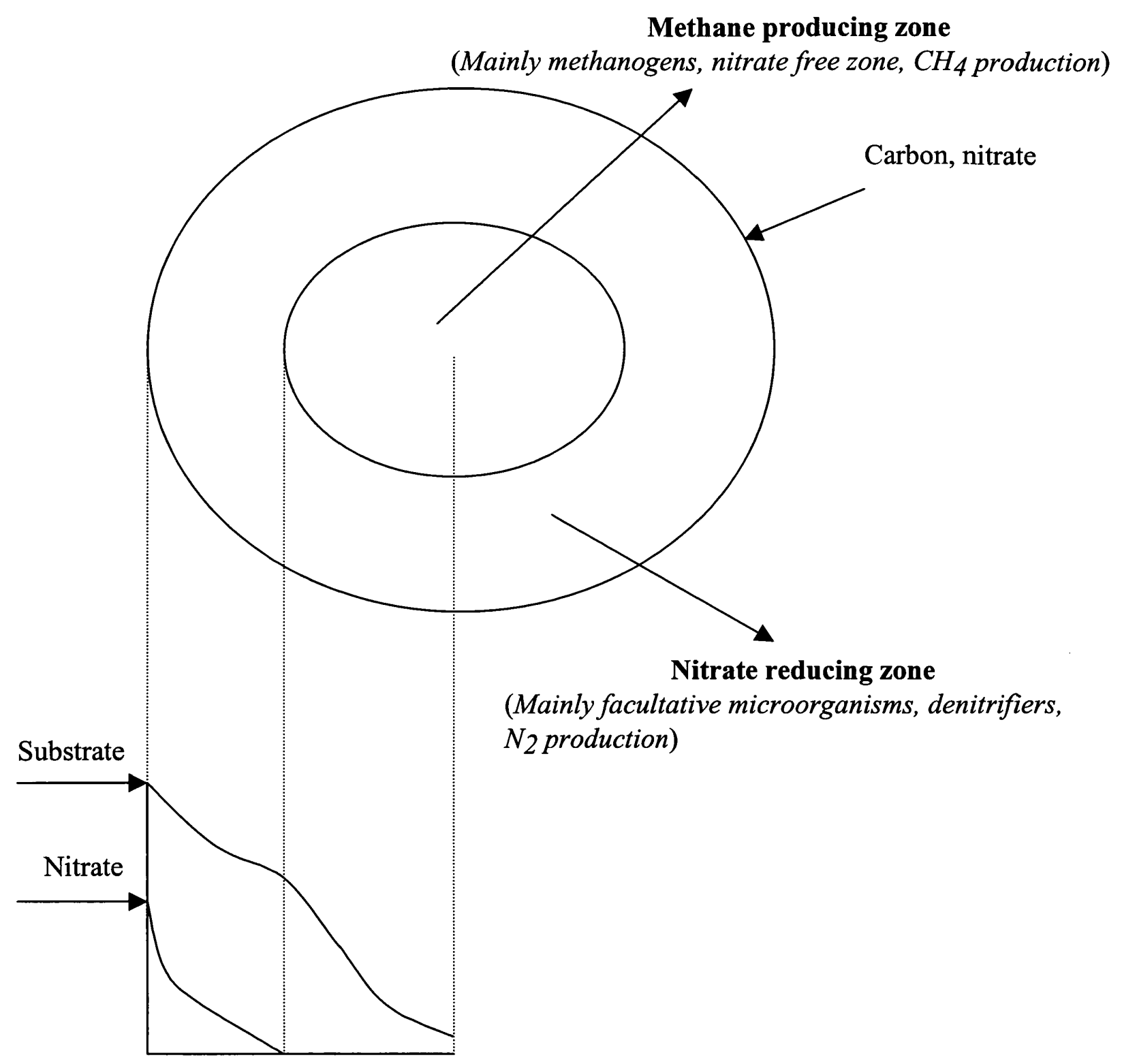

Figure 6.10 Proposed biochemical structure of methanogenic granular sludge for simultaneous denitrification and methanogenesis. Nitrates and some carbonaceous matter would be utilised in the outer zone(s) of the granule by facultative populations, while the remaining carbon content would penetrate into the core of the granule for methane production. 


\section{CHAPTER 7}

\section{PHYSICAL AND MICROBIAL ECOLOGY OF ANAEROBIC GRANULES}

This chapter discusses the importance of granular morphology in determining its properties, microbial ecology of the granules and the effect of phase separation on the microbial characteristics of anaerobic granules in granular bed baffled reactor.

\subsection{INTRODUCTION}

It has been widely reported that the efficiency of granular anaerobic systems has a direct correlation with the properties and ultrastructure of granules (Arcand et al., 1994; Batstone and Keller, 2001). Granular characteristics vary with the type of wastewater, seed sludge and retention time of an anaerobic ecosystem (Wijbenga and Bos, 1988; Grotenhuis et al., 1991a).

The particle size distribution of methanogenic granular sludge has been found to be a useful tool in the evaluation of growth, stability and settleability of granules (Hulshoff Pol et al., 1986; Grotenhuis et al., 1991a). Thus, granular size distribution within a system can estimate the effectiveness of wastewater treatment in the bioreactor. Granular size distribution is believed to be influenced by a number of factors such as granule growth rate, influent solids concentration, washout, breaking, attrition, availability of nutrients, substrate limitation within the granules, shear forces, production of extracellular biopolymers, gas production and formation of inorganic precipitates (Tramper et al., 1984; Grotenhuis et al., 1991a; Pereboom, 1994). An increase in the diameter of the granular sludge has been correlated with the increase in settling velocity (Hulshoff Pol et al., 1986). It has also been reported that large sized granular distribution curves are obtained with high substrate concentrations, whereas smaller sized granules are obtained with low substrate concentrations (Grotenhuis et al., 
1991a). Although, extensive research has been performed on granular characteristics, little information is available on the various causes of granule disintegration in anaerobic ecosystem.

Five techniques - image analysis, laser analysis, sieving, calculations from settling velocities and microscopic sizing have been widely used by researchers to determine the particle size distribution of granular sludge (Laguna et al., 1999). Image and laser analyses are expensive methods (Laguna et al., 1999). Sieving causes erosion of granules in the sieves and fairly large samples are required (Hulshoff Pol et al., 1986). Empirical equations have been used to relate settling velocities and granular size by assuming shape of granules as sphere (Hulshoff Pol et al., 1986; Grotenhuis et al., 1991a; Batstone and Keller, 2001). Microscopic sizing, though tedious, is believed to be inexpensive, reliable and require fairly small amount of samples. Due to these advantages of the microscopic technique, this approach was used for determining the size distribution of the granules in this study.

Due to the diverse nature of biological aggregates generated in wastewater treatment systems, the settling velocities of many aggregates have been found not to obey Stokes' law (Johnson et al., 1996). This law is only applicable if particles are spherical in shape and fall through a laminar flow regime (Tang and Raper, 2002). The literature revealed significant attention paid towards the flow regime of granular sedimentation by using Galileos' number (Hulshoff Pol et al., 1986, Grotenhuis et al., 1991a). This formula is derived for spherical particles settling in the intermediate region due to high Reynolds' number. However, the morphology of granules, which is equally important when determining granular properties, surprisingly has not been paid greater attention. The "spherical shape" of granules seems to be an inherited language from one researcher to another, with little emphasis on the use of expressions adequately representing granular morphology. The non-sphericity of the particle plays an important role in changing the drag force. The higher the deviation from a sphere, the higher the drag force, so the nonspherical particle will settle at a slower rate than a spherical shape particle of the same density and volume (Tang and Raper, 2002).

Anaerobic granules are dense microbial structures that consist of different trophic groups. Electron micrographs have been widely used for the identification of different 
microbial groups and their probable locations in the granules (Macleod et al., 1990; Fang et al., 1994). In general, granules formed during the treatment of wastewaters (such as glucose, sucrose and brewery wastewaters), in which the final reaction (methanogenesis) is the rate limiting factor, tend to form a multi-layered ultrastructures with a wide diversity of microorganisms (Macleod et al., 1990; Fang et al., 1994). Facultative bacteria have been found to be the dominant microorganisms in the outer layer, while oxygen sensitive methanogens are dominant in the core of the granules (Shen and Guiot, 1996). A large number of cavities have also been reported in the core layer and have been identified as potential sites of gas production (Bochem et al., 1982; Macleod et al., 1990). Macleod et al., (1990) proposed a three layered structure of glucose-fed granules as shown in Figure 7.1. Granular growth on a single step substrate (acetate or formate) encourages the development of simple uniform microstructures (Fang et al., 1995). Furthermore, complex uniform structures were observed for granules grown on propionate (Grotenhuis et al., 1991b; Fang et al., 1995).

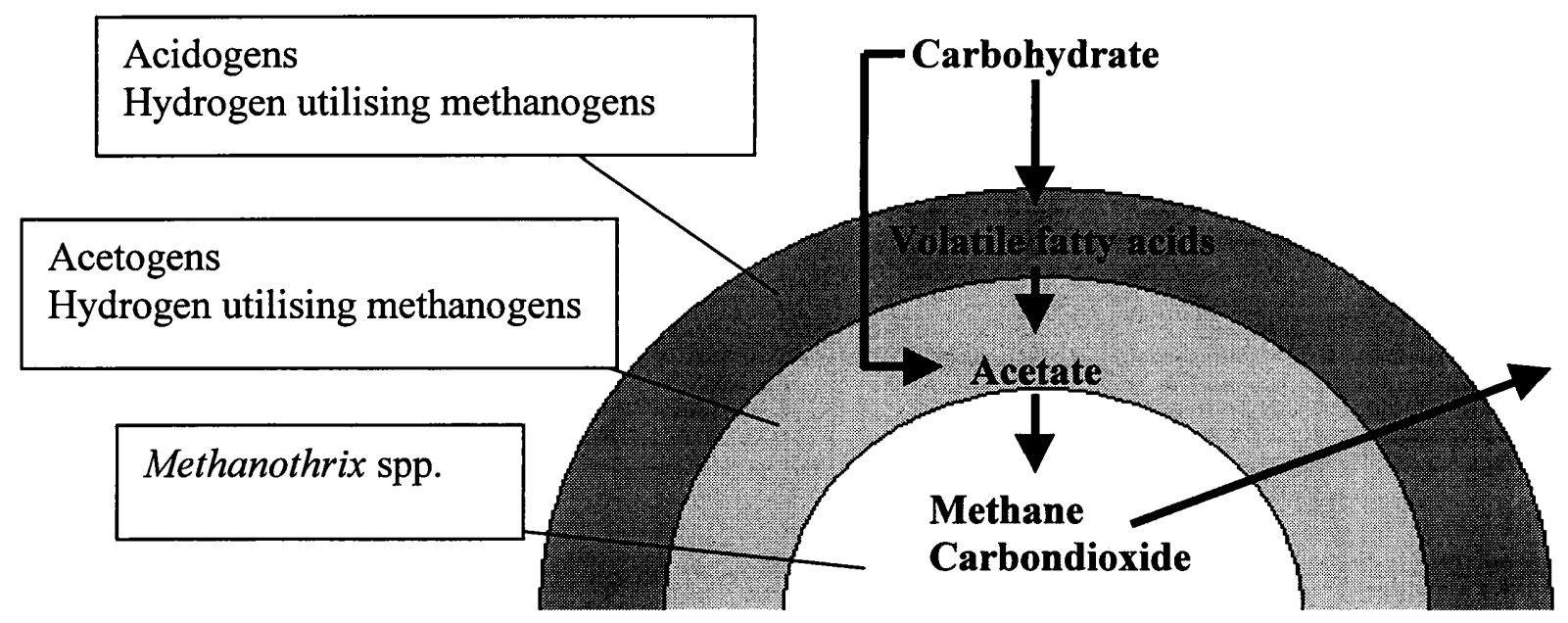

Figure 7.1 Proposed granular structure showing arrangement of metabolic groups in different layers related to substrate diffusion for carbohydrate-fed granules (from Macleod et al., 1990).

Only a small number of microscopic studies (Bhatti et al., 1995) have been carried out to measure the response or changes in the granular consortia brought from one anaerobic ecosystem to another. Moreover, little microscopic evidence is available on the effect of phase separation on the ecology of granules grown in a single stage system. In such anaerobic configuration, like the granular bed baffled reactor (GRABBR), it is 
suggested that stage microbial degradation might have a different effect on the ultrastructure of granules in different zones.

Unlike other completely mixed type anaerobic reactors, the GRABBR encourages phase separation at high loadings, accommodating different groups of microorganisms in different compartments or zones within the system. Acidogenesis is the dominant reaction in the compartments closer to the influent point, whilst methanogens are the dominant microorganisms in the downstream compartments. The methanogenic dominant zone usually retains the original seed granular form. However, granule disintegration and flotation take place in the acidogenic dominant zone. The breaking of granules causes an increase in non-granular microbial mass in the upstream compartments. In the literature, little is known of the causes of granular disintegration in stage anaerobic systems. Hence, the analysis of electron micrographs of granular consortia from acidogenic and methanogenic dominant phases of GRABBR, originally seeded with granules from a completely mixed system, i.e. upflow anaerobic sludge blanket (UASB), could give a better insight into microbial responses in different environmental conditions.

In the literature available to date, emphasis has been on the layering of the granular structure and presence of different types of methanogenic, acidogenic and syntrophic populations (Macleod et al., 1990; Fang et al., 1994). Although granular consortia are accepted as biofilms (Shen and Guiot, 1996), they have not been fully investigated as biofilm structures. Therefore, this study will also attempt to discover microbial species, other than those reported by a number of researchers (Macleod et al., 1990; Fang et al., 1994; Bhatti et al., 1995), which could also be a part of biofilm structures. Hence, the aims of this study were to investigate:

- Importance of the morphology of anaerobic granules in determining granular properties.

- Size distribution of seed granular sludge and possible causes of granule disintegration. 
- Microbial ecology of granules and changes brought about by different environmental conditions on the granular structure subjected to different substrate conditions.

\subsection{EXPERIMENTAL CONDITIONS}

The samples for electron microscopy were obtained from Compartment 1 and 5 of GRABBR at the end of the experimental study detailed in Chapter 3.

\subsection{RESULTS}

\subsubsection{Particle Size Distribution}

Various sizes of seed UASB granules were observed along both axes by microscopic investigation as shown in Figures 7.2 and 7.3 respectively.. Dimensions along the long axis varied from $0.62 \mathrm{~mm}$ to $2.54 \mathrm{~mm}$, whereas along the short axis varied from 0.42 $\mathrm{mm}$ to $2.1 \mathrm{~mm}$. The mean dimension along the long axis was $1.12 \mathrm{~mm}$ (standard deviation $\pm 0.34 \mathrm{~mm}$ and variance $\pm 0.12 \mathrm{~mm}$ ), while for the short axis it was $0.87 \mathrm{~mm}$ (standard deviation $\pm 0.29 \mathrm{~mm}$ and variance $\pm 0.08 \mathrm{~mm}$ ). . More than $45 \%$ and $74 \%$ of the granules were observed to be less than $1 \mathrm{~mm}$ along the long and short axes respectively. In order to judge the accuracy of the analysis, standard error bars were plotted on each set of bar data. The average error values were calculated as $2.41 \%$ and $1.78 \%$ on each bar data, whereas a maximum error of $5.65 \%$ and $3.46 \%$ was determined for the long and short axis respectively. The majority of granules observed from an image analyser were ellipsoid in shape as shown in Figure 7.4.

\subsubsection{Electron Microscopy}

The granules obtained from Compartment 5 (methanogenic dominant zone) of GRABBR retained the same ultrastructure as the seed inoculum obtained from the UASB reactor. Thus, only studies with granules from Compartment 5 (methanogenic dominant zone) and Compartment 1 (acidogenic dominant zone) of the GRABBR are reported. 


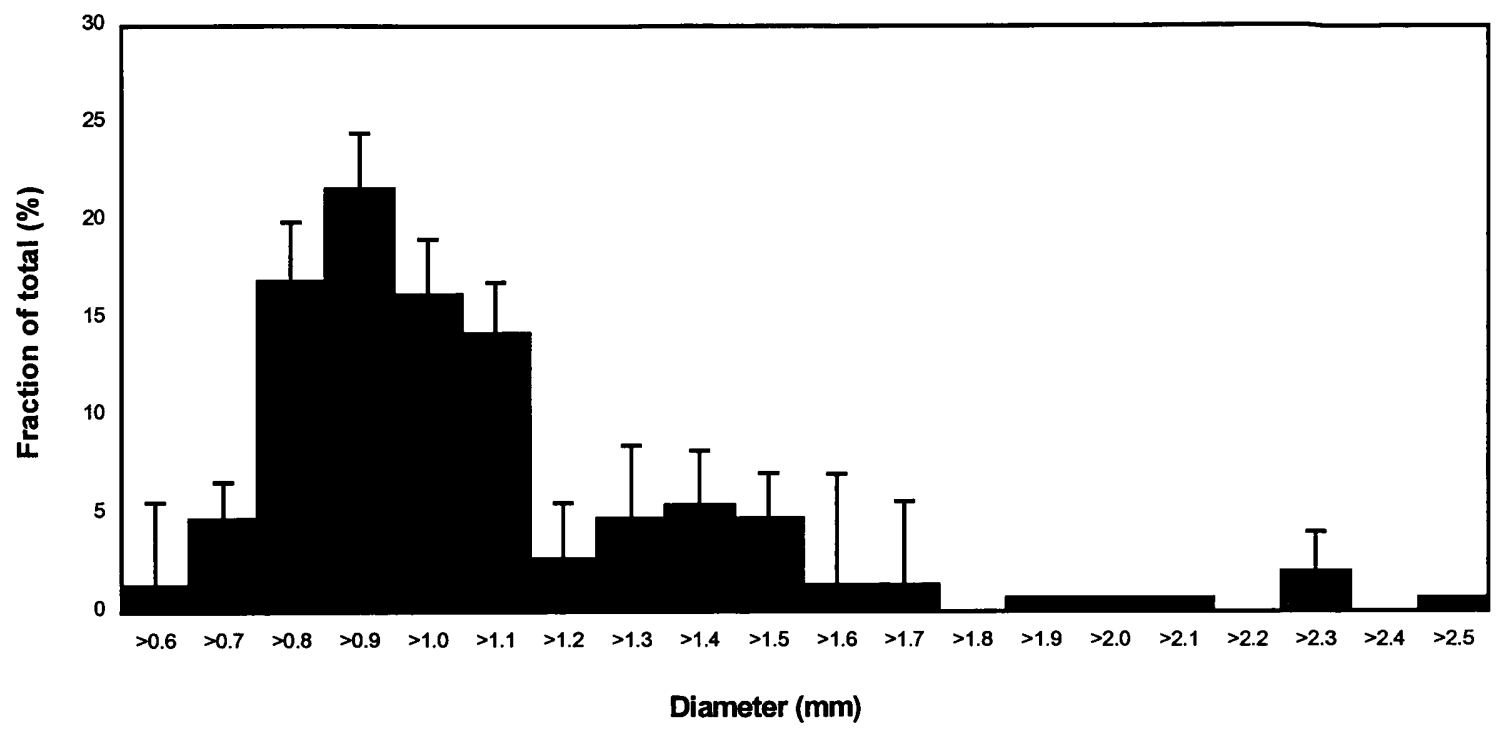

Figure 7.2 Granular size distribution along long axis of seed granules obtained from upflow anaerobic sludge blanket system using vernier measuring microscope (Average and maximum error bars were calculated as $2.41 \%$ and $5.65 \%$ respectively).

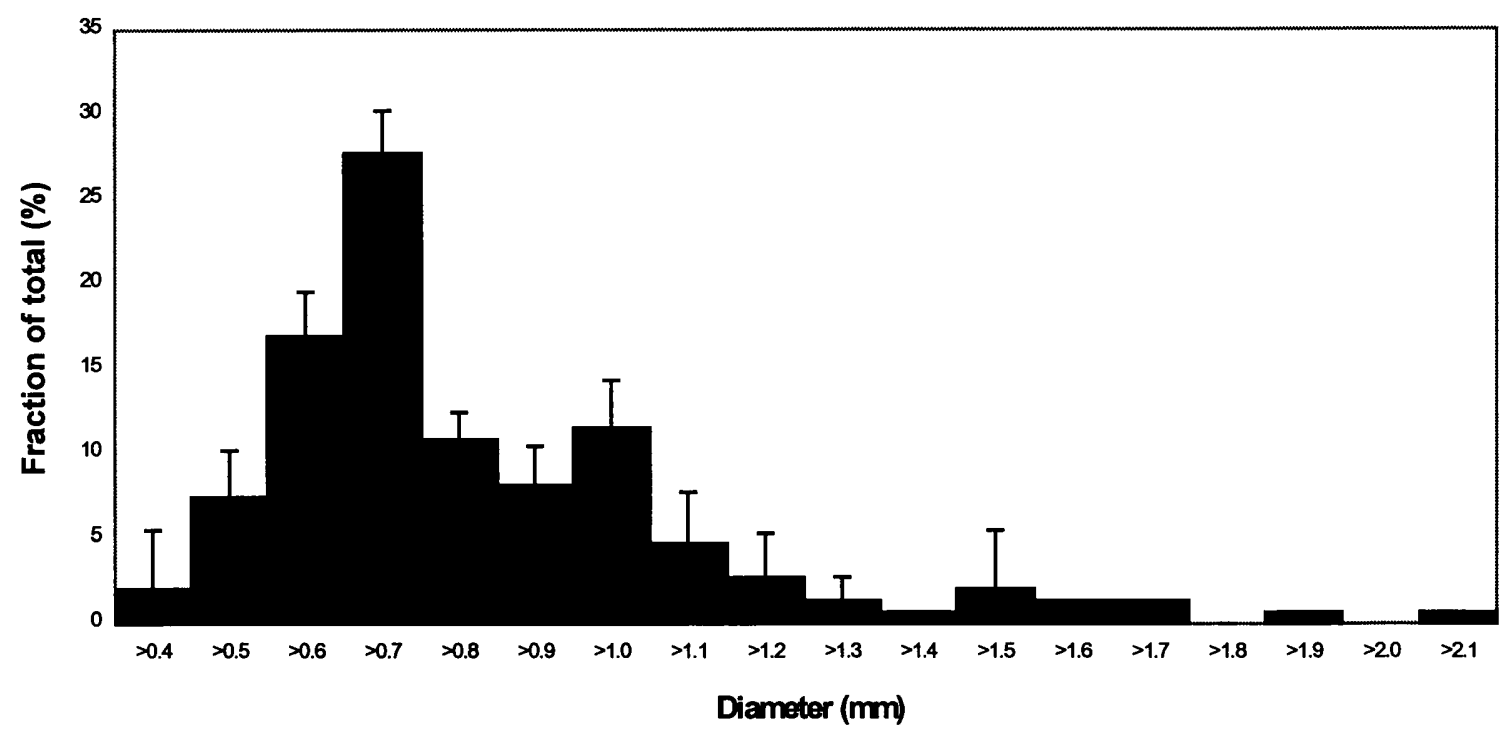

Figure 7.3 Granular size distribution along short axis of seed granules obtained from upflow anaerobic sludge blanket system using vernier measuring microscope (Average and maximum error bars were calculated as $1.78 \%$ and $3.46 \%$ respectively). 

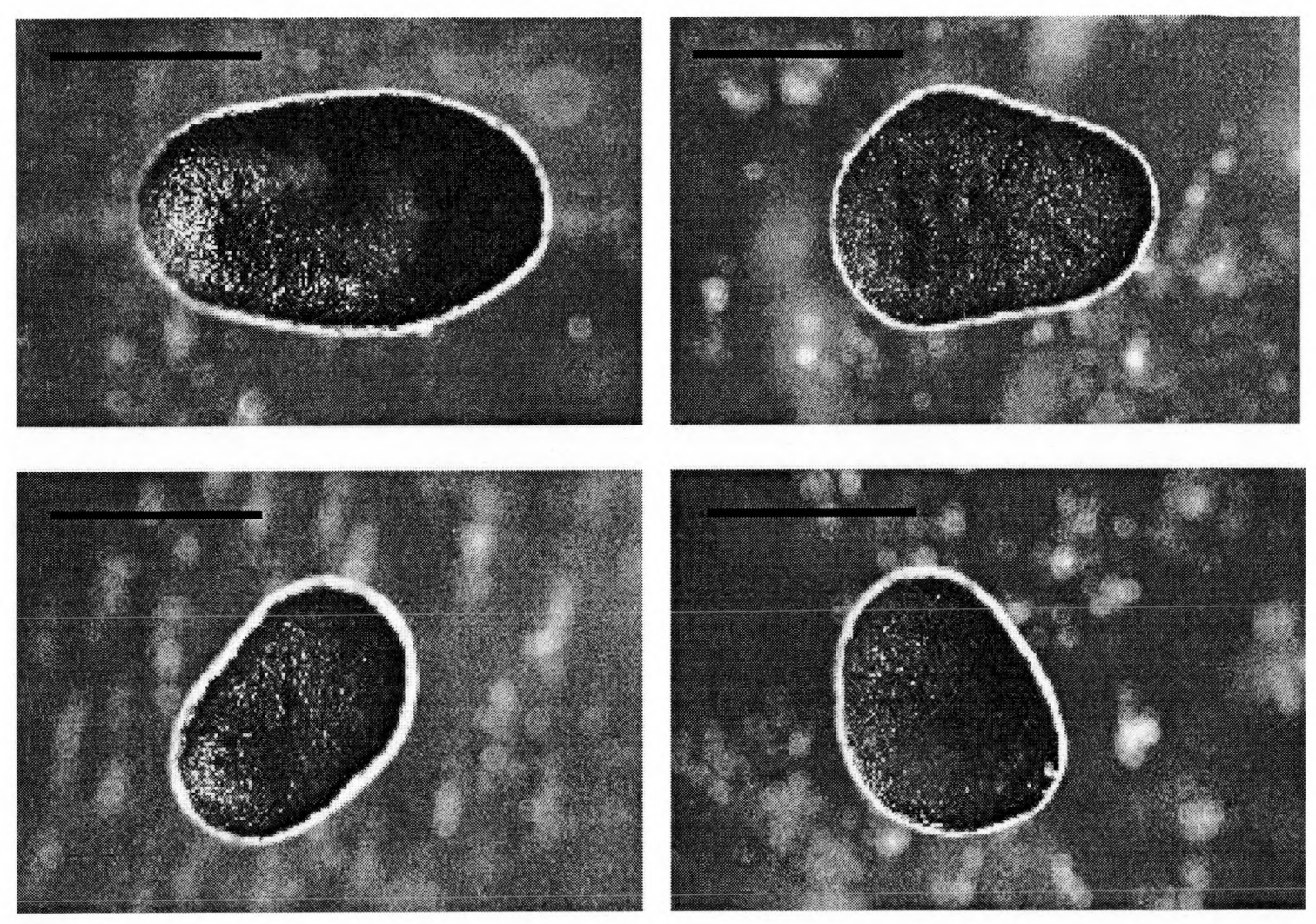

Figure 7.4 Ellipsoid shape of anaerobic granules obtained from upflow anaerobic sludge blanket system was evident from image analyser $($ Bar $=1.25 \mathrm{~mm})$.

\subsubsection{Transmission Electron Microscope}

The granules from the methanogenic dominant zone, i.e. Compartment 5, exhibited five apparent microbial zones (Figure 7.5a), whilst granules from the acidogenic dominant zone, i.e. Compartment 1 , consisted of four such zones from the outer surface to the core (Figure 7.5b). The zoning or boundary was not distinct between the different groups of microorganisms in the acidogenic dominant zone samples, as with the methanogenic dominant zone granules. Granules from the methanogenic dominant zone consisted of a relatively smooth and regular exterior layer (Figure 7.5a). While, granules from the acidogenic dominant zone exhibited irregular outer surfaces with less dense internal structures (Figure 7.5b). A densely packed outer zone of microorganisms was observed in the methanogenic dominant zone granules (Figure 7.6). Methanothrix-like microorganisms were dominant in the core zone of both granules (Figure 7.7), though lower numbers were observed in the acidogenic dominant zone samples (Figure 7.5). 
Regular shape viruses were observed in the ghost cells of granules (Figure 7.8), thus suggesting the presence of bacteriophage. The cell division of rod shaped morphotypes was evident in the granular samples (Figure 7.9). The cells consisted of a nuclear area and cytoplasmic material, with peptidoglycan sandwiched between cytoplasmic membranes on the division plane. Coccoid cells or transverse sections of a bundle or rod shaped bacteria were also observed (Figure 7.10). Moreover, structures resembling spirochaete bacteria were also visible in the granular biomass (Figure 7.11).

\subsubsection{Scanning Electron Microscope}

The texture (surface topography) of the methanogenic dominant zone granules was more regular, rigid and stable with a densely packed outer layer (Figure 7.12a), while, granules from the acidogenic dominant zone exhibited fissures, a less stable structure and broken parts with a rough exterior surface (Figure 7.12b). A protozoa-like structure was sighted on the exterior surface of a granule (Figure 7.13). A further close-up of this structure revealed openings, which could be the excystment scars or vacuoles. A network of methanogen-like species was observed in the core zone with large numbers of cavities (Figure 7.14). Extracellular polymeric substances (EPS) were observed within the entire granular structure (Figure 7.15). A large number of bacterial cells were surrounded by EPS, and in some sections EPS was peeled away from the cells (Figure 7.16). The outer layers of a granular sample showed high amount of EPS in the exterior zones (Figure 7.17). A high magnification of the granular biomass showed a regular alignment of methanogen-like bacterial cells (Figure 7.18). The surface of a few observed samples showed layering in two different directions (Figure 7.19), which could be the results of abrasion by other granules or the reactor walls. Micrographs of broken granules, and structures with fissures and broken surfaces were evident during examination of samples (Figure 7.20). 


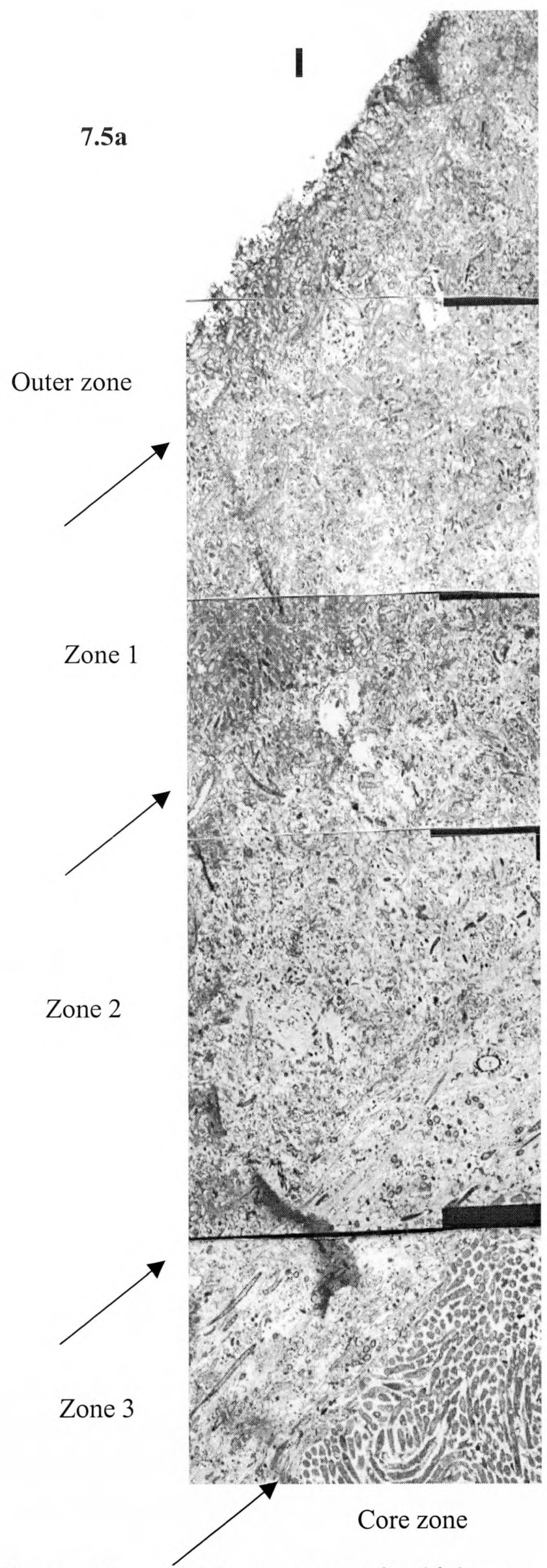

Figure 7.5 (a) Five apparent microbial zones are visible from outer surface to the core of the granule sampled from methanogenic dominant zone of granular bed baffled reactor (GRABBR). Vast diversity of bacterial species is evident with few open spaces. Methanothrix spp. is dominant in the central core $(\mathrm{Bar}=2 \mu \mathrm{m})$. (b) Four apparent microbial zones are visible from outer layer to the core of the granule sampled from acidogenic dominant zone of GRABBR. The exterior surface is adversely affected with no defined boundary due to high acidogenic activities in this zone of GRABBR. Layering within the granule is not distinct with few open spaces and relatively less numbers of Methanothrix spp. are visible at the central core $(\mathrm{Bar}=2 \mu \mathrm{m})$. 


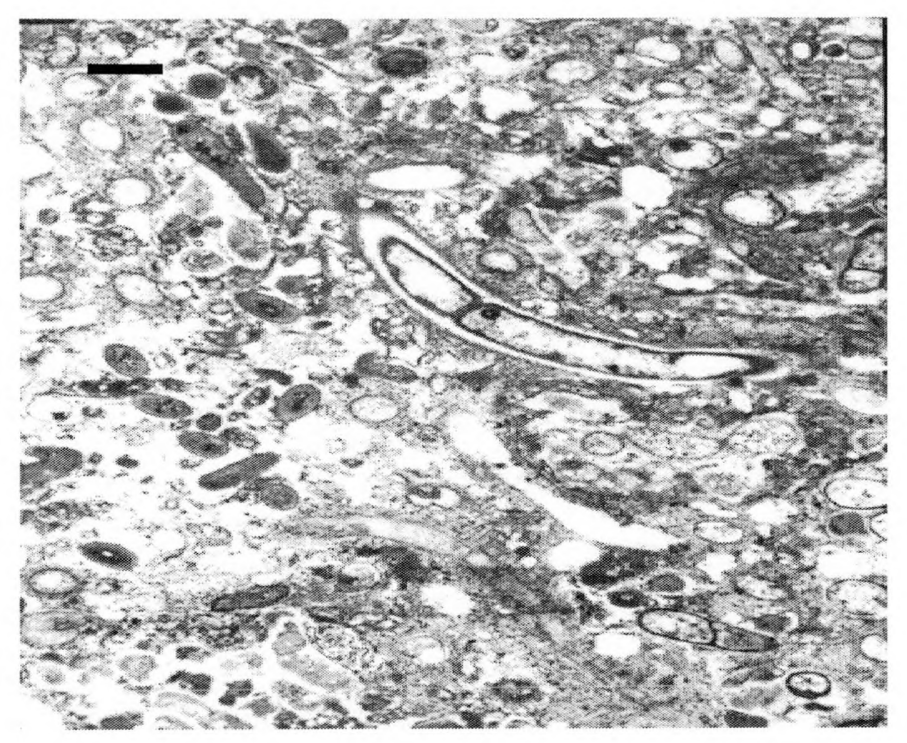

Figure 7.6 Densely packed microorganisms are observed at the exterior layer of granular sludge obtained from methanogenic dominant zone of granular bed baffled reactor $(\mathrm{Bar}=500 \mathrm{~nm})$.

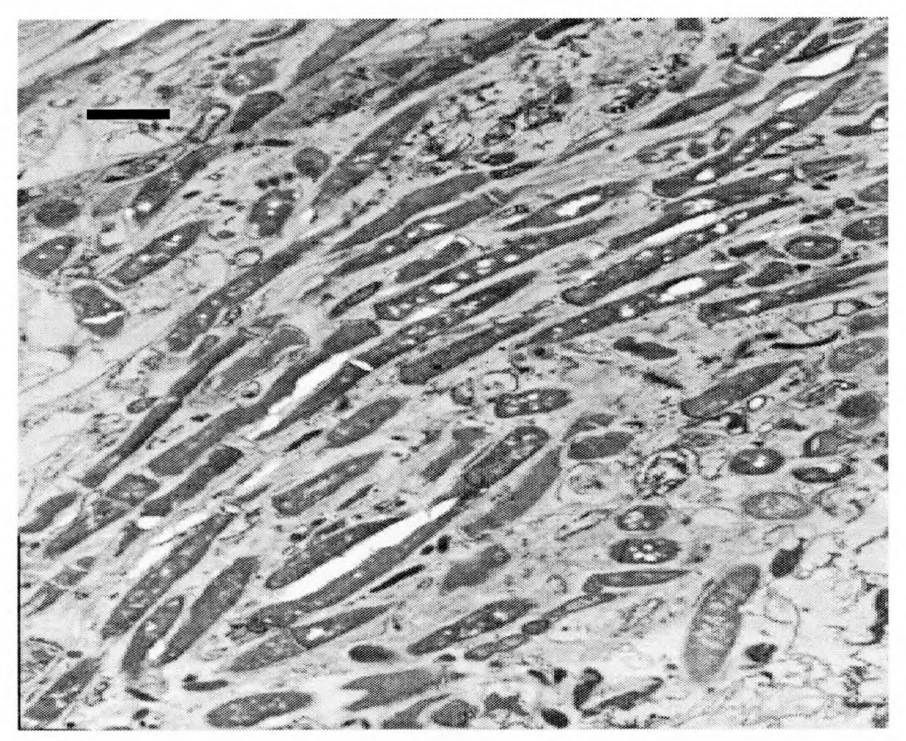

Figure 7.7 Methanothrix-like species are predominant organism in the core of methanogenic granular sludge $(\mathrm{Bar}=1 \mu \mathrm{m})$. 


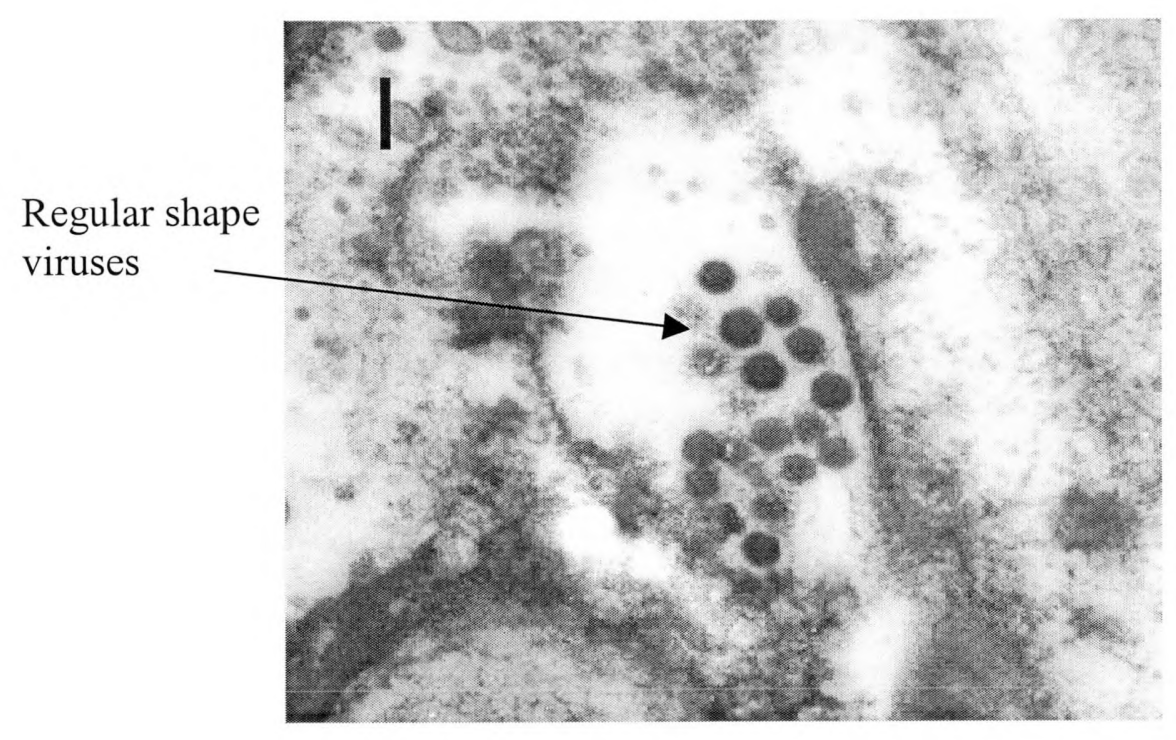

Figure 7.8 Regular shape viruses are visible in the ghost cell of granule. This suggest the presence of bacteriophage $(\mathrm{Bar}=100 \mathrm{~nm})$.

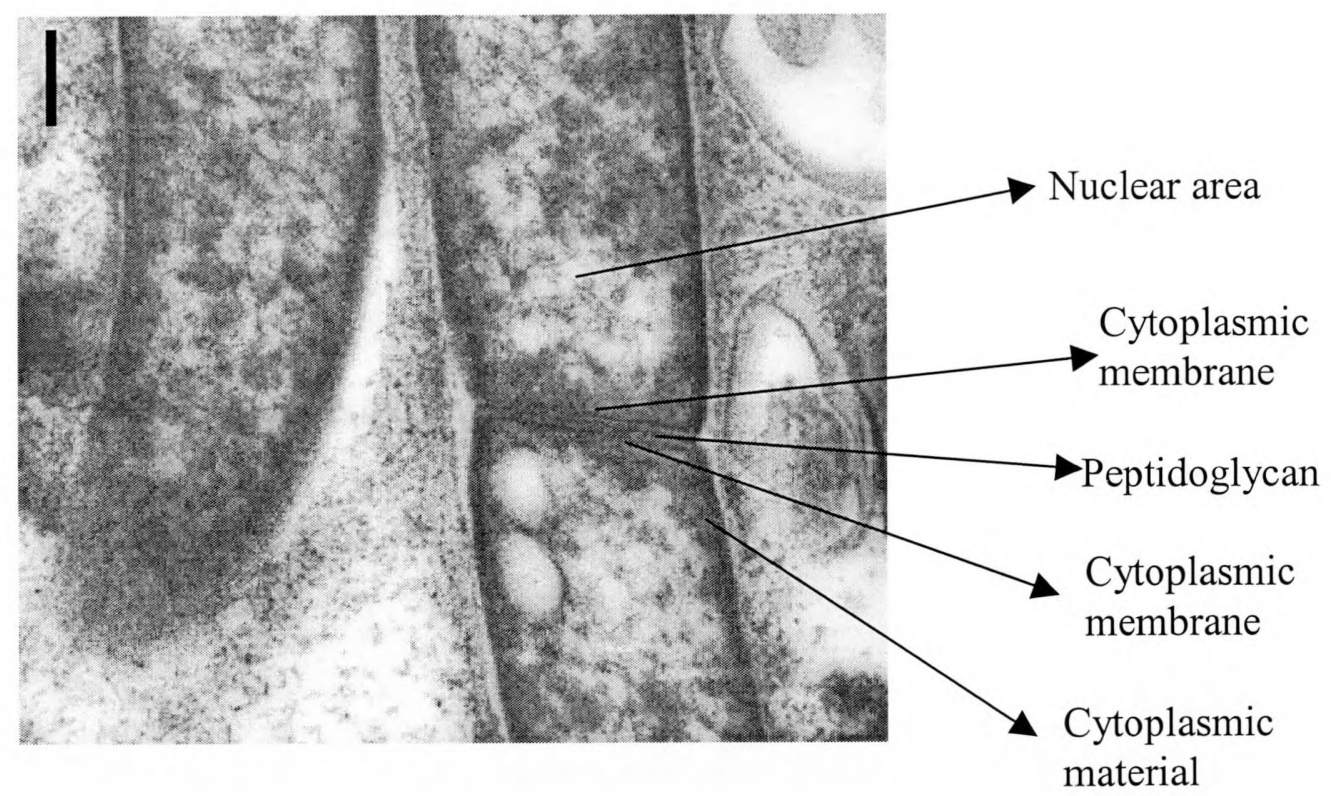

Figure 7.9 Transmission electron micrograph showing cell division of rod shape morphotype with cell wall in between cytoplasm of granule. DNA area is visible within the cell $(\mathrm{Bar}=100 \mathrm{~nm})$. 


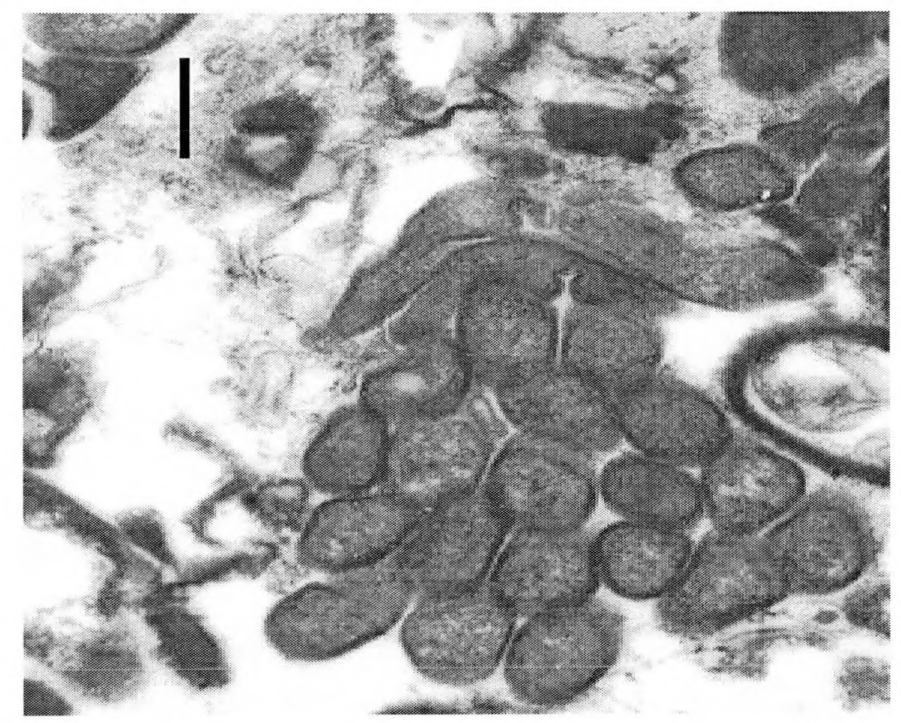

Figure 7.10 Cluster of coccoid cells or transverse section of a bundle or rod shape bacteria in granular biomass $($ Bar $=200 \mathrm{~nm})$.

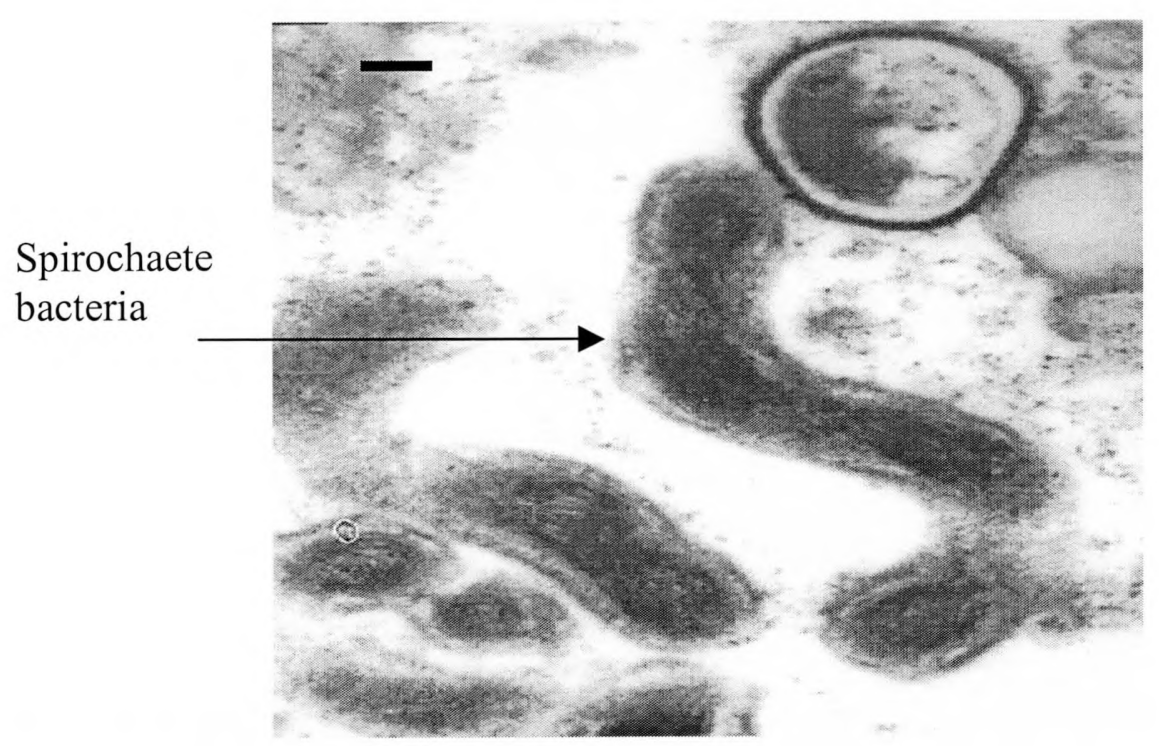

Figure 7.11 Electron micrograph revealing structure resembling with spirochaete bacteria in granular consortium $($ Bar $=50 \mathrm{~nm})$. 


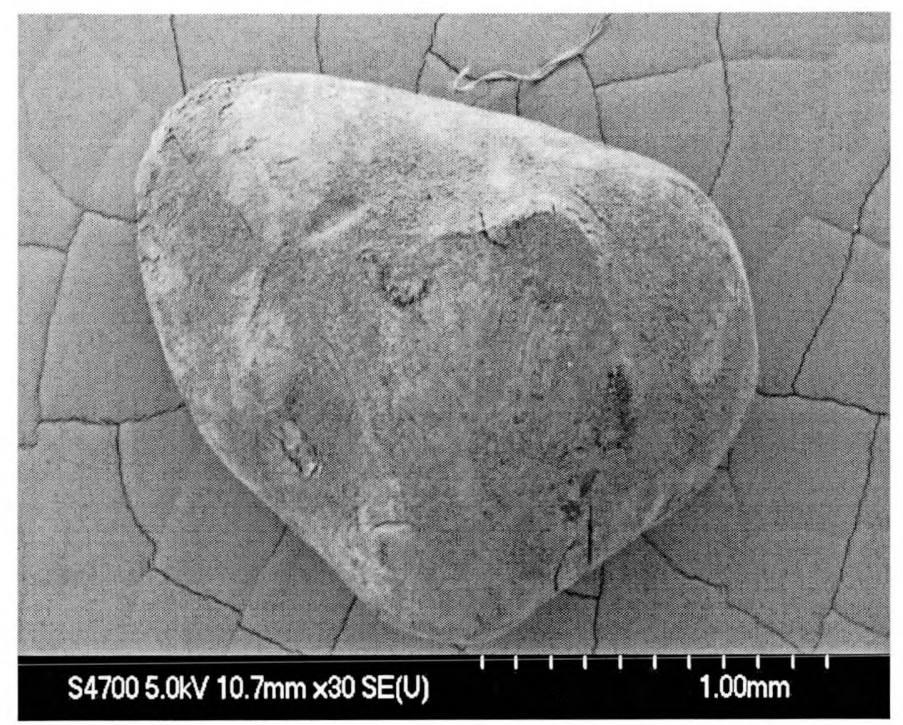

Figure 7.12 (a) Image showing the granule from methanogenic dominant zone of granular bed baffled reactor. As evident from above electron micrograph, the observed samples from this zone mainly revealed densely packed structure with smooth regular surface.

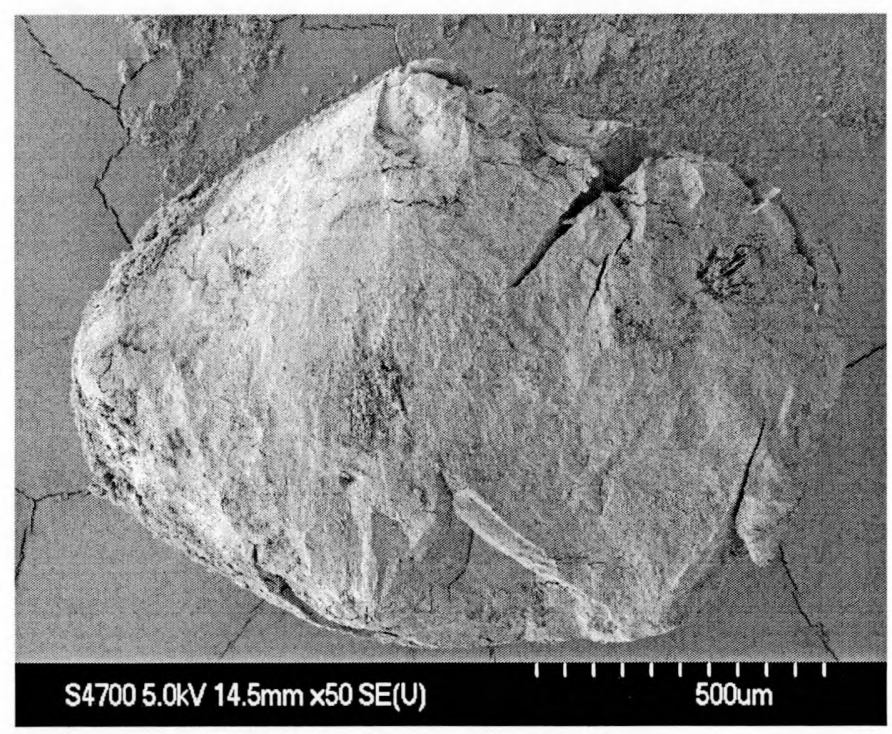

Figure 7.12 (b) Scanning electron micrograph showing the granule from acidogenic dominant zone of granular bed baffled reactor. As shown in above image, the granules from this zone contained fissures with an irregular surface morphology, caused mainly by acidogenic organisms. 


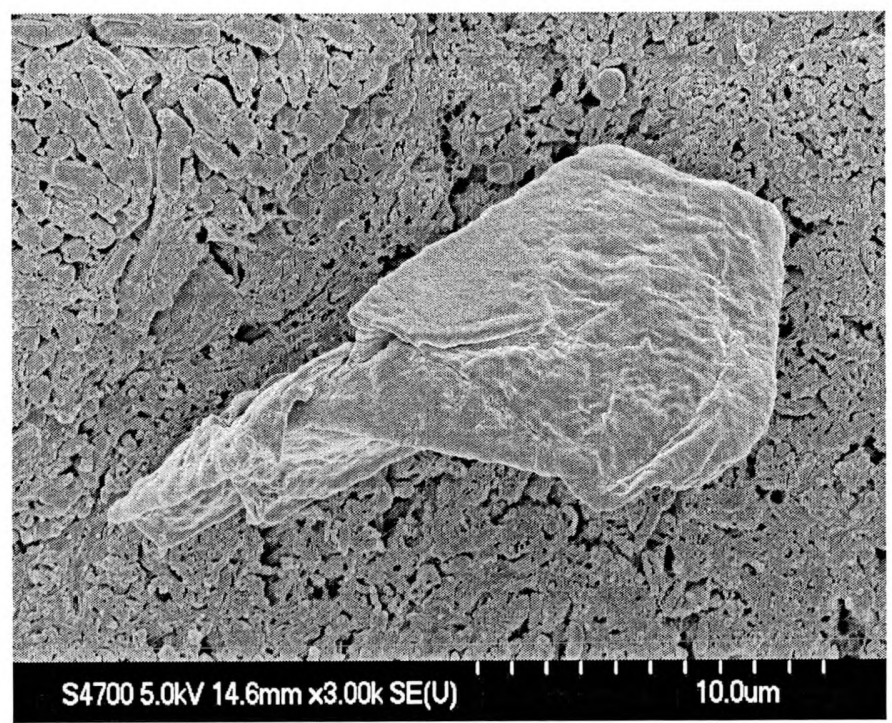

Figure 7.13 (a) Protozoa-like structure is visible on the surface of granule.

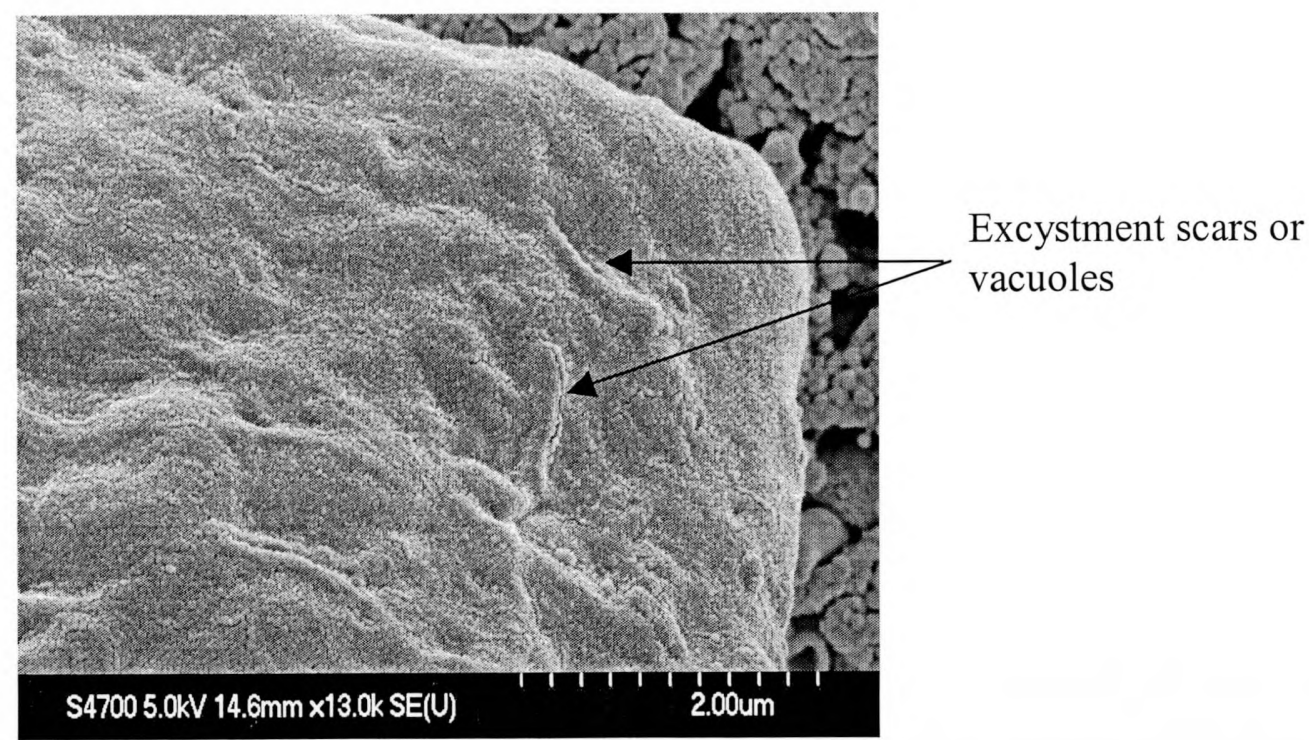

Figure 7.13 (b) High magnification of Fig. 7.13a shows openings on this specie, which could be the plausible excystment scars or vacuoles for waste removal. 


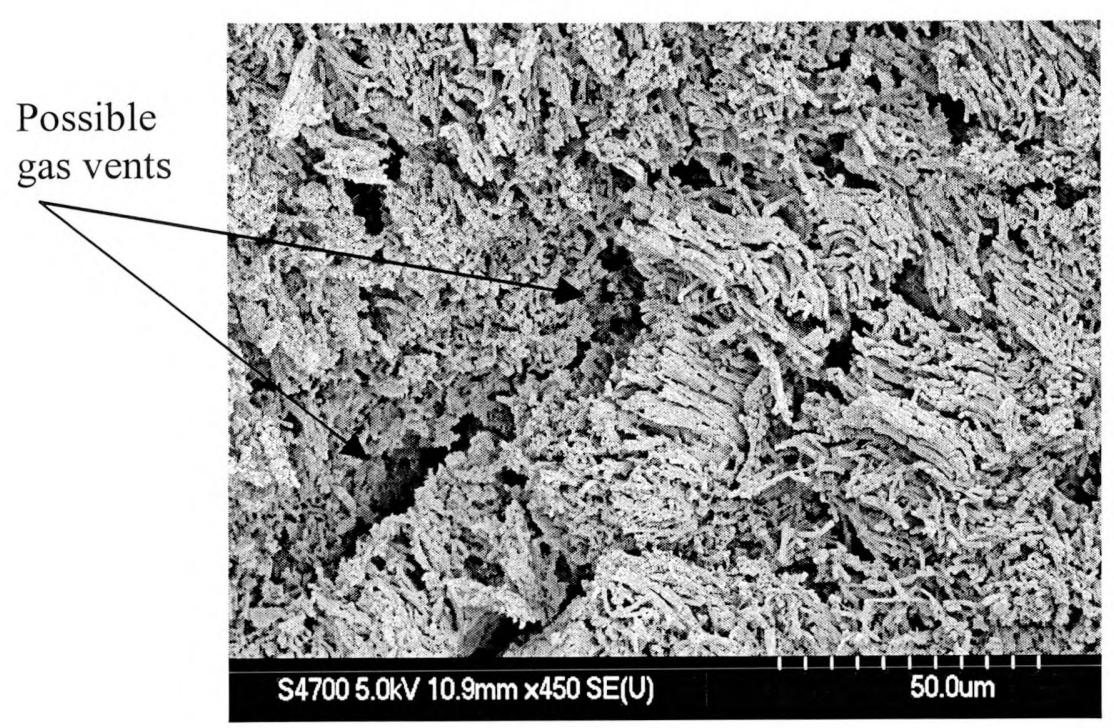

Figure 7.14 Methanogenic species are found to be dominant in the core zone of anaerobic granule. Large numbers of cavities are visible in the core of granular structure, which are believed to be the sites for possible gas vents.

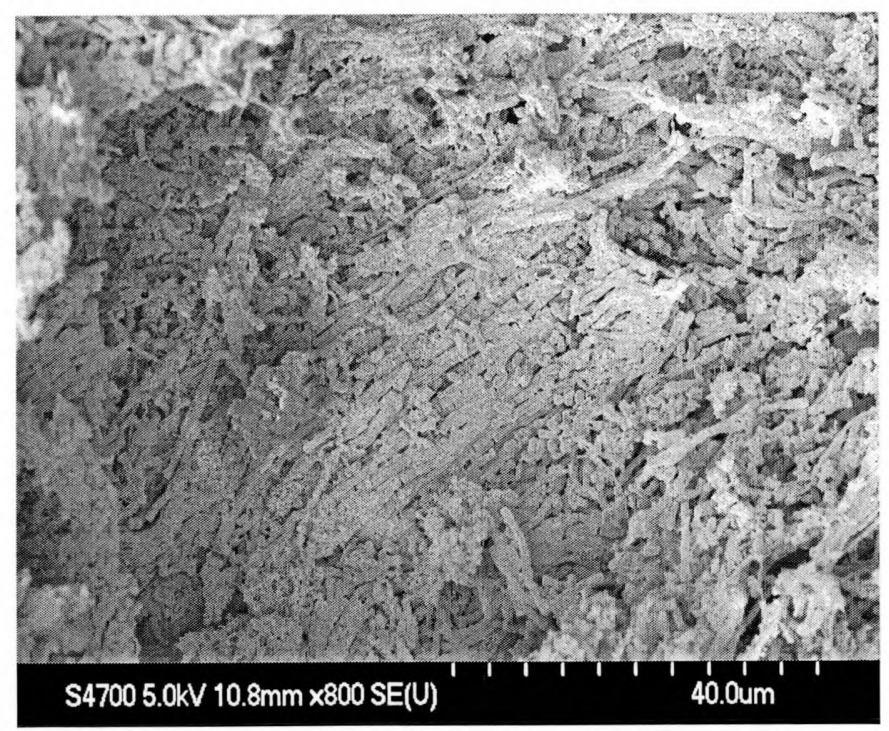

Figure 7.15 Extracellular polymeric substances were observed within the entire granule. It could be acting as a binding material between different groups of microorganisms. 


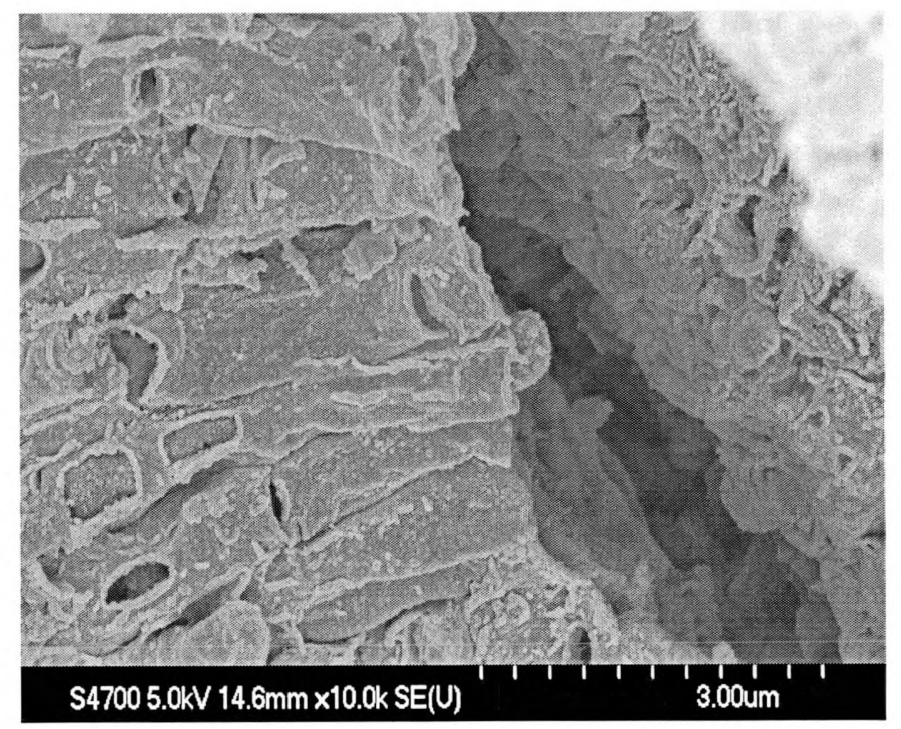

Figure 7.16 (a) Scanning electron micrograph showing bacterial cells in granule covered in extracellular polymeric substances.

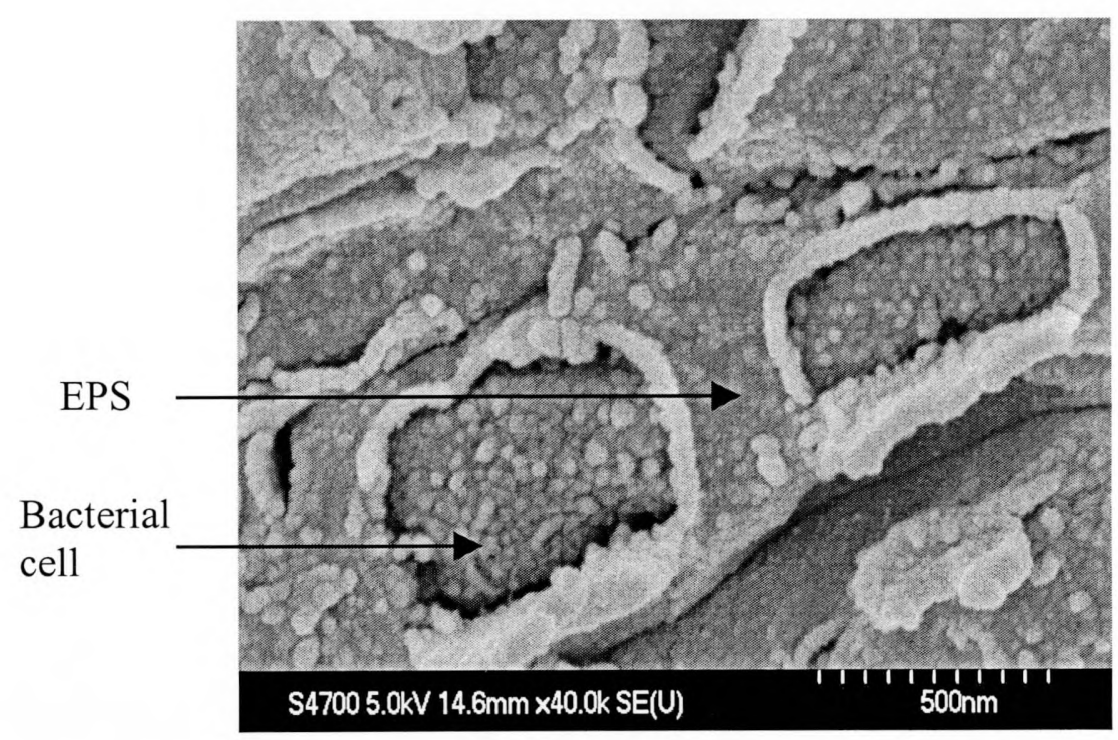

Figure 7.16 (b) High magnification of Fig. 7.16a shows extracellular polymeric substances (EPS) peeled away from the bacterial cell. 


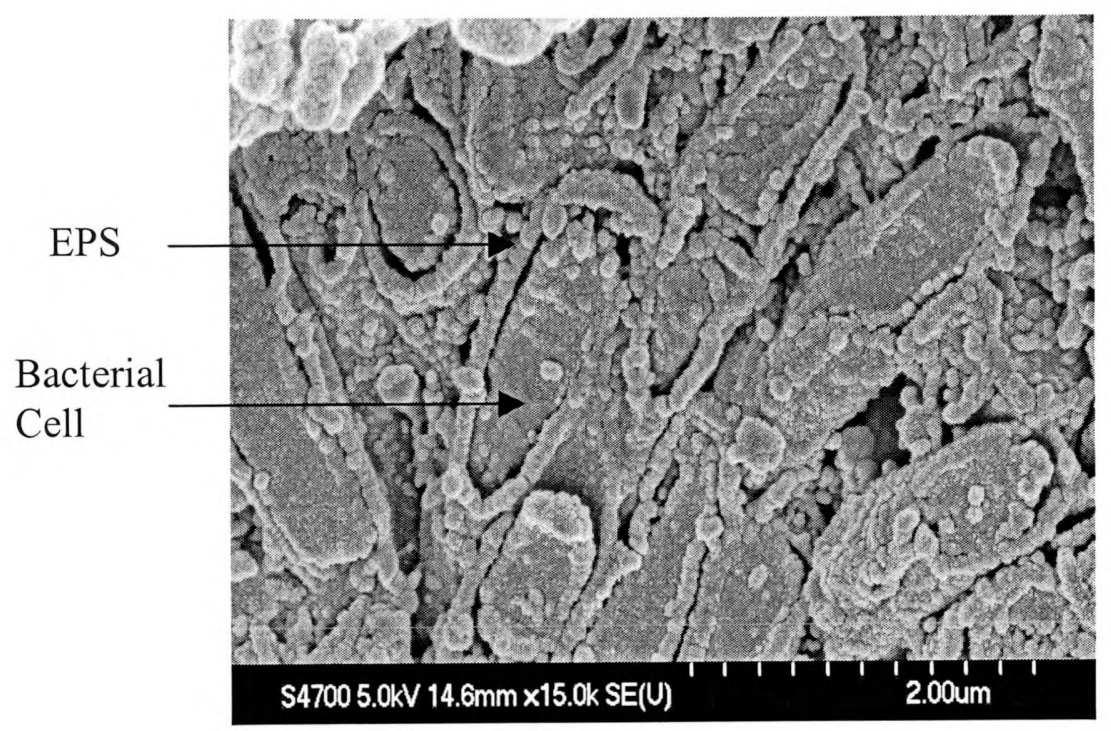

Figure 7.16 (c) Image showing arrangement of bacterial cells in granule surrounded by extracellular polymeric substances (EPS).

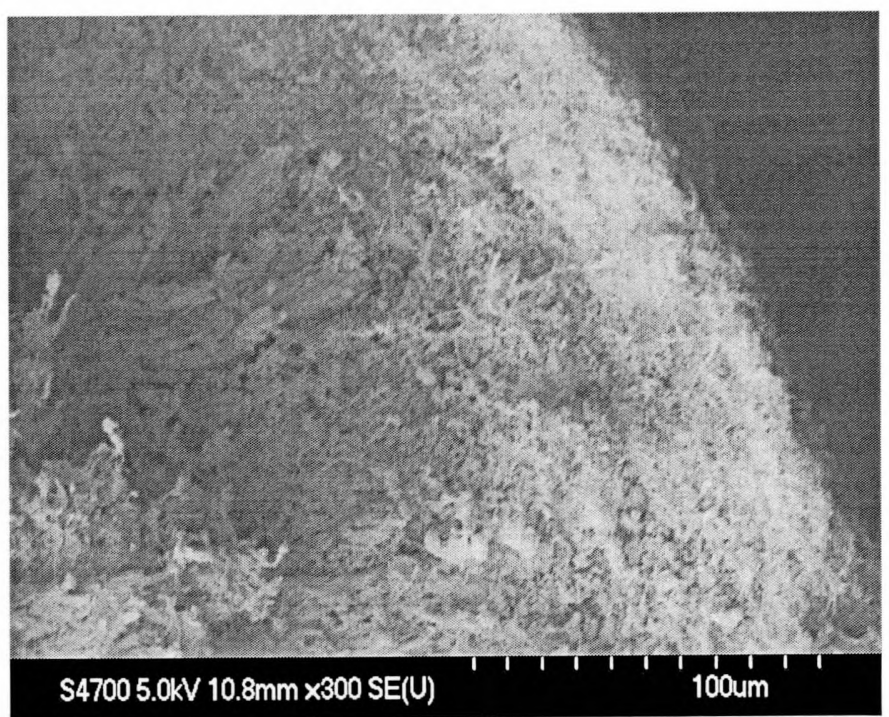

Figure 7.17 Outer zones of granule reveals large amount of extracellular polymeric substances. 


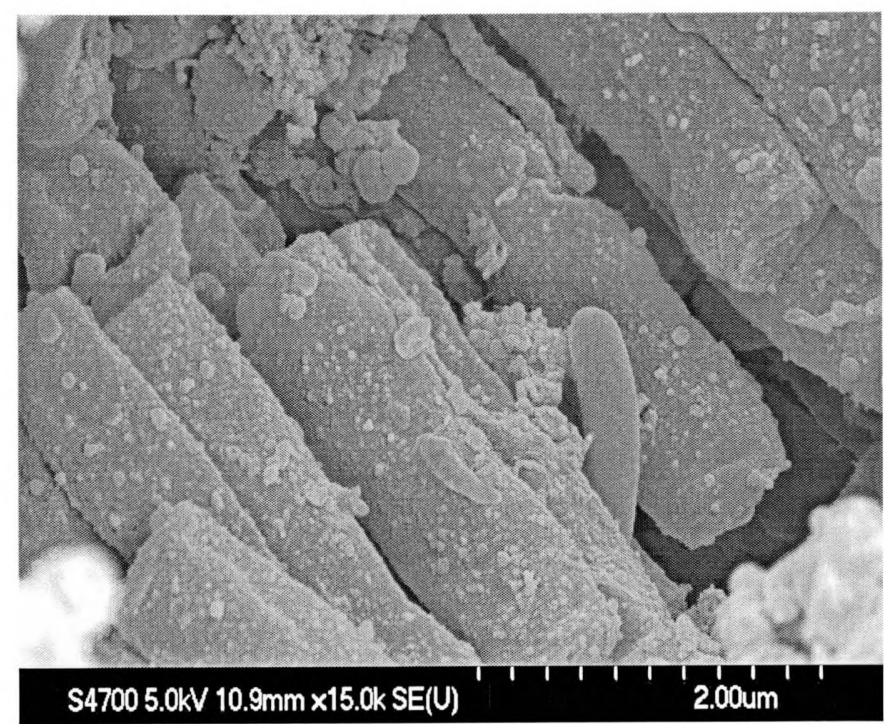

Figure 7.18 High magnification of granule showing a regular alignment of methanogen-like bacterial cells.

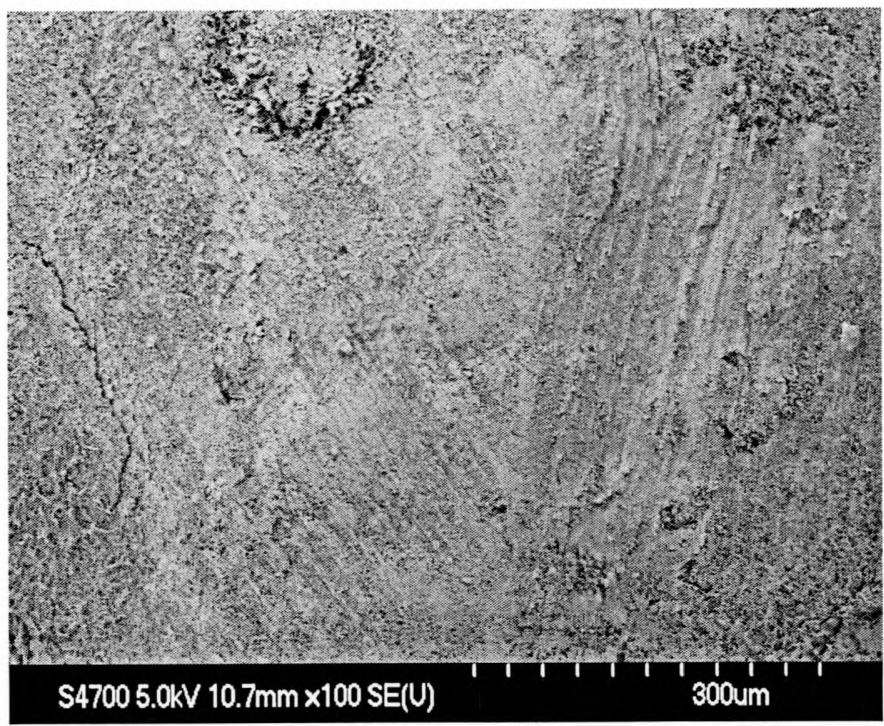

Figure 7.19 Surface of the few granules showed layering / scouring in different directions which could have formed due to the reactor hydrodynamics causing abrasions by other granules or reactor walls. 


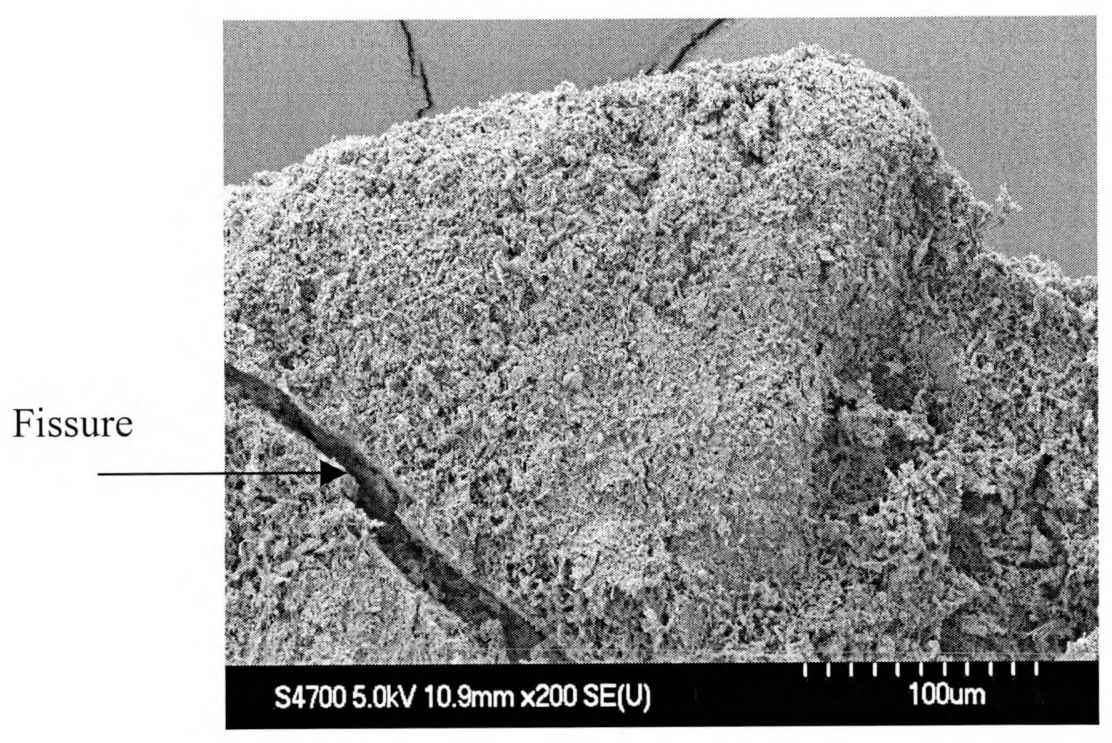

7.20a

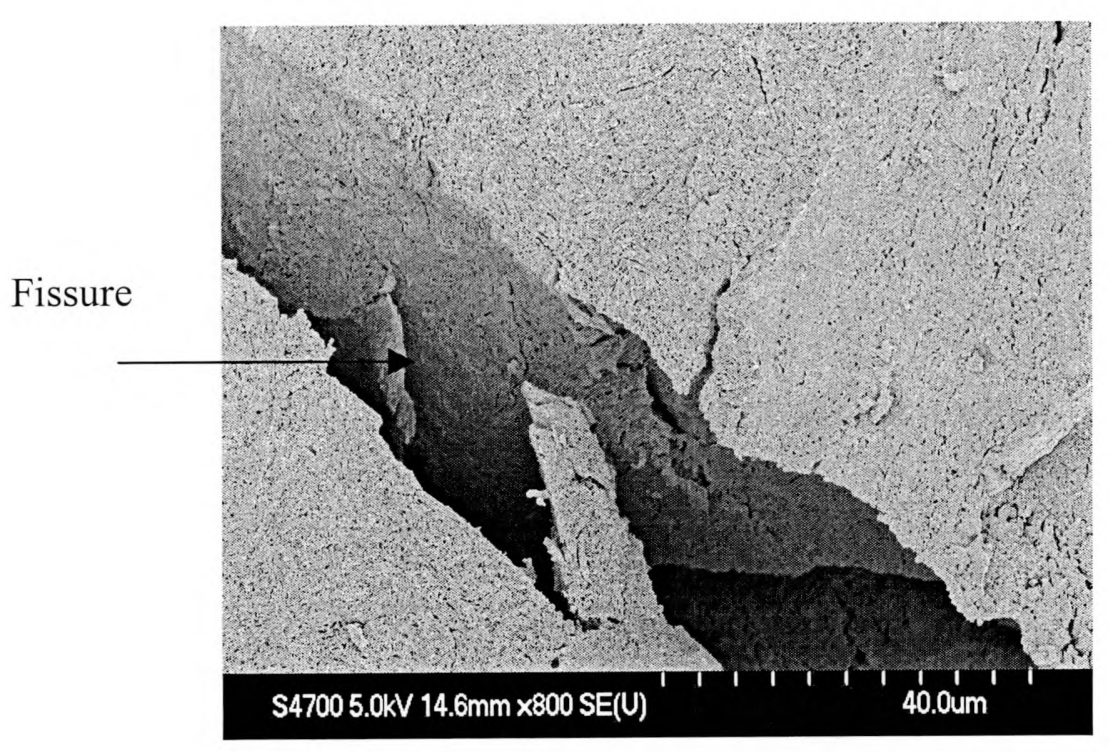

7.20b

Figures 7.20 (a \& b) Scanning electron micrographs showing large cracks on the granular structure. These possibly show the signs of granule disintegration. 


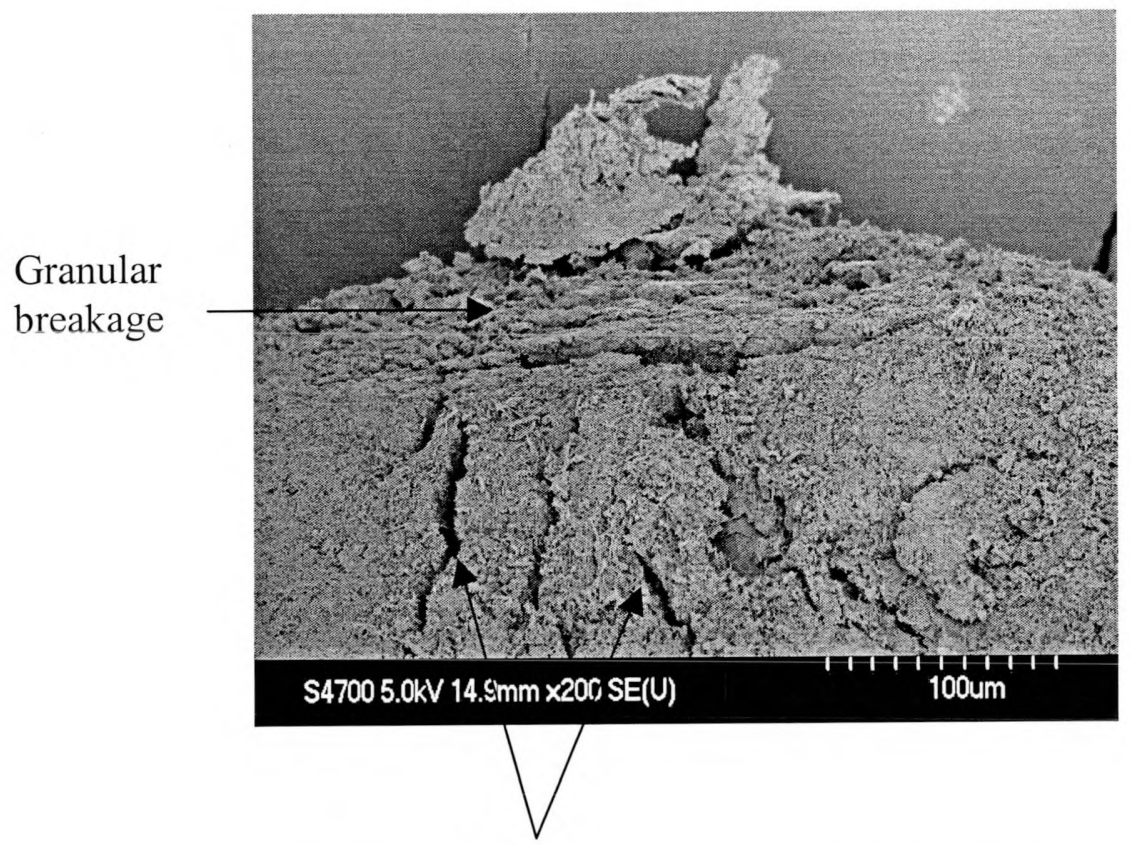

Fissures

Figure 7.20 (c) Micrograph showing the part of broken granule with fissures or excision scars after possible granular disintegration. 


\subsection{DISCUSSION}

The morphology of anaerobic granules observed in this study when compared with previous studies (Hulshoff Pol et al., 1986; Grotenhuis et al., 1991a; Arcand et al., 1994; Shen and Guiot, 1996) presents an apparent contradiction. The traditional granular shape is assumed or considered to be a sphere (Hulshoff Pol et al., 1986; Grotenhuis et al., 1991a; Arcand et al., 1994; Shen and Guiot, 1996). However, most of the granules observed in this study were ellipsoid in shape. A sphere is a figure with every point on its surface equidistant from its centre (Oxford Dictionary, 1995), which is in disagreement with the morphology observed in the majority of granules examined in this study (Figure 7.4). The particle size distribution of granular samples revealed two different dimensions along two axes, which is in contrast to the above-mentioned definition of sphere. The correlation between the size and settling velocity has been obtained by considering granules to be spherically shaped structures (Hulshoff Pol et al., 1986; Grotenhuis et al., 1991a; Batstone and Keller, 2001). Grotenhuis et al. (1991a) observed different size distributions for the same sample when calculated from an equation derived from the Galileo's number (which applies to spherical particles in intermediate regime) and an image analysis method. Batstone and Keller (2001) observed a difference of more than two-fold between the measured and theoretical settling velocity of protein grown granules determined by water column and Galileo's number respectively. Similar discrepancies were observed in the experimental and calculated velocities of granular size aggregates by assuming them as spheres (Beetfink and Heuvel, 1988). It is believed that due to the non-spherical shape of granules, an error of high magnitude was observed in these studies by using relationships applicable to spherical shape particles. This shows that proper assessment of granule morphology is fundamental before applying any derivation based upon the shape of granules. This study has shown that the adopted model expression for settling velocity or size distribution should consider the ellipsoidal shape of the granules.

Terminal settling velocities are calculated by monitoring sedimentation of granules in a water column (Hulshoff Pol et al., 1986; Batstone and Keller, 2001). However, other factors, such as the possibility of a continuous upflow velocity exerting pressure on granules and the turbulence produced in the liquid medium due to continuous gas 
production, can affect the terminal velocity of the granules in anaerobic systems. In other words, the actual settling velocity in the bioreactor may be lower than that calculated. Thus, further research is required to ascertain the influence of upflow velocity and gas production on settling characteristics.

Particle size distribution graphs showed the presence of two prominent populations of sizes along each axis. Peak values were in the range of 0.9 to $1.0 \mathrm{~mm}$ (larger population) and 1.4 to $1.5 \mathrm{~mm}$ (smaller population) along the long axis. The distribution curve along the short axis revealed larger and smaller populations in the range of 0.7 to $0.8 \mathrm{~mm}$ and 1.0 to $1.1 \mathrm{~mm}$ respectively. The presence of two populations along both axes is the reason the curves do not follow a normal distribution. Furthermore, particle size distribution curves along both axes (Figures 7.2 and 7.3) show that most of the aggregates tend to have smaller sizes, revealing their role in maintaining the stability and balance in the reactor system, as illustrated by other researchers (Beetfink and Staugaard, 1986; Yan and Tay, 1997). It can be predicted from the size distribution curves along both axes that there was a dynamic equilibrium between growth and disintegration of seed granules in the UASB system. Disintegration may be attributed to the reactor operational and microbial environment, which supports a particular size range of granules.

Viruses and protozoa-like structures were observed in the granular sludge. The occurrence of these organisms has been previously reported in biofilms and wastewater sludges (Schwartzbrod and Mathieu, 1986; Quignon et al., 1997; Brown et al., 1998). Protozoa are the consumers of bacteria and their observation on the surface layer of a granule is believed to play a vital role in controlling the growth of bacterial cells in this zone. The presence of viruses could be responsible for destroying cells and weakening the internal structure of the granules. The observation of viruses in anaerobic granular sludge is not surprising as sludges from mesophilic anaerobic digestion processes contain a viable amount of viruses (Bertucci et al., 1977; Carrington et al., 1991).

The electron micrographs revealed that microbial populations in granular consortia behaved differently under different substrate conditions. A deficient bacteriological structure of the granules from the acidogenic dominant zone (Figures $7.5 \mathrm{~b}$ and $7.12 \mathrm{~b}$ ) was probably due to the presence of a high amount of un-acidified substrate present in 
this zone. This tends to suggest that conditions in the acidogenic dominant zone of the GRABBR were unfavourable for microorganisms within granules to maintain stable structure. However, the granules maintained compact and dense structure in the methanogenic dominant zone (Figures $7.5 \mathrm{a}$ and $7.12 \mathrm{a}$ ), which was mainly receiving acidified substrate.

The images of granules from the acidogenic dominant zone revealed fissures, broken surfaces and relatively fewer bacterial species within the structure (Figures $7.5 \mathrm{~b}$ and 7.12b) when compared with the methanogenic dominant zone samples. This could be due to the result of a fermentation process in this zone, an environment suitable for facultative microorganisms. This condition might have encouraged granular outer-zone species, mainly facultative organisms, to leave granular consortia, thus leaving insufficient protection for the core zone strict anaerobic microorganisms (mainly methanogens) to survive, and ultimately breakage of granules in this zone. It appears that methanogenic populations (anaerobic microorganisms) in the core of the granular sludge are protected by the less oxygen-sensitive facultative organisms predominantly in the outer zones. An other cause of granule disintegration, as described above, could be the presence of some species, like viruses. Moreover, the natural process of granular growth up to a certain size range and its disintegration, depending upon the operational and environmental conditions, could also cause granule breaking. It is believed that in the acidogenic dominant zone, fermentative activities would be most likely responsible for granule disintegration. While the natural process of disintegration and the presence of bacteriophage would most probably represent the disintegration process of granular consortia in other zones of an anaerobic system. On the basis of this explanation, a schematic diagram of granular disintegration in the acidogenic dominant zone of stage anaerobic system with carbohydrate feed is shown in Figure 7.21. The micrographs of cracked and broken granules (Figure 7.20) might possibly represent stages in the disintegration process of granular consortia occurring via one of the above process. 


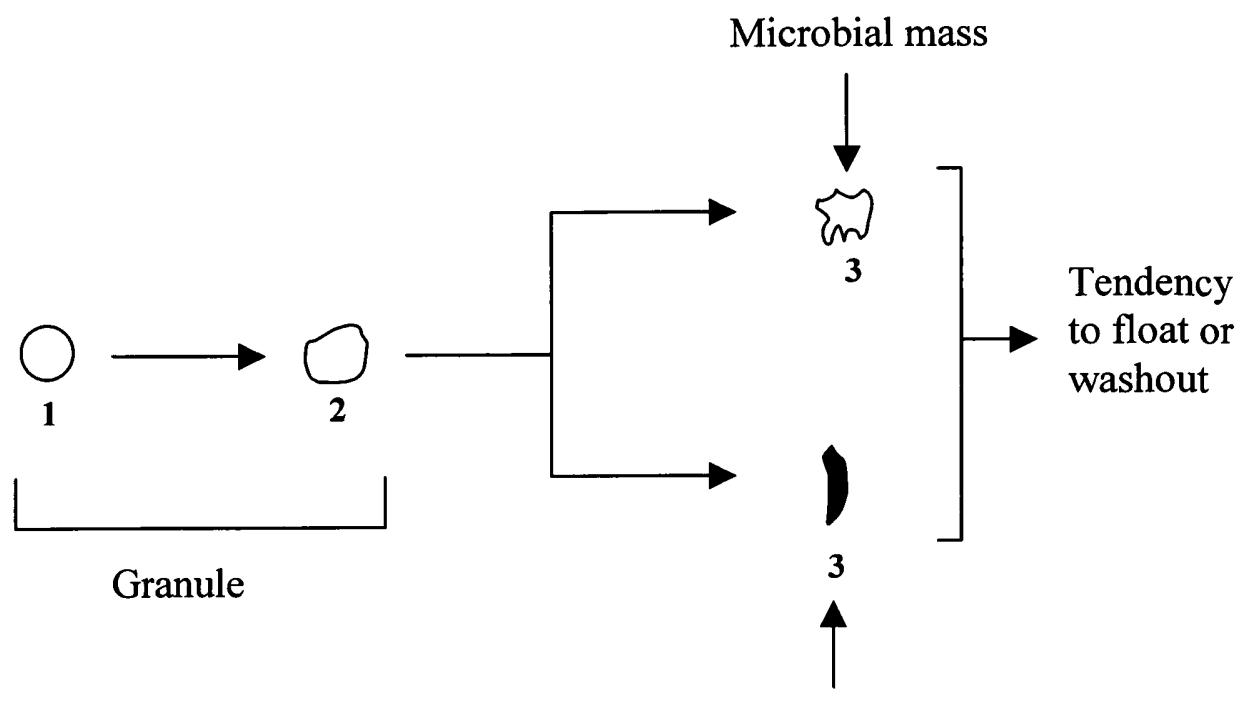

Debris of broken granule

Figure 7.21 Schematic diagram of possible granule breaking in the acidogenic dominant environment of stage anaerobic reactor. (1) Granular sludge present as inoculum. (2) Un-acidified substrate in the acidogenic dominant zone of the system may favour the environment for granular organisms to lose their structure due to increased acidogenic activities. (3) Ultimately, disintegration of granular consortium into sheath like debris of granule combined with the formation of new microbial mass, which might be washed out from the reactor due to their non-granular nature and light dense structure.

The granules examined in this study exhibited a considerable diversity of microorganisms. Electron microscopy observations showed mixed populations of various sizes with rods, cocci and filament-like species in the samples. Changes in the environmental ecosystem of granules from a completely mixed unit (UASB reactor) to a phase separation unit (GRABBR), brought about changes to the granules in the acidogenic dominant zone. More than three microbial zones were apparent in the granular consortia (Figure 7.5), demonstrating that the anaerobic granules have a more complex structure and bacteriology than previously reported by other researchers (Macleod et al., 1990; Fang et al., 1994). It is believed that the substrate (paper mill wastewater) on which granules were originally grown have contributed to such a layered structure. The dominance of Methanothrix-like microorganisms in the centre core is an indication of this species role in granule formation. A large number of Methanothrix-like populations have also been observed in the core zone of anaerobic 
granules by other researchers (Macleod et al., 1990; Fang et al., 1994). Methanogenlike species in the granular consortia consisted of a large number of cavities, which could be the possible gas vents for methane production (Figure 7.14), as also observed by other writers (Bochem et al., 1982; Macleod et al., 1990). The presence of a large amount of EPS in the observed samples may be the product of the consortium of microorganisms present in the granular structure. They are believed to be the means for maintenance of the compact internal structure of the granules, as also reported by other authors (Ross, 1984; Macleod et al., 1990).

\subsection{CONCLUSIONS}

This study revealed the morphology of granules as ellipsoid. This was evident by microscopic images and two axes size distribution. Discrepancies in the determination of granular parameters in the previous studies could be attributed to the wrong assumption that granules are spheres. Hence, proper evaluation of the granular morphology should be made before determining any physical property using shape dependent empirical relationships. The granular structure was found to possess a more complex bacteriology than previously reported, with more than three apparent zones. A vast diversity of microorganisms was observed in the granular consortia attached closely together by EPS, with Methanothrix-like species dominant in the core. Viruses were also observed, which could be the causal agents for the breaking of granules. Granular consortia were found to lose their structure and microbial populations in the acidogenic dominant zone of the GRABBR, mainly due to high fermentative activities in this zone, encouraging facultative microorganisms of granules to leave the structure. The biofilm structures were preserved in other zone(s), where they received mainly acidified substrate, causing their disintegration either by natural disintegration process or bacteriophage. 


\section{CHAPTER 8}

\section{COMBINED INTEGRATED SYSTEM FOR BREWERY WASTEWATER TREATMENT}

This chapter elucidates the practical application of the granular bed baffled reactor with industrial (brewery) wastewater for carbon and nitrogen removal with two-stage anaerobic-aerobic configuration.

\subsection{INTRODUCTION}

With the implementation of various European Union (EU) Directives relating to wastewater treatment and disposal, reliable and cost effective systems are required for treating high strength wastewaters in order to comply with these stringent standards. In the United Kingdom, the water companies treat most of the high strength industrial effluents in the municipal sewage works by aerobic processes. The water companies charge the industrial sector for discharging wastewater into the sewerage system by using the Mogden Formula (Ofwat, 2003). This formula calculates the unit charge (pence) per $\mathrm{m}^{3}$ of wastewater on the basis of effluent volume and pollutant load. Thus the amount payable by a specific industrial sector on their effluent discharge will depend on the pre-treatment the effluent receives prior to its discharge into the sewerage system. Due to the high organic strength of some industrial wastewaters, e.g. food / beverage and agriculture processing effluents, an industry may end up paying a high disposal cost to the water company, which in turn needs to meet consent conditions imposed on their discharges to controlled waters set by the local environment agency. Furthermore, water authorities can also put restrictions on discharge of an industrial effluent into the local sewage works in order to meet water quality standards of the regulating body. 
The application of anaerobic systems has flourished in the last two decades for the treatment of effluents from food and beverage processing wastewaters, pulp and paper, and the chemical sector (Frankin, 2001). This is mainly due to the ease with which these effluents are adapted to anaerobic microorganisms. Among these industrial applications, food and beverage processing plants produce large volumes of wastes, which if not treated, potentially cause severe pollution to the receiving waters. These wastewaters generally have high organic strength (chemical oxygen demand, COD and biochemical oxygen demand, BOD), high solids content and are sometimes rich in nutrient content (organic/ammoniacal nitrogen and phosphorus). Complete treatment of this type of wastewater in a sewage treatment plant by water companies could be expensive for heavy industrial polluters on the long term.

In order to achieve discharge standards for direct discharge into a water body, anaerobic technology alone may not meet the desired effluent quality. A combined anaerobic/aerobic two-stage treatment process is considered as the most economical solution for complete organic carbon removal from high strength industrial wastewaters. The bulk of organic matter will be removed in the anaerobic system and the remaining carbon will be removed in the aeration unit, but with a minimal aeration cost. However, if the industrial effluent is also rich in nitrogenous compounds, only a small portion of organic nitrogen will be converted to ammonium for cell synthesis during anaerobic treatment, and the remaining ammonium in the effluent of anaerobic process can be nitrified in the subsequent aerobic unit. However, this nitrified ammonium (in the form of nitrate) requires a denitrification unit and external carbon source for complete nitrogen removal, as effluent from an aerobic unit will probably contain insufficient amount of carbon to achieve complete denitrification. Integration of denitrification and methanogenesis in a single reactor has been reported as an alternative method to the conventional treatment concept of anaerobic carbon removal followed by nitrificationdenitrification processes for nitrogen removal (Kuroda et al., 1988; Hanaki and Polprasert, 1989; Akunna et al., 1992 \& 1994b; Lin and Chen, 1995; Hendriksen and Ahring, 1996a; Bernet et al., 2000). This has been discussed in detail in Chapter 5.

Breweries are large industrial consumers of water as well as producers of wastewater. Due to the high biodegradability and varying nature of brewery waste, anaerobic processes have been widely used for their effluent treatment (Frankin, 2001). This 
industrial sector has also been specifically mentioned in the EU Directive for the control of their effluent discharge (European Union Council of Ministers - European Urban Waste Water Treatment Directive 91/271/EEC, 1991).

The studies reported in Chapters 3, 4 and 5 with synthetic medium showed the novel aspects of a granular bed baffled reactor (GRABBR). These studies have shown the capabilities of a GRABBR for removing carbonaceous and nitrogenous pollution. The study reported in this Chapter was designed to use a GRABBR for treating natural industrial wastewaters. The aim of this study was two-fold:

- To investigate the effectiveness of a GRABBR with brewery wastewater in terms of treatment efficiency at varying operational conditions.

- To examine the feasibility of a GRABBR for two-stage anaerobic-aerobic configuration for both organic carbon and nitrogen removal from the brewery wastewater at various influent to nitrate recycling ratios from nitrification unit.

\subsection{MATERIALS AND METHODS}

\subsubsection{Nitrification Unit}

The nitrification unit was a 10 litre perspex-made cylindrical unit. The seed for the nitrification unit was obtained from an activated sludge treatment plant treating domestic sewage from Kerrimuir. The nitrification unit was operated at room temperature $\left(18\right.$ to $\left.22^{\circ} \mathrm{C}\right)$. The aeration in the nitrification unit was provided by using air module pump device (LH Fermentation Ltd., Slough UK), with aeration range of 0 to $2.51 \mathrm{~min}^{-1}$. The aeration rate was controlled through a knob on the aeration equipment. Continuous mixing was provided with stirrer in the nitrification unit. The two-stage complete experimental set-up is shown in Figure 8.1.

\subsubsection{Experimental Design}

The GRABBR was started with an organic loading rate (OLR) of $2.16 \mathrm{~kg} \mathrm{COD} \mathrm{m}^{-3} \mathrm{~d}^{-1}$, corresponding to a hydraulic retention time (HRT) of $55.5 \mathrm{hrs}$. Loading rates were 
increased to $3.36,5$ and $13.38 \mathrm{~kg} \mathrm{COD} \mathrm{m}^{-3} \mathrm{~d}^{-1}$, corresponding to HRTs of $36 \mathrm{hrs}, 22 \mathrm{hrs}$ and $19.23 \mathrm{hrs}$ respectively. The influent COD was maintained at about $5000 \mathrm{mg}^{-1}$ up to a loading rate of $5 \mathrm{~kg} \mathrm{COD} \mathrm{m}^{-3} \mathrm{~d}^{-1}$, thereafter increases in OLR from 5 to $13.38 \mathrm{~kg} \mathrm{COD}$ $\mathrm{m}^{-3} \mathrm{~d}^{-1}$ were mainly achieved by increasing the feed concentration to a COD of 10720 $\mathrm{mg} \mathrm{l^{-1 }}$.

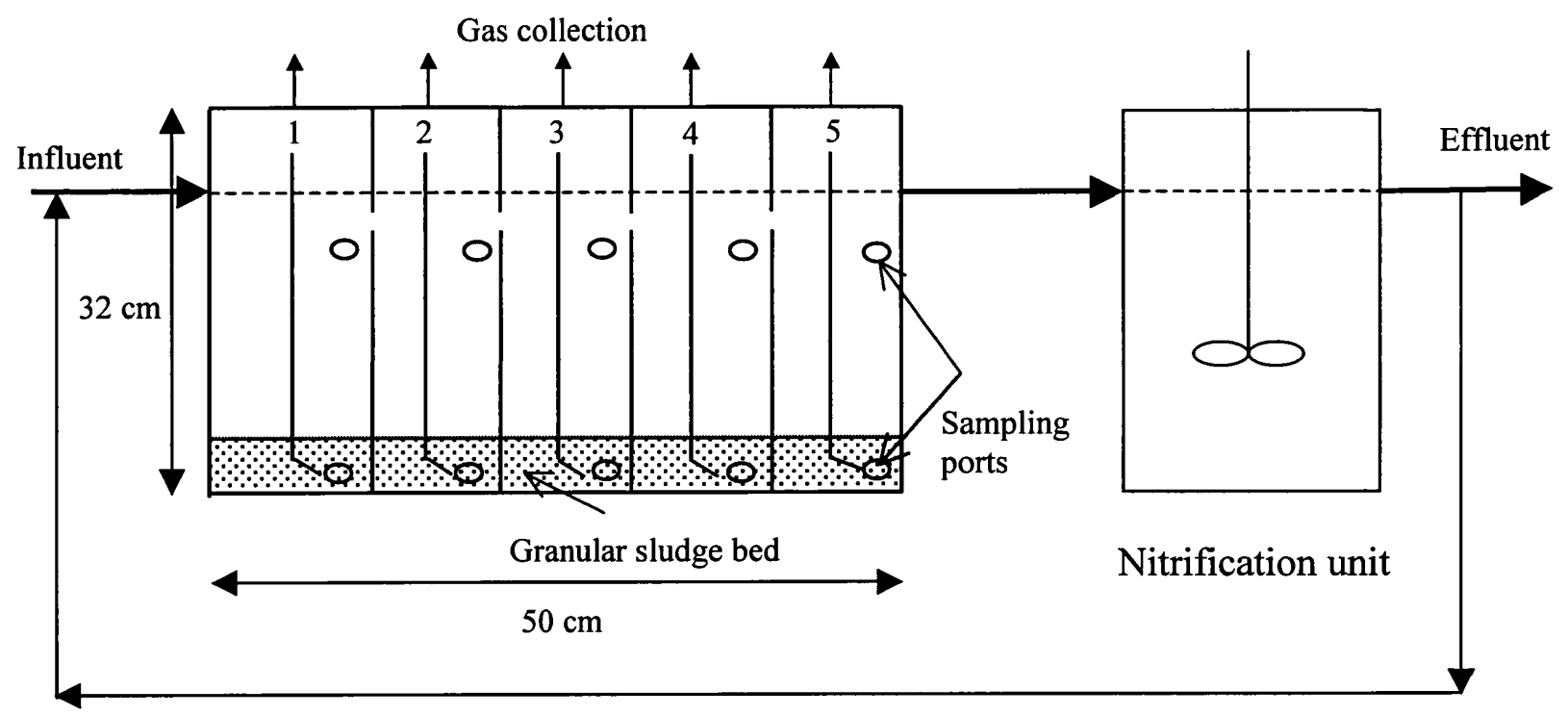

Nitrified effluent recirculation

Figure 8.1 Schematic diagram of combined carbon and nitrogen removal in granular bed baffled reactor with downstream aerobic (nitrification) unit.

Before commencing the combined carbon and nitrogen removal study (anaerobicaerobic configuration), the HRT of the GRABBR was adjusted to $72 \mathrm{hrs}$ when the feed COD concentration was $10720 \mathrm{mg} \mathrm{l}^{-1}$. The ammoniacal nitrogen $\left(\mathrm{NH}_{4}-\mathrm{N}\right)$ loading rate and OLR of the GRABBR were $0.13 \mathrm{~kg} \mathrm{NH}_{4} \mathrm{~m}^{-3} \mathrm{~d}^{-1}$ and $3.57 \mathrm{~kg} \mathrm{COD} \mathrm{m}^{-3} \mathrm{~d}^{-1}$ respectively. Long HRT was applied to obtain stable nitrification performances at different recycling ratios. Once steady state conditions were achieved, the aerobic unit was connected with the effluent of the GRABBR to produce a nitrified effluent from ammonia. This was achieved by aerating the anaerobically pre-treated effluent for a period of time to oxidise ammonia in the aerobic unit. The effluent from the aerobic unit was not recycled until full nitrification was achieved. Three recycling ratios of influent to nitrified effluent were studied, viz. 1:1, 1:1.5 and 1:2. The nitrified effluent from the aerobic unit was added to the stream of the GRABBR influent just before the point of 
entrance to the first compartment by using a peristaltic pump. The choice of this point for nitrate addition followed the results of previous studies (reported in Chapter 5), where it was concluded that denitrification in the upstream compartments (acidogenic dominant zone) of the GRABBR would bring about greater stability for simultaneous denitrification and methanogenesis. The flow conditions of this study are shown in Table 8.1. No $\mathrm{pH}$ correction was applied in this study.

Table 8.1 Flow conditions for integrated system (granular bed baffled reactor and nitrification unit) for brewery wastewater treatment.

\begin{tabular}{lcccc}
\hline Parameter & \multicolumn{4}{c}{ Influent to nitrate recycling ratios } \\
\cline { 2 - 5 } & $1: 0$ & $1: 1$ & $1: 1.5$ & $1: 2$ \\
\hline Nitrified effluent $\left(\mathrm{l} \mathrm{d}^{-1}\right)$ & 0 & 3.33 & 5 & 6.66 \\
$\mathrm{GRABBR}^{\mathrm{a}}$ feed $\left(\mathrm{l} \mathrm{d}^{-1}\right)$ & 3.33 & 6.66 & 8.33 & 10 \\
$\mathrm{HRT}^{\mathrm{b}}(\mathrm{hrs})$ & 72 & 36 & 30 & 24 \\
\hline
\end{tabular}

${ }^{\mathrm{a}}$ Granular bed baffled reactor

${ }^{\mathrm{b}}$ Hydraulic retention time

\subsection{RESULTS AND DISCUSSION}

This section is divided into two parts. The first part reports the performance of the reactor with brewery wastewater prior to nitrogen removal. The second study reports the integrated system for nitrogen and carbon removal with the GRABBR and nitrification unit.

\subsubsection{Reactor Performance Prior to Nitrogen Removal}

The reactor achieved a COD removal of $93 \%$ to $96 \%$ during all applied OLRs, at steady state conditions, as shown in Figure 8.2. The first compartment COD removals were $43 \%, 27 \%$ and $30 \%$ at OLRs of $2.16,3.36$ and $5 \mathrm{~kg} \mathrm{COD} \mathrm{m}^{-3} \mathrm{~d}^{-1}$ respectively, with an effluent COD removal of over 95\%. At steady state conditions, the first three compartments removed COD of $94 \%$ to $96 \%$ at OLRs of 2.16 to $5 \mathrm{~kg} \mathrm{COD} \mathrm{m}^{-3} \mathrm{~d}^{-1}$, hence necessitating only three compartments for complete treatment. An increase in OLR from 5 to $13.38 \mathrm{~kg} \mathrm{COD} \mathrm{m}^{-3} \mathrm{~d}^{-1}$ was mainly achieved by increasing the feed COD concentration, which brought about a wider spread of COD profile to the compartments 
of the GRABBR. This increase in OLR created noticeable phase separation between different microorganisms, mainly acidogenesis and methanogenesis, along the length of the reactor, involving all the compartments in different microbial activities. Phase separation between acidogenesis and methanogenesis provided optimum growth conditions for fast-growing acid producing bacteria and the slow-growing methanogenic population. This condition was favourable for improving reactor performance and stability. Increasing the organic and hydraulic loading rates led to a decrease in the methanogenic zone, due to an extension of the acidogenic activities in the upstream compartments of the system, an observation also reported in Chapters 3 and 4.

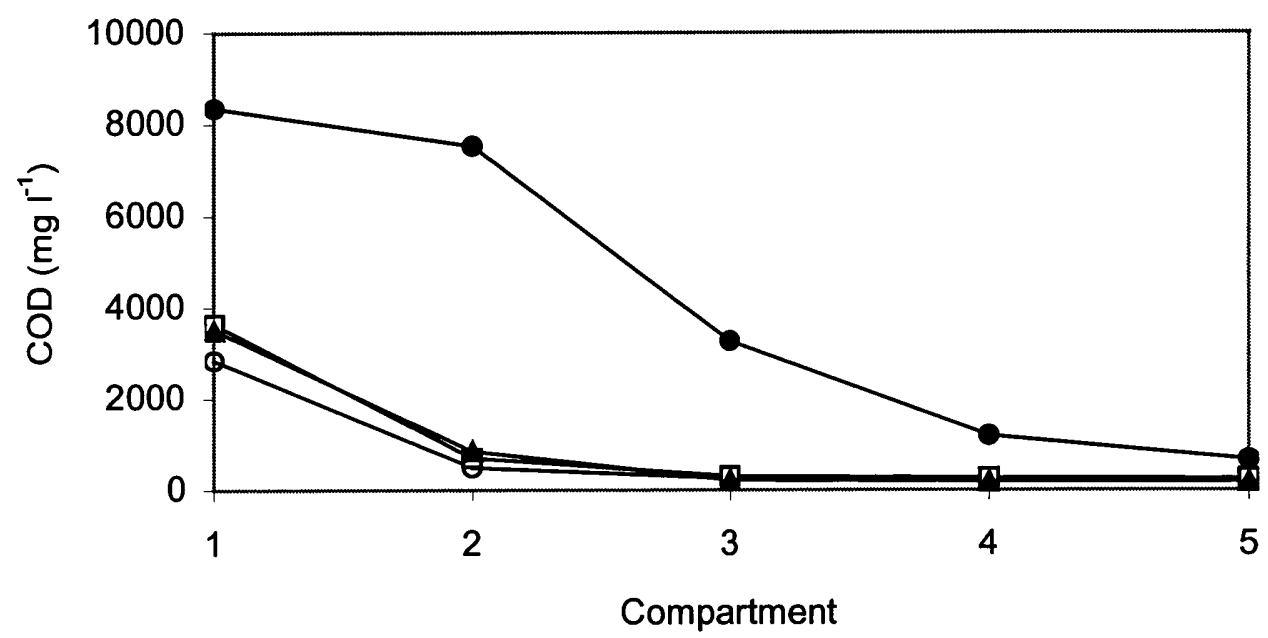

Figure 8.2 Chemical oxygen demand (COD) concentrations in each compartment of granular bed baffled reactor at different organic loading rates: (O) $13.38 \mathrm{~kg} \mathrm{COD} \mathrm{m}^{-3} \mathrm{~d}^{-}$ ${ }^{1}$, (A) $5 \mathrm{~kg} \mathrm{COD} \mathrm{m}^{-3} \mathrm{~d}^{-1}$, () $3.36 \mathrm{~kg} \mathrm{COD} \mathrm{m}^{-3} \mathrm{~d}^{-1}$, (O) $2.16 \mathrm{~kg} \mathrm{COD} \mathrm{m}^{-3} \mathrm{~d}^{-1}$.

The volatile fatty acid (VFA) profile in the first compartment at an OLR of 3.36 and 5 $\mathrm{kg} \mathrm{COD} \mathrm{m} \mathrm{m}^{-1}$ is shown in Figure 8.3. It seems from these results (Figure 8.3), and the synthetic wastewater study (Chapters 3 and 4), that a GRABBR type configuration enhances butyrate production over propionate, particularly at high loads (Chapters 3 and 4). Acetate and butyrate are considered as optimal fermentation products for the methanogenic phase (Zoetemeyer et al., 1982; Ren et al., 1997; Azbar et al., 2001). Propionate is not directly subjected to methanogenesis and accumulates readily in anaerobic reactors (Bhatia et al., 1985; Tartakovsky and Guiot, 1997; Shin et al., 2001). Hence, formation of butyrate is desirable over propionate, because it is easily 
metabolised to methane. Thus, the acidogenic dominant zone of the GRABBR enhances the production of more favourable substrates for the methanogenic phase.

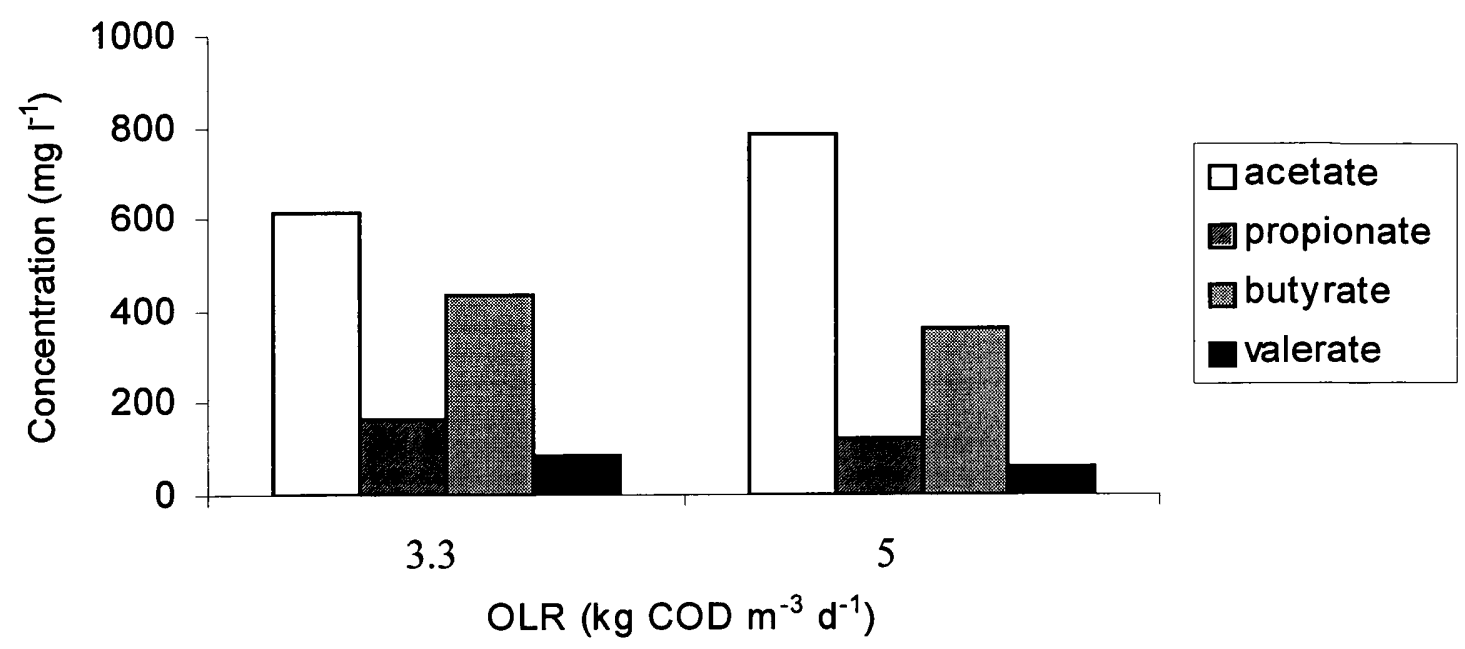

Figure 8.3 Volatile fatty acid profile in the first compartment of the granular bed baffled reactor at organic loading rate (OLR) of 3.36 and $5 \mathrm{~kg} \mathrm{COD} \mathrm{m}^{-3} \mathrm{~d}^{-1}$.

The $\mathrm{pH}$ in different compartments varied between 6.5 and 7.6 at various operational conditions. There was a general increase in the $\mathrm{pH}$ levels downstream of the reactor, similar to the results in previous studies (Chapters 3 and 4). The $\mathrm{pH}$ in the first compartment remained greater than 6.5 throughout the experimental study.

Gas production increased with increases in organic load, increasing from 16 to $62 \mathrm{ld}^{-1}$ of biogas for an OLR of 2.16 to $13.38 \mathrm{~kg} \mathrm{COD} \mathrm{m}^{-3} \mathrm{~d}^{-1}$. A graph of methane production and composition against loading rates is shown in Figure 8.4. A high methane yield was observed in this study, varying from 0.37 to $0.47 \mathrm{~m}^{3} \mathrm{CH}_{4} \mathrm{~kg}^{-1} \mathrm{COD}_{\text {removed. The }}$ reported methane yield for most of the anaerobic systems is $0.35 \mathrm{~m}^{3} \mathrm{CH}_{4} \mathrm{~kg}^{-1}$ $\mathrm{COD}_{\text {removed }}$ (Pohland, 1992). Improved gas yield in this study is believed to be due to the effectiveness of the phase separation process with granular bed. A high gas yield has also been reported in other phase separated and/or two-phase systems (Ghosh et al., 1975; Speece et al., 1997). This methane rich gas can be utilised for generating heat or electrical energy. For example, the specific biogas production from brewery wastewater

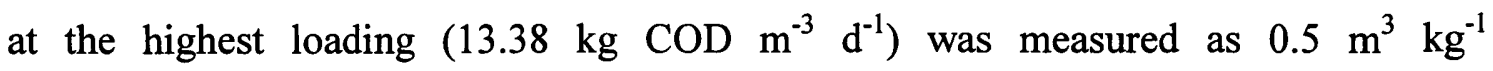
$\mathrm{COD}_{\text {removed. }}$ Based on the experimental results, and assuming a large-scale $100 \mathrm{~m}^{3}$ GRABBR treating brewery wastewater of COD concentration of $10.7 \mathrm{~g} \mathrm{l}^{-1}, 620 \mathrm{~m}^{3} \mathrm{~d}^{-1}$ 
of biogas will be produced if the reactor is operated at an OLR of $13.38 \mathrm{~kg} \mathrm{COD} \mathrm{m}^{-3} \mathrm{~d}^{-1}$ and achieves a COD removal of $93 \%$. Assuming the calorific value of biogas as $22 \mathrm{MJ}$ $\mathrm{m}^{-3}$ (British BioGen, 2003), the biogas yield will be equivalent to $13640 \mathrm{MJ} \mathrm{d}^{-1}$. Assuming a mere $30 \%$ conversion to electricity, the daily electrical energy produced by a GRABBR treating $100 \mathrm{~m}^{3}$ of this brewery wastewater will be $1137 \mathrm{kWh}$. This energy recovery could be used for various applications in the brewery process.

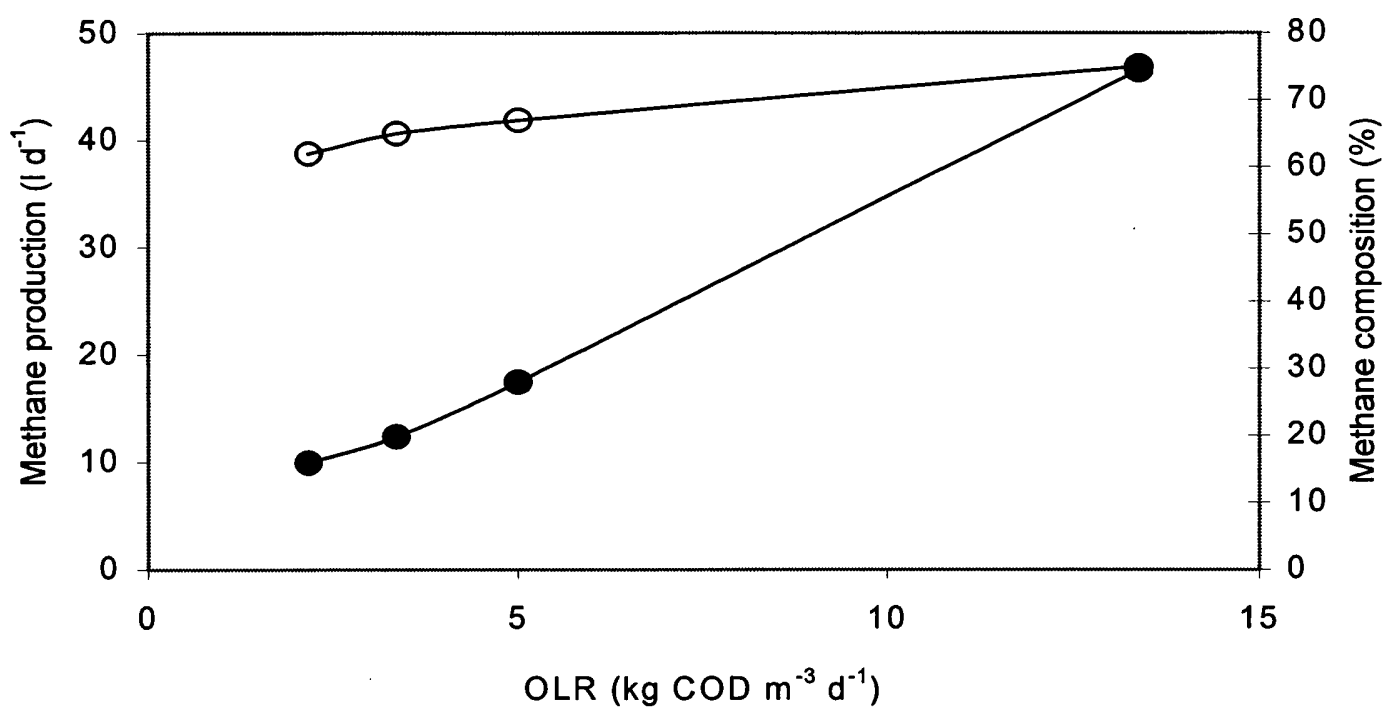

Figure 8.4 Methane production ( $(\bullet)$ and composition $(O)$ for different organic loading rates (OLRs) at steady state conditions for brewery wastewater treatment in granular bed baffled reactor.

The GRABBR was also found to be efficient in biomass retention. Effluent total suspended solids (TSS) were measured in the range of 30 to $135 \mathrm{mg} \mathrm{l}^{-1}$. Similar to the synthetic wastewater studies reported in Chapters 3 and 4, breaking and flotation of granular sludge in the early compartments was observed. Effluent TSS also contained non-granular biomass, produced predominantly in the upstream acidogenic compartments.

\subsubsection{Reactor Performance during Nitrate Addition}

The profiles of COD, NOx-N (nitrate and nitrite nitrogen) and ammonium nitrogen $\left(\mathrm{NH}_{4}-\mathrm{N}\right)$ for a two-stage (GRABBR and aerobic) configuration are shown in Figures $8.5,8.6$ and 8.7 respectively. 


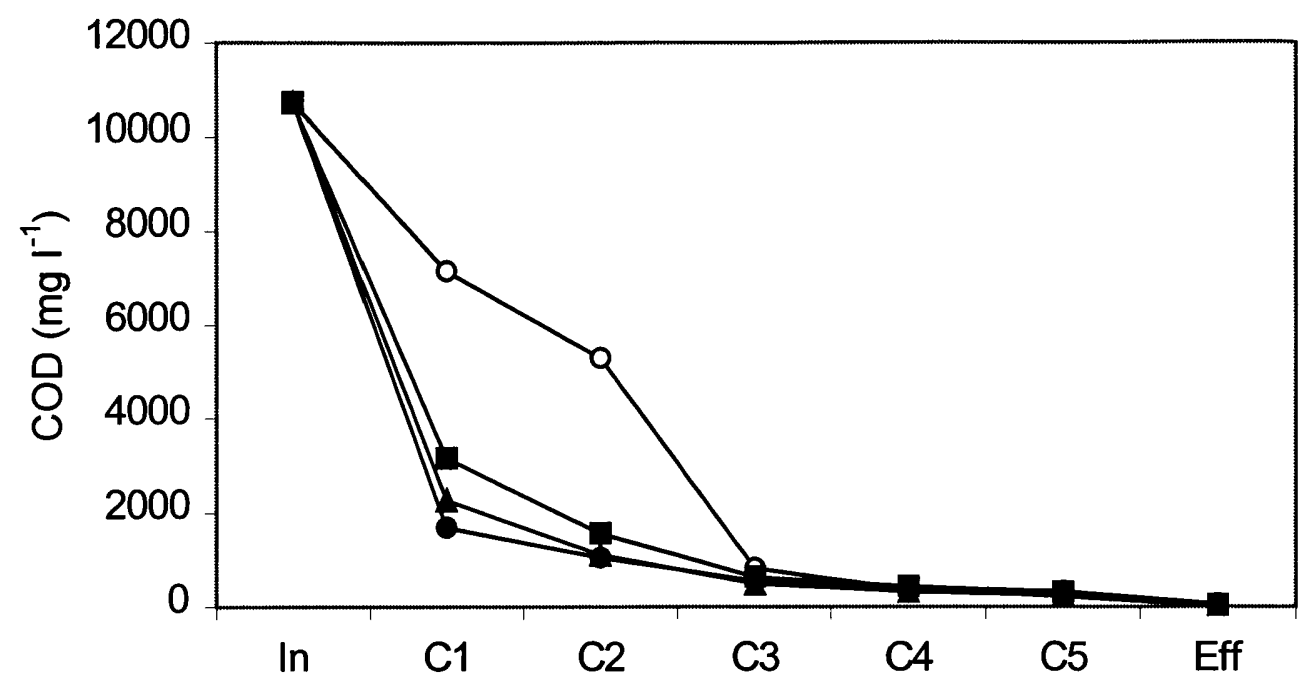

Figure 8.5 Chemical oxygen demand (COD) profile at different recycling ratios of influent to nitrified effluent. Recycling ratio of zero (O), recycling ratio of $1(\mathbb{G})$, recycling ratio of $1.5(\mathbf{A})$ and recycling ratio of $2(\mathbf{)})$ Key: $\mathrm{C} 1, \mathrm{C} 2, \mathrm{C} 3, \mathrm{C} 4$ and $\mathrm{C} 5$ represents compartments of granular bed baffled reactor, In = influent of granular bed baffled reactor and Eff = effluent of aerobic unit.

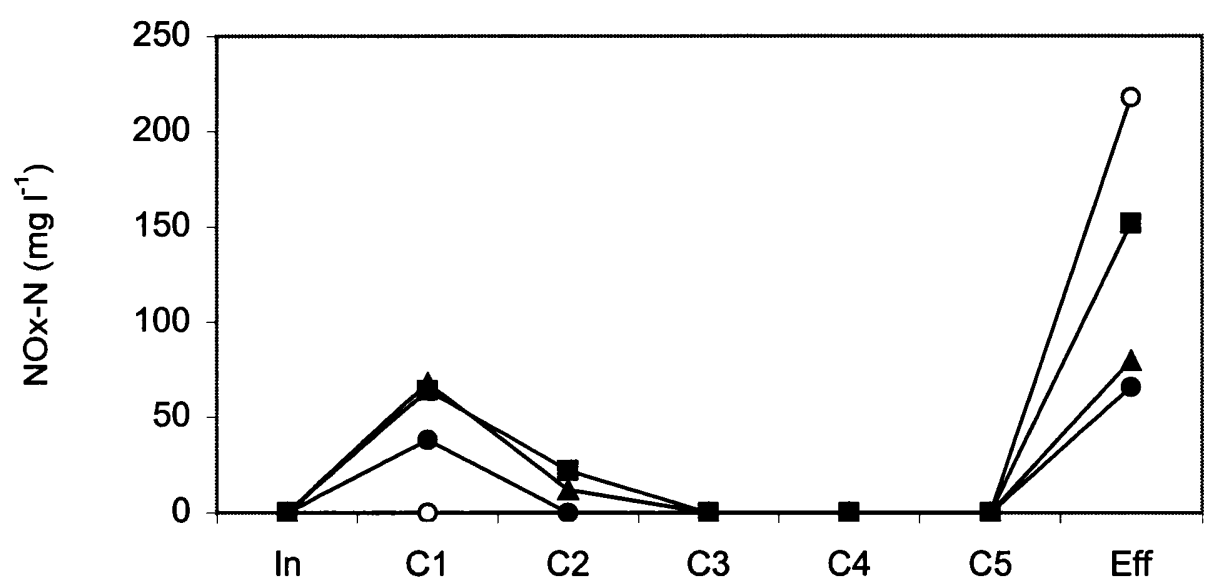

Figure 8.6 NOx-N (nitrate and nitrite nitrogen) profile at different recycling ratios of influent to nitrified effluent. Recycling ratio of zero $(O)$, recycling ratio of $1(\square)$, recycling ratio of $1.5(\Delta)$ and recycling ratio of $2(\Theta) . K e y: \mathrm{C} 1, \mathrm{C} 2, \mathrm{C} 3, \mathrm{C} 4$ and $\mathrm{C} 5$ represents compartments of granular bed baffled reactor, In = influent of granular bed baffled reactor and Eff = effluent of aerobic unit. 


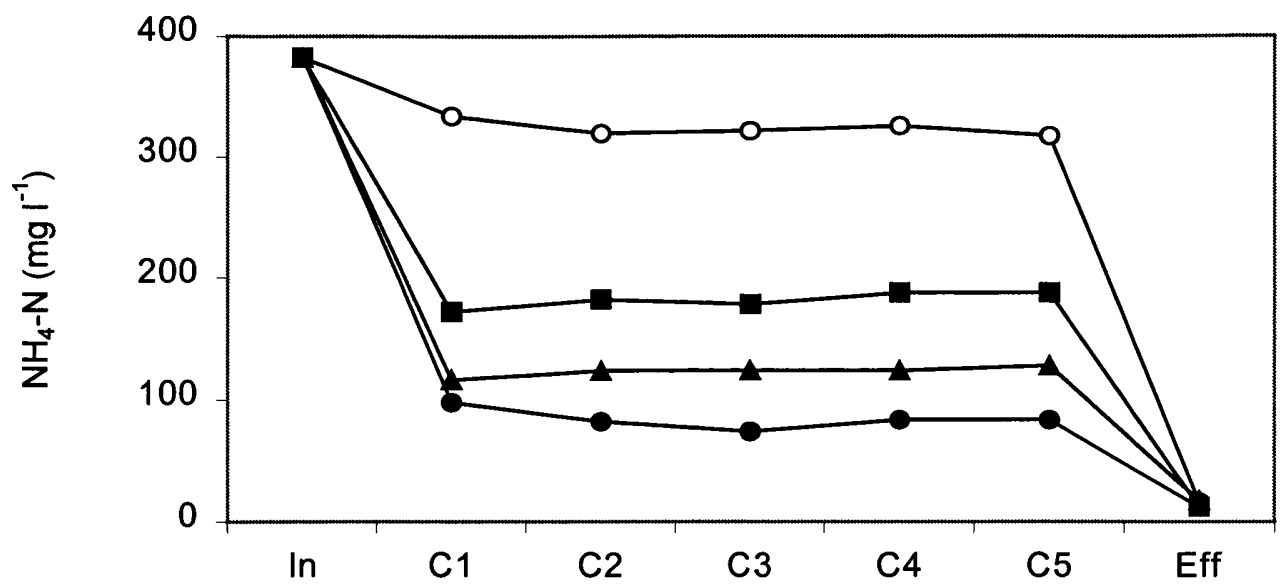

Figure 8.7 Ammonium nitrogen $\left(\mathrm{NH}_{4}-\mathrm{N}\right)$ profile at different recycling ratios of influent to nitrified effluent. Recycling ratio of zero $(O)$, recycling ratio of $1(\square)$, recycling ratio of $1.5(\boldsymbol{\Delta})$ and recycling ratio of $2(\boldsymbol{O})$. Key: C1, C2, C3, C4 and C5 represents compartments of granular bed baffled reactor, $\mathrm{In}=$ influent of granular bed baffled reactor and Eff = effluent of aerobic unit.

COD and ammonium concentrations in the influent of the GRABBR were reduced during recycling of the nitrified wastewater mainly due to the dilution of the feed. However, the $\mathrm{NH}_{4}-\mathrm{N}$ loading rate $\left(\mathrm{kg} \mathrm{NH}_{4} \mathrm{~m}^{-3} \mathrm{~d}^{-1}\right)$ and organic loading rate (kg COD $\mathrm{m}^{-3} \mathrm{~d}^{-1}$ ) remained constant due to the decrease in HRT with a continuous dilution. The nitrate concentrations varied between 66 and $210 \mathrm{mg} \mathrm{NO}_{3}-\mathrm{N} \mathrm{1}^{-1}$, while nitrite concentrations varied between 4 and $8 \mathrm{mg} \mathrm{NO}_{2}-\mathrm{N} \mathrm{l}^{-1}$ in the aerobic unit for the three recycling ratios of influent to nitrified effluent $(1: 1,1: 1.5$ and 1:2). All the nitrates added to the GRABBR were denitrified in the first two compartments. The GRABBR was subjected to nitrate loading rates of 533 to $760 \mathrm{mg} \mathrm{NO}_{3}-\mathrm{N}^{-1} \mathrm{~d}^{-1}$ for the recycling ratios of 1 to 2. In general, denitrifying microorganisms in the GRABBR adapted quickly to the changes in the operational conditions. Almost all the ammonia was converted to nitrate with small traces of nitrite in the aerobic unit during all recycling ratios. An overall COD removal of over $99 \%$ was observed during all the recycling ratios. 
Organic matter and nitrate were removed simultaneously in the GRABBR at different recycling ratios of influent to nitrified effluent. Prior to nitrate addition, $16 \%$ of ammonium nitrogen was assimilated in the upstream compartments of the GRABBR for cell synthesis. The anaerobic effluent contained an ammonium concentration of about $320 \mathrm{mg} \mathrm{l}^{-1}$ before ammonia oxidation in the aerobic unit. During nitrate recirculation, removal of nitrates fed into the GRABBR is believed to take place via denitrification rather than ammonification. This observation was made on the basis that no noticeable increase in the ammonium concentration was noted during the different recycling ratios.

A high COD removal in the GRABBR provided favourable conditions, i.e. low COD concentrations, for the nitrification process in the following aerobic unit. Nitrification processes are reported to be inhibited by a high substrate carbon content (Hanaki et al., 1990, Im et al., 2001). High concentrations of carbon can simulate the growth of heterotrophic bacteria, which out compete nitrifiers for their basic substrate, i.e. ammonia and oxygen (Sharma and Ahlert, 1977). Furthermore, the nature of the substrate can also affect the degree of inhibition of the nitrification process, with VFA being less toxic to the nitrifiers (Barber and Stuckey, 2000b). It is believed that the VFA (simpler form of carbon) was the main organic substrate entering the nitrification unit.

Methane production was observed throughout the experimental period, and this suggests that methanogenesis occurred simultaneously with denitrification, both contributing in COD removal mainly as a result of nitrate removal and methane production in different compartments. Recycling of NOx-N from the nitrification unit to the GRABBR brought about decreases in methane production. This might be due to less COD being available for methane production. Methane composition was recorded in the range of $25 \%$ to $50 \%$ during nitrate recirculation. The disadvantage of an integrated system for combined nitrogen and carbon removal is that the biogas produce is a mixture of methane and nitrogen gas, hence a less useful energy source (Mosquera-Corral et al., 2001). However, a GRABBR system may offer the advantage of separately collecting the gas produced from the denitrifying (acidogenic) and methanogenic zones, thus recovering only the biogas with a high calorific value from the methanogenic dominant zone. 


\subsection{CONCLUSIONS}

The GRABBR achieved a high COD removal, biomass retention and methane yield under various OLRs at steady state conditions with brewery wastewater prior to nitrate addition. Noticeable phase separation between acidogenesis and methanogenesis was observed at a high OLR with granular breaking and flotation in the acidogenic dominant zone. In the GRABBR type system, denitrification and carbon removal can be ensured in a single unit. Due to nitrate addition in the acidogenic dominant zone, sufficient carbon would always be available for the completion of the denitrification process of the reactor, and the rest will be converted to methane, mainly in the downstream compartments. The results for the brewery effluent showed the suitability of the combined integrated system (GRABBR and nitrification unit) for simultaneous denitrification and methanogenesis for carbon and nitrogen removal. The GRABBR can be operated at high OLRs, and an active denitrification zone can be developed in the acidogenic dominant zone by recycling nitrified effluent into the feed of the GRABBR. The entire system (GRABBR and nitrification unit) ensured a COD removal of over $99 \%$, with complete nitrate removal in the GRABBR. The NOx-N levels (mainly in the form of nitrate) in the final effluent of aerobic unit decreasing with an increase in the influent to effluent recycling ratio. Furthermore, biogas from methane rich compartments can be removed separately for energy production. 


\section{CHAPTER 9}

\section{GENERAL DISCUSSION}

This chapter briefly discusses the results of this study in the light of current literature, and explains the originality of the work. Finally, the main conclusions are drawn with suggestions for further work.

In this study, the properties of an anaerobic baffled reactor (ABR) and granular sludge have been brought together to create an anaerobic granular bed baffled reactor (GRABBR). This reactor configuration was designed to obtain three characteristics, viz. plug flow, phase separation and granular bed, in a single anaerobic system. The system was investigated for organic matter and nitrate removal at various operational conditions with a defined chemical mixture of glucose wastewater and natural wastewater in the form of brewery effluent. Furthermore, biomass in the system was examined to investigate the effect of phase separation and nitrate addition on its biochemical and microbiological properties.

\subsection{REACTOR PERFORMANCE FOR ORGANIC MATTER REMOVAL}

The GRABBR performance with synthetic glucose and brewery wastewaters under various operational conditions is summarised in Table 9.1. With synthetic glucose and brewery wastewaters, high treatment efficiencies of the GRABBR system were mainly attributed to its plug flow, (multi) phase separation and granular bed properties. At lower volumetric organic loading rates (OLRs), with long hydraulic retention times (HRTs), the reactor behaved as a completely mixed system due to the high treatment efficiencies achieved in the first compartment. Noticeable phase separation was observed when higher OLRs were applied to the GRABBR. This resulted mainly in acidogenesis occurring in the upstream compartments and methanogenesis in the downstream compartments. An increase in OLR allowed a greater number of 
compartments to contribute to wastewater treatment due to the spread of microbial activities. This characteristic of the reactor was found advantageous while treating a wastewater stream subjected to rapid hydraulic shock loads, as reported in Chapter 4. This shows the suitability of the GRABBR for treating industrial wastewaters with highly variable production rates. Soluble chemical oxygen demand (SCOD) removal efficiencies with synthetic wastewater at maximum applied OLR $\left(20 \mathrm{~kg} \mathrm{COD} \mathrm{m}^{-3} \mathrm{~d}^{-1}\right)$ were $94 \%$ to $98 \%$, for both steady increment and hydraulic shock load studies. However, a simple ABR at the same OLR, with an advantage of relatively longer HRT, only achieved a COD removal of about 75\% (Bachmann et al., 1985; Boopathy and Tilche, 1992). This shows the effectiveness of the GRABBR over simple ABR systems. Furthermore, the reactor was efficiently operated continuously for 55 days at an OLR of $20 \mathrm{~kg} \mathrm{COD} \mathrm{m}^{-3} \mathrm{~d}^{-1}$ (6 hrs HRT) with synthetic wastewater, showing the capability of the system to perform on a long-term basis at high OLRs with short HRTs. This study shows that a GRABBR can be operated in a number of phases, depending upon the operational conditions and number of compartments, with each compartment representing a separate phase. The system also operates as an alternative to a two-phase anaerobic digestion system, which could save the cost of an extra unit traditionally employed to achieve similar goals in treatment of complex or high strength wastewaters to separate acidogenesis and methanogenesis (Pohland and Ghosh, 1971; Cohen et al., 1980 \& 1982; Dinopoulou and Lester, 1989; Anderson et al., 1994; Ince, 1998; Shin et al., 2001).

Granule breaking and flotation were observed in the upstream compartments, where acidogenesis was dominant. However, granular sludge in the downstream compartments (methanogenic dominant zone) retained the original granular structure. At high OLR, the production of acid in the early compartments and its consumption in the latter compartments created zones of acidogenesis and methanogenesis in these respective compartments. The effect of increasing OLR was to increase the acidogenic zone at the expense of the methanogenic zone.

Short HRTs (high OLRs) can cause potential problems of biomass washout within the system. Compartmentalisation and granular bed characteristics of the GRABBR offered a good resistance to biomass washout at short HRTs. Effluent total suspended solids concentrations were generally low under various operating conditions. Firstly, the 
baffles minimised inter-compartmental solid washout, and secondly, denser granular sludge bed possessed good settling characteristics. The downstream granular bed also acted as a filtration bed for non-granular biomass produced in the upstream acidogenic phase. Most of the effluent solids consisted of non-granular biomass formed in the upstream compartments of GRABBR.

Table 9.1 Chemical oxygen demand removal efficiencies under different operational conditions at steady state for glucose and brewery wastewaters using granular bed baffled reactor.

\begin{tabular}{llllll}
\hline Substrate & $\begin{array}{l}\text { OLR }^{\mathrm{a}} \\
\left(\mathrm{kg} \mathrm{COD} \mathrm{m}^{-3} \mathrm{~d}^{-1}\right)\end{array}$ & $\begin{array}{l}\mathrm{COD}_{\text {influent }} \\
\left(\mathrm{g} \mathrm{l}^{-1}\right)\end{array}$ & $\begin{array}{l}\mathrm{HRT}^{\mathrm{b}} \\
(\mathrm{hrs})\end{array}$ & $\begin{array}{l}\text { Flow rate } \\
\left(1 \mathrm{~d}^{-1}\right)\end{array}$ & $\begin{array}{l}\mathrm{COD}^{\mathrm{c}} \\
\text { removal } \\
(\%)\end{array}$ \\
\hline Glucose $^{\mathrm{d}}$ & $1-20$ & 5 & $120-6$ & $2-40$ & $96-98$ \\
Glucose $^{\mathrm{e}}$ & $2.5-20$ & 5 & $48-6$ & $5-40$ & $94-97$ \\
Brewery $^{\mathrm{f}}$ & $2.16-13.38$ & $5-10.7$ & $55.5-19.23$ & $4.3-12.5$ & $93-96$ \\
\hline
\end{tabular}

${ }^{a}$ OLR: Organic loading rate

${ }^{\mathrm{b}}$ HRT: Hydraulic retention time

${ }^{c}$ COD: Chemical oxygen demand. For brewery wastewater study, the values represent total COD removal, while for glucose wastewater studies, the percentages are soluble COD removal

${ }^{\mathrm{d}}$ The study lasted for 148 days and OLRs were steadily increased by decreasing HRTs

e The study lasted for 33 days and OLRs were rapidly increased by decreasing HRTs

${ }^{\mathrm{f}}$ The study lasted for 68 days

The metabolic pathways of glucose and brewery wastewater fermentation in the GRABBR favoured acetate and butyrate production, particularly at high OLRs. High degradation rates of these acids were observed in the methanogenic dominant zone. It is believed that the low $\mathrm{pH}$ levels within the acidogenic dominant zone of the system played a vital role for such microbial selection with synthetic medium. With glucose wastewater studies, low $\mathrm{pH}$ levels in the GRABBR could have encouraged high concentrations of acetate and butyrate, as also reported by other authors (Inanc et al., 1996; Azbar et al., 2001; Horiuchi et al., 2002). This condition is energetically less favourable to the acidogens, but enhances the bioavailabily of essential easily biodegradable intermediate products in the methanogenic phase (Azbar et al., 2001). In other words, the acidogenic phase in the GRABBR produced favourable substrate conditions for the methanogenic phase. On the other hand, the $\mathrm{pH}$ levels of the medium 
in the upstream compartments of the GRABBR were relatively high in the brewery wastewater study, but interestingly acetate and butyrate were still the major acid products. This shows that the GRABBR configuration stimulates production of intermediate products in the acidogenic phase favourable to the methanogenic zone, or may be the nature of the wastewater for such microbial selection within the system.

The methane yield varied from 0.30 to $0.38 \mathrm{~m}^{3} \mathrm{CH}_{4} \mathrm{~kg}^{-1} \mathrm{COD}_{\text {removed with higher loads }}$ causing a decrease in the yield for the synthetic glucose wastewater studies. The methane composition varied from $50 \%$ to $70 \%$. However, higher methane yields were observed with brewery wastewater ( 0.37 to $\left.0.47 \mathrm{~m}^{3} \mathrm{CH}_{4} \mathrm{~kg}^{-1} \mathrm{COD}_{\text {removed }}\right)$, with methane composition varying from $62 \%$ to $75 \%$. This high methane yield and composition found with the brewery wastewater could be due to the nature of the organic substrates in the wastewater. The high methane yield in all the studies confirms the GRABBR as a high rate anaerobic system.

\subsection{BIOMASS CHARACTERISTICS IN ACIDOGENIC PHASE}

High acidogenic activities in the upstream compartments of the GRABBR caused breaking of granular sludge to produce non-granular biomass in the form of debris of broken granules and new microbial mass. It can be hypothesised that breaking of the granules in the acidogenic phase of a GRABBR is a common characteristic associated with such compartmentalised granular bed systems. High consumption (up to $30 \%$ ) of influent ammoniacal nitrogen $\left(\mathrm{NH}_{4}-\mathrm{N}\right)$ was observed in the acidogenic dominant zone, and believed to be the result of high biomass growth. This was an indication of the differential growth characteristics of the microbial populations in the front and rear compartments of the GRABBR. The whitish non-granular mass formed in the acidogenic dominant zone of glucose wastewater studies was identified as Gramnegative Klebsiella pneumoniae ( $83 \%$ probability), a known facultative anaerobic microorganisms. 


\subsection{COMBINED DENITRIFICATION AND CARBON REMOVAL IN GRABBR}

\subsubsection{Treatment of Glucose Wastewater for Organic Carbon and Nitrogen Removal}

The methanogenic and acidogenic dominant zones exhibited high denitrification capabilities, with no nitrite accumulation, suggesting that the microbial environment in these zones have denitrifying potentials. The nitrate removal rates in the acidogenic and methanogenic dominant zones increased with increase in nitrate concentration (50 to $200 \mathrm{mg} \mathrm{l}^{-1} \mathrm{NO}_{3}-\mathrm{N}$ ), varying from 46 to $175 \mathrm{mg} \mathrm{NOx}-\mathrm{N} \mathrm{l}^{-1} \mathrm{~h}^{-1}$ and 43 to $189 \mathrm{mg} \mathrm{NOx-N}$ $\mathrm{l}^{-1} \mathrm{~h}^{-1}$ respectively. Interestingly, the methanogenic dominant environment demonstrated slightly higher nitrate and carbon removal rates than an acidogenic dominant environment. This may be because volatile fatty acids (VFAs) were the main microbial substrate in the methanogenic dominant zone, which are efficient compounds for denitrification as compared to glucose (Akunna et al., 1993 \& 1994a; Fass et al., 1994; Hendriksen and Ahring, 1996a). The other reason could be the presence of a highly active biomass in the form of anaerobic granules in the methanogenic dominant zone, which may have possessed high denitrifying potentials. Though, relatively higher denitrification and SCOD removal rates were achieved when nitrates were added to the methanogenic dominant zone as compared to when being added to the acidogenic dominant zone, in order to avoid inhibition of nitrates to methane producing microorganisms, back mixing of nitrogen oxides to the preceding compartments and incomplete denitrification, nitrate addition in the acidogenic dominant zone would ensure a more stable and reliable reactor operation. This would also eliminate any requirement for a pre-denitrification stage, as the number of compartments would be sufficient enough to denitrify nitrates along the length of the reactor with methane production occurring mainly in the downstream compartments of the GRABBR. Moreover, this arrangement would be advantageous for collecting biogas from methane rich (mainly downstream) compartments of the GRABBR, thus minimising the cost of methane separation from the total biogas.

No noticeable dissimilatory nitrate reduction to ammonia (DNRA) was observed in the GRABBR and nitrate conversion to nitrogen gas was the major pathway for nitrate 
removal. It seems that compartmentalisation enhanced nitrate reduction activities by ensuring a relatively low $\mathrm{COD} / \mathrm{NO}_{3}-\mathrm{N}$ ratio in the nitrate added compartment, which might have encouraged nitrate removal via denitrification. Low $\mathrm{COD} / \mathrm{NO}_{3}-\mathrm{N}$ ratios have been reported to increase denitrification activities over DNRA (Akunna et al., 1993 \& 1994a). The addition of nitrate increased the overall SCOD removal efficiency of the reactor when compared to conditions prior to nitrate addition due to extra carbon consumption during nitrate removal. Methane production was observed during nitrate addition, indicating that simultaneous denitrification and methanogenesis occurred in the GRABBR.

\subsubsection{Treatment of Brewery Wastewater for Organic Carbon and Nitrogen Removal}

The application of a combined integrated system was investigated by incorporating carbon and nitrate removal in the GRABBR, with a separate nitrification unit for converting ammonia to nitrate. Organic matter and nitrate were removed simultaneously in the GRABBR at different recycling ratios of influent to nitrified effluent $(1: 1,1: 1.5$ and 1:2). During all recycling ratios, COD removal of over $99 \%$ was observed by the overall system. All the nitrates added to the GRABBR were eliminated in the first two compartments of the system, predominantly via denitrification. Almost all ammonia was converted to nitrate nitrogen with only small traces of nitrite nitrogen in the aerobic unit during all recycling ratios. Methane production was observed throughout the experimental period, showing that methanogenesis occurred simultaneously with denitrification. This study is an example of an industrial application of a GRABBR as a reliable and stable anaerobic system for complete organic carbon and nitrogen removal.

\subsection{SIMULTANEOUS NITRATE REDUCTION AND METHANE PRODUCTION IN BATCH ASSAYS}

Batch experiments were conducted to evaluate the possibility of simultaneous denitrification and methane production with acidogenic and methanogenic dominant zone sludges with different carbon sources, i.e. acetate, VFA and glucose. In general, acetate and VFA cultures exhibited slightly higher methane production and/or nitrate removal as compared to glucose cultures for both type of sludges under nitrate added 
and nitrate free conditions. This suggests that the simpler forms of carbon (acetate and VFA) are more efficient substrates in terms of carbon and nitrate removal than glucose.

The methanogenic dominant zone sludge, which was granular in structure, showed better nitrate removal capabilities with all substrate cultures when compared to the acidogenic dominant zone sludge. This confirms the reactor study where higher denitrifying rates were achieved when nitrates were added in the methanogenic dominant zone. The acidogenic dominant zone biomass, after being acclimatised with nitrates, exhibited higher nitrate reduction potentials for all substrate cultures, but with no methane production. This nitrate acclimatised acidogenic sludge was mainly nongranular and demonstrated higher denitrifying rates than methanogenic dominant zone sludge previously unadapted to nitrate (Table 6.3). This suggests that nitrate adaptation increases the number of denitrifying microbes. Simultaneous denitrification and methane production was observed with all substrates with methanogenic dominant zone sludge, indicating the importance of granular structure for the combined activities. The batch study shows that anaerobic granular microorganisms not only possess high methanogenic activities but also denitrification capabilities. Since the long term affect of acidogenesis on granular biomass is to produce a non-granular sludge, which is less active in methanation, it is suggested that acclimatisation of acidogenic dominant sludge by a gradual increase in influent NOx-N will bring about increased denitrification rates (in the acidogenic dominant zone), and consequently an increase in methane production in the GRABBR.

This study differs from earlier reported work, which suggests that methane production and nitrate removal can not proceed simultaneously in a completely mixed environment (Akunna et al., 1993 \& 1994a; Lin and Chen, 1995; Quevedo et al., 1996). They observed methane production only after complete elimination of nitrate from the wastewaters. The main explanation for this observation could be the nature of the biomass, as most of these studies were conducted with dispersed or flocculent type sludges. The studies reported here show that the reversible inhibition may be due to the non-granular nature of biomass used by these authors (Akunna et al., 1993 \& 1994a; Lin and Chen, 1995; Quevedo et al., 1996). The methanogenic bacteria may have been readily exposed to nitrogen oxides, and was not able to play their role until all nitrates 
were eliminated. But in granular biomass, these microorganisms are protected by facultative populations that revive NOx-N reduction.

Hendriksen and Ahring (1996b) observed methane production only after complete elimination of nitrogen oxides with granular sludge. Although difficult to prove, a combination of different factors could have contributed to this observation. It may be that the coexistence of facultative (or denitrifying) and methanogenic organisms in the granular structure were not having a strong association. Moreover, it may be possible that the microbial populations within the granules were not having a layered arrangement, as observed in this study, which was evident from the electron micrographs (Chapter 7). In another study, the application of entrapped microorganisms in gels has been attempted for nitrate and carbon removal (Lin and Chen, 1995), however methane production was only observed after complete nitrate elimination. Furthermore, these structures are less stable with a short life cycle (Liu and Tay, 2002).

It can be hypothesised from this study that in a layered anaerobic granular sludge with a strong association of facultative bacteria and methanogens, simultaneous denitrification and methane production can occur simultaneously. When carbon and nitrate are present in the culture, outer layers of the granules (consisting mainly of facultative microorganisms), remove nitrate from the system, while core or inner methanogenic microbial layers convert relatively simple forms of substrate to methane. Naturally forming biofilms in the form of anaerobic granular sludge offer an adequate solution for the integration of carbon and nitrate removal.

\subsection{GRANULAR MORPHOLOGY}

The morphology of anaerobic granules in this study was observed to be ellipsoid, which was in disagreement with that reported in the previous studies, which suggested a spherical granular shape (Hulshoff Pol et al., 1986; Grotenhuis et al., 1991a; Arcand et al., 1994; Shen and Guiot, 1996; Batstone and Keller, 2001). Microscopic observations and particle size distribution of granular samples revealed two different dimensions along two-axes, which characterises these particles as ellipsoids and not spheres. Furthermore, particle size distribution graphs along both axes exhibited the presence of two prominent populations of sizes along each axis. 
Granular properties have been a useful tool to ensure a successful anaerobic reactor operation, particularly in terms of treatment efficiency and biomass retention within the system. The settling properties and particle size distribution of granules have been calculated by assuming granules as spherical shaped particles using the correlation between the size and settling velocity (Hulshoff Pol et al., 1986; Grotenhuis et al., 1991a; Batstone and Keller, 2001). This resulted in large deviations in results for settling velocities and size distribution calculated by using empirical equations when compared with experimentally measured values. It is believed that due to the nonspherical shape of granules, errors have been made in these earlier studies (Grotenhuis et al., 1991a; Batstone and Keller, 2001). This shows that a proper assessment of granule morphology is fundamental before applying any derivation or empirical equation based upon the shape of granules.

\subsection{MICROBIAL ECOLOGY AND DISINTEGRATION OF GRANULES}

Scanning and transmission electron micrographs revealed that the core of anaerobic granular sludge consists predominantly of Methanothrix-like species. Methanogenic granules consisted of five apparent microbial zones with a vast diversity of species from the outer surface to the core of the granule. Observation of more than three microbial zones within the granule shows that the granular structure possesses more complex bacteriology than previously reported by other researchers (Macleod et al., 1990; Fang et al., 1994). Granules in the methanogenic dominant zone of the GRABBR were densely packed with smooth regular surface. On the other hand, granules subjected to acidogenic activities revealed relatively fewer numbers of species with an irregular fissured surface. Furthermore, layering (zoning) in these granules was not distinct, with four apparent microbial zones. These images and visual observation shows that the fermentation process in the upstream compartments of the GRABBR disfigured the granular structure. This could be due to mainly the affinity of hydrophilic cells (mainly facultative microorganisms dominant in the outer zones of anaerobic granule) of the granular consortium to be in the liquid phase of the acidogenic dominant environment. It is believed that most of the hydrophobic microorganisms (i.e. methanogens) in an anaerobic granular sludge, which play a vital role in the aggregation of bacterial species (van Loosdrecht et al., 1987a \& 1987b) and granule formation (Grotenhuis et al., 1992), 
would not have a strong association under highly active acidogenic environment. Viruses in the granules could also be responsible for destroying cells and weakening the internal structure of granules, thus possibly causing the breaking of granules into smaller granules. It can be hypothesised that the main cause of granule disintegration in the acidogenic dominant zone (upstream compartments of the GRABBR) could be due to fermentative activities, while bacteriophage and the natural process of disintegration in the other zones (downstream compartments of GRABBR) of anaerobic system.

It has been reported that granules dominant of hydrophobic bacteria on the outer layers strongly adhere to biogas bubbles formed in anaerobic systems, and are susceptible to washout (Daffonchio et al., 1995; Thaveesri et al., 1995). Therefore, a granular structure enriched with hydrophilic cells on surface or outer layers, with a strong association of hydrophobic microorganisms in the core, is expected to bring greater stability within the system with high biomass retention. Hence, a layered structure, with fermentative or facultative microorganisms in the outer zones and methanogens in the inner layers of anaerobic granule, is the preferred granular structure for the start-up of anaerobic system rather than homogenous layered granular aggregate.

Extracellular polymeric substances (EPS), cell division within the granules, coccoid cells, protozoa-like organisms and spirochaete bacteria were observed by scanning and electron microscope. EPS is believed to act as a binding material for the microorganisms in the granules to keep a compact granular structure. Protozoa are microorganisms that play an important role as bacterial predators, and are believed to control the growth of bacterial cells on the exterior zone of granular structure.

\subsection{GRANULATION}

An acidogenic environment does not seem to initiate granule formation, as the breaking of granules was observed in the acidogenic dominant zone with synthetic glucose and brewery wastewaters. Methanogens or an environment dominated by methanogenic activities is believed to initiate self-immobilisation of bacterial species to form anaerobic granules, as a granular structure was retained in the downstream compartments of the GRABBR. This theory was further supported by the microscopic observations in this study as reported in Chapter 7, which revealed methanogen-like 
species as the main population in the core of granules. Hence, it can be hypothesised that reactor hydrodynamics and methanogenic dominant environments are two important factors for initiating the granulation process.

\subsection{ADDITIONAL ADVANTAGES OF GRANULAR BED BAFFLED REACTOR}

The GRABBR system can achieve enhanced treatment performance by controlling and manipulating the gaseous phase. Venting of gas from the acidogenic dominant zone of a stage system has been found to be efficient for overall process stability (Harper and Pohland, 1987). This arrangement is possible with GRABBR, and even gas alterations can be made with the required amount of gas passed or recycled to the subsequent stages.

In UASBs and expended granular sludge bed (EGSB) configurations, high gas production or flow rates could cause channelling, which could be extended throughout the upflow height of these systems as gas bubbles travel from the bed to the entire height of the system. In the GRABBR type system, even if there is channelling in any compartment, it would most probably be restricted to that compartment rather than affecting the entire system.

In upflow compartmentalised anaerobic configurations, if granule breaking occurs in the lower acidogenic zone of the system then the granular sludge in the upper methanogenic zone will settle out in the lower zones. This will offer no protection to the methanogenic zone, unless a sufficient amount of granules is formed within the system. In the GRABBR, if there is a breaking of granular sludge in the upstream compartments, the granular sludge in the methanogenic dominant zone (downstream compartments) would be preserved from the adverse conditions of acidogenesis as it will not be back mixed. 


\subsection{CONCLUSIONS}

Based on the results obtained in this study, the following conclusions can be drawn:

1. The reactor is capable of recovering quickly following large increments in OLRs (or reduction in HRTs), and provides high capacity storage to metabolise intermediate products when operated in the mode of hydraulic shock loads.

2. The reactor configuration and microbial environment encourages the acidogenic dominant zone to produce intermediate products suitable for degradation in the methanogenic dominant zone.

3. At low OLRs, the system operates as a completely mixed system due to the ability of only one compartment to accomplish complete treatment. Phase separation between acidogenesis and methanogenesis mainly occurs at high OLRs (short HRTs), involving greater number of compartments to contribute in wastewater treatment. Increases in OLRs bring about increase in the size of acidogenic zone.

4. The dense granular bed in the GRABBR reduces the effect of channelling at short HRTs to provide optimum contact between biomass and wastewater. The highly active nature and good settling characteristics of methanogenic granular biomass offer high biomass retention and enhance methanogenic activities within the system.

5. The granular structure in the acidogenic dominant zone of a GRABBR is susceptible to breaking while they are maintained in the methanogenic dominant zone. This suggests that acidogens are mainly dispersed biomass forming microorganisms with hydrophilic characteristics, while the environment dominant of methanogenic organisms, predominantly hydrophobic cells, may initiate granule formation.

6. Proper assessment of granular morphology is vital before applying any empirical relationships dependent on the shape factor. The trend of considering or assuming anaerobic granules as spherical particles needs serious attention. 
7. The simpler forms of carbon substrates, like acetate and VFA, are more efficient compounds to achieve high denitrification and methanation rates than glucose.

8. Simultaneous denitrification and methane production in a GRABBR is attributed to a microbial arrangement in a multi-layered granular structure, containing a vast diversity of organisms with a strong association of facultative and methanogenic populations predominantly located in the outer and inner zones, respectively, and phase separation characteristics of system.

9. The long term reactor stability and efficiency in terms of organic carbon and nitrate removal can be achieved by introducing nitrate feed into the acidogenic dominant zone of GRABBR. This arrangement will bring about complete nitrate removal, minimise nitrate inhibition to methanogenesis (or methanogenic dominant zone) and collection of methane rich biogas from the selected phase.

\subsection{SUMMARY}

The GRABBR can achieve high COD removal efficiency, denitrification rates and methane yield with synthetic and natural wastewaters. This is mainly attributed to the reactor's compartmentalised design, granular bed and plug-flow characteristics. The findings of this project suggest that the application of a GRABBR is suitable for the treatment of multiple pollutants of complex or high strength wastewaters, due to its multi-phase granular bed features, where each phase or compartment acts as a separate specialised treatment unit.

\subsection{SUGGESTIONS FOR FURTHER WORK}

The following areas of study are recommended for further work:

1. A comparative study of GRABBR and EGSB systems for treating sulphate rich wastewaters. In the GRABBR, ease of gas venting feature may efficiently control hydrogen sulphide $\left(\mathrm{H}_{2} \mathrm{~S}\right)$ accumulation in the upstream compartments (acidogenic phase), and thus might offer high reactor stability in terms of organic matter and sulphate removal when compared to EGSB system. 
2. A comparative study of GRABBR systems with varying number of compartments to investigate the influence of compartmentalisation on the reactor performance, particularly in terms of phase separation, biomass retention and pollutants removal.

3. Investigation of GRABBR by designing compartments with high height to width ratios. It would be interesting to examine the influence of more upflow path pattern of the wastewater on various substrate degradation rates and granulation process.

4. Determination of settling velocities of granules by using empirical relationships derived for elliptical and spherical particles, and their deviation from experimentally measured values.

5. Evaluation of the reactor with highly concentrated and dilute wastewaters. The high biomass activity and good settling characteristics of granular sludge is expected to bring greater reactor stability in terms of organic matter removal.

6. Improvement of the reactor configuration in terms of providing suitable nongranular inocula in the compartments where methanogenic granular sludge is likely to break or float.

7. The GRABBR should be investigated for process industries generating variety of wastewater streams. Feeding each pollutant stream into separate compartment to create their specialised treatment zone could bring the effluent quality within discharge limits with considerable economic gains.

This work has provided some useful knowledge to scale up the reactor on pilot-plant size for treating high strength industrial wastewaters. On the concept of this work, recently a study was undertaken on a pilot plant scale for treating brewery effluent. 


\section{REFERENCES}

Abeling, U. and Seyfried, C. F. (1992). Anaerobic-aerobic treatment of high-strength ammonium wastewater - Nitrogen removal via nitrite. Wat. Sci. Technol., 26, $1007-$ 1015.

Adams, C. E. and Eckenfelder, W. W. (1977). Nitrification design approach for high strength ammonia wastewaters. J. Wat. Poll. Cont. Fed., 49, 413-421.

Akunna, J. C., Bizeau, C. and Moletta, R. (1992). Denitrification in anaerobic digesters: possibilities and influence of wastewater COD/N-NOx ratio. Environ. Technol., 13, 825-836.

Akunna, J. C., Bizeau, C. and Moletta, R. (1993). Nitrate and nitrite reductions with anaerobic sludge using various carbon sources: glucose, glycerol, acetic acid, lactic acid and methanol. Wat. Res., 27, 1303-1312.

Akunna, J. C., Bernet, N. and Moletta, R. (1994a). Nitrate reduction by anaerobic sludge using glucose at various nitrate concentrations: ammonification, denitrification and methanogenic activities. Environ. Technol., 15, 41-49.

Akunna, J. C., Bizeau, C., Moletta, R., Bernet, N. and Heduit, A. (1994b). Combined organic carbon removal and complete nitrogen removal using anaerobic and aerobic upflow filters. Wat. Sci. Technol., 30, 297-306.

Akunna, J. C., Bernet, N., and Moletta, R. (1998). Effect of nitrate on methanogenesis at low redox potential. Environ. Technol., 19, 1249-1254.

Akunna, J. C. and Clark, M. (2000). Performance of a granular-bed anaerobic baffled reactor (GRABBR) treating whisky distillery wastewater. Bioresour. Technol., 74, 257261. 
Akunna, J. C. and Baloch, M. I. (2002). Treatment of brewery and distillery wastewaters using anaerobic granular bed baffled reactor (GRABBR). In: Proc. of the $2^{\text {nd }}$ Aqua Enviro/CIWEM Biennial Conference on Management of Wastewaters, 15-17 April, Edinburgh, Scotland, Horan N. J., ed., 2, 311-316.

Akunna, J. C. and Baloch, M. I. (2003). GRABBR: A new system configuration for the treatment of high strength wastewaters. IWA Asian Waterqual 2003 Conference, 20-22 Oct., Bangkok, Thailand, 8 pages on CD-ROM.

Alibhai, K. R. K. and Forster, C. F. (1986a). Physiochemical and biological characteristics produced in anaerobic upflow sludge blanket reactors. Enzyme Microb. Technol., 8, 601-606.

Alibhai, K. R. K. and Forster, C. F. (1986b). An examination of the granulation process in UASB reactors. Environ. Technol. Lett., 7, 193-200.

American Public Health Association (APHA). (1992). Standard methods for the examination of water and wastewater. $18^{\text {th }}$ Ed., Washington, D.C., USA.

Anderson, G. K., Donnelly, T. and Letten, D. J. (1980). Anaerobic treatment of highstrength industrial wastewaters. In: Treatment and disposal of solid and industrial wastes, Curi, K., ed., Pergamon Press, New York, USA, 31-142.

Anderson, G. K. and Saw, C. B. (1984). State of the art of anaerobic digestion for industrial applications in the United Kingdom. In: Proc. $39^{\text {th }}$ Purdue Industrial Wastes Conf., Purdue Univ., 783-793.

Anderson, G. K., Kasapgil, B. and Ince, O. (1994). Microbiological study of two-stage anaerobic digestion during start-up. Wat. Res., 28, 2383-2392.

Anthonisen, A. C., Loehr, R. C., Prakasam, T. B. S. and Srinath, E. G. (1976). Inhibition of nitrification by ammonia and nitrous acid. J. Wat. Poll. Cont. Fed., 48, $835-852$. 
Antoniou, P., Hamilton, J., Koopman, B., Jain, R., Holloway, B., Lyberatos, G. and Svoronos, S. A. (1990). Effect of temperature and $\mathrm{pH}$ on the effective maximum specific growth rate of nitrifying bacteria. Wat. Res., 24, 97-101.

Arcand, Y., Guiot S. R., Desrochers, M. and Chavarie, C. (1994). Impact of the reactor hydrodynamics and organic loading on the size and activity of anaerobic granules. Chem. Eng. J., 56, B23-35.

Azbar, N., Ursillo, P. and Speece, R. E. (2001). Effect of process configuration and substrate complexity on the performance of anaerobic processes. Wat. Res., 35, 817829.

Bachmann, A., Beard, V. L. and McCarty, P. L. (1983). Comparison of fixed film reactors with a modified sludge blanket reactor. In: Fixed film biological processes for wastewater treatment, Y. C. Wu and E. D. Smith, eds., Noyes Data Corp., Park Ridge, New Jersey, USA, 384-402.

Bachmann, A., Beard, V. L. and McCarty, P. L. (1985). Performance characteristics of anaerobic baffled reactor. Wat. Res., 19, 99-106.

Bae, B-U., Shin, H-S., Paik, B-C. and Chung, J-C. (1995). Re-activation characteristics of preserved anaerobic granular sludges. Bioresour. Technol., 53, 231-235.

Bae, J. H., Song, K. B. and Cho, K. M. (1997). Comparison of operational characteristics of UASB and ABR: Organic removal efficiency and variations of $\mathrm{P}_{\mathrm{H} 2}$ and $\mathrm{P}_{\mathrm{CO}}$. In: Proc. of the $8^{\text {th }} I A W Q$ Int. Conf. on Anaerobic Digestion, 25-29 May, Sendai, Japan, Vol. 1, 164-171.

Balderston, W. L. and Payne, W. J. (1976). Inhibition of methanogenesis in salt sediments and whole-cell suspensions of methanogenic bacteria by nitrogen oxides. Appl. Environ. Microbiol., 32, 264-269.

Baloch, M. I. and Akunna, J. C. (2002). Simultaneous denitrification and anaerobic digestion in granular bed baffled reactor (GRABBR). CSCE/EWRI of ASCE 
International Conference on Environmental Engineering, 21-24 July, Niagara Falls, Canada, 9 pages on CD-ROM.

Baloch, M. I. and Akunna, J. C. (2003a). Effect of rapid hydraulic shock loads on the performance of granular bed baffled reactor. Environ. Technol., 24, 361-368.

Baloch, M. I. and Akunna, J. C. (2003b). Granular bed baffled reactor (Grabbr): Solution to a two-phase anaerobic digestion system. J. Environ. Engrg. (ASCE), 129, 1015-1021.

Banik, G. C., Ellis, T. G. and Dague, R. R. (1997). Structure and methanogenic activity of granules from an ASBR treating dilute wastewater at low temperatures. Wat. Sci. Technol., 36, 149-156.

Barber, W. P. and Stuckey, D. C. (1998). The influence of start-up strategies on the performance of an anaerobic baffled reactor. Environ. Technol., 19, 489-501.

Barber, W. P. and Stuckey, D. C. (1999). The use of the anaerobic baffled reactor for wastewater treatment: a review. Wat. Res., 33, 1559-1578.

Barber, W. P. and Stuckey, D. C. (2000a). Nitrogen removal in a modified anaerobic baffled reactor (ABR): 1. Denitrification. Wat. Res., 34, 2413-2422.

Barber, W. P. and Stuckey, D. C. (2000b). Nitrogen removal in a modified anaerobic baffled reactor (ABR): 2. Nitrification. Wat. Res., 34, 2423-2432.

Batstone, D. J. and Keller, J. (2001). Variation of bulk properties of anaerobic granules with wastewater type. Wat. Res., 35, 1723-1729.

Beccari, M., Passino, R., Ramodori, R. and Tandoi, V. (1983). Kinetics of dissimilatory nitrate and nitrite reduction in suspended growth culture. J. Wat. Poll. Cont. Fed., 55, 58-64. 
Beetfink, H. H. and Staugaard, P. (1986). Structure and dynamics of anaerobic bacterial aggregates in a gas-lift reactor. Appl. Environ. Microbiol., 52, 1139-1146.

Beetfink, H. H. and van den Heuvel, J. C. (1988). Physical properties of bacterial aggregates in a continuous-flow reactor with biomass retention. In: Proc. of the GASMAT Workshop: Granular anaerobic sludge; Microbiology and Technology, Lettinga, G., Zehnder, A. J. B., Grotenhuis, J. T. C. and Hulshoff Pol, L. W. (Eds.), 2527 October, Pudoc, Wageningen, The Netherlands, 162-169.

Bellouti, M., Alves, M. M. and Mota, M. (1997). Flocs vs granules: differentiation by fractal dimension. Wat. Res., 31,1227-1231.

Bernet, N., Delgenes, N. and Moletta, R. (1996a). Denitrification by anaerobic sludge in piggery wastewater. Environ. Technol., 17, 293-300.

Bernet, N., Habouzit, F. and Moletta, R. (1996b). Use of an industrial effluent as a carbon source for denitrification of a high-strength wastewater. Appl. Microbiol. Biotechnol., 46, 92-97.

Bernet, N., Delgenès, N., Akunna, J. C., Delgenès, J. P. and Moletta, R. (2000). Combined anaerobic-aerobic SBR for the treatment of piggery wastewater. Wat. Res., 34, 611-619.

Bertucci, J. J., Lue-Hing, C., Zenc, D. and Sedita S. J. (1977). Inactivation of viruses during anaerobic sludge digestion. J. Wat. Poll. Cont. Fed., 46, 1642-1651.

Bhatia, D., Vieth, W. R. and Venkatasubramaniant, K. (1985). Steady-state and transient behaviour in microbial methanification: I. Experimental results. Biotechnol. Bioeng., 27, 1192-1198.

Bhatti, Z. I., Furukawa, K. and Fujita, M. (1995). Comparative composition and characteristics of methanogenic granular sludges treating industrial wastes under different conditions. J. Ferment. Bioeng., 79, 273-280. 
Bilanovic, D., Battistoni, P., Cecchi, F., Pavan, P. and Mata-Alvarez, J. (1999). Denitrification under high nitrate concentration and alternating anoxic conditions. Wat. Res., 33, 3311-3320.

BioMérieux sa (1998). API 20E: Identification system for Enterobacteriaceae and other Gram-negative rods. Manual 07584 B - 04/98, Marcy l'Etoile, France.

Bochem, H. P., Schoberth, S. M., Sprey, B. and Wengler, P. (1982). Thermophilic biomethanation of acetic acid: morphology and ultrastructure of granular consortium. Can. J. Microbiol., 28, 500-510.

Bode, H., Seyfried, C. F. and Kraft, A. (1987). High-rate denitrification of concentrated nitrate wastewater. Wat. Sci. Technol., 19, 163-174.

Boopathy, R., Larsen, V. F. and Senior, E. (1988). Performance of anaerobic baffled reactor $(\mathrm{ABR})$ in treating distillery waste water from a Scotch whisky wastewater. Biomass, 16, 133-143.

Boopathy, R. and Tilche, A. (1991). Anaerobic digestion of high-strength molasses wastewater using a hybrid anaerobic baffled reactor. Wat. Res. 25, 785-790.

Boopathy, R. and Sievers, D. M. (1991). Performance of a modified anaerobic baffled reactor to treat swine waste. Trans. ASAE, 34, 2573-2578.

Boopathy, R. and Tilche, A. (1992). Pellitization of biomass in a hybrid anaerobic baffled reactor (HABR) treating acidified wastewater. Bioresour. Technol., 40, 101-107.

Bories, A., Raynal, J. and Bazile, F. (1988). Anaerobic digestion of high-strength distillery wastewater (cane molasses sugar) in a fixed-film reactor. Biological Wastes, 23, 251-267.

Borja, R., Banks, C. J. and Wang, Z. (1995). Effect of organic loading rate on anaerobic treatment of slaughterhouse wastewater in a fluidised-bed reactor. Bioresour. Technol., 52, 157-162. 
Borzacconi, L., Ottonello, G., Castelló, E., Peláez, H. and Viñas, M. (1999). Denitrification in a carbon and nitrogen removal system for leachate treatment: performance of an UASB reactor. Wat. Sci. Technol., 40, 145-151.

Brenner, D. J. (1984). Family I. Enterobacteriaceae. Bergey's manual of systematic bacteriology, Kreig, N. R. and Holt, J. G., eds., Vol. 1, William and Wilkins, Baltimore, USA., 408-516.

British BioGen (2003). Anaerobic digestion of farm and food processing residues Good practice guidelines. http://www.britishbiogen.co.uk/gpg/adgpg/adgpg.pdf. (Accessed 20/02/03), London, UK.

Brond, S. and Sund, C. (1994). Biological removal of nitrogen in toxic industrial effluents, high in ammonia. Wat. Sci. Technol., 29, 231-240.

Brown, D. A., Beveridge, T. J., Keevil, C. W. and Sherriff, B. L. (1998). Evaluation of microscopic techniques to observe iron precipitation in a natural microbial biofilm. FEMS Microbiol. Ecol., 26, 297-310.

Bull, M. A., Sterritt, R. M. and Lester, J. N. (1983). The influence of COD, hydraulic, temperature and $\mathrm{pH}$ shocks on the stability of an unheated fluidised bed reactor. $J$. Chem. Technol. Biotechnol., 33B, 221-230.

Buresh, R. J. and Patrick, W. H. (1978). Nitrate reduction to ammonium in anaerobic soil. Soil Sci. Soc. Am. J., 42, 913-918.

Carley, B. N. and Mavinic, D. S. (1991). The effects of external carbon loading on nitrification and denitrification of a high-ammonia landfill leachate. J. Wat. Poll. Cont. Fed., 63, 51-59.

Carrington, E. G., Pike, E. B., Auty, D. and Morris, R. (1991). Destruction of faecal bacteria, enteroviruses and ova of parasites in wastewater sludge by aerobic thermophilic and anaerobic mesophilic digestion. Wat. Sci. Technol., 24, 377-380. 
Chang, Y., Nishio, N. and Nagai, S. (1994). Characteristics of granular methanogenic sludge grown on phenol synthetic medium and methanogenic fermentation of phenolic wastewater in a UASB reactor. J. Ferment. Bioeng., 79, 348-353.

Chen, K. C. and Lin, Y. F. (1993). The relationship between denitrifying bacteria and methanogenic bacteria in a mixed culture system of acclimated sludges. Wat. Res., 27, 1749-1759.

Chen, K. C., Lin, Y. F. and Houng, J. Y. (1997). Performance of a continuous stirred tank reactor with immobilized denitrifiers and methanogens. Wat. Environ. Res., 69, 233-239.

Chong, G. M. W. and Loehr, R. C. (1978). Kinetics of microbial nitrification: nitratenitrogen oxidation. Wat. Res., 12, 605-609.

Christensen, M. H. and Harremoes, P. (1977). Biological denitrification of sewage: a literature review. Prog. Wat. Technol., 8, 509-555.

Clarens, M., Bernet, N., Delgenès, J. P. and Moletta, R. (1998). Effects of nitrogen oxides and denitrification by Pseudomonas stutzeri on acetotrophic methanogenesis by Methanosarcina mazei. FEMS Microbiol. Ecol., 25, 271-276.

Cohen, A., Breure, A. M., van Andel, J. G. and van Deursen, A. (1980). Influence of phase separation on the anaerobic digestion of glucose. I. Maximum SCOD turn over rate during continuous operation. Wat. Res., 14, 1439-1448.

Cohen, A., Breure, A. M., van Andel, J. G. and van Deursen, A. (1982). Influence of phase separation on the anaerobic digestion of glucose. II. Stability and kinetic responses to shock loadings. Wat. Res., 16, 449-455.

Cole, J. A. (1978). The rapid accumulation of large quantities of ammonia during nitrite reduction by Escherichia coli. FEMS Microbiol. Lett., 4, 327-329. 
Daffonchio, D., Thaveesri, J. and Verstraete, W. (1995). Contact angle measurement and cell hydrophobicity of granular sludge from upflow anaerobic sludge bed reactor. Appl. Environ. Microbiol., 61, 3676-3680.

de Zeeuw, W. and Lettinga, G. (1983). Start-up of UASB-reactors. In: Proc. Eur. Symp. Anaerobic Waste Water Treatment, November, Noordwijkerhout, The Netherlands, 348-368.

de Zeeuw, W. (1988). Granular sludge in UASB reactors. In: Proc. of the GASMAT Workshop: Granular anaerobic sludge; Microbiology and Technology, Lettinga, G., Zehnder, A. J. B., Grotenhuis, J. T. C. and Hulshoff Pol, L. W. (Eds.), 25-27 October, Pudoc, Wageningen, The Netherlands, 132-145.

Delgenès, J. P., Rustrian, E., Bernet, N. and Moletta, R. (1998). Combined biodegradation of carbon, nitrogen and phosphorus from wastewaters. J. Molecular Catalysis B: Enzymatic, 5, 429-433.

Dinopoulou, G. and Lester, J. N. (1989). Optimisation of a two-phase anaerobic digestion system treating a complex wastewater. Environ. Technol. Lett., 10, 799-814.

Dolfing, J. and Bloemen, W. G. B. M. (1985). Activity measurements as a tool to characterize the microbial composition of methanogenic environments. J. Microbiol. Methods, 4, 1-12.

Dolfing, J., Griffioen, A., van Neerven, A. R. W. and Zevenhuizen, L. P. T. M. (1985). Chemical and bacteriological composition of granular methanogenic sludge. Can. J. Microbiol., 31, 744-750.

Dolfing, J. (1987). Microbiological aspects of granular methanogenic sludge. Ph.D. Thesis, Agricultural University, Wageningen, The Netherlands. 
Driessen, W. and Yspeert, P. (1999). Anaerobic treatment of low, medium and high strength effluent in the agro-industry. Wat. Sci. Technol., 40, 221-228.

Dubourguier, H. C., Prensier, G. and Albagnac G. (1988a). Structure and microbial activities of granular anaerobic sludge. In: Proc. of the GASMAT Workshop: Granular anaerobic sludge; Microbiology and Technology, Lettinga, G., Zehnder, A. J. B., Grotenhuis, J. T. C. and Hulshoff Pol, L. W. (Eds.), 25-27 October, Pudoc, Wageningen, The Netherlands, 18-33.

Dubourguier, H. C., Buisson, M. N., Tissier, J. P., Prensier, G. and Albagnac, G. (1988b). Structural characteristics and metabolic activities of granular methanogenic sludge on a mixed defined substrate. In: Proc. of the GASMAT Workshop: Granular anaerobic sludge; Microbiology and Technology, Lettinga, G., Zehnder, A. J. B., Grotenhuis, J. T. C. and Hulshoff Pol, L. W. (Eds.), 25-27 October, Pudoc, Wageningen, The Netherlands, 78-86.

Environmental Canada (1986). Anaerobic treatment of dairy effluent. Report EPS 3/FP/1, Environment Canada, Ottawa.

European Union Council of Ministers (1991). Council Directive of 21 May 1991 concerning urban waste water treatment. Official J. European Communities, 135/40.

Faisal, M. and Unno, H. (2001). Kinetic analysis of palm oil mill wastewater treatment by a modified anaerobic baffled reactor. Biochem. Eng. J., 9, 25-31.

Fang, H. H. P., Chui, H. K. and Li, Y. Y. (1994). Microbial structure and activity of UASB granules treating different wastewaters. Wat. Sci. Technol., 30, 87-96.

Fang, H. H. P, Chui, H. K. and Li, Y. Y. (1995). Effect of degradation kinetics on the microstructure of anaerobic biogranules. Wat. Sci Technol., 32, 165-172. 
Fass, S., Ganaye, V., Manem, J. and Block, J. C. (1994). Volatile fatty acids as carbon sources in denitrification. Environ. Technol., 15, 459-467.

Fdz-Polanco, F., Villaverde, S., Urueña, M. A. and García-Encina, P. A. (2002). Novel biological processes for advanced wastewater treatment. In: Water recycling and resource recovery in industry: analysis, technologies and implementation. Lens, $\mathrm{P}$., Hulshoff Pol, L., Wilderer, P. and Asano, T. (Eds.), IWA Publishing, London, 359-385.

Font, X., Adroer, N., Poch, M. and Vicent, T. (1997). Evaluation of an integrated system for pig slurry treatment. J. Chem. Technol. Biotechnol., 68, 75-81.

Foresti, E. (2002). Anaerobic treatment of domestic sewage: established technologies and perspectives. Wat. Sci. Technol., 45, 181-186.

Fox, P. and Venkatasubbiah, V. (1996). Coupled anaerobic/aerobic treatment of highsulfate wastewater with sulfate reduction and biological sulfide oxidation. Wat. Sci. Technol., 34, 359-366.

Francis, C. W. and Callahan, M. W. (1975). Biological denitrification and its application in treatment of high nitrate waste water. J. Environ. Qual., 4, 153-163.

Frankin, R. J. (2001). Full-scale experiences with anaerobic treatment of industrial wastewater. Wat. Sci. Technol., 44, 1-6.

Garcia, J. L. (1982). Relations between acidogenesis and the utilisation of lactate, sulphate and nitrate during anaerobic digestion. In: Proc. Symp. Int. Advances in Anaerobic Digestion, Mexico, 20-30.

Garrido, J. M., Méndez, R. and Lema, M. (2001). Simultaneous urea hydrolysis, formaldehyde removal and denitrification in a multifed upflow filter under anoxic and anaerobic conditions. Wat. Res., 35, 691-698.

Ghosh, S., Conrad, J. R. and Klass, D. L. (1975). Anaerobic acidogenesis of wastewater sludge. J. Wat. Poll. Cont. Fed., 47, 30-45. 
Gonzalez-Gil, G., Lens, P. N. L., van Aelst, A., van As, H., Versprille, A. I. and Lettinga, G. (2001). Cluster structure of anaerobic aggregates of an expanded granular sludge bed reactor. Appl. Environ. Microbiol., 67, 3683-3692.

Grobicki, A. and Stuckey, D. C. (1991). Performance of the anaerobic baffled reactor under steady-state and shock loading conditions. Biotechnol. Bioeng., 37, 344-355.

Grobicki, A. and Stuckey, D. C. (1992). Hydrodynamic characteristics of the anaerobic baffled reactor. Wat. Res., 26, 371-378.

Grotenhuis, J. T. C., Kissel, J. C., Plugge, C. M., Stams, A. J. M. and Zehnder, A. J. B. (1991a). Role of substrate concentration in particle size distribution of methanogenic granular sludge in UASB reactors. Wat. Res., 25, 21-27.

Grotenhuis, J. T. C., Smit, M., Plugge, C. M., Yuansheng, X., van Lammeren, A. A. M., Stams, A. J. M. and Zehnder, A. J. B. (1991b). Bacteriological composition and structure of granular sludge adapted to different substrates. Appl. Environ. Microbiol., 57, 1942-1949.

Grotenhuis, J. T. C., Plugge, C. M., Stams, A. J. M. and Zehnder, A. J. B. (1992). Hydrophobicities and electrophoretic mobilities of anaerobic bacterial isolates from methanogenic granular sludge. Appl. Environ. Microbiol., 58, 1054-1056.

Grover, R., Marwaha, S. S. and Kennedy, J. F. (1999). Studies on the use of an anaerobic baffled reactor for the continuous anaerobic digestion of pulp and paper mill black liquors. Process Biochem., 34, 653-657.

Guiot, S. R., Safi, B., Frigon, J. C., Mercier, P., Mulligan, C., Tremblay, R. and Samson, R. (1995). Performances of full-scale novel multiplate anaerobic reactor treating cheese whey effluent. Biotechnol. Bioeng., 45, 398-405. 
Gujer, W. and Zehnder, A. J. B. (1983). Conversion processes in anaerobic digestion. Wat. Sci. Technol., 17, 127-167.

Gullicks, H. A. and Cleasby,. J. L. (1990). Nitrification performance of a pilot-scale trickling filter. J. Wat. Poll. Cont. Fed., 62, 40-49.

Hach. (1992). Water Analysis Handbook. $2^{\text {nd }}$ Ed., Hach Company, Loveland, Colorado, USA.

Hanaki, K. and Polprasert, C. (1989). Contribution of methanogenesis to denitrification with an upflow filter. J. Wat. Poll. Cont. Fed., 61, 1604-1611.

Hanaki, K., Wantawin, C. and Ohgaki, S. (1990). Effects of the activity of heterotrophs on nitrification in a suspended growth reactor. Wat. Res., 24, 289-296.

Harper, S. R. and Pohland, F. G. (1987). Enhancement of anaerobic treatment efficiency through process modification. J. Wat. Poll. Cont. Fed., 59, 152-161.

Hendriksen, H. V. and Ahring, B. K. (1996a). Integrated removal of nitrate and carbon in an upflow anaerobic sludge blanket (UASB) reactor: operating performance. Wat. Res., 30, 1451-1458.

Hendriksen, H. V. and Ahring, B. K. (1996b). Combined removal of nitrate and carbon in granular sludge: substrate competition and activities. Antonie van Leeuwenhoek, 69, 33-39.

Hickey, R. F., Wu, W. M., Veiga, M. C. and Jones, R. (1991). Start-up, operation, monitoring and control of high-rate anaerobic treatment systems. Wat. Sci. Technol., 24, 207-255.

Hilton, M. G. and Archer, D. B. (1988). Anaerobic digestion of a sulfate-rich molasses wastewater: inhibition of hydrogen sulfide production. Biotechnol. Bioeng., 31, 885888. 
Holt, C. J., Matthew, R. G. S. and Terzis, E. (1997). A comparative study using the anaerobic baffled reactor to treat a phenolic wastewater. In: Proc. of the $8^{\text {th }} I A W Q$ Int. Conf. on Anaerobic Digestion, 25-29 May, Sendai, Japan, Vol. 2, Sendai, Japan, 40-47.

Horiuchi, J. I., Shimizu, T., Tada, K., Kanno, T. and Kobayashi, M. (2002). Selective production of organic acids in anaerobic acid reactor by $\mathrm{pH}$ control. Bioresour. Technol., 82, 209-213.

Horsley, R. W., Roscoe, J. V. and Talling, I. B. (1982). Nitrate reduction by Pseudomonas spp.: antagonism by fermentative bacteria. J. Appl. Bacteriol., 52, 57-66.

Hulshoff Pol, L. W., Zeeuw, W. J., Velzeboer, C. T. M. and Lettinga, G. (1983). Granulation in UASB-reactors. Wat. Sci. Technol., 15, 291-304.

Hulshoff Pol, L. W., van de Worp, J. J. M., Lettinga, G. and Beverloo, W. A. (1986). Physical characterisation of anaerobic granular sludge. In: Proc. NVA/EWPCA Conf. Anaerobic treatment, a grown-up technology, Aquatech '86, Amsterdam, The Netherlands, Industrial presentations (Europe) B. V. Schiedam, The Netherlands, 89101.

Hulshoff Pol, L. W. (1989). The phenomenon of granulation of anaerobic sludge. Ph.D. thesis, Agricultural University, Wageningen, The Netherlands.

Im, J-H., Woo, H-J., Choi, M-W., Han, K-B. and Kim, C-W. (2001). Simultaneous organic and nitrogen removal from municipal landfill leachate using an anaerobicaerobic system. Wat. Res., 35, 2403-2410.

Inanc, B., Matsui, S. and Ide, S. (1996). Propionic acid accumulation and controlling factors in anaerobic treatment of carbohydrate: effects of $\mathrm{H}_{2}$ and $\mathrm{pH}$. Wat. Sci. Technol., 34, 317-325.

Ince, O. (1998). Performance of a two-phase anaerobic digestion system when treating dairy wastewater. Wat. Res., 32, 2707-2713. 
Iza, J., Colleran, E., Paris, J. M. and Wu, W. M. (1991). International workshop on anaerobic treatment technology for municipal and industrial wastewaters: summary paper. Wat. Sci. Technol., 24, 1-16.

Jeison, D. and Chamy, R. (1999). Comparison of the behaviour of expanded granular sludge bed (EGSB) and upflow anaerobic sludge blanket (UASB) reactors in dilute and concentrated wastewater treatment. Wat. Sci. Technol., 40, 91-97.

Johnson, C. P., Li, X. and Logan, B. E. (1996). Settling velocities of fractal aggregates. Environ. Sci. Technol., 30, 1911-1918.

Kasper, H. F. and Wuhrmann, K. (1978). Kinetic parameters and relative turn-overs of some important catabolic reactions in digesting sludge. Appl. Environ. Microbiol., 36, $1-7$.

Kasper, H. F., Tiedje, J. M. and Firestone, R. B. (1981). Denitrification and dissimilatory nitrate reduction to ammonium in digested sludge. Can. J. Microbiol., 27, 878-885.

Kato, M. T., Field, J. A., Versteeg, P. and Lettinga, G. (1994). Feasibility of expanded granular sludge bed reactors for the anaerobic treatment of low-strength soluble wastewaters. Biotechnol. Bioeng., 44, 469-479.

Klüber, H. D. and Conrad, R. (1998). Inhibitory effects of nitrate, nitrite, $\mathrm{NO}$ and $\mathrm{N}_{2} \mathrm{O}$ on methanogenesis by Methanosarcina barkeri and Methanobacterium bryantii. FEMS Microbiol. Ecol., 25, 331-339.

Kosaric, N., Blaszczyk, R., Orphan, L. and Valladares. J. (1990). The characteristics of anaerobic granules from UASB reactors. Wat. Res., 24, 1473-1477.

Kuroda, M., Shima, H. and Sakakibara, Y. (1988). A study on simultaneous treatment of organic matter and nitrate with a biofilm consisting of methane fermentative bacteria and denitrifying bacteria. Proc. Environ. Sanitary Eng. Res., 24, 231-239. 
Laguna, A., Ouattara, A., Gonzalez, R. O., Baron, O, Famá, G., El Mamouni, R., Guiot, S., Monroy, O. and Macarie, H. (1999). A simple and low cost technique for determining the granulometry of upflow anaerobic sludge blanket reactor sludge. Wat. Sci. Technol., 40, 1-8.

Langenhoff, A. A. M, Intrachandra, N. and Stuckey, D. C. (2000). Treatment of dilute soluble and colloidal wastewater using an anaerobic baffled reactor: influence of hydraulic retention time. Wat. Res., 34, 1307-1317.

Langenhoff, A. A. M. and Stuckey, D. C. (2000). Treatment of dilute wastewater using an anaerobic baffled reactor: effect of low temperature. Wat. Res., 34, 3867-3875.

Lettinga, G., van Velsen, A. F. M., de Zeew, W. and Hobma, S. W. (1979). Feasibility of upflow anaerobic sludge blanket (UASB) process. In: Proc. of the National Conf. of Environmental Engineering, ASCE, San Francisco, USA, 9-11.

Lettinga, G., van Velsen, A. F. M., Hobma, S. W., de Zeew, W. and Kalpwijk, A. (1980). Use of upflow sludge blanket (USB) reactor concept for biological wastewater treatment, especially for anaerobic treatment. Biotechnol. Bioeng., 22, 699-734.

Lettinga, G., Roersma, R. and Grin, P. (1983). Anaerobic treatment of raw domestic sewage at ambient temperature using a granular bed UASB reactor. Biotechnol. Bioeng., 25, 1701-1723.

Lettinga, G. and Hulshoff Pol, L. W. (1991). UASB process design for various types of wastewaters. Wat. Sci. Technol., 24, 87-107.

Lettinga, G. (1995). Anaerobic digestion and wastewater treatment systems. Antonie van Leeuwenhoek, 67, 3-28.

Lim, D. V. (1989). Cell morphology and microscopy. Microbiology, West, St. Paul, Minn., USA. 
Lin, Y. F. and Chen, K. C. (1995). Denitrification and methanogenesis in a coimmobilized mixed culture system. Wat. Res., 29, 35-43.

Liu, Y. and Tay, J-H. (2002). The essential role of hydrodynamic shear force in the formation of biofilm and granular sludge. Wat. Res., 36, 1653-1665.

Macleod, F. A., Guiot, S. R. and Costerton, J. W. (1990). Layered structure of bacterial aggregates produced in an upflow anaerobic sludge bed and filter reactor. Appl. Environ. Microbiol., 56, 1598-1607.

Mahoney, E. M., Varangu, L. K., Cairns, W. L., Kosaric, N. and Murray, R. G. E. (1987). The effect of calcium on microbial aggregation during UASB start-up. Wat. Sci. Technol., 19, 249-260.

Maurer, M., Muncke, J. and Larsen, T. A. (2002). Technologies for nitrogen recovery and reuse. In: Wat. recycling and resource recovery in industry: Analysis, technologies and implementation. Lens, P., Hulshoff Pol, L., Wilderer, P. and Asano, T. (Eds.), IWA Publishing, London, 491-510.

McCarty, P. L. (1964). Anaerobic waste treatment fundamentals. Public Works, September, 107-112, October, 123-126, November, 91-94.

McCarty, P. L. (1981). One hundred years of anaerobic treatment. In: The Second Int. Symp. on Anaerobic digestion 1981. Hughes, D. E. Stafford, D. A., Wheatley, B. I., Baader, W., Lettinga, G., Nyns, E. J., Verstraete, W. and Wentworth, R. L. (Eds.), 6-11 Sept., Elsevier Biomedical Press B. V., Travemunde, Germany, 3-22.

McCarty, P. L. and Smith, D. P. (1986). Anaerobic wastewater treatment. Environ. Sci. Technol., 20, 1200-1206.

McCarty, P. L. and Mosey, F. E. (1991). Modelling of anaerobic digestion processes (a discussion of concepts). Wat. Sci. Technol., 24, 17-33. 
Metcalf and Eddy. (1991). Wastewater Engineering - treatment, disposal and reuse. $3^{\text {rd }}$ Ed., McGraw-Hill, In., New York, U.S.A.

Monteith, H. D., Bridle, T. R. and Sutton, P. M. (1980). Industrial waste carbon sources for biological denitrification. Prog. Wat. Technol., 12, 127-141.

Morvai, L., Miháltz, P. and Czakó, L. (1992). The kinetic basis of a new start-up method for ensure the rapid granulation of anaerobic sludge. Wat. Sci. Technol., 25, 113-122.

Mosquera-Corral, A., Sánchez, M., Campos, J. L., Méndez, R. and Lema, J. M. (2001). Simultaneous methanogenesis and denitrification of pretreated effluents from a fish canning industry. Wat. Res., 35, 411-418.

Nachaiyasit, S. and Stuckey, D. C. (1995). Microbial response to environmental changes in an anaerobic baffled reactor (ABR). Antonie van Leeuwenhoek, 67, 111-123.

Nachaiyasit, S. and Stuckey, D. C. (1997a). The effect of shock loads on the performance of an anaerobic baffled reactor (ABR). 1. Step changes in feed concentration at constant retention time. Wat. Res., 31, 2737-2746.

Nachaiyasit, S. and Stuckey, D. C. (1997b). The effect of shock loads on the performance of an anaerobic baffled reactor (ABR). 2. Step and transient hydraulic shocks at constant feed strength. Wat. Res., 31, 2747-2754.

Nommik, H. (1956). Investigation on Denitrification in soil. Acta Agric. Scand., 6, 195228.

Ofwat (2003). Tariff structure and charges 2003-04 report. Office of water services, Birmingham, UK.

Oxford Dictionary (1995). The Concise Oxford Dictionary. $9^{\text {th }}$ Ed., Oxford University Press, New York, USA. 
Patureau, D., Davison, J., Bernet, N. and Moletta, R. (1994). Denitrification under various aeration conditions in Comamonas sp., strain SGLY2. FEMS Microbiol. Ecol., 14, 71-78.

Paul, J. W., Beauchamp, E. G., and Trevors, J. T. (1989). Acetate, propionate, butyrate, glucose and sucrose as carbon sources for denitrifying bacteria in soil. Can. J. Microbiol., 35, 754-759.

Pavlostathis, S. G. and Giraldo-Gomez, E. (1991). Kinetics of anaerobic treatment: a critical review. Critical Reviews in Environmental Control, 21, 411-490.

Payne, W.J. (1981). Denitrification. John Wiley and Sons, New York, NY.

Peña, M. R., Rodriguéz, J. and Sepulveda, M. (2000). UASBs or anaerobic ponds in warm climates? A preliminary answer from Colombia. Wat. Sci. Technol., 42, 59-65.

Pereboom, J. H. F. (1994). Size distribution model for methanogenic granules from full scale UASB and IC reactors. Wat. Sci. Technol., 30, 211-221.

Pohland, F. G. and Bloodgood, D. E. (1963). Laboratory studies on mesophilic and thermophilic anaerobic sludge digestion. J. Wat. Poll. Cont. Fed., 35, 11-42.

Pohland, F. G. and Ghosh, S. (1971). Developments in anaerobic treatment process. Biotechnol. Bioeng. Symp., 2, 85-106.

Pohland, F. G. (1992). Anaerobic treatment: fundamental concepts, applications, and new horizons. In: Design of anaerobic processes for the treatment of industrial and municipal wastes. Malina, J. F. and Pohland, F. G. (Eds.), Water Quality Management Library, Vol. 7, Technomic publishing Inc., Lancaster, Pennsylvania, USA, 1-40.

Polprasert, C., Kemmadamrong, P. and Tran, F. T. (1992). Anaerobic baffle reactor (ABR) process for treating a slaughterhouse wastewater. Environ. Technol., 13, 857865. 
Pozo, R., Diez, V. and Beltrán, S. (2000). Anaerobic pre-treatment of slaughterhouse wastewater using fixed-film reactors. Bioresour. Technol., 71, 143-149.

Prakasam, T. B. S. and Loehr, R. C. (1972). Microbial nitrification and denitrification in concentrated wastes. Wat. Res., 6, 869-869.

Quevedo, M., Guynot, E. and Muxi, L. (1996). Denitrifying potential of methanogenic sludge. Biotechnol. Lett., 18, 1563-1368.

Quignon, F., Kiene, L., Levi, Y., Sardin, M. and Schwartzbrod, L. (1997). Virus behaviour within a distribution system. Wat. Sci. Technol., 35, 311-318.

Randall, C. W., Barnard, J. L. and Stensel, H. D. (1992). Design and retrofit of wastewater treatment plants for biological nutrient removal. Water Quality Management Library, Vol. 5, Technomic Publishing Co. Inc., Lancaster, Pennsylvania, USA.

Rebac, S., van Lier, J. B., Lens, P., van Cappellen, J., Vermeulen, M., Stams, A. J. M., Dekkers, F., Swinkels, K. T. M. and Lettinga, G. (1998). Psychrophilic (6-15 $\left.{ }^{\circ} \mathrm{C}\right)$ highrate anaerobic treatment of malting wastewater in a two-module expanded granular sludge bed system. Biotechnol. Prog., 14, 856-864.

Ren, N., Wang, B. and Huang, J-C. (1997). Ethanol type fermentation from carbohydrate in high rate acidogenic reactor. Biotechnol. Bioeng., 54, 428-433.

Robertson, L. A. and Kuenen, J. G. (1984). Aerobic denitrification: a controversy revived. Arch. Microbiol., 139, 351-354.

Romli, M., Greenfield, P. F. and Lee, P. L. (1994). Effect of recycle on a two-phase high-rate anaerobic wastewater treatment system. Wat. Res., 28, 475-482.

Ross, W. R. (1984). The phenomenon of sludge pellitisation in the anaerobic treatment of a maize processing waste. Wat. SA, 10, 197-204. 
Rustrian, E., Delgenes, J. P., Bernet, N. and Moletta, R. (1997). Nitrate reduction in acidogenic reactor: influence of wastewater $\mathrm{COD} / \mathrm{N}-\mathrm{NO}_{3}$ ratio on denitrification and acidogenic activity. Environ. Technol., 18, 309-315.

Rustrian, E., Delgenes, J. P., Bernet, N. and Moletta, R. (1999). Acidogenic activity: process of carbon source generation for biological nutrient removal. Wat. Sci. Technol., 40, 25-32.

Sanchez Riera, F., Cordoba, P. and Sineriz, F. (1985). Use of the UASB reactor for the anaerobic treatment of stillage from sugar cane molasses. Biotechnol. Bioeng., 27, 17101716.

Sayed, S., van Campen, L. and Lettinga, G. (1987). Anaerobic treatment of slaughterhouse waste using a granular sludge UASB reactor. Biological Wastes, 21, 1128.

Schink, B. and Thauer, R. K. (1988). Energetics of syntrophic methane formation and the influence of aggregation. In: Proc. of the GASMAT Workshop: Granular anaerobic sludge; Microbiology and Technology, Lettinga, G., Zehnder, A. J. B., Grotenhuis, J. T. C. and Hulshoff Pol, L. W. (Eds.), 25-27 October, Pudoc, Wageningen, The Netherlands, 5-17.

Schmidt, J. and Ahring, B. K. (1993). Effects of magnesium on thermophilic acetatedegrading granules in upflow anaerobic sludge blanket (UASB) reactors. Enzyme Microb. Technol., 15, 304-310.

Schmidt, J. and Ahring, B. K. (1996). Granular sludge formation in upflow anaerobic sludge blanket (UASB) reactors. Biotechnol. Bioeng., 49, 229-246.

Schwartzbrod, L. and Mathieu, C. (1986). Virus recovery from wastewater treatment plant sludges. Wat. Res., 20, 1011-1013. 
Seeler, T. A. and Jennett, J. C. (1978). Treatment of a wastewater from a chemically synthesized pharmaceutical manufacturing process with the anaerobic filter. In: Proc. $33^{\text {rd }}$ Purdue Industrial Wastes Conf., Purdue Univ., 687-695.

Shen, C. F., Kosaric, N. and Blaszczyk, R. (1993). The rate of selected heavy metals $(\mathrm{Ni}, \mathrm{Co}$ and $\mathrm{Fe}$ ) on anaerobic granules and their extracellular polymeric substance (EPS). Wat. Res., 27, 25-33.

Shen, C. F. and Guiot, S. R. (1996). Long-term impact of dissolved $\mathrm{O}_{2}$ on the activity of anaerobic granules. Biotechnol. Bioeng., 49, 611-620.

Shin, H. S., Han, S. K., Song, Y. C. and Lee, C. Y. (2001). Performance of UASB reactor treating leachate from acidogenic fermenter in the two-phase anaerobic digestion of food waste. Wat. Res., 35, 3441-3447.

Skrinde, J. R. and Bhagat, S. K. (1982). Industrial wastes as carbon sources in biological denitrification. J. Wat. Poll. Cont. Fed., 54, 370-377.

Smith, M. S. (1982). Dissimilatory reduction of $\mathrm{NO}_{2}^{-}$to $\mathrm{NH}_{4}^{+}$and $\mathrm{N}_{2} \mathrm{O}$ by a soil Citrobacter sp.. Appl. Environ. Microbiol., 43, 854-860.

Speece, R. (1983). Anaerobic biotechnology for industrial wastewater treatment. Environ. Sci. Technol., 17, 416-427.

Speece, R. E., Duran, M., Demirer, G., Zhang, H. and DiStefano, T. (1997). The role of process configuration in the performance of anaerobic systems. Wat. Sci. Technol., 36, 539-547.

Stensel, H. D., Loehr, R. C. and Lawrence, A. W. (1973). Biological kinetics of suspended-growth denitrification. J. Wat. Poll. Cont. Fed., 45, 249-261.

Suthersan, S. and Ganczarczyk, J. J. (1986). Inhibition of nitrite oxidation during nitrification: some observations. Wat. Poll. Res. J. Can., 21, 257-266. 
Switzenbaum, M. S. and Jewell, W. J. (1980). Anaerobic attached film expanded-bed reactor treatment. J. Wat. Poll. Cont. Fed., 52, 1953-1965.

Szwerinski, H., Arvin, E. and Harremoes, P. (1986). pH-decrease in nitrifying biofilms. Wat. Res., 20, 971-976.

Takai, T., Hirata, A., Yamauchi, K. and Inamori, Y. (1997). Effects of temperature and VFA on nitrification-denitrification activity in small-scale anaerobic-aerobic recirculation biofilm process. Wat. Sci. Technol., 35, 101-108.

Tang, P. and Raper, J. A. (2002). Modelling the settling behaviour of fractal aggregates - a review. Powder Technol., 123, 114-125.

Tartakovsky, B., and Guiot, S. R. (1997). Modeling and analysis of layered stationary anaerobic granular biofilms. Biotechnol. Bioeng., 54, 122-130.

Thaveesri, J., Daffonchio, D., Liessens, B., Vandermeren, P. and Verstraete, W. (1995). Granulation and sludge bed stability in upflow anaerobic sludge bed reactors in relation to surface thermodynamics. Appl. Environ. Microbiol., 61, 3681-3686.

Tiedje, J. M. (1988). Ecology of denitrification and dissimilatory nitrate reduction to ammonium. In: Biology of anaerobic microorganisms. Zehnder, A. J. B., ed., John Wiley \& Sons, New York, USA, 179-244.

Tilche, A. and Yang, X. (1988). Light and scanning electron microscope observations on the granular biomass of experimental SBAF and HABR reactors. In: Proc. of the GASMAT Workshop: Granular anaerobic sludge; Microbiology and Technology, Lettinga, G., Zehnder, A. J. B., Grotenhuis, J. T. C. and Hulshoff Pol, L. W. (Eds.), 2527 October, Pudoc, Wageningen, The Netherlands, 170-178. 
Tilche, A., Bortone, G., Forner, G., Indulti, M., Stante, L. and Tesini, O. (1994). Combination of anaerobic digestion and denitrification in a hybrid upflow anaerobic filter integrated in a nutrient removal treatment plant. Wat. Sci. Technol., 30, 405-414.

Tramper, J., van Groenestijn, J. W., Luyben, K. C. A. M. and Hulshoff Pol, L. W. (1984). Some physical and kinetic properties of granular anaerobic sludge. In Innovations in Biotechnology. Houwink E. H. and van der Meer R. R. (Eds.), Elsevier Science, Amsterdam, 145-155.

Tritt, W. P. (1992). The anaerobic treatment of slaughterhouse wastewater in fixed-bed reactors. Bioresour. Technol., 41, 201-207.

Turk, O. and Mavinic, D. S. (1989). Stability of nitrite build-up in an activated sludge system. J. Wat. Poll. Cont. Fed., 61, 1440-1448.

U.K. Royal Commission on Environmental Pollution (2003). The Commission Reports. http://www.rcep.org.uk/reports.html. (Accessed 07/05/2003), London, UK.

U.S. EPA. (1993). Nitrogen Control. Report EPA/625/R-93/010. Office of Research and Development, and Office of Water, Washington, D.C., USA.

U.S. EPA (2003). Effluent guidelines and standards. http://www.epa.gov/waterscience/guide/. (Accessed 10/08/2003), Office of Water, Washington, D.C., USA.

Uyanik, S., Sallis, P. J. and Anderson, G. K. (2002a). The effect of polymer addition on granulation in an anaerobic baffled reactor (ABR). Part I: process performance. Wat. Res., 36, 933-943.

Uyanik, S., Sallis, P. J. and Anderson, G. K. (2002b). The effect of polymer addition on granulation in an anaerobic baffled reactor (ABR). Part II: compartmentalization of bacterial populations. Wat. Res., 36, 944-955. 
van Lier, J. B., Groeneveled, N. C. and Lettinga, G. (1996). Development of thermophilic methanogenic sludge in compartmentalized upflow reactors. Biotechnol. Bioeng., 50, 115-124.

van Loosdrecht, M. C. M., Lyklema, J., Norde, W., Schraa, G. and Zehnder, A. J. B. (1987a). The role of cell wall hydrophobicity in adhesion. Appl. Environ. Microbiol., 53, 1893-1897.

van Loosdrecht, M. C. M., Lyklema, J., Norde, W., Schraa, G. and Zehnder, A. J. B. (1987b). Electrophoretic mobility and hydrophobicity as a measure to predict the initial steps of bacterial adhesion. Appl. Environ. Microbiol., 53, 1898-1901.

Vandevivere, P., De Baere, L. and Verstraete, W. (2002). Types of anaerobic digester for solid wastes. In: Biomethanization of the organic fraction of municipal solid wastes, J. Mata-Alvarez, ed., IWA Publishing, Barcelona, Spain, 111-140.

Veiga, M. C., Méndez, R. and Lema, J. M. (1994). Anaerobic filter and DSFF reactors in anaerobic treatment of tuna processing wastewater. Wat. Sci. Technol., 30, 425-432.

Werner, M. and Kayser, R. (1991). Denitrification with biogas as external carbon source. Wat. Sci. Technol., 23, 701-708.

Wheatley, A. D., Fisher, M. B. and Grobicki, A. M. W. (1997). Applications of anaerobic digestion for the treatment of industrial wastewaters in Europe. J. CIWEM, $11,39-46$.

Wiegant, W. M., Hennink, M. and Lettinga, G. (1986). Separation of propionate degradation to improve the efficiency of thermophilic anaerobic treatment of acidified wastewater. Wat. Res., 20, 517-524.

Wijbenga, D. J. and Bos, H. T. P. (1988). Physical and biological factors influencing the growth of anaerobic granular sludge. In: Proc. of the GASMAT Workshop: Granular 
anaerobic sludge; Microbiology and Technology, Lettinga, G., Zehnder, A. J. B., Grotenhuis, J. T. C. and Hulshoff Pol, L. W. (Eds.), 25-27 October, Pudoc, Wageningen, The Netherlands, 229-234.

Wirtz, R. A. and Dague, R. R. (1996). Enhancement of granulation and start-up in the anaerobic sequencing batch reactor. Wat. Environ. Res., 68, 883-892.

Xing, J. and Tilche, A. (1992). The effect of hydraulic retention time on the hybrid anaerobic baffled reactor performance at constant loading. Biomass Bioenergy, 3, 25-29.

Xing, J., Criddle, C. and Hickey, R. (1997). Effects of a long-term periodic substrate perturbation on an anaerobic community. Wat. Res., 31, 2195-2204.

Yan, Y. G. and Tay, J. H. (1997). Characterisation of the granulation process during UASB start-up, Wat. Res., 31, 1573-1580.

Young, J. C. and McCarty, P. L. (1969). The anaerobic filter for wastewater treatment. J. Wat. Poll. Cont. Fed., 41, 160-173.

Zhang, T. C. and Noike, T. (1994). Influence of retention time on reactor performance and bacterial trophic populations in anaerobic digestion processes. Wat. Res., 28, 27-36.

Zoetemeyer, R. J., van den Heuvel, J. C. and Cohen, A. (1982). pH influence on acidogenic dissimilation of glucose in an anaerobic digestor. Wat. Res., 16, 303-311. 


\section{$\underline{\text { APPENDIX }}$}

\section{Refereed Journal Publications}

The two published papers cited below have been removed from the e-thesis because of copyright restrictions.

Baloch, M.I. and Akunna, J.C. (2003) 'Effect of rapid hydraulic shock loads on the performance of granular bed baffled reactor', Environmental technology, 24(3), pp. 361-368. doi: $10.1080 / 09593330309385568$.

Baloch, M.I. and Akunna, J.C. (2003) 'Granular bed baffled reactor (Grabbr): Solution to a two-phase anaerobic digestion system', Journal of Environmental Engineering, 129(11), pp. 1015-1021. doi: $11(1015)$. 